\title{
Policies and Management Practices for Sustainable Oil Palm - Evidence from Indonesia
}

\section{Dissertation}

to obtain the doctoral degree in the International Ph.D. Program for Agricultural Sciences in Goettingen (IPAG) at the Faculty of Agricultural Sciences, Georg-August-University Goettingen, Germany

presented by

Katrin Rudolf

born in Wuppertal, Germany

Goettingen, April 2020 


\section{Thesis committee}

Name of supervisor: Prof. Dr. Meike Wollni

Name of co-supervisor: Prof. Dr. Bernhard Brümmer

Name of co-supervisor: Prof. Dr. Matin Qaim

Date of dissertation: 28.05 .2020 


\section{Summary}

Changing consumption patterns and a growing world population have resulted in an increased demand for vegetable oil. Due to its price advantages and suitable chemical properties, in particular the demand for palm oil has increased making it globally the most widely used vegetable oil in 2019. Palm oil production is geographically highly concentrated in Indonesia and Malaysia that alone provide over $85 \%$ of the global supply. These countries also harbor important parts of moist tropical forests which are one of the world's most biodiverse ecosystems and global carbon sinks. While the area under oil palm cultivation has been growing continuously in the last decades, the area under rainforest has declined. Part of this decline can be directly attributed to oil palm expansion.

Oil palm induced land use changes are associated with environmental degradation. The repercussions are not restricted to the regional or local scale through e.g. a distortion of water and microclimate regulating services, but have global consequences such as biodiversity loss and carbon emissions. Yet, oil palm expansion has contributed to poverty reduction and income growth for many smallholder farmers. The contrast between negative environmental consequences and positive welfare effects highlights the trade-offs associated with oil palm expansion. The present dissertation aims at identifying policies and oil palm management practices that could mitigate these trade-offs.

This thesis comprises three essays. The first two essays focus on policies aiming at biodiversity restoration in oil palm dominated areas. The last essay explores management practices to close yield gaps and to increase soil organic carbon (SOC) in smallholdings. All essays area based on primary data collected from oil palm smallholder farmers in Jambi Province, Indonesia. Jambi Province is one of the hotspots of oil palm expansion and has experienced tremendous land use changes.

The planting of native trees inside or at the border of the plantation has been suggested as one way to increase biodiversity in oil palm plantations. However, little evidence exists on which policy instruments are effective to promote native 
tree planting in oil palm plantations. The first essay of this dissertation addresses this research gap. The agroforestry adoption literature and focus group discussions suggest that missing information and restricted access to seedling markets represent constraints to tree planting. In case these constraints are binding, providing farmers with access to seedlings and information should increase tree planting adoption. To test this hypothesis, a randomized controlled trial was implemented in 2016 and two interventions were designed. The first provided information on tree planting and management through a manual and a video. The second combined information with input provision. In addition to the video and the manual, farmers received six native tree seedlings for free.

We estimate intention-to-treat effects on farmers' tree planting decision in oil palm plantations with a double-hurdle model. Both interventions significantly increase the number of trees planted per hectare in oil palm plantations in comparison to the control group. Under both interventions, a small share of farmers plant many trees in their plantations. However, free seedling provision in addition motivates many farmers to adopt low intensity tree planting. We also analyze tree survival rates. We find that farm-level tree survival is significantly lower for the farmers who received seedlings for free than for the adopting farmers in the control group and for those only receiving information. Non-correspondence between farmers' preferences and the seedlings received can be identified as one driver.

The effective support of ecosystem services operating at larger scales requires to take on a landscape-level perspective. For biodiversity conservation and the support of related ecosystem services, there is evidence that a critical size of conservation area at the landscape level and its spatial connectivity are of importance. The second essay of this dissertation looks into how payments for ecosystem services (PES) schemes for tree planting need to be designed in order to meet these requirements.

PES are compensation mechanisms through which providers of ecosystem services, e.g. farmers putting their land under conservation, are compensated for the resulting costs by the respective beneficiaries. The experimental literature has suggested separate design options to reach a critical size of conservation area, 
and to improve its spatial connectivity. However, evidence is missing on how to simultaneously meet both requirements. To close this research gap, we implemented a framed field experiment in 2018. In a hypothetical scenario, farmers needed to decide whether to keep their land under oil palm cultivation or to switch to a mixed system that integrates other trees. While oil palm cultivation is linked to higher income, the mixed system increases biodiversity. To mirror the landscape-level requirements, biodiversity is only improved if a critical number of farmers plant the mixed system. Moreover, effects are higher if mixed systems are grown on bordering land. To explore the effects of potential PES designs, we analyze two incentive schemes. In the first one, the area threshold, farmers who plant the mixed system are compensated if at least three out of six farmers in a group do so. In the second one, an agglomeration payment, adopting farmers receive compensation if at least three farmers in the group plant the mixed system on bordering land. Our results show that both PES designs increase the likelihood that farmers plant the mixed system in comparison to a baseline scenario without compensation payments. However, once communication is allowed for, the area threshold outperforms the agglomeration payment with regard to environmental effectiveness and overall efficiency, while reaching similar levels of budget efficiency.

Tree planting can also support climate regulating functions by absorbing and storing carbon dioxide. Soil organic carbon (SOC) restoration represents another approach to improve the carbon sequestration in oil palm plantations. In addition, it might strengthen the provision of yield supporting soil ecosystem services. Increasing SOC can be achieved by adding organic material, e.g. through mulching with empty fruit bunches (EFB). EFB remain after the oil fruits have been stripped off in the palm oil mills. EFB are rich in nutrients and can be used as organic fertilizer. This can help to increase smallholders' yields that mostly lie below those of industrial plantations.

Several studies have indicated that mulching can be beneficial to soil carbon and yields. However, evidence is mostly derived from field-trial experimental data in industrial plantations. These trials might not reflect the real-world conditions of 
smallholder farmers. This motivates the third essay in which we look at the effects of EFB mulching on SOC contents and yields in oil palm smallholdings. Based on yearly data covering the years 2015 to 2017, we estimate the effect of mulching on yields with a random effects panel data model. Since the adoption to apply mulching might be endogenous, we employ an instrumental variable estimation. Based on soil samples collected in 2017, we analyze the effect of mulching on SOC. Finally, we look into the impact channels and analyze whether and to what extent the effect of mulching on yields operates through SOC increases. Our results support a positive effect of mulching on SOC contents and yields. However, SOC contents do not appear to be a significant predictor for yields. The effect of mulching on yields therefore likely operates through other channels such as direct nutrient addition.

This dissertation suggests that policies and management practices could help to mitigate environmental-economic trade-offs involved in oil palm cultivation. In case of soil organic carbon restoration, environmental improvements and income generation might be complements. Our results further indicate that biodiversity-friendly farming practices can be promoted with non-monetary interventions. However, to reach a larger share of the population, subsidized inputs or even monetary incentives might be needed. 


\section{Acknowledgement}

First of all, I would like express my gratitude towards my supervisor Prof. Meike Wollni. Thank you for all your support throughout this time! I have learned a lot from your feedback and our personal discussions. Your openness to new ideas and the very respectful working atmosphere have contributed to large parts that I could not only improve my scientific skills during the $\mathrm{PhD}$ time, but also enjoyed most of this time. I would also like to thank Prof. Bernhard Brümmer and Prof. Matin Qaim for joining my thesis committee and Prof. Brümmer for the feedback on my second paper.

I had the chance to write my PhD thesis as part of the CRC 990 EFForTS and spent several months in Indonesia for data collection. I would like to acknowledge the DFG for funding the field work. The data collection would have not been feasible without the help of many persons in Indonesia. A big, big thanks goes to Mega, Rizki, Yuking and Fahrozi! Thank you for your help with all personal and professional problems in Jambi. My deepest thanks goes to all of the assistants who helped me during the data collection. I am grateful to you, Winda, Dattita, Shara, Yanti, Tuti, Rizki, Tina, Yohana, Anto, Ardo, Wila, Juwita, Khoti, Ayu, Andita, Zaki, Tito, April, Dena, Monica, Lia, and Christian. I am aware that working conditions in the field were not always easy. I really acknowledge what you have achieved and I wish you all the best for your future and hope that you can realize your dreams and wishes. I would also like to express my gratitude to all the farmers who participated in the surveys and the experiments. Thank you for your patience and for taking the time to respond (several times) to all of our questions! My gratitude goes to the villagers and the village administrative staff of the villages Ramin, Seponjen, Mekar Sari, Markanding, Sumber Mulya, Mentawak Baru, Mentawak Ulu, Bukit Suban, Pintas Tua, Sungai Jernih, Bangun Seranten, Lubuk Mandarsah, Punti Kalo, Tuo Sumay, Bukit Harapan, Kehidupan Baru, Karya Mukti, Belanti Jaya, Tapah Sari, Tri Mulia Jaya, Lembah Kuamang, Mingkung Jaya, Bukit Kemuning, Tirta Mulya, Pulau Betung, Sungai Puar, Talang Datar, 
Suka Maju and Matra Manunggal in Jambi! Your hospitality really impressed me!

Toni, thanks for joining me during the second field trip! It was a great relief, both personally and professionally, to have somebody with me whom I can trust and who took over part of the responsibility.

From the CRC, I would in particular like to acknowledge the C07 and the C02 team for their readiness to help and to share data and experiences! Thank you, Nina, for coming up with the idea of an interdisciplinary project and for introducing me to the world of soil science. A big thanks to you, Peter, for answering all my statistical questions.

Finishing this $\mathrm{PhD}$ would have not been feasible with all the amazing colleagues and friends from the chair and the department (and the substantial overlap between both) here in Göttingen. First, I would like to thank the "Laufen, Yes we can" group, Andrea, Denise, Hanna, Kathrin and Lisa. Even though most of you were only physically present in the beginning, you really shaped this $\mathrm{PhD}$ time! You, Denise, are the only one who accompanied this $\mathrm{PhD}$ from the beginning till the very end. I am really grateful for experiencing all the ups and downs of these four years together with you and for all your personal and professional help, in particular in the last six months! My dear Miri, thank you so much for all your care during our shared time in Jambi and in the office! I really admire your energy! A big thanks to Marcello, Karina and Jessie for proofreading parts of this thesis and to Jessie for always having an open ear for my English related and all other problems.

To my friends outside of Göttingen and in particular to Charli, Laura, Anne and Sara(h): thanks for all the support throughout this time! Knowing that I can always count on you means a lot to me.

Final möchte ich meiner Familie danken, meinen Eltern, meinem Bruder und Sarah. Vielen Dank für Eure ganze Unterstützung in dieser Zeit! Mama, Papa, ich bin zutiefst dankbar für Euer Vertrauen und dafür, dass Ihr mich meinen Weg ohne großes Hinterfragen habt gehen lassen. Die Gewissheit, zuhause einen Ort zu haben, wo ich immer willkommen bin, gibt mir sehr viel Kraft! 


\section{Contents}

Summary

Acknowledgments $\quad$ v

1 Introduction 1

1.1 Oil palm expansion and its consequences in Indonesia . . . . . . 2

1.2 Policies and management practices to improve the sustainability of oil palm cultivation ................... . . 5

1.3 Research objectives . . . . . . . . . . . . . . . 6

1.4 Study area and data . . . . . . . . . . . . . . . . . . 11

1.5 Outline of dissertation . . . . . . . . . . . . . . . 13

2 Effects of information and seedling provision on tree planting and survival in smallholder oil palm plantations $\quad 15$

2.1 Introduction . . . . . . . . . . . . . . . . . . 16

2.2 Study design, data and estimation strategy . . . . . . . . . . . . 20

2.2.1 Study area and sampling strategy . . . . . . . . . . . . 20

2.2.2 Randomization approach . . . . . . . . . . . . . . 22

2.2.3 Description and implementation of treatments . . . . . . . 22

2.2.4 Econometric specification . . . . . . . . . . . 26

2.3 Results . . . . . . . . . . . . . . . . . . . . . 29

2.3.1 Adoption decision . . . . . . . . . . . . . . . . . . . . 29

2.3.2 Subgroup-specific treatment effects by seed access constraint 34 
2.3.3 Does free seedling delivery discourage tree planting beyond what is given for free? . . . . . . . . . . . . 35

2.3.4 Cost effectiveness considerations . . . . . . . . . . . 37

2.3.5 Tree survival . . . . . . . . . . . . . . . . 38

2.4 Conclusion . . . . . . . . . . . . . . . . . . . . . 43

2.A Appendix ........................... 47

3 Achieving a suitable landscape pattern for biodiversity conservation through payments for ecosystem services - Evidence from $\begin{array}{ll}\text { Indonesia } & 61\end{array}$

3.1 Introduction . . . . . . . . . . . . . . . . . . . 62

3.2 Oil palm expansion in Indonesia . . . . . . . . . . . . . . 65

3.3 The conservation game . . . . . . . . . . . . . . 67

3.3.1 Experimental design . . . . . . . . . . . . . . 67

3.3.2 Theoretical predictions . . . . . . . . . . . . 70

3.3.3 Case study . . . . . . . . . . . . . . . . . . . . . 73

3.3.4 Experimental setting . . . . . . . . . . . . . 74

3.4 Results . . . . . . . . . . . . . . . . . 76

3.4.1 Socio-economic characteristics of the sample . . . . . . 76

3.4.2 Group-level results . . . . . . . . . . . . . . 78

3.4.3 Individual contributions . . . . . . . . . . . . . 87

3.5 Conclusion . . . . . . . . . . . . . . . . . . . 95

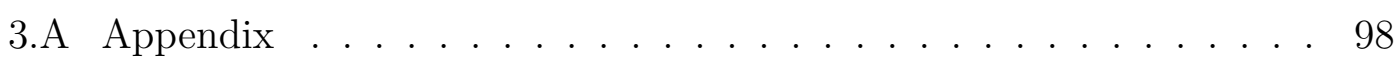

4 The effect of soil conservation practices on yields and soil carbon $\begin{array}{ll}\text { in smallholder oil palm plantations } & 114\end{array}$

4.1 Introduction . . . . . . . . . . . . . . . . . . . . . 115

4.2 Characteristics of empty fruit bunch mulching . . . . . . . . . . 116

4.3 Study region, sampling procedure and data . . . . . . . . . . . . 119

4.3.1 Study region . . . . . . . . . . . . . . . . . . 119

4.3.2 Plot selection and soil sampling . . . . . . . . . . 120 
4.3 .3 Socio-economic data . . . . . . . . . . . . . . . . 122

4.4 Conceptual model and estimation strategy . . . . . . . . . . . . . . 122

4.4 .1 Reduced form estimation . . . . . . . . . . . . . . . . . 122

4.4.2 Pathway analysis . . . . . . . . . . . . . . . 126

4.5 Results . . . . . . . . . . . . . . . . . . . . . . 129

4.5.1 Descriptives and constraints to adoption . . . . . . . . . 129

4.5.2 Reduced form effects of mulching on yields . . . . . . . . . . 132

4.5.3 Pathway analysis . . . . . . . . . . . . . . . 136

4.6 Conclusion . . . . . . . . . . . . . . . . . . . . . 141

4.A Appendix ............................ 144

5 Conclusion $\quad 157$

5.1 Main findings and discussion . . . . . . . . . . . . . . . 158

5.2 Limitations and scope for future research . . . . . . . . . . . . . 160

5.3 Sustainability and policy implications . . . . . . . . . . . . . . . 164

$\begin{array}{lr}\text { References } & 166\end{array}$

$\begin{array}{lr}\text { A General Appendix } & 186\end{array}$

A.1 Appendix Chapter $2 \ldots \ldots$. . . . . . . . . . . . 187

A.2 Appendix Chapter 3 . . . . . . . . . . . . . . . . 200 


\section{List of Tables}

2.1 Baseline descriptives and mean comparison tests . . . . . . . . 23

2.2 Descriptives of outcome variables . . . . . . . . . . . . 30

2.3 Intention-to-treat estimation . . . . . . . . . . . . . . . 31

2.4 Intention-to-treat estimates with distribution winsorized at 99

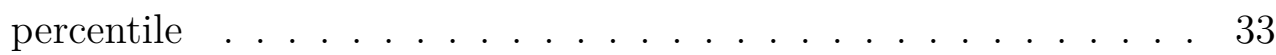

2.5 Heterogeneous Treatment effects . . . . . . . . . . . . . . 35

2.6 Intention-to-treat estimates for planting of self-procured tree seedlings

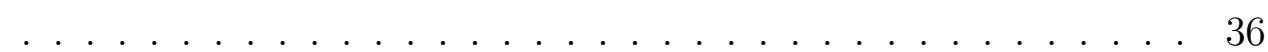

2.7 Total costs and outcomes of interventions . . . . . . . . . . . 37

2.8 Cost effectiveness measures . . . . . . . . . . . . . . . . . 38

2.9 Descriptives of farm-level survival rates (adopters only) . . . . . . 39

2.10 Difference in tree survival rates between different treatment groups 40

2.11 Potential determinants of tree survival . . . . . . . . . . . . . . 41

2.12 Mean comparison test of significant predictors for tree survival . . 42

A2.1 Intention-to-treat estimates for adoption decision . . . . . . . . . 48

A2.2 Intention-to-treat estimates for intensity decision . . . . . . . . . . 49

A2.3 Intention-to-treat effects on the unconditional predicted number of trees planted per hectare . . . . . . . . . . . . . . 50

A2.4 Bootstrap-t confidence intervals for treatment groups . . . . . . 51

A2.5 Heckman selection model . . . . . . . . . . . . . . . 52

A2.6 Weighted Intention-to-treat estimation . . . . . . . . . . . . 53

A2.7 Determinants of selection in follow-up . . . . . . . . . . 54

A2.8 Bounds estimation for Intention-to-treat estimates . . . . . . . . . 55

A2.9 Fractional probit estimation for tree survival . . . . . . . . . . 56 
A2.10 Descriptives of other explanatory variables . . . . . . . . . 57

A2.11 Definition of explanatory variables . . . . . . . . . . . . . 58

$3.1 \quad$ Experimental setup . . . . . . . . . . . . . . . . . 67

3.2 Summary statistics . . . . . . . . . . . . . . . . . 77

3.3 Group-level descriptives for environmental effectiveness and its

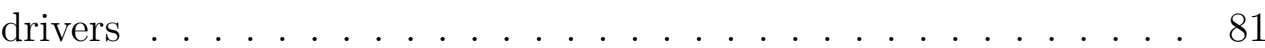

3.4 Efficiency, income and cost measures . . . . . . . . . . . . 86

3.5 Effects of two PES designs on farmers' conservation decision . . . 88

3.6 Effects of three payment levels on farmers' conservation decision . 90

3.7 Subgroup-specific effects of the two PES designs on farmers' conservation decision . . . . . . . . . . . . . . . . 94

A3.1 Number of groups assigned to different PES designs and payment levels $($ rounds 6-20) . . . . . . . . . . . . . . . . . 98

A3.2 Explanation of specific explanatory variables . . . . . . . . . . 100

A3.3 Mean comparison tests between PES designs . . . . . . . . . . . . 101

A3.4 Mean comparison tests between payment levels . . . . . . . . . . . 102

A3.5 P-values of comparison tests for environmental effectiveness outcomes103

A3.6 P-values of comparison tests for efficiency outcomes . . . . . . . . 104

A3.7 Group-level descriptives for environmental effectiveness and its drivers (combined PES-schemes) . . . . . . . . . . . . . . 105

A3.8 Effects of two PES designs on farmers' conservation decision (full

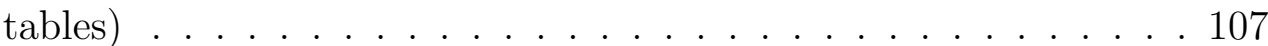

A3.9 Effects of three payment levels on farmers' conservation decision (full tables) . . . . . . . . . . . . . . . . 109

A3.10 Effects of six PES-schemes on farmer's conservation probability . . 111

4.1 Socio-econonomic and descriptive statistics . . . . . . . . . . . 129

4.2 Descriptives of EFB mulching . . . . . . . . . . . . . . . 132

4.3 Instrumental variable estimation of the effect of mulching on yields 133

4.4 Random effects panel data results of mulching on yields . . . . . . 135 
4.5 Pathway analysis of the effect of mulching on yields . . . . . . 136

4.6 Robustness checks . . . . . . . . . . . . . . . . . . . 138

A4.1 Effect of mulching on yields (2015-16 data) . . . . . . . . . . . 144

A4.2 Robustness checks for reduced form results of mulching on yields . 146

A4.3 Explanation of selected variables . . . . . . . . . . . . . . 148

A4.4 First stage results (instrument strategy) . . . . . . . . . . . . . . 149

A4.5 Effect of mulching on yields . . . . . . . . . . . . . . . . 150

A4.6 Pathway analysis of the effect of mulching on yields . . . . . . . 152

A4.7 First stage regression results (pathway analysis) . . . . . . . . . . 154

A4.8 OLS estimation of the direct mulching effect . . . . . . . . . . 155

A4.9 Mean difference tests between EFB farmers and external control

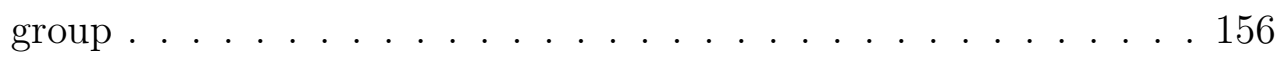




\section{List of Figures}

1.1 Location of Jambi in Indonesia (left) and location of villages in

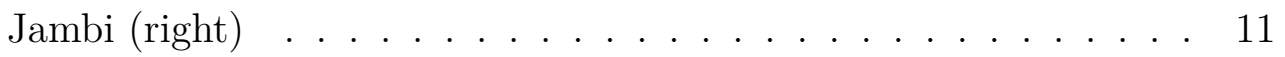

2.1 Location of treatment and control villages in Jambi . . . . . . . . 21

A2.1 Distribution of strictly positive tree planting quantities . . . . . . 47

3.1 Spatial arrangement of six participants . . . . . . . . . 68

3.2 Location of villages for framed field experiment in Jambi . . . . . 74

3.3 Average environmental effects generated . . . . . . . . . . . . 78

3.4 Average share of farmers who conserve (participation) . . . . . . 79

3.5 Average environmental effects generated per conserving farmer (coordination) . . . . . . . . . . . . . . . . . 79

A3.1 Example of poster used for explanation of experiment . . . . . . . 99

A3.2 Average budget efficiency (all groups) . . . . . . . . . . 106

4.1 Location of villages with soil samples in Jambi . . . . . . . . 120

4.2 Soil sampling strategy f . . . . . . . . . . . . . . . 121

4.3 Hypothesized pathways . . . . . . . . . . . . . . . . . 127 
Chapter 1

\section{Introduction}




\subsection{Oil palm expansion and its consequences in Indonesia}

Global demand for vegetable oil has been constantly rising in the last decades (OECD \& FAO, 2019). Population growth, changing consumption patterns and increases in biofuel consumption can be identified as main drivers (OECD \& FAO, 2019). Palm oil is the most widely consumed vegetable oil accounting for around $35 \%$ of the global demand (OECD \& FAO, 2019; Teoh, 2010). Reasons for its strong marketability are inter alia its suitable chemical properties, its long shelf-life as well as cost advantages in comparison to competitor oil crops due to low post-planting requirements for land, labor and other production inputs (Sheil, 2009; The World Bank \& IFC, 2011). As a consequence, palm oil is used as ingredient in a multitude of different products, covering food, cosmetic, and pharmaceutical goods among others (Vijay, Pimm, Jenkins, \& Smith, 2016).

Between 1980 and 2018, global palm oil production has increased by an estimated $1,300 \%$ (FAO, 2019). Due to the climatic requirements of the African oil palm (Elaeis guineensis Jacq), the production area is located in the tropics (Corley \& Tinker, 2016). While oil palm is cultivated in 43 countries (Vijay et al., 2016), its production is highly concentrated in two countries: Indonesia, the biggest producing country since 2008, and Malaysia, which alone produce $87 \%$ of the global supply (Austin et al., 2017; Rist, Feintrenie, \& Levang, 2010). However, in the last decade, production has also increased in South America, West Africa and other countries in South-East Asia (Foster et al., 2011; Vijay et al., 2016) suggesting a further global expansion.

The increase in palm oil production has led to important land use changes in the producing countries. In Indonesia, the area under oil palm cultivation has increased by $50 \%$ over the last 10 years (Bou Dib, Krishna, Alamsyah, \& Qaim, 2018) reaching $6,777,498$ ha in 2018 (FAO, 2019). At the same time, primary forest cover has declined, in particular in Sumatra and Kalimantan, which are the main oil palm producing areas in Indonesia (Carlson et al., 2013; Margono, Potapov, Turubanova, Stolle, \& Hansen, 2014; Margono et al., 2012). While not all oil palm expansion happened on forest area, it represents one of the main drivers of deforestation in Indonesia. Estimates suggest that between $31 \%$ and $54 \%$ of the established plantations replaced primary or secondary forest in the 1990s and 2000s (Austin et al., 2017; Vijay et al., 2016). Oil palm-induced deforestation has slowed down in Kalimantan and Sumatra since 2005 (Austin et al., 2017). Notwithstanding, 
increasing deforestation rates have been reported for newly emerging production areas such as Papua, threatening the regionally still existing primary rainforest (Austin et al., 2017).

Moist tropical forests that can be found in palm oil production areas are among the most biodiverse ecosystems on Earth (Fitzherbert et al., 2008). In particular, the islands of Sumatra and Kalimantan are considered a biodiversity hotspot. Notably, $5 \%$ of all global endemic plants and $2.6 \%$ of all global vertebrates identified can be found in the region (Myers, Mittermeier, Mittermeier, da Fonseca, \& Kent, 2000). Many of these species are specialists and (partially) depending on forest cover for survival (Fitzherbert et al., 2008). Oil palm plantations are characterized by a reduced plant diversity and architectural complexity, and a changed microclimate in comparison to forests (Foster et al., 2011). Consequently, the conversion of forest area into oil palm plantations is associated with reduced species diversity for a wide range of taxa, including butterflies (Koh \& Wilcove, 2008), plants (Drescher et al., 2016), birds and insects (Clough et al., 2016). Estimates suggest that on average across all taxa, only around $15 \%$ of all species found in forests are also present in oil palm plantations and in particular species with high conservation concerns are absent (Fitzherbert et al., 2008). In combination with the high endemism in the region, this highlights the consequences of oil palm expansion for global biodiversity loss.

Besides biodiversity loss, carbon and other greenhouse gas emissions induced by oil palm expansion represent global environmental threats due to their potential effect on global warming. Most carbon is released as a consequence of forest clearing due to fires (Carlson et al., 2013; Fargione, Hill, Tilman, Polasky, \& Hawthorne, 2008), the draining of peat land (Koh, Miettinen, Liew, \& Ghazoul, 2011; Murdiyarso, Hergoualc'h, \& Verchot, 2010) as well as the general removal of (the carbon stored in) above ground biomass (Guillaume et al., 2018). However, the loss of below ground biomass (Kotowska, Leuschner, Triadiati, Meriem, \& Hertel, 2015), as well as a reduction in soil carbon due to e.g. erosion (Guillaume, Damris, \& Kuzyakov, 2015; van Straaten et al., 2015) also contribute to these emissions While both biodiversity loss and carbon emissions represent global environmental problems, some environmental consequences are mostly felt locally through e.g. soil degradation and reduced water and microclimate regulation services (Dislich et al., 2017; Merten et al., 2016).

In contrast to its negative effects on the local and global environment, oil palm expansion has broadly contributed to income growth and improved welfare for 
the local population (Euler, Krishna, Schwarze, Siregar, \& Qaim, 2017; Feintrenie, Chong, \& Levang, 2010; Kubitza, Krishna, Alamsyah, \& Qaim, 2018; Rist et al., 2010). In 2018, the sector contributed to around 3.3\% of Indonesian GDP (Badan Pusat Statistik, 2019) and offered direct and indirect employment opportunities for estimated 4.3 million and 12 million individuals, respectively (Jelsma, Woittiez, Ollivier, \& Dharmawan, 2019). Positive welfare effects are in particular due to the strong involvement of smallholder farmers who produced around $40 \%$ of the national crude palm oil in 2018 (Badan Pusat Statistik, 2019).

However, welfare gains are not evenly distributed in the population. Contractual arrangements with companies and formal land titles could be, among others, identified as welfare determinants (Euler, Hoffmann, Fathoni, \& Schwarze, 2016; Gatto, Wollni, Asnawi, \& Qaim, 2017). As a consequence, in the early oil palm producing areas in Indonesia where oil palm cultivation was promoted by government supported migration schemes, in particular migrant farmers from Java have benefited (McCarthy, 2010). Better access to extension services and land titles explain their often privileged position in comparison to local farmers (Gatto et al., 2017; McCarthy, 2010). Local farmers in contrast are often excluded from oil palm adoption due to knowledge barriers and restricted access to credit markets (Obidzinski, Andriani, Komarudin, \& Andrianto, 2012) resulting in increased inequality between adopting and non-adopting farmers (Bou Dib, Alamsyah, \& Qaim, 2018; McCarthy, 2010). Besides potential conflicts between different types of smallholder farmers, the involvement of large industrial plantations has received considerable criticism in the literature because of land conflicts with the local population and precarious working conditions for laborers (Feintrenie, Chong, \& Levang, 2010; Obidzinski et al., 2012; Rist et al., 2010).

These examples indicate that oil palm expansion has had major environmental, economic and social consequences in Indonesia and thus affected all three dimensions of sustainability (United Nations, 2012). Mostly relevant for this dissertation are the economic and environmental dimensions. For the economic dimension, positive effects can be identified for large shares of oil palm farmers as oil palm expansion has contributed to income growth and poverty reduction. In contrast, the environmental dimension has been negatively affected because of species loss, soil degradation and carbon emissions. The goal of this dissertation is to contribute to the identification of policy and management options that could reduce these economic-ecological trade-offs. Besides being relevant for the oil palm specific context, the results of this thesis potentially can help to inform policies to mitigate environmental problems 
associated with the expansion of other cash crops.

\subsection{Policies and management practices to improve the sustainability of oil palm cultivation}

In order to reduce oil palm related environmental problems, two approaches can be adopted. The first focuses on policies to reduce land expansion and stop deforestation (Phalan, Fitzherbert, Rafflegeau, Struebig, \& Verwilghen, 2009). The second tries to improve the environmental performance of oil palm plantations (Foster et al., 2011; Koh, Levang, \& Ghazoul, 2009). While both approaches should be jointly considered, the second might be particularly promising in high production areas, where land use change is already advanced and little forest area remains. This is the case for many early oil palm production areas in Indonesia (Austin et al., 2017).

To inform policies in high production areas, the present dissertation explores oil palm management practices that can mitigate environmental-economic trade-offs. In addition, it tries to identify policies to promote their adoption and to enhance the environmental and/or economic outcomes. From an environmental perspective, the focus is on policies and management practices aiming at biodiversity and soil carbon restoration. These could mitigate global environmental problems associated with oil palm cultivation, but also improve the farming conditions of the local population through increased pest control or improved yield supporting soil ecosystem services. The following section will introduce two management practices that could reduce related trade-offs.

Planting native trees inside or along the border of oil palm plantations has been proposed as one way to increase biodiversity in oil palm plantations (Koh \& Wilcove, 2007; Miccolis, Robiglio, Cornelius, Blare, \& Castellani, 2019; Teuscher et al., 2016). Mixed oil palm systems harbor a greater species richness and abundance than monoculture systems (Ashraf et al., 2018; Syafiq et al., 2016; Teuscher et al., 2015; Yahya et al., 2017). Although the risk of negative effects on oil palm yields exists, already low planting intensities - with potentially little competition between palms and trees for nutrients, water and light - potentially can increase bird abundance and diversity (Teuscher et al., 2015). Moreover, fruits and timber derived from trees can generate economic returns, add to a healthy nutrition and diversify income sources (Gérard et al., 2017; Lin, 2011; Tscharntke et al., 
2012). This suggests that tree planting might be one option to reduce trade-offs between economic development opportunities for smallholder farmers and negative biodiversity effects.

Besides supporting biodiversity, trees can absorb and store carbon from the atmosphere (Goldman, Thompson, \& Daily, 2007). Soil organic carbon restoration represents another way to increase carbon sequestration in oil palm plantations (Minasny et al., 2017). Since soil organic carbon (SOC) is also linked to many soil ecosystem services that support crop growth, supporting soil carbon sequestration might also positively affect yields. This can help to close the yield gaps reported for smallholder oil palm plantations (Euler et al., 2016; Soliman, Lim, Lee, \& Carrasco, 2016; Woittiez, van Wijk, Slingerland, van Noordwijk, \& Giller, 2017) with likely positive effects on smallholders' income.

The second management practice explored in this dissertation is the mulching with empty fruit bunches (EFB) (Abu Bakar, Darus, Kulaseharan, \& Jamaluddin, 2011; Comte, Colin, Whalen, Grünberger, \& Caliman, 2012; Moradi, Teh Boon Sung, Goh, Husni Mohd Hanif, \& Fauziah Ishak, 2015; Tao et al., 2017). EFB are the bunches which remain after the oil fruits have been stripped off during processing at the palm oil mills. They are rich in carbon and hence could increase SOC contents. Moreover, EFB contain several nutrients and can be used as organic fertilizer. Therefore, EFB mulching represents a management practice likely to increase smallholders' yields.

\subsection{Research objectives}

This dissertation comprises three essays which address two broad research objectives. First, it investigates whether, and if so which policies can promote the uptake of tree planting in oil palm plantations as a means for biodiversity restoration. This research objective is addressed in the first and the second essay that provide experimental evidence on real (first essay) and hypothetical (second essay) tree planting adoption. Second, this thesis tries to quantify the ecological and economic effects of management practices and policies expected to reduce economic-ecological trade-offs. To this end, the second essay analyzes hypothetical farmers' income and landscape-level biodiversity effects generated from tree planting under different policies. The third essay explores the effects of EFB mulching on yields and SOC contents in oil palm smallholdings. The following section will present the addressed research gaps and the essay-specific research objectives. 
The first essay addresses the question of how the adoption of native tree planting can be promoted among smallholder farmers in Jambi Province, Sumatra. Focus group discussions and the agroforestry adoption literature (Meijer, Catacutan, Ajayi, Sileshi, \& Nieuwenhuis, 2015; van Noordwijk et al., 2008) indicate that knowledge and seed access barriers prevent tree planting. Consequently, providing information and seedlings likely could spur adoption.

Information provision through extension approaches can support the adoption of technologies aiming at agricultural income improvements (Benyishay \& Mobarak, 2018; Duflo, Kremer, \& Robinson, 2008; Kondylis, Mueller, \& Zhu, 2017; van Campenhout, Walukano, Nattembo, Nazziwa-Nviiri, \& Blom, 2017). Free or subsidized input provision can spur the uptake of technologies which are easy to use and do not generate negative side effects (Carter, Laajaj, \& Yang, 2013; Dupas, 2014). However, tree planting in oil palm plantations represents a very particular technology in that it aims at income diversification and especially biodiversity conservation, a global public good that might be linked to small direct monetary benefits to the farmers. The public benefits generated can explain the focus of the literature on monetary incentives as tree planting promoting policies (Jack, 2013; Jack, Oliva, Severen, Walker, \& Bell, 2015; Pagiola et al., 2007). This is despite potential advantages of non-monetary interventions and in particular extension approaches in comparison to compensation payments where negative side effects such as increased inequality and problems of unsecured financing have been reported (Muradian et al., 2013).

Neither the effects of information dissemination, nor the effects of free input provision on the adoption of a primarily environmentally motivated agricultural technology have received a lot of attention in the literature. The few exceptions are mostly based on cross-sectional data and often lack a clear identification strategy (e.g. Matata, Ajayi, and Oduol 2010, Meijer et al. 2015 for a review, Ruseva, Evans, and Fischer 2015, Gregorio, Herbohn, Harrison, and Smith 2015). To the best of my knowledge, there exists only one experimental paper that looks at information and subsidized seedling provision on tree planting on private land (Jack et al., 2015). Yet, the design does not allow to estimate the effects of the interventions on the number of trees planted. The latter is, however, important to derive more informed policy conclusions since a positive relationship between the number of trees in oil palm plantations and biodiversity effects is likely (Teuscher et al., 2015). Despite its relevance for global biodiversity loss, the specific oil palm context has so far been neglected in the literature. 
To provide evidence on the effects of information and free seedling provision on the number of trees planted per hectare in oil palm plots, a randomized controlled trial (RCT) was implemented. Two interventions were designed: The first provided only information about tree planting in oil palm plantations, while the second combined information with free seedling provision. The first essay presents intentionto-treat effects of the interventions on the number of trees planted per hectare in oil palm plantations. In addition, it analyzes whether free seedling provision discourages tree planting beyond what is provided for free by looking at the number of self-procured trees planted. Finally, heterogeneous treatment effects depending on the constraints farmers face, cost-effectiveness measures, as well as tree survival and its potential drivers are explored.

Tree planting might generate positive biodiversity effects at the local plantation level. For an efficient up-scaling from the local to the regional level, it is important to take into consideration landscape-level requirements for biodiversity conservation. These comprise both the composition of the landscape, i.e. the proportion of different habitat types, and its configuration, i.e. the spatial arrangement of the different land-uses (Goldman et al., 2007; Liere, Jha, \& Philpott, 2017).

The effects of landscape composition, as measured by the area size under natural or semi-natural habitat, on species diversity are likely characterized by non-linearities and threshold (Kupsch et al., 2019; Martensen, Ribeiro, Banks-Leite, Prado, \& Metzger, 2012; Ochoa-Quintero, Gardner, Rosa, Ferraz, \& Sutherland, 2015; Tscharntke, Batáry, \& Dormann, 2011). If the area falls below these thresholds, species diversity might decline abruptly and the risk of species extinction might arise (Fahrig, 2003; Pardini, Bueno, Gardner, Prado, \& Metzger, 2010). The configuration of a landscape measures inter alia how well natural or restored patches are connected. Connectivity between habitat is important for species exchange between different patches (Holzschuh, Steffan-Dewenter, \& Tscharntke, 2010). Moreover, conserved or restored areas might serve as corridors which could link remaining forest patches and facilitate movements of forest dependent species (Gilbert-Norton, Wilson, Stevens, \& Beard, 2010; Höbinger, Schindler, Seaman, Wrbka, \& Weissenhofer, 2012; Koh et al., 2009). A suitable landscape for conservation of a broad range of species is thus likely characterized by a critical size of conservation area that is further spatially connected. The question of how policies need to be designed to create such landscape patterns is the topic of the second essay.

The second essay looks at financial compensation mechanisms to promote tree planting adoption. Tree planting in this essay entails larger scale conversion of 
plantations into mixed oil palm-tree systems and the cutting of parts of the plantations. This likely leads to considerable income reductions for farmers motivating the analysis of financial compensation mechanisms such as payments for ecosystem services (PES) schemes. PES are voluntary, often financial, transactions between beneficiaries and providers of ecosystem services that are conditional on agreed rules of natural resource management and aim at providing environmental benefits (Wunder, 2015). To increase their environmental effectiveness, PES schemes should be designed to meet the landscape level requirements for biodiversity conservation.

In order to generate an environmentally relevant conservation area size, some authors have suggested to make compensation mechanisms subject to reaching the required area at a predefined scale (Cadsby \& Maynes, 1999; Le Coent, Preget, \& Thoyer, 2014; Midler, Pascual, Drucker, Narloch, \& Soto, 2015; Narloch, Pascual, $\&$ Drucker, 2012). Others have analyzed options to increase the spatial connectivity between conserved plots, either by offering bonus payments if bordering land is put under conservation (Banerjee, 2018; Parkhurst \& Shogren, 2007; Parkhurst et al., 2002) or by making the spatial connectivity of the conserved areas a prerequisite for compensation (Wätzold \& Drechsler, 2014). However, both aspects have only been analyzed separately yet. Most studies analyzing PES design options are based on laboratory or framed field experiments, whose results are highly dependent on the scenario created within the experiment. Therefore, an extrapolation of which design options are most suited to reach both critical area thresholds and an increased connectivity between conserved plots is difficult. Moreover, experimental evidence on the effectiveness of bonus payments is almost entirely based on laboratory experiments conducted with students (e.g. Banerjee 2018; Banerjee, Cason, de Vries, and Hanley 2017). Evidence is therefore needed on whether these policy instruments are also promising when real decision makers make (hypothetical) land use decisions outside the fully controlled laboratory environment.

To close this research gap, I implemented a framed field experiment with oil palm smallholders. In the experiment, farmers needed to decide whether to maintain their oil palm plantation or whether to switch to a mixed system in which around $40 \%$ of the oil palms have been cut and replaced with native trees. Because of the positive effects of trees on bird and other pollinator diversity (see above), the planting of native trees generates biodiversity effects. These effects are represented as donations to an environmental NGO (e.g. Ibanez, Moureau, and Roussel 2017; Kuhfuss, Hanley, Preget, Thoyer, and de Vries 2017). Drawing on evidence from forest, other semi-natural or restored areas (Gilbert-Norton et al., 2010; Hass et 
al., 2018; Ochoa-Quintero et al., 2015; Tscharntke et al., 2011) and on evidence of positive effects of rainforest proximity on bird diversity in oil palm plots (Azhar et al., 2011), biodiversity effects are only generated if a critical mass of farmers conserve, and effects are greater if bordering land is put under conservation.

The second essay compares two PES designs that differ in the requirements for receiving compensation payments. In the first, farmers who conserve receive compensation if at least three farmers in a group of six do so. In the second, conserving farmers are compensated if three farmers with bordering land conserve in the group. In addition, the essay analyzes the effects of different payment levels and of communication on farmers' decision to plant the mixed system in their plantations. At the group level, it explores the magnitude of the hypothetical biodiversity outcomes generated under the two PES designs. Finally, budget efficiency and overall welfare effects will be discussed.

The third essay analyses whether EFB mulching increases yields and SOC in smallholder oil palm plantations. Several papers have indicated that EFB mulching can increase yields and SOC contents (Abu Bakar et al., 2011; Moradi et al., 2015; Tao et al., 2017; Teh Boon Sung, Joo, Chien, \& Seng, 2011), but that effects are context specific (Comte et al., 2013). Most evidence on the effects of EFB mulching is derived from experimental studies in industrial plantations. Despite their growing importance in the palm oil sector (Badan Pusat Statistik, 2019), to the best of my knowledge, the effects of EFB mulching in smallholdings have not been analyzed yet. However, smallholder farmers manage their plantations under conditions which can be substantially different to those in experimental studies (Duflo et al., 2008). An extrapolation of the results from experimental studies to smallholder plantations is consequently difficult.

The third essay combines panel data on yields and management practices with cross-sectional data derived from soil samples taken in smallholder plantations to assess the effects of EFB mulching on yields and SOC contents. Given the potential endogeneity of EFB mulching, identification of these effects is based on instrumental variable estimation. Furthermore, the essay analyzes whether the effects of EFB mulching on yields operates through improvements in SOC contents. This adds to the scarce evidence on whether SOC is important to support yields of perennial crops such as oil palm (e.g. Gérard et al. (2017); Tao et al. (2017)). 
Figure 1.1: Location of Jambi in Indonesia (left) and location of villages in Jambi (right)
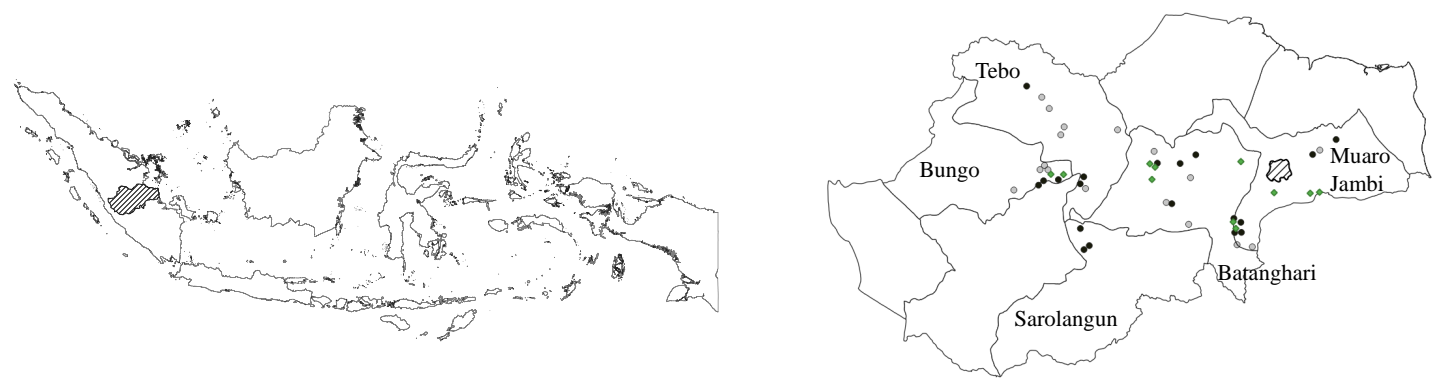

Lines in right picture indicate regency delimiters and shaded area indicates the location of Jambi city. Dots refer to the villages in which the RCT was implemented. Black dots indicate the subsample of the villages with additional soil samples. Green triangles indicate the villages in which the framed field experiment was implemented.

\subsection{Study area and data}

As part of the collaborative research center 990 Ecological and Socioeconomic Functions of Tropical Lowland Rainforest Transformation Systems (Sumatra, Indonesia) (EFForTS), the research presented in this thesis was conducted in Jambi Province, in Sumatra, Indonesia (Figure 1.1). Oil palm was introduced in Jambi in the 1980s through the government-led transmigration program. Within its framework, poor farmers were relocated from the overpopulated islands of Java and Bali to less populated ones, mostly to Sumatra. These new settlers received two to three hectares of land for oil palm cultivation as well as access to inputs and extension. Since the 1980s, the province has turned into one of the hotspots of oil palm cultivation in Indonesia and has been affected by tremendous land use changes. Between 1990 and 2016, the area under oil palm cultivation has increased fourfold and bypassed rubber as the main crop in the region in 2012 (Bou Dib, Alamsyah, \& Qaim, 2018). While oil palm is not the sole driver of deforestation, unprotected forest cover decreased by more than $75 \%$ in a similar time span (1990-2011) (Clough et al., 2016). In 2018, Jambi Province ranked seventh with regard to the area under oil palm cultivation among all 34 provinces (Badan Pusat Statistik, 2019). While the national average of smallholder engagement is around $46 \%$ as measured in terms of production area, it amounts to $75 \%$ in Jambi and is thus substantially higher (Badan Pusat Statistik, 2019). 
This dissertation builds on various primary data collected in Jambi between 2015 and 2018. Chapter 2 uses data from a representative household survey that covers the lowland area of Jambi. The lowland area has been most heavily affected by the discussed transformation of rainforest into oil palm and rubber plantations (Gatto, Wollni, \& Qaim, 2015). It comprises five regencies, Muaro Jambi, Batanghari, Sarolangun, Tebo, and Bungo (Figure 1.1). In 2015, 36 oil palm growing villages were selected. To capture the heterogeneity of oil palm cultivation in Jambi, 27 of these villages are transmigrant while nine are local villages. Transmigrant villages refer to those villages that were founded under the transmigration program and that are mostly inhabited by migrants from Java. In contrast, most individuals living in local villages have Melayu background (Krishna, Euler, Siregar, \& Qaim, 2017). The transmigrant villages were randomly selected out of a list of all transmigrant villages where at least $70 \%$ of the households were engaged in oil palm cultivation. Since many local farmers are growing rubber, this threshold was lowered to $30 \%$ for local villages. Per village, 22 to 24 households that grow oil palm without contractual arrangements (independent farmers) were randomly selected leading to a total sample size of 817 farmers. Data collection took place in 2015 and 2016 and information on oil palm management, native tree planting and socio-economics was assessed. The attrition rate between both years is $10 \%$. In the beginning of 2016 , a RCT was implemented. The randomization strategy is discussed in chapter 2. For the analysis of the RCT, chapter 2 mostly uses 2015 baseline socio-economics, and information on tree planting and survival collected in 2016.

Chapter 4 builds on a subsample of the former data set. Out of the 36 villages, 18 villages were randomly selected. Due to high non-response rates, eventually a 19 th village was included in the sample. These villages cover all five districts of the lowland area. To construct the sample, farmers interviewed in 2016 were stratified according to whether they applied EFB mulching on at least one plot or not. 32 farmers applying EFB mulching and 97 control farmers are part of the final sample. For these farmers, additional information on soil conservation practices and oil palm management was collected in 2017. Per farmer, one plot was selected for soil sampling to assess SOC contents. The identification of the effect of EFB mulching on yields is based on panel data covering the years 2015-2017. The instrumentation strategy uses the GPS location of the villages, as well as the GPS location of the palm oil mills found in Jambi. Information on the latter was retrieved from the Universal Mill List (World Resources Institute et al., 2019). The analyses of the effect of mulching on SOC contents, and of the pathways through which mulching 
affects yields use the 2017 data. To conduct robustness checks for the effects of mulching on SOC contents, the data is combined with soil and socio-economic data collected in 37 oil palm plantations by another research team of the CRC (Euler et al., 2017; Guillaume, Holtkamp, Damris, Brümmer, \& Kuzyakov, 2016).

Chapter 3 uses data from the framed field experiment implemented in 2018. The study area is restricted to the three regencies in the lowland area with the highest share of oil palm cultivation area in 2016, which are Muaro Jambi, Batanghari and Bungo (Badan Pusat Statistik Provinsi Jambi, 2019). 11 villages were selected. Since transmigrant villages account for the largest share of oil palm in Jambi (Gatto et al., 2015), eight transmigrant and three local villages were included. Village selection was not done randomly and hence the sample is not representative for the three regencies. The criterion for the inclusion into the sample was that at least $25 \%$ of the farmers in the village grew oil palm. Moreover, I tried to include villages where little $\mathrm{CRC}$ research was conducted before. This was meant to reduce the potential influence of stimuli farmers might have received by former interviews, and the time load put on the farmers and the village employees. In particular, I took care to avoid the villages in which the RCT presented in chapter 2 was conducted since the informational campaign might have affected the results of the framed field experiment. In each village, 36 households were randomly selected. Only households owning and managing oil palm plantations are part of the sample. In each household, the person in charge of managing the oil palm plantation was interviewed. Due to logistical problems in one village, only 12 farmers could finally be selected to be part of the survey. Therefore, 12 additional farmers were selected in two other villages leading to 48 farmers in these villages. In total, the sample comprises 396 farmers.

\subsection{Outline of dissertation}

This dissertation is organized as follows: Chapter 2 analyzes the effects of information and seedling provision on the number of trees planted per hectare in oil palm plantations and on tree survival. Chapter 3 explores whether PES schemes can promote tree planting and how different PES designs affect individual tree planting probabilities and group-level environmental outcomes. The effects of EFB mulching on yields and SOC are presented in chapter 4. Chapter 5 summarizes the main findings and presents limitations as well as sustainability and policy implications. The relevant sections of the questionnaire for chapters 2 and 4 as 
well as the experimental protocol and the ethical approval for chapter 3 can be found in the General Appendix. 


\section{Chapter 2}

\section{Effects of information and \\ seedling provision on tree \\ planting and survival in \\ smallholder oil palm plantations}

This chapter has been accepted for publication in the Journal of Environmental Economics and Management. It is co-authored by Miriam Romero, Rosyani Asnawi, Bambang Irawan and Meike Wollni. MR designed and implemented the RCT and conducted the baseline survey. RA and BI helped with the implementation of the RCT in Jambi. MR und KR jointly conducted the follow-up survey. KR developed the idea of this essay, analyzed the data and wrote the paper. MR commented on first draft. MW commented on results and helped revising the manuscript. I would like to thank Esther Gehrke for the helpful comments on the first draft of this paper as presented in the DARE doctoral seminar. Furthermore, I am grateful to two anonymous reviewers who provided very helpful comments and suggestions in the submission process of the related paper. 


\section{$2.1 \quad$ Introduction}

Agricultural expansion is a major driver of biodiversity loss, which is currently at unprecedentedly high levels, as emphasized in the recent report of the Intergovernmental Science-Policy Platform on Biodiversity and Ecosystem Services (Diaz, Settele, \& Brondizio, 2019). In South-East Asia, agricultural expansion during the last three decades has been mainly driven by oil palm production (Gibbs et al., 2010). Responding to high demand in international markets, the production area has increased six fold between 1990 and 2017 (FAO, 2019). The region is now the main producer of palm oil in the world, accounting for over $85 \%$ of global palm oil production (FAO, 2019). Approximately $31 \%$ to $50 \%$ of the oil palm plantations are established on land that was formerly forest area (Austin et al., 2017; Meijaard et al., 2018; Vijay et al., 2016). Since tropical rainforests globally show the highest level of biodiversity (Diaz et al., 2019) and since only around $15 \%$ of the recorded species living in primary forests can be found in oil palm plantations (Fitzherbert et al., 2008), this expansion has led to a drastic decrease in local and global biodiversity.

The limited range of taxa found in oil palm plantations is in particular due to the reduced vegetation complexity within the plantations (Koh et al., 2009). One approach to increase the structural complexity is the planting of native trees inside oil palm plantations (Zemp, Ehbrecht, et al., 2019). Positive biodiversity effects of polycultural plantations, where trees and other crops are grown within oil palm plantations, in comparison to pure monocultural plantations have been shown for bird, arthropod and bat communities (Ashraf et al., 2018; Ghazali et al., 2016; Syafiq et al., 2016; Teuscher et al., 2016; Yahya et al., 2017). Most of these studies do not consider different planting intensities of trees or other crops, and therefore cannot derive empirical evidence on the relationship between the number of trees planted and biodiversity effects. One exception is Teuscher et al. (2016) analyzing biodiversity effects of native tree islands in oil palm plantations, who systematically vary tree island size $^{1}$, but do not find a statistically significant correlation with biodiversity effects after one year of tree planting. However, in a study with smallholder oil palm farmers, Teuscher et al. (2015) show that already small increases in the number of trees planted per hectare can positively affect bird abundance and species richness in oil palm plantations.

\footnotetext{
${ }^{1}$ Tree islands refer to native trees planted in clusters within oil palm plantations. Teuscher et al. (2016) study tree islands with 6, 25, 100 and 400 trees.
} 
The present study addresses the question of how native tree planting can be promoted in oil palm plantations of small-scale farmers in Sumatra, Indonesia. Small-scale farmers are increasingly engaged in oil palm cultivation, accounting for approximately $50 \%$ of the total oil palm area in Sumatra (Badan Pusat Statistik, 2019), and thus represent key addressees of policies promoting sustainable plantation management. Various studies have documented that smallholder farmers and their families have benefited significantly from oil palm cultivation in terms of income gains (Euler et al., 2017; Feintrenie, Schwarze, \& Levang, 2010; Kubitza, Krishna, Alamsyah, \& Qaim, 2018). Smallholder oil palm plantations in our study area typically resemble large-scale plantations in terms of being homogeneous monocultural stands, and only few farmers maintain individual trees - usually remnants - in their plantations (Teuscher et al., 2015). ${ }^{2}$ From a farmer's perspective, planting native trees in their oil palm plantations bears the risk of affecting oil palm yields negatively. Lower oil palm yields may result from competition for light, water and nutrients between trees and oil palms (Teuscher et al., 2015) although some studies have also reported insignificant or tentative evidence of positive yield effects (Corley \& Tinker, 2016; Miccolis et al., 2019). Moreover, farmers may also derive benefits from native trees, such as fruits and timber and increased resilience through the diversification of income sources.

Relatively little is known about what instruments are suitable to induce biodiversity-friendly land uses such as native tree planting. Most studies focusing on agroforestry-like practices or tree planting analyze the effects of existing payments for ecosystem services (PES) contracts that compensate adopters financially for their planting efforts (Pagiola et al., 2007; Wunder \& Albán, 2008). Relatively few studies compare different policy designs with regard to their effectiveness to induce tree planting. Exceptions are Jack (2013) who compares a lottery and an auction PES contract design for tree planting, and Jack et al. (2015) who analyze the effect of varying levels of seedling subsidies and reward payments on tree planting and survival. The focus on financial rewards can be motivated by limited private benefits and by the positive externalities generated through tree planting (Jack et al., 2015). Nonetheless, in particular in developing countries, market inefficiencies that hinder technology adoption can stem from several sources and individuals might face constraints simultaneously in several dimensions (Foster \& Rosenzweig, 2010; Knowler \& Bradshaw, 2007). Among others, a lack of information and missing access to input markets have been identified to impede the uptake of tree planting

\footnotetext{
${ }^{2}$ In our study area, around $28 \%$ of the farmers have trees in their plantations.
} 
(Romero, Wollni, Rudolf, Asnawi, \& Irawan, 2019) and agroforestry (Meijer et al., 2015; van Noordwijk et al., 2008). Despite their importance, these potential barriers have so far received little attention in the literature analyzing policy incentives for tree planting.

More generally for the case of agricultural technologies, previous studies have shown that information provision can effectively spur adoption among small-scale farmers in developing countries (Aker, 2011). Most of these studies, however, focus on productivity-enhancing technologies such as soil fertility management (Benyishay \& Mobarak, 2018; Kondylis et al., 2017), fertilizer application (Duflo et al., 2008) or generally improved management practices (Cole \& Fernando, 2016; van Campenhout, van Asten, Rashed, Vandevelde, \& Walukano, 2017). However, farmers might be reluctant to adopt an agricultural technology that is not primarily intended to increase income or productivity, but rather to diversify income and production patterns, and in particular to improve regional and global environmental conditions. While there is evidence that farmers' land use choices are also affected by environmental and social motives (Greiner \& Gregg, 2011), rigorous evaluations of the effect of information provision on land management decisions with primarily environmental motives are scarce.

In the presence of positive environmental externalities, additional incentives in the form of free or subsidized input provision may be justified and necessary to significantly increase technology uptake. Free or subsidized input provision can potentially relieve constraints, such as missing access to input markets or high transaction costs (Bensch \& Peters, 2020; Omotilewa, Ricker-Gilbert, \& Ainembabazi, 2019), frequently hindering technology adoption among small-scale farmers in developing countries. However, some scholars have questioned the suitability of free or heavily subsidized input provision based on two main arguments: First, free provision might reduce product use or the maintenance given to the goods in comparison to when a positive price is charged. Possible explanations are linked to the inability of the providers to differentiate between individuals deriving low and high utility from the respective technology use, so called screening effects, or to the lower sunk costs of losing the good (Ashraf, Berry, \& Shapiro, 2010; Thaler, 1980). In particular for long-lived goods such as trees, lack of maintenance after adoption might lead to low survival rates of the seedlings planted. Second, the one-time free or subsidized provision might negatively affect future or further acquisition of the good by setting a price benchmark too low for free market transactions (Bensch \& Peters, 2020; Dupas, 2014; Omotilewa et al., 2019). 
Recent empirical evidence shows that the subsidized provision of goods which are easy to use and do not generate negative side effects does not reduce product use (Carter et al., 2013; Dupas, 2014), or the willingness to pay for the good in markets (Omotilewa et al., 2019). The picture is less clear for goods that require continued care such as improved stoves, for which both positive effects of free provision on stove maintenance (Bensch \& Peters, 2020) and high abandonment rates have been reported (Hanna, Duflo, \& Greenstone, 2016). In particular, there is scarce evidence on how free input provision affects use and care for goods with limited private, but substantial public environmental benefits. In contrast to goods aiming at improved private health outcomes or increased agricultural income, the decision to adopt a technology with positive environmental externalities, such as tree planting, might also be motivated by altruistic or environmental motives. These intrinsic motivations can potentially interact with the external interventions that subsidize the respective action. As a result, tree planting activities that go beyond the subsidized material might be discouraged or farmers might stop tree planting and maintenance activities when subsidies cease (Gneezy, Meier, \& Rey-Biel, 2011).

Previous research on the effect of free or subsidized seedling provision on tree planting in general supports a positive correlation (Ruseva et al., 2015). Yet, some authors have raised concern over potential negative effects on the local seedling supply system, which could imply negative effects on further acquisitions (Gregorio et al., 2015; Harrison, Gregorio, \& Herbohn, 2008). There is hardly any experimental literature quantifying the effect of subsidized seedlings provision on tree planting and maintenance, with the exceptions of Romero et al. (2019), who find that the free provision of seedlings increases the probability of tree planting, and Jack et al. (2015), who observe a positive relationship between the size of the take-up subsidy and tree planting, but no significant effect on tree survival. None of these studies analyze planting intensity - the number of trees planted - and can therefore draw insights on whether the provision of free or subsidized seedlings discourages further planting efforts.

In this study, we use a randomized controlled trial to test the effects of two distinct policy interventions on tree planting and survival. The first intervention provides information on native tree planting in oil palm plantations. The second intervention combines the provision of information with the provision of free seedlings. The combined intervention allows us to identify whether providing farmers with free seedlings in addition to information dissemination significantly 
increases farmers' tree planting activities in oil palm plantations, compared to the pure information intervention. In a double-hurdle framework, the probability of farmers to plant seedlings in oil palm plantations and their planting intensity, measured as the number of trees planted per hectare, are analyzed. We also assess whether the provision of free seedlings discourages tree planting beyond what is provided for free. To derive more explicit policy implications, we compare the cost effectiveness of the two interventions with respect to the total number of trees planted and survived. Finally, since the ecological effectiveness of the interventions is subject to tree survival, we analyze the drivers of farmers' performance in terms of their tree survival rates. Next, section 2.2 describes the experimental design, the interventions, the data collection process, as well as the estimation strategy. Results on tree planting and survival as well as cost effectiveness considerations are presented in section 2.3. Section 2.4 concludes.

\subsection{Study design, data and estimation strategy}

\subsubsection{Study area and sampling strategy}

Our study took place in Jambi Province, one of the hotspots of oil palm cultivation in Indonesia (Krishna et al., 2017). Oil palm was introduced in Jambi in the 1980s through a government program which supported the expansion of oil palm. Within this so-called transmigration program, poor farming households were relocated from the overpopulated islands of Java and Bali to less populated ones, mostly to Sumatra (Euler et al., 2016). These new settlers received two to three hectares of land for oil palm cultivation as well as extension services and inputs for oil palm cultivation.

We focus on five regencies in Jambi - Muaro Jambi, Batanghari, Sarolangun, Tebo, and Bungo - that represent the lowland area of Jambi, which has been mainly affected by rainforest transformation into oil palm and rubber plantations (Gatto et al., 2015) (Figure 2.1). In total, 36 oil palm growing villages were selected, $75 \%$ of which are transmigrant villages and $25 \%$ local villages. ${ }^{3}$ To construct the sampling frame, we listed all transmigrant villages in the study area that have a main focus

\footnotetext{
${ }^{3}$ By transmigrant (local) villages, we understand villages in which mostly transmigrant (local) farmers live. Local farmers belong to the Melayu ethnic group while transmigrant farmers are mostly Javanese. Since especially local Melayu farmers, who are more and more switching from rubber to oil palm cultivation, will drive the further expansion of oil palm, we opted to include both village types in the sample.
} 
Figure 2.1: Location of treatment and control villages in Jambi

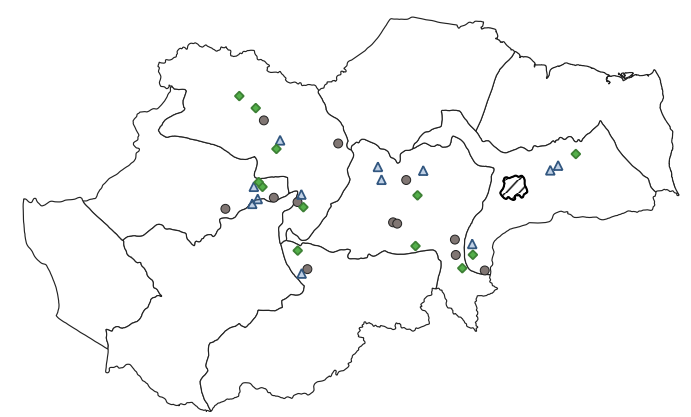

The lines indicate the regency delimiters and the shaded area the location of Jambi city. Control villages are indicated by dots. Blue triangles indicate T1 villages. Green rhombi indicate T2 villages.

on oil palm production. ${ }^{4}$ Out of a total of 90 transmigrant villages, we randomly selected 27 villages to be included in our sample. In addition, we identified nine local villages with a main focus on oil palm production in the study area and included them in our sample. ${ }^{5}$ We obtained village level data from the Village Potential Statistics (PODES) census dataset collected in 2008 by the Indonesian Central Bureau of Statistics. To complement the data, we implemented a small village survey in September 2015, which elicited information on seedling market access, extension services and other village-specific information. Lists with all oil palm growing households were provided by the village staff.

Contract-farming arrangements between oil palm smallholders and companies are common in the study region and were in particular promoted at the beginning of oil palm expansion (Gatto et al., 2015). As farmers who are under contract with companies do not have full autonomy over management decisions, which could impact the results of our interventions, we restrict our sample to independent smallholders who grow oil palms without contractual arrangements. Within each of the villages, we randomly selected 22 to 24 households. In total, 817 farmers were part of the sample. We conducted a baseline survey in the villages from October until December 2015 to collect information on the number, the species and the location of trees planted in the last 12 months, as well as household descriptives.

\footnotetext{
${ }^{4}$ The criterion for inclusion was that at least $70 \%$ of the dwellers report oil palm production to be their main occupation.

${ }^{5}$ For local villages we had to adjust the criterion to at least $30 \%$ of the dwellers reporting oil palm production to be their main occupation, because local villages are mainly engaged in rubber production and oil palm expansion is more recent (Euler et al., 2016).
} 
The interviews were carried out by twelve local assistants who were students from the Indonesian universities of Jambi and Bogor Agricultural University. After pre-testing the questionnaire in four villages, the assistants were trained intensively in the classroom and in the field. Follow-up data was collected from October till December 2016. 90\% of all farmers could be interviewed again resulting in a sample of 737 farmers in the follow-up.

\subsubsection{Randomization approach}

In order to reduce the risk of spill-over effects, random assignment was done at village level. Villages were allocated to two treatment arms, Treatment 1 (T1) and Treatment 2 (T2), and one control arm with help of a stratified randomization technique. As stratification variables, we used the migration status of the village (transmigrant or local), whether or not a village had access to seedling markets (Yes/No) and the share of oil palm growing households in the village (above or below $73.5 \%)$. Within each of the generated six strata, an equal number of villages were assigned to the three experimental arms with help of a random number generator. In the end, each arm contained twelve villages.

Table 2.1 presents baseline descriptives of the sample. In order to test whether randomization was successful in creating balance between groups, we conduct 60 mean difference tests. The number of farmers who cut trees in their plantation in 2015 and the household size are statistically different between the treatment groups at the $1 \%$ level. Additionally, we find that the share of farmers who refer to problems of getting seedlings is statistically different between $\mathrm{T} 1$ and the control group at the $1 \%$ level. With regard to the possession of home gardens, farmers in T2 possess slightly more often a home garden than farmers in the control group, but the difference is only marginally significant (p-value: 0.094). Given that some imbalance can occur by chance (Morgan \& Rubin, 2012), the randomization can be considered successful.

\subsubsection{Description and implementation of treatments}

To test the effect of two policy options on tree planting in oil palm plantations, two interventions were designed: one provides only information (T1), while the other one combines information with free provision of six seedlings (T2). Information was delivered through a video that we composed and filmed in collaboration with a local 
Table 2.1: Baseline descriptives and mean comparison tests

\begin{tabular}{|c|c|c|c|c|c|c|c|}
\hline & $\begin{array}{l}(1) \\
\text { Total }\end{array}$ & $\begin{array}{c}(2) \\
\text { Control }\end{array}$ & $\begin{array}{l}(3) \\
\mathrm{T} 1\end{array}$ & $\begin{array}{l}(4) \\
\mathrm{T} 2\end{array}$ & $\begin{array}{c}(5) \\
\mathrm{C}=\mathrm{T} 1\end{array}$ & $\begin{array}{c}(6) \\
\mathrm{C}=\mathrm{T} 2\end{array}$ & $\begin{array}{c}(7) \\
\mathrm{T} 1=\mathrm{T} 2\end{array}$ \\
\hline & \multicolumn{4}{|c|}{ Mean estimates, standard deviation below } & \multicolumn{3}{|c|}{ P-values } \\
\hline \multicolumn{8}{|c|}{ Household head characteristics } \\
\hline $\begin{array}{l}\text { Age of HH head } \\
\text { (in years) }\end{array}$ & $\begin{array}{l}49.52 \\
(10.42)\end{array}$ & $\begin{array}{c}49.14 \\
(10.19)\end{array}$ & $\begin{array}{c}49.62 \\
(10.97)\end{array}$ & $\begin{array}{c}49.79 \\
(10.11)\end{array}$ & 0.686 & 0.645 & 0.902 \\
\hline $\begin{array}{l}\text { Years of education } \\
\text { HH Head }\end{array}$ & $\begin{array}{l}7.53 \\
(3.61)\end{array}$ & $\begin{array}{c}7.67 \\
(3.65)\end{array}$ & $\begin{array}{c}7.42 \\
(3.62)\end{array}$ & $\begin{array}{c}7.49 \\
(3.58)\end{array}$ & 0.480 & 0.598 & 0.835 \\
\hline $\begin{array}{l}\text { Access to env. extension } \\
(1=\text { Yes } / 0=\mathrm{No})\end{array}$ & 0.08 & 0.05 & 0.08 & 0.09 & 0.339 & 0.349 & 0.870 \\
\hline $\begin{array}{l}\text { Gender of HH head } \\
(1=\text { female } / 0=\text { male })\end{array}$ & 0.02 & 0.03 & 0.01 & 0.01 & 0.108 & 0.184 & 0.738 \\
\hline \multicolumn{8}{|c|}{ Household characteristics } \\
\hline $\begin{array}{l}\text { Household size } \\
\text { (No. of persons) }\end{array}$ & $\begin{array}{c}3.96 \\
(1.50)\end{array}$ & $\begin{array}{c}3.93 \\
(1.57)\end{array}$ & $\begin{array}{c}3.83 \\
(1.38)\end{array}$ & $\begin{array}{c}4.13 \\
(1.53)\end{array}$ & 0.474 & 0.110 & $0.009^{* * *}$ \\
\hline $\begin{array}{l}\text { Value of assets } \\
\text { (in } 1,000 \mathrm{IDR} \text { ) }\end{array}$ & $\begin{array}{l}49745.24 \\
(492402)\end{array}$ & $\begin{array}{l}32778.05 \\
(56654.4)\end{array}$ & $\begin{array}{c}84134.21 \\
(846562.7)\end{array}$ & $\begin{array}{c}32011.06 \\
(55756.89)\end{array}$ & 0.262 & 0.949 & 0.253 \\
\hline $\begin{array}{l}\text { Other crops cultivated } \\
(1=\text { Yes } / 0=\mathrm{No})\end{array}$ & 0.28 & 0.29 & 0.26 & 0.29 & 0.655 & 0.994 & 0.715 \\
\hline $\begin{array}{l}\text { Total land owned } \\
\text { (in ha) }\end{array}$ & $\begin{array}{c}5.69 \\
(6.85)\end{array}$ & $\begin{array}{l}5.68 \\
(5.2)\end{array}$ & $\begin{array}{c}5.81 \\
(9.38)\end{array}$ & $\begin{array}{c}5.58 \\
(5.07)\end{array}$ & 0.845 & 0.830 & 0.720 \\
\hline $\begin{array}{l}\text { Home garden } \\
(1=\text { Yes } / 0=\mathrm{No})\end{array}$ & 0.91 & 0.83 & 0.91 & 0.96 & 0.273 & $0.094^{*}$ & 0.216 \\
\hline \multicolumn{8}{|c|}{ Farm characteristics } \\
\hline $\begin{array}{l}\text { Total ha oil palm } \\
\text { managed }\end{array}$ & $\begin{array}{c}4.45 \\
(6.16)\end{array}$ & $\begin{array}{c}4.42 \\
(4.15)\end{array}$ & $\begin{array}{c}4.63 \\
(8.95)\end{array}$ & $\begin{array}{c}4.29 \\
(4.06)\end{array}$ & 0.752 & 0.701 & 0.603 \\
\hline $\begin{array}{l}\text { Share of plots with } \\
\text { systematic land titles }\end{array}$ & $\begin{array}{c}0.68 \\
(0.43)\end{array}$ & $\begin{array}{c}0.7 \\
(0.43)\end{array}$ & $\begin{array}{c}0.66 \\
(0.43)\end{array}$ & $\begin{array}{c}0.7 \\
(0.42)\end{array}$ & 0.452 & 0.942 & 0.586 \\
\hline $\begin{array}{l}\text { Share of plots flooded } \\
\text { in last } 12 \text { months }\end{array}$ & $\begin{array}{c}0.13 \\
(0.32)\end{array}$ & $\begin{array}{c}0.1 \\
(0.28)\end{array}$ & $\begin{array}{c}0.16 \\
(0.35)\end{array}$ & $\begin{array}{c}0.15 \\
(0.33)\end{array}$ & 0.186 & 0.293 & 0.759 \\
\hline Plot age (in years) & $\begin{array}{l}14.83 \\
(6.57)\end{array}$ & $\begin{array}{l}15.52 \\
(6.13)\end{array}$ & $\begin{array}{c}14.4 \\
(6.26)\end{array}$ & $\begin{array}{l}14.59 \\
(7.25)\end{array}$ & 0.222 & 0.503 & 0.842 \\
\hline $\begin{array}{l}\text { Mean number of trees } \\
\text { per ha in OP }\end{array}$ & $\begin{array}{c}3.43 \\
(26.76)\end{array}$ & $\begin{array}{c}5.07 \\
(43.24)\end{array}$ & $\begin{array}{c}2.62 \\
(12.28)\end{array}$ & $\begin{array}{c}2.63 \\
(11.96)\end{array}$ & 0.336 & 0.340 & 0.948 \\
\hline $\begin{array}{l}\text { Farmer planted trees on } \\
\text { his } / \text { her own }(1=\text { Yes } / 0=\text { No })\end{array}$ & 0.17 & 0.15 & 0.18 & 0.16 & 0.428 & 0.829 & 0.626 \\
\hline $\begin{array}{l}\text { Number of trees planted } \\
\text { in OP in the past per ha }\end{array}$ & $\begin{array}{c}1.84 \\
(18.56)\end{array}$ & $\begin{array}{c}2.46 \\
(30.53)\end{array}$ & $\begin{array}{c}1.43 \\
(6.88)\end{array}$ & $\begin{array}{c}1.64 \\
(7.99)\end{array}$ & 0.584 & 0.670 & 0.793 \\
\hline $\begin{array}{l}\text { Trees cut in OP in last } 12 \\
\text { months }(1=\text { Yes } / 0=\text { No })\end{array}$ & 0.03 & 0.03 & 0.06 & 0.01 & 0.16 & 0.122 & $0.004^{* * *}$ \\
\hline $\begin{array}{l}\text { Mean price for oil fruit bunch received } \\
\text { per } \mathrm{kg} \text { ('000 IDR) }\end{array}$ & $\begin{array}{c}1.02 \\
(0.17)\end{array}$ & $\begin{array}{l}1.03 \\
(0.17)\end{array}$ & $\begin{array}{c}0.99 \\
(0.02)\end{array}$ & $\begin{array}{l}1.05 \\
(0.19)\end{array}$ & 0.414 & 0.593 & 0.232 \\
\hline $\begin{array}{l}\text { Seed access constraints } \\
(1=\text { Yes } / 0=\text { No })\end{array}$ & 0.57 & 0.63 & 0.51 & 0.58 & $0.002^{* * *}$ & 0.259 & 0.106 \\
\hline $\begin{array}{l}\text { Information constraints } \\
(1=\mathrm{Yes} / 0=\mathrm{No})\end{array}$ & 0.63 & 0.67 & 0.61 & 0.61 & 0.337 & 0.259 & 0.920 \\
\hline Observations & 817 & 270 & 274 & 273 & & & \\
\hline
\end{tabular}

Columns (1) to (4) show mean estimates and corresponding standard deviations for continuous variables in parentheses. Columns (5) to (7) report p-values of mean difference tests conducted with linear regressions. In all model specifications, stratification variables are included. Stars refer to ${ }^{*} 0.10,{ }^{* *} 0.05$, and ${ }^{* * *} 0.01$ significance level. All standard errors are clustered at village level. 
film-maker, and through an illustrative manual. ${ }^{6}$ In the short movie, a lecturer from the University of Jambi introduced the concept of tree planting in oil palm plantations. He explained that planting native trees can increase local biodiversity with positive effects on pest control, and improve soil fertility, in particular in the case of nitrogen-fixing legume trees. He raised the possibility of negative oil palm yield effects resulting from competition for nutrients and sunlight between trees and oil palms, but also pointed out that fruit and timber trees can generate additional income. The six species distributed in the experiment were mentioned as examples of native species that could be planted with oil palms and that generate economic returns. The planting process and the maintenance activities necessary to support tree survival were presented in detail. Farmers were instructed that native trees could be planted in between existing oil palms or around the border of the plantation. Rather than cutting productive oil palms, we suggested to remove old and dead oil palms and plant native trees in the resulting gaps. The movie did not provide a recommendation on the precise number of trees to be planted. In order to stimulate cognitive and emotional activity of the audience (Bernard, Dercon, Orkin, \& Seyoum Taffesse, 2015), a role model approach was implemented by inviting three farmers from Jambi to participate in the video. The role model farmers described their experience with tree planting and also mentioned the species that they chose to plant in their oil palm plantations. The movie was complemented by an illustrative manual designed by a local artist. The manual provided the same information on potential environmental and economic outcomes of native tree planting as well as instructions on how to plant and maintain trees. It was distributed to the farmers during the movie screenings to be taken home as a later reference.

Since focus group discussions that we conducted in our research area prior to data collection identified missing markets as one obstacle to tree planting, seedlings of six multipurpose trees native to Jambi were distributed for free to each farmer in T2. The selected species included three fruit trees (Archidendron pauciflorum 'Jengkol'; Durio zibethinus 'Durian'; Parkia speciosa 'Petai'), one natural latex (Dyera costulata 'Jelutung'), and two timber trees (Peronema canescens 'Sungkai'; Shorea leprosula 'Meranti'). ${ }^{7}$ Tree choice was made because these trees are native

\footnotetext{
${ }^{6}$ The video and the manual can be found at https://www.uni-goettingen.de/en/604624.html and https://www.youtube.com/watch?v=W0GwYuwt0D4feature=youtu.be.

${ }^{7}$ Scientific name in italics and local name in quotation marks. Two of the three fruit trees are leguminous plants such that they fix nitrogen in the soil, which provides additional nutrients to the oil palms.
} 
to Jambi, known to farmers and provide economic benefits (Gérard et al., 2017). Each farmer in T2 received one of each species leading to a total of six seedlings per person handed out after the end of the video screening. Measured in local prices in Jambi city, the six seedlings are worth approx. 37,500 Indonesian Rupiah (IDR). ${ }^{8}$ In total, 1,458 seedlings were distributed.

The interventions were carried out in February 2016 such that the farmers could plant the trees before the start of the dry period. Five local assistants helped with the implementation. The video screenings took place in the village offices. Farmers were invited to the video session by the village staff via an official letter three days prior to screening. A reminder text message was sent one day before. The attendance of the assigned farmers was controlled with help of an attendance sheet.

In total, $71.1 \%$ of all farmers assigned to the two treatment arms attended the video screening. For the informational intervention (T1) this share was $67.9 \%$, for the combined (information plus seedlings) intervention (T2) it was $74.4 \%$. The difference between both groups is not statistically significant (p-value: 0.164). ${ }^{9}$ Farmers who did not attend the video screening were visited at their houses at a later time to complete a short mid-term survey. At this occasion, the farmers were also provided with the manual and, if assigned to T2, with the seedlings. The survey was also conducted in the control group. $26.3 \%$ of farmers in T1 received only the manual. Seedlings and the manual alone were given to $22.0 \%$ in T2. Accordingly, $5.8 \%$ in $\mathrm{T} 1$ and $4.0 \%$ in $\mathrm{T} 2$ did not receive any of the interventions. Additional non-compliance can occur if other external institutions are present in the study region and provide information and seedlings to the control group. Our results show that around $5 \%$ of all farmers in the sample received tree related extension approaches from other sources, while approx. $9 \%$ of the farmers got seedlings for free from other sources. Since both the number of farmers who got either other extension approaches or seedlings, and the number of trees provided for free are balanced between treatment and control groups, this is unlikely to threaten the internal validity of the results. ${ }^{10}$

In order to reduce possible experimental effects such as the Hawthorne effect

\footnotetext{
${ }^{8}$ This amounts to 2.8 USD using the average exchange rate between IDR and USD at the time of the interventions. Because of transportation costs it is likely that the prices in the villages are higher.

${ }^{9}$ Test for significance was done in a linear regression framework with the sample of treatment villages only and village-level clustered standard errors. Attendance to movie was regressed on a dummy for T2.

${ }^{10}$ Mostly farmers get seedlings for free from their neighbors. Controlling for the external interventions does not change the results presented in section 2.3.
} 
that could undermine the internal and external validity of the results (Simons, Beltramo, Blalock, \& Levine, 2017), farmers were not told that they participated in an experiment. However, we cannot rule out that due to the frequent visiting of the farmers, questions related to tree planting in oil palm plantations might have become more salient to the interviewees (Zwane et al., 2011). Since both treatment and control groups were visited with the same frequency, the effect should be similar across groups, and therefore should not bias the estimates. Additionally, we kept track of information exchange between farmers in the control and treatment villages in order to be able to control for possible spill-over effects. We do not find evidence that information exchange between treatment and control villages about tree planting has happened at a broad scale. ${ }^{11}$

\subsubsection{Econometric specification}

Our main interest lies in the intention-to-treat (ITT) effect of the interventions on the expected number of trees planted per hectare. ${ }^{12}$ We estimate the following model:

$$
Y_{i j}=\beta_{0}+\beta_{1} T_{1 j}+\beta_{2} T_{2 j}+\beta_{3} S_{j}+\beta_{4} X_{i j}+\beta_{5} Y_{i j}^{P R E}+e_{i j}
$$

where $Y_{i j}$ is the outcome variable of interest, i.e., the per hectare number of trees planted in oil palm plantations by farmer $i$ in village $j . T_{1 j}$ takes the value 1 if village $j$ was assigned to T1, $T_{2 j}$ equals 1 if the village was assigned to T2. $S_{j}$ is a vector of stratification variables and the vector $X_{i j}$ contains farmers' baseline characteristics. Following McKenzie (2012) we employ an ANCOVA estimator by including the baseline dependent variable $Y_{i j}^{P R E}$ to reduce the variance of the treatment estimator. ANCOVA is preferred over difference-in-difference estimation in case of low autocorrelation between the pre-treatment and current outcome variable (McKenzie, 2012), as is the case in our data. ${ }^{13} e_{i j}$ is an individual-specific error term that is clustered at the village level. Two model specifications are tested. The first one in addition to the treatment dummies controls for the stratification

\footnotetext{
${ }^{11}$ In our sample, we can detect twelve cases of information exchange between farmers in treatment and control villages. Out of the twelve, only six state that the topic of tree planting was discussed. It is therefore unlikely that spill-over effects threaten the internal validity of our results.

${ }^{12} \mathrm{By}$ trees we understand tall wood trees that have a clearly developed stem and do not have branches at the basis (Roloff and Bärtels 2014). Therefore, other palm species, banana plants and shrubs were not considered in the analysis.

${ }^{13}$ The autocorrelation coefficient is 0.09 in our case.
} 
variables and the baseline dependent variable. In the second specification, we additionally include the baseline characteristics that are imbalanced between groups and the control variables in Table 2.1 to increase the precision of our estimates. ${ }^{14}$

We analyze the planting decision of the farmers using a double-hurdle (DH) model (Cragg, 1971), where adoption is modelled as a two stage process. In a first step, farmers decide about whether to plant trees in their oil palm plantation or not. In the second step, the intensity of adoption, which is the number of trees planted per hectare, is determined. The original model by Cragg (1971) assumes independence between both decisions. This assumption finds statistical support in our data. ${ }^{15}$

The DH-model represents a general version of the Tobit model. In contrast to the latter, it does not assume that both the adoption and the intensity decision are generated by the same stochastic process (Salmon \& Tanguy, 2016). Therefore, the treatment and other control variables can affect the adoption decision differently than the intensity decision (Cragg, 1971). The DH-model is especially appealing in cases where imperfect markets hinder adoption, e.g. due to restricted access to information or seed markets (Shiferaw, Kebede, Kassie, \& Fisher, 2015). As shown in the focus group discussions, these aspects appear to be relevant in our context. To further support the use of the DH-model, a Vuong test is conducted (Shiferaw et al., 2015). The test results suggest that the DH-model is closer to the true data generating process than the Tobit model ( $\mathrm{p}$-value 0.000).

In case of normally distributed residuals, but if negative predicted outcome variables should be prevented, the intensity decision can be estimated with help of a truncated normal distribution (Cragg, 1971; Salmon \& Tanguy, 2016). Due to the highly right-skewed distribution of the strictly positive per hectare number of trees planted (Figure A2.1 in the Appendix) we use a more flexible Generalized Linear Model (GLM) approach with log-link to estimate the effects of the treatments on the conditional intensity decision (Manning \& Mullahy, 2001). The use of the link function is tested with help of a Pregibon test (Belotti, Deb, Manning, \& Norton. Edward C, 2015). The log-link cannot be rejected (p-value: 0.331). ${ }^{16}$ In order to

\footnotetext{
${ }^{14}$ Strong collinear variables were not included in the model. This choice is supported by the joint insignificance of the variables in the unconditional predictive margins estimation of the double hurdle model (p-value of 0.373 ).

${ }^{15}$ Test for independence done with help of a Heckman selection model. Test results and more information are provided in Table A2.5 in the Appendix.

${ }^{16} \mathrm{We}$ additionally run a Pregibon-test for the identity link function. The Pregibon-test suggests a model misspecification (p-value of squared prediction: 0.011). Also the AIC and the BIC are lower when the log-link instead of the identity-link is used.
} 
test for the correct family of distribution for the GLM error term, we use a modified Park test (Manning \& Mullahy, 2001; Salmon \& Tanguy, 2016). We cannot reject the use of the gamma-distribution for the error term (p-value: 0.801).

The GLM-approach is superior to applying a logarithmic transformation to the skewed outcome variable in case of heteroscedasticity in the residuals at the logarithmic scale (Manning \& Mullahy, 2001). We use a modified White test (Wooldridge, 2010) to test for heteroscedasticity in the regression of the logarithmized per hectare number of trees planted on the explanatory variables. The Chi-square test statistic suggests that heteroscedasticity is present in the data (p-value of 0.04). This supports the use of the GLM approach. Manning and Mullahy (2001) highlight substantial increases in standard errors of GLM in comparison to OLS if the log-scaled residuals are heavily tailed. However, the kurtosis of the estimated log-residuals from our preferred GLM is 2.93 and hence below that of a normal distribution. Therefore, precision losses are likely to be small.

We assume a representative household that is maximizing its expected utility from tree planting taking into account the perceived benefits and costs of tree planting. In a first step, the farmer decides whether to plant or not. The decision to adopt depends on the expected utility of adoption. In case the expected utility is positive, we will observe adoption in a perfect market environment. However, in reality, farmers often face constraints which need to be overcome before adoption can occur. In particular, we assume that farmers need to have reached a specific level of knowledge about tree planting before they will adopt the technology. In addition, farmers need to have access to seedlings in order to observe a positive adoption decision. Therefore, we will observe adoption if three conditions are simultaneously fulfilled: A farmer has reached a sufficient level of knowledge, transaction costs of accessing seedling markets are not too high, and a farmer desires a positive quantity of trees in his or her oil palm plantation. Conditional on a positive decision to plant, the farmer will then decide in a next step about the utility maximizing number of trees. Following Belotti et al. (2015), the adoption decision can be described as:

$$
\operatorname{Pr}(y>0 \mid x)=F(x \delta)
$$

where $y$ is our outcome variable of interest, $x$ is a set of explanatory variables, $\delta$ the coefficient of our explanatory variables in the adoption decision and $F$ a 
cumulative distributional function of the error term.

The conditional intensity decision is expressed as:

$$
E(y \mid y>0, x)=g^{-1}(x \beta)
$$

where $g$ is the respective link function of the GLM approach, $x$ the covariates for the intensity decision and $\beta$ the estimated coefficients. For the log-link case, (2) can be written as:

$$
\ln (E(y \mid y>0, x))=x \beta \Rightarrow E(y \mid y>0, x)=\exp (x \beta)
$$

Inferences about the unconditional expected value, which is the overall mean, can be made by combining the probability of adoption and the intensity decision:

$$
E(y \mid x)=\operatorname{Pr}(y>0 \mid x) * E(y \mid y>0, x)
$$

\section{$2.3 \quad$ Results}

During the one-year period between baseline and follow-up survey, 145 farmers $(19.7 \%)$ planted a total number of 2,909 trees in oil palm plantations. ${ }^{17}$ Descriptives of our outcome variables are reported in Table 2.2 .

\subsubsection{Adoption decision}

The intention-to-treat (ITT) estimates are reported in Table 2.3. Given the discrete character of the treatment dummies, we report average marginal effects (AME) of the interventions on the unconditional expected number of trees planted per hectare (eqn. (2.5)), which are shown in the first two columns. Columns (3) and (4) show AME of the interventions on farmers' decision to plant trees (eqn. (2.2)). Columns (5) and (6) report conditional AME on the intensity decision for the subsample of the tree-planting individuals only (eqn. (2.3)). Besides standard p-values, we also report significance levels based on pairs cluster bootstrap-t procedure. This approach provides asymptotic refinements and has been shown to reduce problems of over-rejection in case of a limited number of clusters (Cameron, Gelbach, \&

\footnotetext{
${ }^{17}$ In addition, trees were planted in home gardens (36.2\% of all farmers), in other plots or on fallow land (3.7\% of all farmers). $40.4 \%$ of all farmers did not plant trees at all.
} 
Table 2.2: Descriptives of outcome variables

\begin{tabular}{lcccc}
\hline \hline & Total & Control & $\mathrm{T} 1$ & $\mathrm{~T} 2$ \\
\hline $\begin{array}{l}\text { Share of farmers who } \\
\text { planted in oil palm plots }\end{array}$ & 0.20 & 0.05 & 0.10 & 0.43 \\
& & & $\mathrm{~T} 1=\mathrm{C}^{*}$ & $\begin{array}{c}\mathrm{T} 2=\mathrm{C}^{* * *} \\
\mathrm{~T} 1=\mathrm{T} 2^{* * *}\end{array}$ \\
$\mathrm{~N}$ & 737 & 239 & $245^{1}$ & 253 \\
\hline Number of trees planted & 1.07 & 0.13 & 1.13 & 1.90 \\
per hectare & $(5.561)$ & $(0.826)$ & $(6.581)$ & $(6.801)$ \\
& & & $\mathrm{T} 1=\mathrm{C}^{* *}$ & $\mathrm{~T} 2=\mathrm{C}^{* * *}$ \\
$\mathrm{~N}$ & 736 & 239 & $244^{1}$ & 253 \\
\hline Number of trees planted & 5.47 & 2.90 & 11.48 & 4.40 \\
per hectare by adopters & $(11.608)$ & $(2.718)$ & $(18.268)$ & $(9.839)$ \\
& & & $\mathrm{T} 1=\mathrm{C}^{*}$ & \\
$\mathrm{~N}$ & 144 & 11 & 24 & 109 \\
\hline
\end{tabular}

Standard deviation reported in parentheses for continuous variables. Test for mean difference conducted with a linear regression of the outcome variables on the treatment dummies with clustered standard errors and stratification variables included. In vertical order, p-values for T1 $=$ Control are $0.082,0.049$ and 0.060 for the three outcome variables respectively. For T2 $=$ Control, p-values are 0.000, 0.013 and 0.351 , for $\mathrm{T} 1=\mathrm{T} 20.000,0.358$ and 0.128 .

${ }^{1}$ Different sample size due to the fact that one farmer could not remember how many trees he planted in his oil palm plantation.

${ }^{*} \mathrm{p}<0.1,{ }^{* *} \mathrm{p}<0.05,{ }^{* * *} \mathrm{p}<0.01$

Miller, 2008). ${ }^{18}$ Full model results, i.e., the coefficients and AME of all covariates for the adoption decision, the conditional and unconditional expected number of trees, are reported in Tables A2.1-A2.3 in the Appendix. ${ }^{19}$

Both treatments significantly increase the unconditional expected number of trees planted per hectare (columns (1) and (2)). On the average, farmers in T1 plant 1.0 tree per hectare more than farmers in the control group. Assignment to $\mathrm{T} 2$ increases the number of trees planted per hectare on average by 1.7 trees in comparison to the control group. Although the effect size of T2 is slightly larger than that of $\mathrm{T} 1$, the difference between both treatments is not statistically significant. ${ }^{20}$ This suggests that both interventions are similarly effective in increasing the

\footnotetext{
${ }^{18}$ Bootstrap-t confidence intervals are provided in the Appendix in Table A2.4

${ }^{19}$ With regard to the covariates that are significantly different between treatment arms (balance checks in Table 2.1), we only find that the possession of a home garden, which is however only marginally significantly different between $\mathrm{T} 2$ and the control group, significantly influences the adoption decisions. Imbalances between groups therefore do not appear to threaten the internal validity of the results.

${ }^{20}$ The results for the unconditional expected number of trees planted per hectare are supported by an OLS regression of the number of trees planted per hectare on the treatment dummies alone, or on the treatment dummies in combination with the stratification variables.
} 
Table 2.3: Intention-to-treat estimation

\begin{tabular}{|c|c|c|c|c|c|c|}
\hline & \multicolumn{2}{|c|}{ Uncond. expected val- } & \multicolumn{2}{|c|}{ Adoption decision } & \multicolumn{2}{|c|}{ Cond. expected values } \\
\hline & (1) & (2) & (3) & (4) & (5) & (6) \\
\hline & $\mathrm{E}(\mathrm{Y} \mid \mathrm{X})$ & $\mathrm{E}(\mathrm{Y} \mid \mathrm{X})$ & $\operatorname{Pr}(\mathrm{Y}>0 \mid \mathrm{X})$ & $\operatorname{Pr}(\mathrm{Y}>0 \mid \mathrm{X})$ & $\begin{array}{c}\mathrm{E}(\mathrm{Y} \mid \mathrm{X} \\
\mathrm{Y}>0)\end{array}$ & $\begin{array}{c}\mathrm{E}(\mathrm{Y} \mid \mathrm{X} \\
\mathrm{Y}>0)\end{array}$ \\
\hline $\mathrm{T} 1$ & $\begin{array}{c}0.995^{* * / a} \\
(0.422)\end{array}$ & $\begin{array}{c}0.984^{* * / a} \\
(0.452)\end{array}$ & $\begin{array}{c}0.057^{* / c} \\
(0.033)\end{array}$ & $\begin{array}{c}0.061^{* * / b} \\
(0.029)\end{array}$ & $\begin{array}{c}8.127^{* * *} / \mathrm{a} \\
(2.673)\end{array}$ & $\begin{array}{c}7.938^{* * / b} \\
(3.578)\end{array}$ \\
\hline $\mathrm{T} 2$ & $\begin{array}{c}1.583^{* * * / a} \\
(0.347)\end{array}$ & $\begin{array}{c}1.721^{* * * / a} \\
(0.412)\end{array}$ & $\begin{array}{c}0.381^{* * * / a} \\
(0.028)\end{array}$ & $\begin{array}{c}0.398^{* * * / a} \\
(0.028)\end{array}$ & $\begin{array}{c}0.762 \\
(1.012)\end{array}$ & $\begin{array}{c}1.026 \\
(1.683)\end{array}$ \\
\hline $\mathrm{N}$ & 736 & 736 & 737 & 737 & 144 & 144 \\
\hline $\begin{array}{l}\text { Control } \\
\text { group }^{1}\end{array}$ & $\begin{array}{l}0.172^{* *} \\
(0.078)\end{array}$ & $\begin{array}{l}0.150^{*} \\
(0.089)\end{array}$ & $\begin{array}{c}0.047^{* * *} \\
(0.018)\end{array}$ & $\begin{array}{c}0.042^{* * *} \\
(0.015)\end{array}$ & $\begin{array}{c}3.578^{* * *} \\
(0.778)\end{array}$ & $\begin{array}{c}3.582^{* * *} \\
(1.125)\end{array}$ \\
\hline $\begin{array}{l}\text { P-values } \\
\text { of } \mathrm{t} \text {-test } \\
\text { for } \mathrm{T} 1=\mathrm{T} 2\end{array}$ & 0.296 & 0.208 & 0.000 & 0.000 & 0.011 & 0.047 \\
\hline Controls $^{2}$ & No & Yes & No & Yes & No & Yes \\
\hline
\end{tabular}

Village-level clustered standard errors in parentheses and estimated with Delta method. Columns (1) and (2) show unconditional AME. Columns (3) and (4) report AME for the adoption decision. AME for the intensity equation are reported in columns (5) and (6). A GLM with log-link and gamma distribution was used for estimation. Stratification variables and the pre-treatment (baseline) dependent variable are included in all model specifications.

${ }^{1}$ Predicted mean for control group displayed. Significance level reported for test $\mathrm{E}(\mathrm{Y})=0$.

2 Baseline controls include number of household members, whether a farmer cut trees in OP in 2015, education, whether he or she had a home garden, total area of oil palm managed, the mean price for oil bunches received, whether he or she received environmental extension, the share of plots that were flooded and whether farmers experienced information and/or seed access constraints.

${ }^{*} \mathrm{p}<0.1,{ }^{* *} \mathrm{p}<0.05,{ }^{* * *} \mathrm{p}<0.01 .{ }^{\mathrm{a} / \mathrm{b} / \mathrm{c}}$ refer to significance level $1 \%$ (a), 5\% (b) and $10 \%$ (c) based on bootstrap-t procedure. 1000 replications used for estimating confidence intervals.

expected number of trees per hectare. Yet, the unconditional planting intensity potentially masks underlying decision patterns that may differ under the two policy interventions. Results of the double-hurdle model allow us to distinguish between extensive and intensive margins.

At the extensive margin, columns (3) and (4) show that both treatments have a positive and significant effect on farmers' decision to plant trees in oil palm plantations, although to varying degrees. Assignment to T1 on average increases the probability that smallholders adopt by approx. 6 percentage points in comparison to the control group. The effect of T2 is significantly larger than that of T1; the provision of seedlings and information increases the probability of planting by approx. 39 percentage points on average. We cannot separate the individual effects of information and input provision in $\mathrm{T} 2$, because of the possibility of interactions 
between both (Ashraf, Jack, \& Kamenica, 2013). However, if we assume that negative interaction effects between information and tree seedling provisions are unlikely, the 33 percentage point difference in effect size between T1 and T2 could be interpreted as an upper bound for the effect size of pure seedling provision. These results suggest that input provision is important to motivate tree planting in oil palm plantations for a large share of the farmers.

At the intensive margin, columns (5) and (6) show that the average expected number of planted trees conditional on adoption is not significantly higher in T2 compared to the control group. In contrast, T1 has a significantly positive effect on the conditional number of trees planted per hectare compared to both T2 and the control group. Accordingly, in T2 we observe large numbers of farmers planting on average only few trees each, whereas in $\mathrm{T} 1$ few farmers adopt, but each of them plants a relatively large number of trees. The treatment effects on the unconditional expected number of trees are therefore driven by different underlying mechanisms: T2 particularly increases the planting probability of farmers, whereas the effect of $\mathrm{T} 1$ is driven by a few high-intensity adopters.

\section{Attrition}

From the original 817 farmers interviewed in 2015, 737 could be re-interviewed in the follow-up implying an attrition rate of $10 \%$. To test whether attrition is random, we compare attrition rates between treatment and control groups. This shows that assignment to $\mathrm{T} 2$ reduces the probability of attrition by four percentage points at the $5 \%$ significance level (p-value: 0.03 ). To further test for differential attrition, we run mean comparison tests for attritors' characteristics in the different treatment groups (Duflo, Glennerster, \& Kremer, 2006). ${ }^{21}$ The results show that attritors do not differ systematically between groups except that farmers dropping out in T2 are statistically more often women (p-value: 0.080 ) and older than the farmers remaining in the sample (p-value: 0.026). Robustness checks for our results are conducted based on inverse probability weights and bounds and confirm that our results are not sensitive to attrition (Tables A2.6-A2.8 in the Appendix).

\footnotetext{
${ }^{21}$ Mean comparison tests (here and in subsequent analyses) are based on linear regression models with village-level clustered standard errors.
} 


\section{Outlier analysis}

Several cross-checks for the number of trees planted were implemented in the questionnaire to ensure the validity of the reported quantities of trees planted. Notwithstanding, as a further robustness check, we analyze the extent to which our results are driven by outliers. To this end, the distribution of the strictly positive number of trees planted per hectare is winsorized at the 99 percentile. Seven observations are replaced, four of which are farmers assigned to T1 and three assigned to T2.

Table 2.4: Intention-to-treat estimates with distribution winsorized at 99 percentile

\begin{tabular}{lcccccc}
\hline \hline & \multicolumn{2}{l}{ Uncond. expected val- } & \multicolumn{2}{l}{ Adoption decision } & \multicolumn{2}{l}{ Cond. expected values } \\
& ues & & & & & \\
& $(1)$ & $(2)$ & $(3)$ & $(4)$ & $(5)$ & $(6)$ \\
& $\mathrm{E}(\mathrm{Y} \mid \mathrm{X})$ & $\mathrm{E}(\mathrm{Y} \mid \mathrm{X})$ & $\operatorname{Pr}(\mathrm{Y}>0 \mid \mathrm{X})$ & $\operatorname{Pr}(\mathrm{Y}>0 \mid \mathrm{X})$ & $\mathrm{E}(\mathrm{Y} \mid \mathrm{X}$, & $\mathrm{E}(\mathrm{Y} \mid \mathrm{X}$, \\
$\mathrm{T} 1$ & $0.716^{* *}$ & $0.723^{* *}$ & $0.057^{*}$ & $0.061^{* *}$ & $5.442^{* * *}$ & $5.226^{* *}$ \\
& $(0.299)$ & $(0.333)$ & $(0.033)$ & $(0.029)$ & $(1.708)$ & $(2.582)$ \\
$\mathrm{T} 2$ & $1.366^{* * *}$ & $1.467^{* * *}$ & $0.381^{* * *}$ & $0.398^{* * *}$ & 0.400 & 0.376 \\
& $(0.262)$ & $(0.318)$ & $(0.028)$ & $(0.028)$ & $(0.816)$ & $(1.564)$ \\
$\mathrm{N}$ & 736 & 736 & 737 & 737 & 144 & 144 \\
$\mathrm{P}$-values & & & & & & \\
of t-test & & & & & & \\
for T1=T2 & 0.111 & 0.089 & 0.000 & 0.000 & 0.008 & 0.053 \\
Controls & No & Yes & No & Yes & No & Yes \\
\hline
\end{tabular}

Village-level clustered standard errors in parentheses and estimated with Delta method. Columns (1) and (2) show unconditional AME. Columns (3) and (4) report AME from a logit regression. Columns (5) and (6) report AME from a GLM with log-link and gamma distribution of the error terms. Stratification variables and pre-treatment (baseline) dependent variable included in all model specifications. Before estimation, distribution was winsorized at the 99 percentile.

${ }^{1}$ Baseline controls include number of household members, whether a farmer cut trees in OP in 2015, education, whether he or she had a home garden, total area of oil palm managed, the mean price for oil bunches received, whether he or she received environmental extension, the share of plots that were flooded and whether farmers experienced information and/or seed access constraints.

${ }^{2}$ For completeness, also the results of the participation decision are shown even though they are not affected by winsorizing the distribution.

${ }^{*} \mathrm{p}<0.1,{ }^{* *} \mathrm{p}<0.05,{ }^{* * *} \mathrm{p}<0.01$

The results (Table 2.4) indicate that overall the significance levels of the estimated AME are not affected by outliers. Although the sizes of the estimated coefficients decrease, both treatments still have significantly positive effects on the unconditional number of trees, and $\mathrm{T} 1$ has a significantly positive effect on the conditional number of trees planted per hectare. However, for the unconditional 
expected values, the difference in effect size between T1 and T2 is now statistically significant - at least when including baseline controls. Hence, our finding that both interventions are similarly effective in terms of increasing the unconditional number of trees planted per hectare is dependent on the $1 \%$ of farmers who plant the most.

\subsubsection{Subgroup-specific treatment effects by seed access constraint}

In the previous section, we find that the combined intervention (T2) significantly increases the likelihood of adoption compared to the pure information intervention (T1). Our conceptual model suggests that adoption of tree planting will only occur if individuals, besides having a positive intention to plant trees, are also able to overcome potential knowledge and seedling access barriers (section 2.2.4). This would imply that information provision alone (T1) can only have a positive effect on the tree planting decision of farmers who are not seed access constrained. In contrast, seedling in combination with information provision (T2) can potentially induce adoption even under seed access constraints. In order to test whether T1 and T2 have differential effects on adoption under seed access, farmers are divided into two subgroups: The first comprising farmers who stated in the baseline that access to seeds was limited in their village, and the second consisting of farmers who indicated that seed material was easily available in the village. ${ }^{22}$ To test whether the treatments have a significant effect on the adoption decision in the respective subgroup, we create dummies for the combinations of treatment status (T1 and T2, respectively) and the two subgroups defined above (Glennerster \& Takavarasha, 2013). Results of a linear probability model are presented in Table 2.5. ${ }^{23}$

The results show that the effect of $\mathrm{T} 1$ on adoption is only significant in the absence of seed access constraints, as expected. In contrast, the combined intervention (T2) significantly increases adoption rates in both subgroups. Accordingly, our results support the need of a comprehensive approach, like the combined intervention in $\mathrm{T} 2$, to induce adoption in the presence of multiple constraints.

\footnotetext{
${ }^{22}$ Farmers were asked to rate on a 5 -point Likert scale whether they agree that native tree seedlings are easily available in the village, where (strongly) disagree indicates a perceived constraint. Accordingly, farmers were asked to assess the general situation in their village, and not whether they personally had tried to access seedlings. Descriptive statistics for the two categories are reported in Table 2.1 .

${ }^{23}$ We use a linear probability model because we are interested in probabilities. The sign of the interactions might differ when logarithmized odds ratios, as used in the logistic regression, instead of probabilities are compared between different groups (Ganzach, Saporta, \& Weber, 2000).
} 
Table 2.5: Heterogeneous Treatment effects

\begin{tabular}{lcc}
\hline \hline & $(1)$ & $(2)$ \\
& Planting in OP & Planting in OP \\
\hline T1, seed access & 0.014 & 0.024 \\
constraints=1 & $(0.034)$ & $(0.032)$ \\
& $0.105^{* *}$ & $0.114^{* *}$ \\
T1, no seed access & $(0.050)$ & $(0.049)$ \\
constraints=1 & $0.385^{* * *}$ & $0.392^{* * *}$ \\
T2, seed access & $(0.050)$ & $(0.049)$ \\
constraints=1 & $0.376^{* * *}$ & $0.392^{* * *}$ \\
T2, no seed access & $(0.042)$ & $(0.044)$ \\
constraints=1 & 0.016 & 0.021 \\
& $(0.027)$ & $(0.030)$ \\
Seed access constrained $=1$ & $0.080^{* *}$ & 0.138 \\
& $(0.039)$ & $(0.122)$ \\
Constant & 737 & 737 \\
N & No & Yes \\
Controls & & \\
\hline
\end{tabular}

Village-level clustered standard errors in parentheses. Coefficients from a linear probability model reported. Stratification variables and lagged outcome variable included in both model specifications.

${ }^{1}$ Baseline controls include number of household members, whether a farmer cut trees in OP in 2015, education, whether he or she had a home garden, total area of oil palm managed, the mean price for oil bunches received, whether he or she received environmental extension and the share of plots that were flooded

${ }^{*} \mathrm{p}<0.1,{ }^{* *} \mathrm{p}<0.05,{ }^{* * *} \mathrm{p}<0.01$

\subsubsection{Does free seedling delivery discourage tree planting beyond what is given for free?}

Section 2.3.1 shows that the effect of $\mathrm{T} 2$ on the conditional expected number of trees planted per hectare is significantly smaller than that of T1 (Table 2.3). We consider two potential interpretations for the lower average conditional planting intensity in T2. First, we observe that a large share of adopters in T2 (77\%) plant only six or less trees. It is possible that the free provision of seedlings motivates adoption among farmers who derive relatively low utility from tree planting. For these farmers, free input provision might act as a subsidy, such that adoption only occurs if inputs are provided for free. This interpretation is in line with findings from the experimental literature on sorting effects (Lazear, Malmendier, \& Weber, 2012). Second, a common concern regarding the provision of free inputs is that it might 
undermine further acquisitions of the good (Omotilewa et al., 2019). Accordingly, the provision of free seedlings in T2 may discourage additional planting efforts beyond what is given for free. This could be due to motivational crowding (Gneezy et al., 2011) or due to an anchoring effect. The latter could either be a price anchoring that sets the benchmark price for trees at zero, or a quantity anchoring if farmers in T2 interpreted the number of seedlings provided as being optimal. To assess whether the lower conditional planting intensity of adopters in T2 reflects a lower willingness of these farmers to procure additional seedlings, we re-estimate our models considering only the number of self-procured seedlings planted in oil palm plots (i.e., not provided for free through our intervention) (Table 2.6).

Table 2.6: Intention-to-treat estimates for planting of self-procured tree seedlings

\begin{tabular}{|c|c|c|c|c|c|c|}
\hline & \multicolumn{2}{|c|}{$\begin{array}{l}\text { Uncond. expected val- } \\
\text { ues }\end{array}$} & \multicolumn{2}{|c|}{ Adoption decision } & \multicolumn{2}{|c|}{ Cond. expected values } \\
\hline & $(1)$ & $(2)$ & (3) & (4) & (5) & (6) \\
\hline & $\mathrm{E}(\mathrm{Y} \mid \mathrm{X})$ & $\mathrm{E}(\mathrm{Y} \mid \mathrm{X})$ & $\operatorname{Pr}(\mathrm{Y}>0 \mid \mathrm{X})$ & $\operatorname{Pr}(\mathrm{Y}>0 \mid \mathrm{X})$ & $\begin{array}{l}\mathrm{E}(\mathrm{Y} \mid \mathrm{X} \\
\mathrm{Y}>0)\end{array}$ & $\begin{array}{l}\mathrm{E}(\mathrm{Y} \mid \mathrm{X} \\
\mathrm{Y}>0)\end{array}$ \\
\hline \multirow[t]{2}{*}{$\mathrm{T} 1$} & $1.072^{* *}$ & $1.267^{* *}$ & $0.056^{*}$ & $0.061^{* *}$ & $8.837^{* * *}$ & $10.479^{* * *}$ \\
\hline & $(0.433)$ & $(0.536)$ & $(0.033)$ & $(0.028)$ & $(2.532)$ & $(3.661)$ \\
\hline \multirow[t]{2}{*}{$\mathrm{T} 2$} & $1.001^{* *}$ & $1.615^{* *}$ & $0.063^{* *}$ & $0.070^{* * *}$ & $6.924^{* *}$ & $11.678^{* *}$ \\
\hline & $(0.407)$ & $(0.779)$ & $(0.027)$ & $(0.023)$ & $(3.107)$ & $(5.737)$ \\
\hline $\mathrm{N}$ & 736 & 736 & 737 & 737 & 63 & 63 \\
\hline $\begin{array}{l}\text { P-values } \\
\text { of t-test } \\
\text { for } \mathrm{T} 1=\mathrm{T} 2\end{array}$ & 0.902 & 0.679 & 0.850 & 0.752 & 0.624 & 0.853 \\
\hline Controls $^{1}$ & No & Yes & No & Yes & No & Yes \\
\hline
\end{tabular}

Village-level clustered standard errors in parentheses and estimated with Delta method. Columns (1) and (2) show unconditional AME. Columns (3) and (4) report AME for the adoption decision. AME for the intensity equation are reported in columns (5) and (6). A GLM with log-link and gamma distribution was used for estimation. Stratification variables and the pre-treatment (baseline) dependent variable are included in all model specifications.

1 Baseline controls include number of household members, whether a farmer cut trees in OP in 2015, education, whether he or she had a home garden, total area of oil palm managed, the mean price for oil bunches received, whether he or she received environmental extension, the share of plots that were flooded and whether farmers experienced information and/or seed access constraints.

${ }^{*} \mathrm{p}<0.1,{ }^{* *} \mathrm{p}<0.05,{ }^{* * *} \mathrm{p}<0.01$

Results show that both interventions have very similar effects on the number of self-procured seedlings. Effect sizes of $\mathrm{T} 1$ and $\mathrm{T} 2$ on the adoption decision, the unconditional, and conditional number of trees planted do not significantly differ from each other. Thus, in both groups we observe similar (albeit small) shares of farmers motivated to incur additional planting efforts beyond what is provided for 
Table 2.7: Total costs and outcomes of interventions

\begin{tabular}{lcccc}
\hline \hline & \multicolumn{2}{c}{ Total number of trees } & \multicolumn{2}{c}{ Total program costs } \\
& $\begin{array}{c}\text { Trees planted in } \\
\text { oil palm plots }\end{array}$ & $\begin{array}{c}\text { Surviving trees in } \\
\text { oil palm plots }\end{array}$ & $\begin{array}{c}\text { With sunk costs } \\
\text { (USD) }\end{array}$ & $\begin{array}{c}\text { Without sunk } \\
\text { costs (USD) }\end{array}$ \\
\hline T1 & 1140 & 666 & 4591 & 3001 \\
T2 & 1606 & 1226 & 7025 & 5435 \\
$\mathrm{C}$ & 163 & 135 & 0 & 0 \\
\hline
\end{tabular}

Sunk costs include the salaries for the local movie-maker and the artist who designed the manual. Running costs include assistants' salary and per diem, car rental, printing of the manual and costs for the tree seedlings. Costs due to video or manual design were equally accounted for in T1 and T2. For conversion of local currency in USD, official 2016 exchange rate was used.

free by the intervention and displaying similarly high levels of conditional planting intensity on the average. Thus, there is no indication that the free provision of seedlings in T2 crowds out own tree planting efforts; it rather seems to encourage tree planting also among farmers deriving lower utility from tree planting.

\subsubsection{Cost effectiveness considerations}

To be able to draw more informed policy recommendations, tree-planting outcomes induced by the two interventions should be assessed in relation to the costs incurred. So far we have considered the number of trees planted per hectare as relevant outcome indicator to assess the effectiveness of the interventions. Tree planting is certainly a necessary first step towards more biodiversity-friendly plantation management, however, ultimately environmental effects are only generated if trees survive. When assessing cost-effectiveness, we therefore consider not only the total number of trees planted due to the intervention, but also the total number of trees that survived after one year. The first year is a crucial time period for tree survival, as trees are especially vulnerable during this early stage and require more care (Jack et al., 2015). The numbers reported in Table 2.7 indicate that in total T2 has resulted in around $41 \%$ more trees planted and $84 \%$ more trees survived compared to T1. Yet, total costs incurred by T2 are also higher: when considering the sunk costs of designing the information campaign (video and manual), total costs are around $53 \%$ higher, without sunk costs they are around $81 \%$ higher in T2 compared to T1.

Based on these numbers, we calculate cost effectiveness measures for the two policy interventions (Table 2.8). Since we are interested in the incremental effect of the interventions (compared to no intervention), we subtract the number of trees 
Table 2.8: Cost effectiveness measures

\begin{tabular}{lccccc}
\hline \hline & \multicolumn{2}{c}{ With sunk costs } & \multicolumn{2}{c}{ Without sunk costs } & \\
& $\begin{array}{c}\text { Trees planted } \\
\text { in oil palm } \\
\text { plots per USD } \\
\text { spent }\end{array}$ & $\begin{array}{c}\text { Surviving trees } \\
\text { in oil palm } \\
\text { plots per USD } \\
\text { spent }\end{array}$ & $\begin{array}{c}\text { Trees planted } \\
\text { in oil palm } \\
\text { plots per USD } \\
\text { spent }\end{array}$ & $\begin{array}{c}\text { Surviving trees } \\
\text { in oil palm } \\
\text { plots per USD } \\
\text { spent }\end{array}$ & N \\
\hline $\mathrm{T} 1$ & 0.22 & 0.11 & 0.33 & 0.18 & 245 \\
& $(1.55)$ & $(1.07)$ & $(2.37)$ & $(1.63)$ & \\
$\mathrm{T} 2$ & 0.21 & 0.15 & 0.27 & 0.19 & 253 \\
& $(0.90)$ & $(0.77)$ & $(1.16)$ & $(1.00)$ & \\
P-values & 0.881 & 0.718 & 0.688 & 0.897 & \\
of T1=T2 & & & & & \\
\hline
\end{tabular}

Cost effectiveness measures present the number of planted or survived trees per farmer divided by the per capita costs of the interventions. We subtract the average number of trees planted per household in the control group from the number of trees planted per household in the treatment groups to express the incremental effect of our interventions. Test for difference in cost effectiveness between $\mathrm{T} 1$ and $\mathrm{T} 2$ done in a linear regression with village-level clustered standard errors and stratification variables.

planted/survived in the control group. Cost effectiveness measures are reported with and without the sunk costs of designing the information material. A comparison of the measures reported in Table 2.8 reveals that the two interventions perform very similarly in terms of aggregate cost effectiveness - none of the measures differ significantly between the two interventions. Accordingly, while costs of T2 are substantially higher than those of $\mathrm{T} 1$, the better aggregate tree outcomes generated by $\mathrm{T} 2$ compensate for the higher program costs.

\subsubsection{Tree survival}

An important leverage point for improving the cost-effectiveness of the interventions is raising the tree survival rate. At the aggregate level, only around $58 \%$ and $76 \%$ of the planted trees in T1 and T2, respectively, survived (Table 2.7). Since tree planting and maintenance activities are implemented at the farm level, any measures to enhance tree survival would best be targeted at farmers. Table 2.9 presents average tree survival rates at farm level by treatment group. Since tree planting is a pre-condition for tree survival, only adopters are considered in the analyses in this subsection. The average survival rates reported in Table 2.9 differ from the aggregate measures reported in the previous subsection, since many farmers in T2 plant only small numbers of trees in comparison to farmers in $\mathrm{T} 1$ and the control group - therefore in the latter groups it is more likely that even a small 
reduction in the survival rate can imply a large loss in the number of trees. ${ }^{24}$ The descriptive comparison reveals that adopters in T2 perform significantly lower with respect to tree survival rates than adopters in T1 and the control group (Table 2.9). There is no significant difference in survival rates achieved by farmers in $\mathrm{T} 1$ and the control group. These results are supported by estimates from a fractional probit regression regressing farm-level tree survival rates on treatment assignment (Table 2.10, column (1)). ${ }^{25}$

Table 2.9: Descriptives of farm-level survival rates (adopters only)

\begin{tabular}{cccccccc}
\hline \hline & $(1)$ & $(2)$ & $(3)$ & $(4)$ & $(5)$ & $(6)$ & $(7)$ \\
& Overall & Control & $\mathrm{T} 1$ & $\mathrm{~T} 2$ & $\mathrm{~T} 1=\mathrm{C}$ & $\mathrm{T} 2=\mathrm{C}$ & $\mathrm{T} 1=\mathrm{T} 2$ \\
\hline & 0.660 & 0.923 & 0.854 & 0.590 & 0.462 & $0.000^{* * *}$ & $0.022^{* *}$ \\
& $(0.399)$ & $(0.140)$ & $(0.320)$ & $(0.408)$ & & & \\
$\mathrm{N}$ & 144 & 11 & 24 & 109 & & & \\
\hline
\end{tabular}

In columns (1) to (4), standard deviations are reported in parentheses. Columns (5) to (7) show p-values of mean difference test with clustered standard errors.

${ }^{*} \mathrm{p}<0.1,{ }^{* *} \mathrm{p}<0.05,{ }^{* * *} \mathrm{p}<0.01$

We identify four different categories of factors that are likely to be associated with farmers' performance regarding tree survival in our context. If these factors are unbalanced between treatment groups, they can help explain the differential survival rates between treatment groups. First, the planting pattern might determine tree survival. Many trees planted together in clusters are more resilient and hence likely to show higher survival rates (Goldman et al., 2007). We control for both the number of trees planted by the farmer and the share planted in clusters. Second, farmers' characteristics such as experience and skills and the related maintenance given to trees might positively influence tree survival. ${ }^{26}$ Also, farmers who received seedlings for free may invest less effort in maintenance, due to either a lower intrinsic interest in trees or due to lower sunk costs of seedling loss (Ashraf et al., 2010; Thaler, 1980). Third, we expect that the plot conditions, including exposure to flooding and drought, oil palm plantation age, the number of oil palms planted per hectare and whether a river borders the plot, affect tree survival. Fourth, the species choice might be a significant predictor for tree survival. Even though the

\footnotetext{
${ }^{24}$ The lower aggregate number of surviving trees in $\mathrm{T} 1$ is driven by two farmers. These farmers planted together 300 trees, but none of the planted trees survived.

${ }^{25}$ Since both zero and one appear with a positive frequency in our data set, we rely on a fractional probit estimation instead of a beta regression to explain survival rates. Fractional probit estimation is preferred over OLS due to the bounded nature of the dependent variable.

${ }^{26}$ We proxy skills with education and wealth. Variable choice is discussed in Table A2.11 in the Appendix.
} 
Table 2.10: Difference in tree survival rates between different treatment groups

\begin{tabular}{lcc}
\hline \hline & $(1)$ & $(2)$ \\
& Tree survival rate & Tree survival rate \\
\hline T1 & -0.366 & -0.366 \\
& $(0.437)$ & $(0.437)$ \\
T2 & $-1.196^{* * *}$ & \\
& $(0.297)$ & $-1.022^{* * *}$ \\
T2 - no planting beyond & & $(0.354)$ \\
intention & & $-1.394^{* * *}$ \\
T2 - planting in excess & & $(0.282)$ \\
of intention & & $1.424^{* * *}$ \\
Constant & $1.424^{* * *}$ & $(0.241)$ \\
& $(0.241)$ & 138 \\
$\mathrm{~N}$ & 144 & \\
\hline
\end{tabular}

Coefficients from a fractional probit estimation are reported. Village-level clustered standard errors in parentheses. In column (2), farmers in T2 who did not plant the distributed tree species were excluded from the analysis. P-values of test for T1=T2 in column (1): 0.014, for test $\mathrm{T} 1=\mathrm{T} 2$-no planting beyond intention: 0.143 , for test $\mathrm{T} 1=\mathrm{T} 2$-planting in excess of intention: 0.009; for test T2-no planting beyond intention=T2-planting in excess of intention: 0.099 in column (2).

${ }^{*} \mathrm{p}<0.1,{ }^{* *} \mathrm{p}<0.05,{ }^{* * *} \mathrm{p}<0.01$

species distributed in the experiment were chosen because they are native to Jambi and known by the farmers, they might not have been optimal species to plant with oil palms. In addition, it could be that exogenously distributed seedlings do not correspond to smallholders' preferences.

We test for these potential correlations conditional on tree planting adoption, and thus are leaving the randomized framework of our experiment. We regress tree survival rates on a range of farm and household factors belonging to the different categories using a fractional probit model. Columns (1) and (2) in Table 2.11 report those variables that turn out to be significant predictors of tree survival rates (full model results are reported in Table A2.9 in the Appendix).

We find ample support for the relevance of the second category of factors identified above. Prior experience with tree planting in oil palm plantations and maintenance given to the trees ${ }^{27}$ are significantly and positively associated with

\footnotetext{
${ }^{27} \mathrm{We}$ acknowledge that reverse causality between survival rate and maintenance might be present in case seedlings die early, such that maintenance is no longer given. Yet, our informational session indicated that maintenance should be given directly after planting the trees. This reduces the risk of reverse causality in the treatment groups. In addition, it is unlikely that reverse causality is systematically linked to T2, since both treatment groups received the same set of information.
} 
Table 2.11: Potential determinants of tree survival

\begin{tabular}{lccc}
\hline \hline & $\begin{array}{c}(1) \\
\text { Tree survival } \\
\text { rate }\end{array}$ & $\begin{array}{c}(2) \\
\text { Tree survival } \\
\text { rate }\end{array}$ & $\begin{array}{c}(3) \\
\text { Survival rate } \\
\text { of distributed } \\
\text { species (only } \\
\text { T2 adopters) }\end{array}$ \\
\hline Share of provided species in & $-0.275^{* * *}$ & $-0.199^{* *}$ & \\
total trees planted & $(0.081)$ & $(0.093)$ & \\
Share of plots with a river & $0.144^{* * *}$ & $0.171^{* * *}$ & 0.096 \\
bordering & $(0.055)$ & $(0.057)$ & $(0.059)$ \\
Experience with tree planting in & $0.206^{* * *}$ & $0.233^{* * *}$ & $0.234^{* * *}$ \\
OP (1=Yes) & $(0.059)$ & $(0.056)$ & $(0.049)$ \\
Maintenance done to trees & $0.181^{* * *}$ & $0.200^{* * *}$ & $0.209^{* * *}$ \\
(1=Yes) & $(0.055)$ & $(0.051)$ & $(0.053)$ \\
Distance from Jambi to village & & $-0.002^{*}$ & \\
(in km) & & $(0.001)$ & \\
Number of free seedlings & & & $-0.029^{* * *}$ \\
planted in excess of intention & & & $(0.010)$ \\
$\mathrm{N}$ & 141 & 141 & 101 \\
\hline
\end{tabular}

AME from fractional probit estimations shown. Village-level clustered standard errors estimated with help of Delta method and displayed in parentheses. Columns (1) and (2) include the whole sample of adopters and all species planted. In column (3), the analysis is restricted to the species distributed in T2, and accordingly only includes the adopting farmers in T2 who plant the provided tree species in their oil palm plantations.

${ }^{*} \mathrm{p}<0.1,{ }^{* *} \mathrm{p}<0.05,{ }^{* * *} \mathrm{p}<0.01$

the probability of tree survival at the farm level. Regarding the third category of factors, only the share of plots that border a river is positively and significantly correlated with the tree survival rate in both model specifications. Trees are often planted along the river side, where light and water availability are higher. Finally, regarding the fourth category, we find that the share of the species distributed in the experiment in overall species planted is significantly and negatively correlated with the tree survival rate. To further explore the relevance of the significant predictors in explaining the lower tree survival rates exhibited by farmers in T2 compared to $\mathrm{T} 1$ and the control group, we report mean difference tests in Table 2.12. ${ }^{28}$

From the variables that exhibit a significant correlation with the tree survival rate, only the share of the distributed tree species in total trees planted is signifi-

\footnotetext{
${ }^{28}$ Adopters in $\mathrm{T} 1$ and in the control group are merged into one comparison group, given that their survival rates are not statistically different. The combined survival rate for adopters in the control group and $\mathrm{T} 1$ is 0.876 . This is statistically different from the survival rate in $\mathrm{T} 2$, which is 0.590 (p-value: 0.004). Descriptives of the other variables are shown in Table A2.10 in the Appendix, for which we do not find any systematical differences between treatment groups either.
} 
Table 2.12: Mean comparison test of significant predictors for tree survival

\begin{tabular}{lcccc}
\hline \hline Variable & $\begin{array}{c}(1) \\
\text { Overall }\end{array}$ & $\begin{array}{c}(2) \\
\text { Control }+ \\
\mathrm{T} 1\end{array}$ & $\begin{array}{c}(3) \\
\mathrm{T} 2\end{array}$ & $\begin{array}{c}(4) \\
\text { Control } \\
+\mathrm{T} 1=\mathrm{T} 2\end{array}$ \\
\hline Maintenance $^{1}(1=$ Yes $)$ & 0.333 & 0.314 & 0.339 & 0.810 \\
$\begin{array}{l}\text { Experience with tree planting } \\
\begin{array}{l}\text { (1=Yes) } \\
\text { Share of plots which border a }\end{array}\end{array}$ & 0.230 & 0.286 & 0.211 & 0.539 \\
river $^{2}$ & 0.204 & 0.118 & 0.231 & 0.156 \\
Share of tree species provided in & $(0.400)$ & $(0.327)$ & $(0.418)$ & \\
total & 0.700 & 0.278 & 0.832 & $0.000^{* * *}$ \\
trees planted & $(0.439)$ & $(0.441)$ & $(0.346)$ & \\
$\mathrm{N}$ & 144 & 35 & 109 & \\
\hline
\end{tabular}

In columns (1) to (3), standard deviation reported in parentheses for continuous variables. Column (4) shows p-values of mean difference tests with clustered standard errors.

${ }^{1}$ Maintenance includes fertilizer and/or manure application and/or weeding.

${ }^{2}$ Characteristics of plots in which farmers planted trees.

cantly different between treatment groups (Table 2.12). Thus, our species choice might be one relevant reason why we observe a lower tree survival rate among farmers in T2. In fact, a rather low survival rate of three of the species, Meranti, Durian and Jelutung, is also found in an ecological experiment in the study area (Zemp, Gérard, et al., 2019). While native to Jambi, these tree species may not perform well when planted in immediate proximity to oil palms.

In addition, it could be that the tree species distributed in the experiment do not correspond to farmers' preferences, or that farmers' in T2 were given more seedlings of selected species for free than they actually intended to plant. To explore this further, we calculate the number of "preferred" seedlings received by farmers in T2 - this is the number of seedlings out of the six tree species distributed for free, for which the farmer had previously indicated a positive planting intention. ${ }^{29}$ The number of "preferred" seedlings was then subtracted from the number of the freely distributed seedlings that were actually planted in order to obtain the number of free seedlings that were planted in excess of the farmer's originally stated intention. In Table 2.11 column (3) we restrict our analysis to adopters in T2 in order to explore whether the number of free seedlings planted in excess of intention

\footnotetext{
${ }^{29}$ Farmers in T2 were asked after the information campaign but before the seedlings were handed out how many trees of each of the six species they would plant in their oil palm plantation if provided for free.
} 
explains survival rates of the distributed species. Indeed, we find a significantly negative effect indicating that farmers who planted more than they intended possibly because they received the seedlings for free- exhibit lower tree survival rates among the distributed species. This may at least to some extent explain the lower overall tree survival rates observed among farmers in T2 (Table 2.10). In Table 2.10 column (2) we split T2 farmers into two subgroups - those who planted free seedlings in excess of intentions and those who did not - and compare average tree survival rates between these two subgroups, T1, and the control group. The results show that survival rates in the subgroup of T2 farmers planting in excess of intentions are significantly lower compared to all other groups ( $p$-values reported below Table 2.10). Thus, non-correspondence between our species choice and farmers' preferences seems to represent an important factor influencing the effectiveness of interventions - even if it does not fully explain lower survival rates in $\mathrm{T} 2$ since the survival rate achieved by $\mathrm{T} 2$ farmers not planting beyond their intentions is still significantly lower than that of the control group.

Finally, we cannot rule out that other factors, which are confounded with the share of our tree species in total tree species planted and which we cannot control for are the underlying reasons for the low survival rate of the distributed species and hence for the lower tree survival rate observed among farmers in T2. In particular, it could be the case that the age of the seedlings was not ideal for immediate planting. Moreover, since the seedlings were brought from Jambi to the respective villages, it could be that the delivered seedlings did not arrive in a good state at the farmers' houses due to poor quality roads in part of the study region. Some evidence for the latter is provided by the significant and negative correlation between the distance from Jambi to the respective village and the tree survival rate that is however small in size (column (2) in Table 2.11).

\subsection{Conclusion}

Results from a randomized controlled trial implemented in Jambi Province, Indonesia, suggest that information (T1) and information in combination with seedling provision (T2) are effective in stimulating tree planting in smallholder oil palm plantations. Both treatments lead on average to a higher predicted number of trees planted per hectare in comparison to the control group. The combined intervention (T2) leads to a higher planting probability but lower conditional planting intensity than sole information provision (T1). Our results suggest that the lower average 
conditional number of trees planted per hectare in $\mathrm{T} 2$ is driven by a large share of farmers planting only the seedlings provided for free. Nonetheless, the free provision of seedlings in $\mathrm{T} 2$ does not seem to discourage additional planting efforts - which are carried out by similar shares of farmers with similar planting intensities in both treatment groups. From a policy perspective, comparing the cost-effectiveness of the two interventions is critical. Although the combined intervention incurs higher program costs due to seedling purchase and delivery, it is also more effective in terms of the total number of trees planted and survived. As a result, we find no significant difference in cost-effectiveness between the two interventions.

In order to generate broader biodiversity effects and allow for ecological scaling effects from the local to the regional level, diversified plantations will need to be spread over a large area. This could enable species movements between diversified plantations and could act as corridors to link remaining forest patches (Koh et al., 2009). While both interventions in our experiment motivated a small share of farmers to make substantial planting efforts, the combined intervention (T2) additionally induced low-intensity planting (up to six trees per hectare) among a large share of farmers. This more likely generates a landscape design where diversified plantations are spread over a large area. Here, a potential advantage of the combined intervention is that it also motivates adoption of tree planting among farmers who had initially stated that seedlings were not easily available in their village. Thus, in particular in remote areas of developing countries, where seed markets may be missing or characterized by high transaction costs, combining information with seedling provision may be the more viable approach to achieving considerable uptake of tree planting.

An important leverage point to increasing cost-effectiveness of the interventions is increasing tree survival rates, in particular in the context of free seedling provision, where we found farm-level survival rates to be significantly lower. Our results suggest that here species choice is critical and should be based on recent evidence from ecological experiments (Zemp, Gérard, et al., 2019) and in particular reflect farmers' preferences. Also, seedling quality and logistics of seed delivery are important challenges that need to be addressed, as they can otherwise jeopardize the success of the intervention. Involving local nurseries, thereby reducing transport distances, can be promising, also in terms of local value creation and strengthening capacities along the value chain. Furthermore, tree mortality is generally lower for farmers with more experience in tree planting. The integration of practical training elements into the extension approach might thus be a way to increase 
tree survival. Finally, further research could also experiment with the number of seedlings provided to farmers to assess how it influences their planting decision and the number of trees planted. This will generate important insights regarding the feasibility of up-scaling tree planting intensities among larger numbers of farmers, which will be important for the generation of broader biodiversity effects.

A limitation of our study is that we did not measure biodiversity outcomes, e.g. in terms of arthropod or bird diversity, and therefore cannot establish the relationship between the number of native trees planted or survived and actual biodiversity outcomes. Several recent studies comparing monoculture and polyculture practices in oil palm smallholdings have found significant positive effects of the latter on arthropod, bird and bat communities (Ashraf et al., 2018; Ghazali et al., 2016; Syafiq et al., 2016; Yahya et al., 2017). However, polycultural farming here refers to complex agricultural systems combining oil palms with other crops such as banana, coconut, tapioca, corn, and sugar cane, as well as fruit trees such as jackfruit, mango and cacao. Accordingly, the studies have not been designed to derive the relationship between (native) tree planting intensity and biodiversity outcomes. Only Teuscher et al. (2015) explicitly analyze the effects of the number of trees in oil palm on bird abundance and species diversity. In their sample of 120 smallholder oil palm farmers, predicted bird diversity conditional on the number of trees ranges from 2.58 species (when there are zero trees) to 5.15 species (in case of 125 trees). Over the same range of trees, bird abundance ranges from 3.66 individuals to 8.05 individuals. The response of tree diversity and abundance to tree planting is non-linear, indicating a strong decrease in the marginal effect of additional trees on bird diversity and abundance with increasing number of trees. The results presented by Teuscher et al. (2015) suggest that if six trees are planted in a one-hectare monoculture oil palm plantation (with no native trees to start with), as done by a large share of the farmers receiving free seedlings in our study, the predicted increase in bird diversity ranges around 0.6 species and in bird abundance around one individual. However, it needs to be taken into account that ecological effects measured at the plot level depend also on other factors such a ground vegetation cover and chemical inputs (Azhar, Lindenmayer, Wood, Fischer, \& Zakaria, 2014; Yahya et al., 2017). Further, feedback effects between landscape and plot-level characteristics exist such that plot-level effects cannot be easily extrapolated to the landscape level (Tscharntke et al., 2012).

The expansion of oil palm plantations in South East Asia is a key driver of global biodiversity loss (Diaz et al., 2019). Ecological research has suggested that 
the introduction of more structural complexity, e.g. in form of diversified oil palm systems, can sustain increased biodiversity outcomes compared to monoculture landscapes (Koh et al., 2009; Syafiq et al., 2016; Yahya et al., 2017). Our research suggests that in particular the combination of information with free seedlings robustly motivates smallholder farmers to increase the number of trees planted in their oil palm plantations, thereby promoting the uptake of more diversified plantations. With regard to the external validity of our results, two aspects deserve mentioning. Many smallholders in Jambi, Indonesia, were previously part of an outgrower scheme or have received extension services from large-scale plantations, propagating homogeneous plantation structures. This has resulted in some skepticism among smallholder farmers about planting trees together with oil palms as shown in focus group discussions held prior to data collection. Hence, if in other contexts prior concerns are less pronounced, farmers may be more inclined to experiment with tree planting in oil palm plots (Slingerland, Khasanah, van Noordwijk, Susanti, \& Meilantina, 2019). Second, the baseline survey took place while our study region was experiencing forest fires and haze (Field et al., 2016). This might have made environmental problems more salient to the local population and thus increased their interest in tree planting. Therefore, similar studies in other oil palm producing areas would be useful to explore the extent to which our results can be generalized to other contexts. 


\section{A Appendix}

Figure A2.1: Distribution of strictly positive tree planting quantities
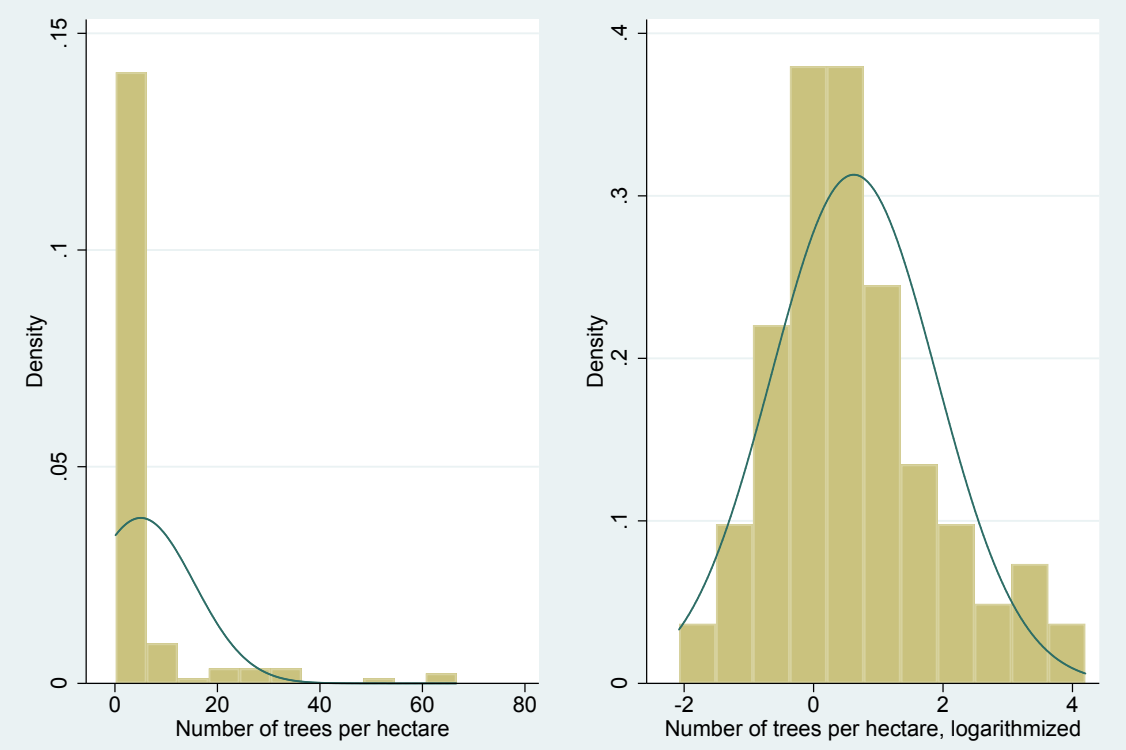

Blue line indicates normal distribution 
Table A2.1: Intention-to-treat estimates for adoption decision

\begin{tabular}{|c|c|c|c|c|}
\hline & Estimated & oefficients & Margin & Effects \\
\hline & (1) & $(2)$ & $(3)$ & $(4)$ \\
\hline & Planting in $\mathrm{OP}$ & Planting in $\mathrm{OP}$ & Planting in $\mathrm{OP}$ & Planting in $\mathrm{OP}$ \\
\hline $\mathrm{T} 1$ & $0.872^{*} / \mathrm{c}$ & $0.994^{* * / b}$ & $0.057^{* * / c}$ & $0.061^{* * / b}$ \\
\hline & $(0.510)$ & $(0.472)$ & $(0.033)$ & $(0.029)$ \\
\hline $\mathrm{T} 2$ & $2.772^{* * * / a}$ & $3.051^{* * * / a}$ & $0.381^{* * * / a}$ & $0.398^{* * * / a}$ \\
\hline & $(0.419)$ & $(0.392)$ & $(0.028)$ & $(0.028)$ \\
\hline Access to seeds & -0.199 & -0.231 & -0.025 & -0.028 \\
\hline & $(0.221)$ & $(0.231)$ & $(0.027)$ & $(0.028)$ \\
\hline Local village & -0.279 & -0.431 & -0.035 & -0.052 \\
\hline & $(0.285)$ & $(0.338)$ & $(0.035)$ & $(0.040)$ \\
\hline Oil palm share $>73.5 \%$ & -0.277 & $-0.316^{*}$ & -0.035 & $-0.039^{*}$ \\
\hline & $(0.195)$ & $(0.178)$ & $(0.024)$ & $(0.021)$ \\
\hline Total number of trees & $0.030^{* *}$ & $0.032^{* *}$ & $0.004^{* *}$ & $0.004^{* *}$ \\
\hline planted per ha in OP & $(0.012)$ & $(0.013)$ & $(0.002)$ & $(0.002)$ \\
\hline Number HH members & & 0.032 & & 0.004 \\
\hline & & $(0.062)$ & & $(0.007)$ \\
\hline Trees cut in $\mathrm{OP}$ & & -0.205 & & -0.025 \\
\hline & & $(0.831)$ & & $(0.101)$ \\
\hline Years of education & & $0.071^{* *}$ & & $0.009^{* *}$ \\
\hline & & $(0.030)$ & & $(0.004)$ \\
\hline Home garden & & $-1.275^{* * *}$ & & $-0.155^{* * *}$ \\
\hline & & $(0.384)$ & & $(0.048)$ \\
\hline Total hectare & & -0.018 & & -0.002 \\
\hline OP managed & & $(0.022)$ & & $(0.003)$ \\
\hline FFB price per $\mathrm{kg}$ & & -0.224 & & -0.027 \\
\hline & & $(0.705)$ & & $(0.085)$ \\
\hline Environmental extension & & $0.925^{* *}$ & & $0.113^{* * *}$ \\
\hline received & & $(0.367)$ & & $(0.043)$ \\
\hline Share of plots flooded & & 0.178 & & 0.022 \\
\hline & & $(0.303)$ & & $(0.037)$ \\
\hline Information constraints & & 0.336 & & 0.041 \\
\hline & & $(0.226)$ & & $(0.028)$ \\
\hline Seed access constraints & & -0.240 & & -0.029 \\
\hline & & $(0.270)$ & & $(0.033)$ \\
\hline Constant & $-2.746^{* * *}$ & $-2.252^{* *}$ & & \\
\hline & $(0.393)$ & $(0.940)$ & & \\
\hline Observations & 737 & 737 & 737 & 737 \\
\hline McFadden pseudo R2 & 0.195 & 0.226 & & \\
\hline
\end{tabular}

Logit estimation used. Columns (1) and (2) report estimated coefficients. Columns (3) and (4) derived AME. Village-level clustered standard errors in parentheses. Delta method used to estimate standard errors for AME.

${ }^{*} \mathrm{p}<0.1,{ }^{* *} \mathrm{p}<0.05,{ }^{* * *} \mathrm{p}<0.01$

$\mathrm{a} / \mathrm{b} / \mathrm{c}$ refer to significance level $1 \%$ (a), $5 \%$ (b) and 10\% (c) based on bootstrap-t procedure. 1000 replications used for estimating confidence intervals. Due to computational complexity, bootstrapped confidence intervals were only computed for the treatment variables. 
Table A2.2: Intention-to-treat estimates for intensity decision

\begin{tabular}{|c|c|c|c|c|}
\hline & Estimated & Coefficients & Margin & Effects \\
\hline & $\begin{array}{c}(1) \\
\text { Trees planted } \\
\text { per ha }\end{array}$ & $\begin{array}{c}(2) \\
\text { Trees planted } \\
\text { per ha }\end{array}$ & $\begin{array}{c}(3) \\
\text { Trees planted } \\
\text { per ha }\end{array}$ & $\begin{array}{c}(4) \\
\text { Trees planted } \\
\text { per ha }\end{array}$ \\
\hline $\mathrm{T} 1$ & $\begin{array}{l}1.185^{* * * / a} \\
(0.267)\end{array}$ & $\begin{array}{c}1.168^{* * * / a} \\
(0.415)\end{array}$ & $\begin{array}{c}8.127^{* * * / a} \\
(2.673)\end{array}$ & $\begin{array}{c}7.938^{* * / b} \\
(3.578)\end{array}$ \\
\hline $\mathrm{T} 2$ & $\begin{array}{c}0.193 \\
(0.262)\end{array}$ & $\begin{array}{c}0.252 \\
(0.432)\end{array}$ & $\begin{array}{c}0.762 \\
(1.012)\end{array}$ & $\begin{array}{l}1.026 \\
(1.683)\end{array}$ \\
\hline Access to seeds & $\begin{array}{l}-0.327 \\
(0.320)\end{array}$ & $\begin{array}{l}0.006 \\
(0.306)\end{array}$ & $\begin{array}{l}-1.753 \\
(1.759)\end{array}$ & $\begin{array}{l}0.036 \\
(1.711)\end{array}$ \\
\hline Local village & $\begin{array}{c}0.418 \\
(0.389)\end{array}$ & $\begin{array}{c}0.552 \\
(0.511)\end{array}$ & $\begin{array}{l}2.241 \\
(2.183)\end{array}$ & $\begin{array}{c}3.088 \\
(3.214)\end{array}$ \\
\hline Oil palm share $>73.5 \%$ & $\begin{array}{c}-0.888^{* * *} \\
(0.312)\end{array}$ & $\begin{array}{c}-0.882^{* * *} \\
(0.301)\end{array}$ & $\begin{array}{c}-4.762^{* * *} \\
(1.798)\end{array}$ & $\begin{array}{c}-4.932^{* * *} \\
(1.754)\end{array}$ \\
\hline $\begin{array}{l}\text { Total number of trees } \\
\text { planted per ha in OP }\end{array}$ & $\begin{array}{l}0.012 \\
(0.015)\end{array}$ & $\begin{array}{l}0.016 \\
(0.020)\end{array}$ & $\begin{array}{l}0.062 \\
(0.079)\end{array}$ & $\begin{array}{l}0.089 \\
(0.123)\end{array}$ \\
\hline Number HH members & & $\begin{array}{l}-0.032 \\
(0.095)\end{array}$ & & $\begin{array}{l}-0.179 \\
(0.529)\end{array}$ \\
\hline Trees cut in $\mathrm{OP}$ & & $\begin{array}{l}-0.029 \\
(0.668)\end{array}$ & & $\begin{array}{l}-0.162 \\
(3.728)\end{array}$ \\
\hline Years of education & & $\begin{array}{c}0.013 \\
(0.024)\end{array}$ & & $\begin{array}{c}0.071 \\
(0.137)\end{array}$ \\
\hline Home garden & & $\begin{array}{l}-0.420 \\
(0.431)\end{array}$ & & $\begin{array}{l}-2.349 \\
(2.475)\end{array}$ \\
\hline Total hectare OP managed & & $\begin{array}{c}-0.159^{* * *} \\
(0.018)\end{array}$ & & $\begin{array}{c}-0.892^{* * *} \\
(0.212)\end{array}$ \\
\hline FFB price per $\mathrm{kg}$ & & $\begin{array}{l}0.030 \\
(0.962)\end{array}$ & & $\begin{array}{c}0.167 \\
(5.394)\end{array}$ \\
\hline $\begin{array}{l}\text { Environmental extension } \\
\text { received }\end{array}$ & & $\begin{array}{l}0.418 \\
(0.322)\end{array}$ & & $\begin{array}{l}2.336 \\
(1.934)\end{array}$ \\
\hline Share of plots flooded & & $\begin{array}{l}0.400 \\
(0.338)\end{array}$ & & $\begin{array}{l}2.238 \\
(1.722)\end{array}$ \\
\hline Information constraints & & $\begin{array}{l}-0.004 \\
(0.261)\end{array}$ & & $\begin{array}{l}-0.023 \\
(1.459)\end{array}$ \\
\hline Seed access constraints & & $\begin{array}{l}0.098 \\
(0.243)\end{array}$ & & $\begin{array}{l}0.548 \\
(1.396)\end{array}$ \\
\hline Constant & $\begin{array}{c}1.559^{* * *} \\
(0.519)\end{array}$ & $\begin{array}{c}1.980 \\
(1.568)\end{array}$ & & \\
\hline $\begin{array}{l}\text { Observations } \\
\text { BIC }\end{array}$ & $\begin{array}{c}144 \\
725.6\end{array}$ & $\begin{array}{c}144 \\
737.5\end{array}$ & 144 & 144 \\
\hline
\end{tabular}

Results presented from a GLM model with log-link and gamma distribution of error terms for the subsample of adopters only. Columns (1) and (2) present estimated coefficients. Columns (3) and (4) report derived AME. Village-level clustered standard errors in parentheses. Delta method used to estimate standard errors.

${ }^{*} \mathrm{p}<0.1,{ }^{* *} \mathrm{p}<0.05,{ }^{* * *} \mathrm{p}<0.01$

$\mathrm{a} / \mathrm{b} / \mathrm{c}$ refer to significance level $1 \%$ (a), $5 \%$ (b) and $10 \%$ (c) based on bootstrap-t procedure. 1000 replications used for estimating confidence intervals. For the bootstrapped model, the dummy for cutting trees in oil palm plantations in the last 12 months was not included. This is because the dummy did not vary between some clusters prohibiting the estimation of the parameters in several pseudo samples. Due to computational complexity, bootstrapped confidence intervals were only computed for the treatment variables. 
Table A2.3: Intention-to-treat effects on the unconditional predicted number of trees planted per hectare

\begin{tabular}{|c|c|c|}
\hline & $\begin{array}{c}(1) \\
\text { Trees planted } \\
\text { per ha }\end{array}$ & $\begin{array}{c}(2) \\
\text { Trees planted } \\
\text { per ha }\end{array}$ \\
\hline $\mathrm{T} 1$ & $\begin{array}{l}0.995^{* * / a} \\
(0.422)\end{array}$ & $\begin{array}{l}0.984^{* * / a} \\
(0.452)\end{array}$ \\
\hline $\mathrm{T} 2$ & $\begin{array}{l}1.583^{* * *} / \mathrm{a} \\
(0.347)\end{array}$ & $\begin{array}{l}1.721^{* * *} / \mathrm{a} \\
(0.412)\end{array}$ \\
\hline Access to seeds & $\begin{array}{l}-0.459 \\
(0.387)\end{array}$ & $\begin{array}{l}-0.115 \\
(0.363)\end{array}$ \\
\hline Local village & $\begin{array}{c}0.217 \\
(0.477)\end{array}$ & $\begin{array}{c}0.278 \\
(0.657)\end{array}$ \\
\hline Oil palm share $>73.5 \%$ & $\begin{array}{l}-1.131^{* * *} \\
(0.405)\end{array}$ & $\begin{array}{c}-1.173^{* * *} \\
(0.406)\end{array}$ \\
\hline $\begin{array}{l}\text { Total number of trees } \\
\text { planted per ha in OP }\end{array}$ & $\begin{array}{l}0.033^{*} \\
(0.018)\end{array}$ & $\begin{array}{c}0.039 \\
(0.026)\end{array}$ \\
\hline Number HH members & & $\begin{array}{l}-0.013 \\
(0.112)\end{array}$ \\
\hline Trees cut in $\mathrm{OP}$ & & $\begin{array}{l}-0.158 \\
(0.921)\end{array}$ \\
\hline Years of education & & $\begin{array}{l}0.067^{*} \\
(0.037)\end{array}$ \\
\hline Home garden & & $\begin{array}{c}-1.326^{* *} \\
(0.579)\end{array}$ \\
\hline Total hectare & & $-0.190^{* * *}$ \\
\hline OP managed & & $(0.049)$ \\
\hline FFB price per $\mathrm{kg}$ & & $\begin{array}{l}-0.080 \\
(1.146)\end{array}$ \\
\hline $\begin{array}{l}\text { Environmental extension } \\
\text { received }\end{array}$ & & $\begin{array}{l}1.088^{* *} \\
(0.484)\end{array}$ \\
\hline Share of plots flooded & & $\begin{array}{c}0.585 \\
(0.401)\end{array}$ \\
\hline Information constraints & & $\begin{array}{c}0.238 \\
(0.334)\end{array}$ \\
\hline Seed access constraints & & $\begin{array}{l}-0.042 \\
(0.323)\end{array}$ \\
\hline Observations & 736 & 736 \\
\hline
\end{tabular}

Village-level clustered standard errors in parentheses. Delta method used to estimate standard errors. AME for the unconditional expected number of trees per hectare.

${ }^{*} \mathrm{p}<0.1,{ }^{* *} \mathrm{p}<0.05,{ }^{* * *} \mathrm{p}<0.01$

$\mathrm{a} / \mathrm{b} / \mathrm{c}$ refer to significance level $1 \%$ (a), $5 \%$ (b) and $10 \%$ (c) based on bootstrap-t procedure. 1000 replications used for estimating confidence intervals. Due to computational complexity, bootstrapped confidence intervals were only computed for the treatment variables. 
Table A2.4: Bootstrap-t confidence intervals for treatment groups

\begin{tabular}{ccccc}
\hline \hline & \multicolumn{2}{c}{$(1)$} & & \multicolumn{2}{c}{$(2)$} & \\
& $\mathrm{T} 1$ & $\mathrm{~T} 2$ & $\mathrm{~T} 1$ & $\mathrm{~T} 2$ \\
\hline Coefficients adoption & $90 \%$-CI & $99 \%$-CI & $95 \%$-CI & $99 \%$-CI \\
decision & {$[0.104 ; 1.568]$} & {$[1.824 ; 4.086]$} & {$[0.165 ; 1.692]$} & {$[2.147 ; 3.950]$} \\
AME adoption & $90 \%$-CI & $99 \%$-CI & $95 \%$-CI & $99 \%$-CI \\
decision & {$[0.008 ; 0.102]$} & {$[0.297 ; 0.465]$} & {$[0.004 ; 0.113]$} & {$[0.291 ; 0.448]$} \\
Coefficients intensity & $95 \%$-CI & $90 \%$-CI & $95 \%$-CI & $90 \%$-CI \\
decision & {$[0.664 ; 1.778]$} & {$[-0.151 ; 0.884]$} & {$[0.082 ; 2.123]$} & {$[-0.683 ; 1.243]$} \\
AME intensity & $99 \%$-CI & $90 \%$-CI & $95 \%$-CI & $90 \%$-CI \\
decision & {$[1.147 ; 29.485]$} & {$[-0.710 ; 3.029]$} & {$[3.106 ; 17.365]$} & {$[-2.051 ; 3.695]$} \\
AME unconditional & $99 \%$-CI & $99 \%$-CI & $99 \%$-CI & $99 \%$-CI \\
expected value & {$[0.273 ; 3.303]$} & {$[0.384 ; 3.709]$} & {$[0.195 ; 3.594]$} & {$[0.725 ; 3.830]$} \\
\hline
\end{tabular}

1000 replications are used for bootstrapping. The table shows the confidence level for the highest significance level. In case coefficients or AME is not significant at 10\% level, $90 \%$ confidence intervals are displayed. Columns (1) are estimated based on the model without covariates. Columns (2) include the same covariates as used in Tables A2.1 to A2.3. 
Table A2.5: Heckman selection model

\begin{tabular}{lcc}
\hline \hline & $(1)$ & $(2)$ \\
& $\begin{array}{c}\text { Trees } \\
\text { planted per ha } \\
(\log .)\end{array}$ & $\begin{array}{c}\text { Selection equation } \\
\text { T1 }\end{array}$ \\
T2 & 0.434 & $0.466^{* *}$ \\
& $(0.379)$ & $(0.230)$ \\
Access to seeds & -0.565 & $1.640^{* * *}$ \\
& $(0.409)$ & $(0.190)$ \\
Local village & $-0.501^{* *}$ & -0.0658 \\
& $(0.228)$ & $(0.132)$ \\
Oil palm share $>73.5 \%$ & 0.194 & -0.159 \\
& $(0.261)$ & $(0.182)$ \\
Constant & $-0.685^{* * *}$ & $-0.219^{* *}$ \\
& $(0.192)$ & $(0.104)$ \\
Home garden & $1.968^{* * *}$ & $-0.980^{* * *}$ \\
& $(0.699)$ & $(0.242)$ \\
\end{tabular}

Observations

737

737

Estimated coefficients from a Heckman selection model. Standard errors clustered at village level and reported in parentheses.

Wald test of indep. eqns. $($ rho $=0)$ : $\operatorname{chi} 2(1)=0.83$ Prob $>\operatorname{chi} 2=0.3637$.

${ }^{*} \mathrm{p}<0.1,{ }^{* *} \mathrm{p}<0.05,{ }^{* * *} \mathrm{p}<0.01$

Further explanation of test for independence: To ensure that only positive values are predicted by the quantity equation, we follow Wooldridge (2010) and apply a logarithmic transformation to the number of trees planted per hectare. We assume that the possession of a home garden affects the planting decision; as farmers with a home garden will often choose to plant trees there rather than in their oil palm plantation. At the same time, we assume that home garden is not a relevant predictor for the number of trees planted, which is supported by the insignificance of the coefficient of home garden in the conditional expected value estimation in Table A2.2. Consequently, the possession of a home garden represents a valid exclusion restriction and overcomes collinearity problems often encountered when conducting a Wald test of independence (Dow \& Norton, 2003). The test suggests that we cannot reject the independence assumption (p-value: 0.364 ). The validity of the test based on the significance of the inverse mills ratio (IMR) is further supported by the Variance inflation factor (VIF) of the regression of the IMR on the remaining parameters in the model. The resulting sizes of the VIF of 14.10 and 14.30 for the two model specifications tested are well below 30 which is considered the critical level for conducting this test (Madden, 2008). This supports the use of the DH-model. 
Table A2.6: Weighted Intention-to-treat estimation

\begin{tabular}{|c|c|c|c|c|c|c|}
\hline & $\begin{array}{l}\text { Unconditi } \\
\text { values } \\
\quad(1) \\
\mathrm{E}(\mathrm{Y} \mid \mathrm{X})\end{array}$ & $\begin{array}{l}(2) \\
\mathrm{E}(\mathrm{Y} \mid \mathrm{X})\end{array}$ & $\begin{array}{c}\text { Adoption de } \\
\quad(3) \\
\operatorname{Pr}(\mathrm{Y}>0 \mid \mathrm{X})\end{array}$ & $\begin{array}{l}\text { cision } \\
\qquad(4) \\
\operatorname{Pr}(Y>0 \mid \mathrm{X})\end{array}$ & $\begin{array}{l}\text { Conditional } \\
\text { values } \\
(5) \\
\mathrm{E}(\mathrm{Y} \mid \mathrm{X} \\
\mathrm{Y}>0)\end{array}$ & $\begin{array}{c}\text { expected } \\
(6) \\
\mathrm{E}(\mathrm{Y} \mid \mathrm{X} \\
\mathrm{Y}>0)\end{array}$ \\
\hline $\mathrm{T} 1$ & $\begin{array}{l}0.982^{* *} \\
(0.414)\end{array}$ & $\begin{array}{l}0.964^{* *} \\
(0.438)\end{array}$ & $\begin{array}{l}0.055^{*} \\
(0.033)\end{array}$ & $\begin{array}{l}0.059^{* *} \\
(0.029)\end{array}$ & $\begin{array}{c}8.173^{* * *} \\
(2.617)\end{array}$ & $\begin{array}{l}7.908^{* *} \\
(3.559)\end{array}$ \\
\hline $\mathrm{T} 2$ & $\begin{array}{c}1.583^{* * *} \\
(0.348)\end{array}$ & $\begin{array}{c}1.715^{* * *} \\
(0.414) \\
\end{array}$ & $\begin{array}{c}0.381^{* * *} \\
(0.028)\end{array}$ & $\begin{array}{c}0.398^{* * *} \\
(0.028)\end{array}$ & $\begin{array}{c}0.721 \\
(1.005) \\
\end{array}$ & $\begin{array}{c}0.953 \\
(1.712) \\
\end{array}$ \\
\hline 18 & 736 & 736 & 736 & 736 & 144 & 144 \\
\hline $\begin{array}{l}\text { P-values of } \\
\text { t-test } \\
\text { for } \mathrm{T} 1=\mathrm{T} 2\end{array}$ & 0.281 & 0.190 & 0.000 & 0.000 & 0.009 & 0.044 \\
\hline Controls $^{1}$ & No & Yes & No & Yes & No & Yes \\
\hline
\end{tabular}

Village-level clustered standard errors in parentheses and estimated with Delta method.

Columns (1) and (2) show unconditional AME. Columns (3) and (4) report AME from a logit regression. Columns (5) and (6) report AME from a GLM with log-link and gamma distribution of the error terms. Stratification variables and past number of trees planted per hectare in oil palm plantations included in all model specification. Inverse probability weights applied.

${ }^{1}$ Baseline controls include number of household members, whether a farmer cut trees in OP in 2015, education, whether he or she had a home garden, total area of oil palm managed, the mean price for oil palm bunches received, whether he or she received environmental extension, the share of plots that were flooded and whether farmers experienced information and/or seed access constraints.

Drawing on Fitzgerald et al. (1998) weights are constructed with help of auxiliary variables that determine selection in the follow-up sample while being of minor importance for the outcome analysis. Results of the Selection Equation are presented in Table A2.7. ${ }^{*} \mathrm{p}<0.1,{ }^{* *} \mathrm{p}<0.05,{ }^{* * *}$ $\mathrm{p}<0.01$ 
Table A2.7: Determinants of selection in follow-up

\begin{tabular}{|c|c|c|}
\hline & $\begin{array}{c}(1) \\
\text { selection }\end{array}$ & $\begin{array}{c}(2) \\
\text { selection }\end{array}$ \\
\hline $\mathrm{T} 1$ & $\begin{array}{c}0.02 \\
(0.129)\end{array}$ & $\begin{array}{c}0.003 \\
(0.131)\end{array}$ \\
\hline $\mathrm{T} 2$ & $\begin{array}{c}0.206 \\
(0.128)\end{array}$ & $\begin{array}{c}0.161 \\
(0.123)\end{array}$ \\
\hline Years of education & $\begin{array}{l}0.023^{*} \\
(0.014)\end{array}$ & $\begin{array}{c}0.006 \\
(0.016)\end{array}$ \\
\hline Trees planted in $\mathrm{OP}$ & $\begin{array}{l}-0.265 \\
(0.614)\end{array}$ & $\begin{array}{l}-0.497 \\
(0.595)\end{array}$ \\
\hline $\begin{array}{l}\text { Total hectare oil palm } \\
\text { managed }\end{array}$ & $\begin{array}{l}-0.011 \\
(0.008)\end{array}$ & $\begin{array}{l}-0.011 \\
(0.008)\end{array}$ \\
\hline $\begin{array}{l}\text { Environmental } \\
\text { extension received }\end{array}$ & $\begin{array}{c}0.040 \\
(0.266)\end{array}$ & $\begin{array}{l}-0.032 \\
(0.276)\end{array}$ \\
\hline Home garden & $\begin{array}{l}0.228^{*} \\
(0.131)\end{array}$ & $\begin{array}{l}0.323^{* *} \\
(0.146)\end{array}$ \\
\hline Local village & $\begin{array}{c}0.159 \\
(0.157)\end{array}$ & $\begin{array}{c}0.198 \\
(0.169)\end{array}$ \\
\hline Oil palm share $>73.5 \%$ & $\begin{array}{c}0.006 \\
(0.121)\end{array}$ & $\begin{array}{l}-0.038 \\
(0.146)\end{array}$ \\
\hline Access to seeds & $\begin{array}{c}0.091 \\
(0.126)\end{array}$ & $\begin{array}{c}0.085 \\
(0.126)\end{array}$ \\
\hline Number HH members & & $\begin{array}{l}0.0003 \\
(0.041)\end{array}$ \\
\hline Age & & $\begin{array}{c}-0.012^{* * *} \\
(0.007)\end{array}$ \\
\hline Gender & & $\begin{array}{c}-0.903^{* *} \\
(0.389)\end{array}$ \\
\hline Trees cut in OP & & $\begin{array}{c}0.133 \\
(0.207)\end{array}$ \\
\hline Year of planting & & $\begin{array}{l}-0.011 \\
(0.009)\end{array}$ \\
\hline Other crops & & $\begin{array}{l}-0.137 \\
(0.124)\end{array}$ \\
\hline Mean estimate for eleven assistants1 & & $\begin{array}{l}-0.329 \\
(0.261)\end{array}$ \\
\hline Constant & $\begin{array}{l}0.801^{* * *} \\
(0.215)\end{array}$ & $\begin{array}{c}24.74 \\
(18.63)\end{array}$ \\
\hline $\mathrm{N}$ & 817 & 817 \\
\hline McFadden pseudo R2 & 0.017 & 0.057 \\
\hline
\end{tabular}

${ }^{1}$ Out of eleven dummy variables for the assistants collecting the baseline data, only two are statistically significant at the $10 \%$ level.

Probit model employed. Standard errors in parentheses are clustered at village level. Model 2 includes additional auxiliary covariates. In order to get unbiased estimates for the outcome variable of interest, weights are constructed by dividing (1) and (2). Estimates are used to construct Inverse Probability weights.

${ }^{*} \mathrm{p}<0.1,{ }^{* *} \mathrm{p}<0.05,{ }^{* * *} \mathrm{p}<0.01$ 
Table A2.8: Bounds estimation for Intention-to-treat estimates

\begin{tabular}{|c|c|c|c|c|c|c|}
\hline & \multicolumn{2}{|c|}{$\begin{array}{l}\text { Unconditional expected val- } \\
\text { ues } \\
\text { Lee bounds }\end{array}$} & $\begin{array}{l}\text { Adoption } \\
\text { Manski-H }\end{array}$ & $\begin{array}{l}\text { sion } \\
\text { ritz bounds }\end{array}$ & & \multirow[b]{2}{*}{ Upper } \\
\hline & Lower & Upper & Lower & Upper & $\begin{array}{l}\text { Lee bounds } \\
\text { Lower }\end{array}$ & \\
\hline \multirow[t]{3}{*}{$\mathrm{T} 1$} & 0.635 & 1.002 & -0.061 & 0.156 & 0.050 & 0.057 \\
\hline & {$[-2.360$} & {$[0.164$} & {$[-0.116$} & {$[0.103$} & {$[-0.020$} & {$[0.010$} \\
\hline & $3.630]$ & $0.840]$ & $-006]$ & $0.209]$ & $0.121]$ & $0.104]$ \\
\hline \multirow[t]{3}{*}{$\mathrm{T} 2$} & 0.632 & 1.845 & 0.247 & 0.432 & 0.360 & 0.403 \\
\hline & {$[0.115$} & {$[0.960$} & {$[0.174$} & {$[0.367$} & {$[0.284$} & {$[0.330 ;$} \\
\hline & $1.150]$ & $2.730]$ & $0.320]$ & $0.496]$ & $0.436]$ & $0.476]$ \\
\hline
\end{tabular}

Bounds presented for ITT regression without covariates. Confidence intervals in parentheses. Manski- Horowitz bounds (MH-bounds) assume worse and best case scenarios for the attritors, i.e. farmers dropping out of the control group adopt and those dropping out of the treatment group do not (and vice versa). Since MH bounds are uninformative if applied to non-bounded outcome variables (Lee, 2009) they are only presented for the adoption decision.

Besides random assignment of the treatments, the Lee bounds assume that treatment status can affect selection only in one direction. Since attrition is highest in the control group, this monotonicity assumption is likely to be fulfilled. Since Lee bounds are often smaller, they are more informative. This is also why we interpret the results from the bounds as support for our previous results, despite the non-significance of $\mathrm{T} 1$ for the adoption decision when $\mathrm{MH}$-bounds are used. However, the MH-Bounds provide a helpful indication whether the monotonicity assumption imposed by the method proposed by Lee (2009) is realistic. Lee-Bounds need to lie within the wider MH-bounds.

Since we cannot disentangle sample selection because of attrition and because of adoption for the intensity decision, we do not present bounds for the conditional expected number of trees per hectare 
Table A2.9: Fractional probit estimation for tree survival

\begin{tabular}{|c|c|c|c|c|c|c|}
\hline & $\begin{array}{c}(1) \\
\text { Tree } \\
\text { survival } \\
\text { rate }\end{array}$ & $\begin{array}{c}(2) \\
\text { Tree } \\
\text { survival } \\
\text { rate }\end{array}$ & $\begin{array}{c}(3) \\
\text { Survival } \\
\text { rate of of } \\
\text { dis- } \\
\text { tributed } \\
\text { species }\end{array}$ & $\begin{array}{c}(4) \\
\text { Tree } \\
\text { survival } \\
\text { rate, mfx }\end{array}$ & $\begin{array}{c}(5) \\
\text { Tree } \\
\text { survival } \\
\text { rate, mfx }\end{array}$ & $\begin{array}{c}(6) \\
\text { Survival } \\
\text { rate of } \\
\text { dis- } \\
\text { tributed } \\
\text { species, } \\
\text { mfx }\end{array}$ \\
\hline Share of trees & 0.071 & -0.027 & -0.119 & 0.022 & -0.008 & -0.039 \\
\hline planted in island & $(0.405)$ & $(0.418)$ & $(0.430)$ & $(0.124)$ & $(0.124)$ & $(0.141)$ \\
\hline $\begin{array}{l}\text { Share of provided } \\
\text { species in total } \\
\text { trees planted }\end{array}$ & $\begin{array}{c}-0.898^{* * *} \\
(0.267)\end{array}$ & $\begin{array}{c}-0.670^{* *} \\
(0.306)\end{array}$ & & $\begin{array}{c}-0.275^{* * *} \\
(0.081)\end{array}$ & $\begin{array}{c}-0.199^{* *} \\
(0.093)\end{array}$ & \\
\hline $\begin{array}{l}\text { Total number of } \\
\text { trees planted }\end{array}$ & $\begin{array}{c}0.000 \\
(0.001)\end{array}$ & $\begin{array}{l}-0.000 \\
(0.002)\end{array}$ & $\begin{array}{c}0.001 \\
(0.001)\end{array}$ & $\begin{array}{c}0.000 \\
(0.000)\end{array}$ & $\begin{array}{l}-0.000 \\
(0.000)\end{array}$ & $\begin{array}{c}0.000 \\
(0.000)\end{array}$ \\
\hline Mean plot age & $\begin{array}{c}0.013 \\
(0.019)\end{array}$ & $\begin{array}{c}0.012 \\
(0.017)\end{array}$ & $\begin{array}{c}0.011 \\
(0.019)\end{array}$ & $\begin{array}{c}0.004 \\
(0.006)\end{array}$ & $\begin{array}{c}0.004 \\
(0.005)\end{array}$ & $\begin{array}{c}0.004 \\
(0.006)\end{array}$ \\
\hline $\begin{array}{l}\text { Mean number of } \\
\text { oil palms }\end{array}$ & $\begin{array}{l}-0.002 \\
(0.005)\end{array}$ & $\begin{array}{l}-0.005 \\
(0.005)\end{array}$ & $\begin{array}{l}-0.000 \\
(0.006)\end{array}$ & $\begin{array}{l}-0.001 \\
(0.002)\end{array}$ & $\begin{array}{l}-0.001 \\
(0.001)\end{array}$ & $\begin{array}{l}-0.000 \\
(0.002)\end{array}$ \\
\hline $\begin{array}{l}\text { Share of plots with } \\
\text { a river bordering }\end{array}$ & $\begin{array}{l}0.470^{* *} \\
(0.184)\end{array}$ & $\begin{array}{l}0.574^{* * *} \\
(0.200)\end{array}$ & $\begin{array}{c}0.293 \\
(0.181)\end{array}$ & $\begin{array}{l}0.144^{* * *} \\
(0.055)\end{array}$ & $\begin{array}{l}0.171^{* * *} \\
(0.057)\end{array}$ & $\begin{array}{c}0.096 \\
(0.059)\end{array}$ \\
\hline $\begin{array}{l}\text { Share of flood } \\
\text { prone plots }\end{array}$ & $\begin{array}{l}-0.135 \\
(0.536)\end{array}$ & $\begin{array}{l}-0.353 \\
(0.507)\end{array}$ & $\begin{array}{l}-0.533 \\
(0.581)\end{array}$ & $\begin{array}{l}-0.041 \\
(0.164)\end{array}$ & $\begin{array}{l}-0.105 \\
(0.150)\end{array}$ & $\begin{array}{l}-0.175 \\
(0.187)\end{array}$ \\
\hline $\begin{array}{l}\text { Share of drought } \\
\text { prone plots }\end{array}$ & $\begin{array}{l}-0.275 \\
(0.232)\end{array}$ & $\begin{array}{l}-0.226 \\
(0.240)\end{array}$ & $\begin{array}{l}-0.405 \\
(0.307)\end{array}$ & $\begin{array}{l}-0.084 \\
(0.071)\end{array}$ & $\begin{array}{l}-0.067 \\
(0.070)\end{array}$ & $\begin{array}{l}-0.133 \\
(0.098)\end{array}$ \\
\hline Years of education & $\begin{array}{c}0.029 \\
(0.028)\end{array}$ & $\begin{array}{c}0.023 \\
(0.026)\end{array}$ & $\begin{array}{c}0.034 \\
(0.030)\end{array}$ & $\begin{array}{c}0.009 \\
(0,009)\end{array}$ & $\begin{array}{c}0.007 \\
(0.008)\end{array}$ & $\begin{array}{c}0.011 \\
(0.010)\end{array}$ \\
\hline $\begin{array}{l}\text { Experience with } \\
\text { tree planting in } \mathrm{OP}\end{array}$ & $\begin{array}{l}0.674^{* * *} \\
(0.193)\end{array}$ & $\begin{array}{l}0.784^{* * *} \\
(0.192)\end{array}$ & $\begin{array}{l}0.713^{* * *} \\
(0.149)\end{array}$ & $\begin{array}{l}0.206^{* * *} \\
(0.059)\end{array}$ & $\begin{array}{l}0.233^{* * *} \\
(0.056)\end{array}$ & $\begin{array}{c}0.234^{* * *} \\
(0.049)\end{array}$ \\
\hline values of assets in & 0.004 & 0.004 & 0.000 & 0.001 & 0.001 & 0.000 \\
\hline $1,000 \mathrm{IDR}$ & $(0.003)$ & $(0.003)$ & $(0.003)$ & $(0.001)$ & $(0.001)$ & $(0.001)$ \\
\hline maintenance done & $0.591^{* * *}$ & $0.671^{* * *}$ & $0.637^{* * *}$ & $0.181^{* * *}$ & $0.200^{* * *}$ & $0.209^{* * *}$ \\
\hline $\begin{array}{l}\text { to trees }(1=\text { Yes }) \\
\text { Distance to asphalt }\end{array}$ & $(0.193)$ & $\begin{array}{c}(0.187) \\
0.014\end{array}$ & $(0.174)$ & $(0.055)$ & $\begin{array}{c}(0.051) \\
0.004\end{array}$ & \\
\hline road (in $\mathrm{km}$ ) & & $(0.017)$ & & & $(0.005)$ & \\
\hline $\begin{array}{l}\text { Distance to Jambi } \\
\text { city (in } \mathrm{km} \text { ) }\end{array}$ & & $\begin{array}{l}-0.006^{*} \\
(0.003)\end{array}$ & & & $\begin{array}{l}-0.002^{*} \\
(0.001)\end{array}$ & \\
\hline $\begin{array}{l}\text { Species planted in } \\
\text { excess of intent }\end{array}$ & & & $\begin{array}{c}-0.087^{* *} \\
(0.034)\end{array}$ & & & $\begin{array}{c}-0.029^{* * *} \\
(0.010)\end{array}$ \\
\hline Constant & $\begin{array}{c}0.634 \\
(0.969) \\
\end{array}$ & $\begin{array}{c}1.393 \\
(0.956) \\
\end{array}$ & $\begin{array}{l}-0.208 \\
(1.050) \\
\end{array}$ & & & \\
\hline Observations & 141 & 141 & 101 & 141 & 141 & 101 \\
\hline
\end{tabular}

Standard errors clustered at village level reported in parentheses. Columns (1) to (3) report coefficients from a fractional probit estimation. Columns (4) to (6) report derived AME. To control for the ease of transport of the seedlings, we also include the distance between the villages and Jambi city and the distance to the next paved road in column (2). A precise description of the variables can be found in Table A2.11. In columns (3) and (6) only farmers in T2 who planted the distributed species are included.

${ }^{*} \mathrm{p}<0.1,{ }^{* *} \mathrm{p}<0.05,{ }^{* * *} \mathrm{p}<0.01$ 
Table A2.10: Descriptives of other explanatory variables

\begin{tabular}{|c|c|c|c|c|}
\hline Variable & $\begin{array}{c}(1) \\
\text { Overall }\end{array}$ & $\stackrel{(2)}{\text { Control }+\mathrm{T} 1}$ & $\begin{array}{l}(3) \\
\mathrm{T} 2\end{array}$ & $\begin{array}{c}(4) \\
\text { Control }+\mathrm{T} 1 \\
=\mathrm{T} 2\end{array}$ \\
\hline Share of trees planted in islands & $\begin{array}{c}0.066 \\
(0.247)\end{array}$ & $\begin{array}{c}0.086 \\
(0.284)\end{array}$ & $\begin{array}{c}0.060 \\
(0.234)\end{array}$ & 0.622 \\
\hline Total number of trees planted & $\begin{array}{c}24.944 \\
(91.812)\end{array}$ & $\begin{array}{c}37.229 \\
(71.062)\end{array}$ & $\begin{array}{c}21 \\
(97.502)\end{array}$ & 0.358 \\
\hline Mean plantation age & $\begin{array}{l}13.552 \\
(7.606)\end{array}$ & $\begin{array}{l}13.043 \\
(7.413)\end{array}$ & $\begin{array}{l}13.716 \\
(7.693)\end{array}$ & 0.763 \\
\hline Mean number of oil palms per ha & $\begin{array}{l}141.091 \\
(15.936)\end{array}$ & $\begin{array}{l}139.749 \\
(17.072)\end{array}$ & $\begin{array}{l}141.509 \\
(15.624)\end{array}$ & 0.621 \\
\hline Share of plots which are flood prone & $\begin{array}{c}0.105 \\
(0.307)\end{array}$ & $\begin{array}{c}0.147 \\
(0.359)\end{array}$ & $\begin{array}{c}0.092 \\
(0.290)\end{array}$ & 0.584 \\
\hline Share of plots which are drought prone & $\begin{array}{c}0.608 \\
(0.485)\end{array}$ & $\begin{array}{c}0.451 \\
(0.498)\end{array}$ & $\begin{array}{c}0.657 \\
(0.472)\end{array}$ & $0.056^{*}$ \\
\hline Education & $\begin{array}{c}8.188 \\
(3.861)\end{array}$ & $\begin{array}{c}8.600 \\
(4.146)\end{array}$ & $\begin{array}{c}8.055 \\
(3.776)\end{array}$ & 0.457 \\
\hline Asset index (in 1,000 IDR) & $\begin{array}{c}33.835 \\
(58.814) \\
\end{array}$ & $\begin{array}{c}44.157 \\
(55.326)\end{array}$ & $\begin{array}{c}30.521 \\
(59.757) \\
\end{array}$ & 0.310 \\
\hline $\mathrm{N}$ & 144 & 35 & 109 & \\
\hline
\end{tabular}

In columns (1) to (3), standard deviation reported in parentheses. Column (4) shows p-values of test for mean difference with clustered standard errors. Test for equality between the combined group of control and T1, and T2 done with help of a linear regression with village-level clustered standard errors.

${ }^{*} \mathrm{p}<0.1,{ }^{* *} \mathrm{p}<0.05,{ }^{* * *} \mathrm{p}<0.01$ 
Table A2.11: Definition of explanatory variables

\section{Intention-to-Treat Estimation}

\begin{tabular}{|c|c|}
\hline Variable Name & Explanation \\
\hline $\begin{array}{l}\text { Trees planted per hectare } \\
\text { (outcome variable) }\end{array}$ & $\begin{array}{l}\text { We can detect one important outlier in our outcome variable } \\
\text { who planted } 167 \text { trees per hectare for an intercropping } \\
\text { system. } \\
\text { This is over nine times the standard deviation away from the } \\
\text { mean of the farmers who planted in oil palm plots. The } \\
\text { number of trees per hectare of this farmer is replaced with } \\
\text { the observation of the farmer who planted the second highest } \\
\text { number of trees per hectare. }\end{array}$ \\
\hline $\mathrm{T} 1$ & $\begin{array}{l}=1 \text { if the village was assigned to treatment one, the } \\
\text { informational intervention } \\
=0 \text { otherwise }\end{array}$ \\
\hline $\mathrm{T} 2$ & $\begin{array}{l}=1 \text { if the village was assigned to Treatment two, the } \\
\text { structural intervention } \\
=0 \text { otherwise }\end{array}$ \\
\hline Access to seeds ${ }^{*}$ & $\begin{array}{l}=1 \text { if the farmers in the village have access to tree seedlings } \\
=0 \text { otherwise }\end{array}$ \\
\hline Local village ${ }^{*}$ & $\begin{array}{l}=1 \text { if mostly local Melayu farmers live in the village } \\
=0 \text { mostly transmigrant farmers live in the village }\end{array}$ \\
\hline Oil palm share $>73.5 \%^{*}$ & $\begin{array}{l}=1 \text { if more than } 73.5 \% \text { of the farmers in one village are } \\
\text { engaged in oil palm cultivation } \\
=0 \text { otherwise }\end{array}$ \\
\hline Number HH members ${ }^{*}$ & Number of persons in a household \\
\hline Trees cut in $\mathrm{OP}^{*}$ & $\begin{array}{l}=1 \text { if a farmer cut trees in his or her oil palm plantation in } \\
\text { the last } 12 \text { months }\end{array}$ \\
\hline Years of education ${ }^{*}$ & Years of education of household head \\
\hline Home garden ${ }^{*}$ & $\begin{array}{l}=1 \text { if a farmer has a home garden } \\
=0 \text { otherwise }\end{array}$ \\
\hline
\end{tabular}

Total number of trees planted per ha in $\mathrm{OP} *$

Number of trees per hectare a farmer has planted in oil palm plantations, per household. Since the distribution of tree density is highly right skewed, the variable is winsorized. The top $1 \%$ of the distribution is replaced with the 99 percentile.

FFB price per $\mathrm{kg}^{*}$ For prices, we use the mean prices for Fresh Fruit Bunches farmers got in 2015 for the rainy and dry season. For farmers who have not harvested their plots yet, the mean village value is used.

Environmental extension $=1$ if the farmer received any environmental extension in received $^{*}$ the last 12 months $=0$ otherwise 
Share of plots flooded*

Seed access constraint ${ }^{*}$

Information constraint ${ }^{*}$

Values of assets ${ }^{*}$

Experience with tree planting in $\mathrm{OP}^{*}$

Share of plots with river bordering

Share of plots which are flood prone

Mean steepness of plots

Mean age of plot

Total number of trees planted

Share of provided species in total trees planted

Share of trees planted in islands Education*
Number of plots flooded in 2015 divided by total number of plots

Farmers were asked on a five point Likert scale ranging from strongly disagree $(=1)$ to strongly agree $(=5)$ whether seedlings are easily available in the village. Farmers who (strongly) disagree with this statement were classified as seedling constrained $=1$.

Seedling constraint $=0$ otherwise

Farmers were asked on a five point Likert scale ranging from strongly disagree $(=1)$ to strongly agree $(=5)$ whether there is enough information about tree planting available in the village. Farmers who (strongly) disagree with the first were classified as information constrained $=1,=0$ otherwise.

\section{Tree survival equation}

Explanation

Distance from village office to Jambi city based on GPS coordinates (in $\mathrm{km}$ )

Distance from village to next asphalt road (in $\mathrm{km}$ )

$=1$ if a farmer applies fertilizer and/or manure application and/or weeding.

$=0$ otherwise

Asset index in 1,000 IDR. Assets considered for the compilation are television, motorbike, car, fridge, washing machine and cell-phone.

$=1$ if a farmer has trees in his or her oil palm plantation which he or she planted on his or her own. $=0$ otherwise Share of plots a farmer planted trees on which have a river bordering

Share of plots a farmer planted trees on which have been flooded both in 2015 and in 2016.

Mean steepness of plots a farmer planted trees on Variable ranges from 1 to 6 . A one unit increase represents an increase in slope of 10 degrees.

Mean age of the plantation where the farmers planted trees on

Total number of trees a farmer planted

Number of the six species, which were chosen to be distributed in $\mathrm{T} 2$, divided by the total number of trees planted.

Number of trees which are planted in a clustered way divided by the total number of trees planted. Years of education of household head 
Species planted in excess of intent
Farmers were asked after the intervention how many of the six species distributed they would like to plant per ha if provided for free. Based on this, we estimated the number of species a farmer would like to plant. This number was subtracted from the number of species a farmer actually planted to derive the number of species a farmer planted beyond his or her intent.

Variables indicated with a ${ }^{*}$ refer to baseline levels. 


\section{Chapter 3}

\section{Achieving a suitable landscape pattern for biodiversity conservation through payments for ecosystem services - Evidence from Indonesia}

This chapter is co-authored by Meike Wollni. KR developed the research idea, designed the experiment, implemented the experiment, analyzed the data and wrote the paper. MW assisted with the design, commented on the results and the paper and helped with the revision of the paper. 


\subsection{Introduction}

Biodiversity loss represents one of the most urgent ecological problems nowadays. This is highlighted by the 2019 Intergovernmental Science-Policy Platform on Biodiversity and Ecosystem Services report which refers to an accelerating species extinction rate that is at its highest level ever seen (Diaz et al., 2019). In order to protect biodiversity, agricultural land, which makes up around $37 \%$ of all land area (The World Bank, 2016), represents a key element. Intensified agriculture has contributed to biodiversity loss via a simplification in vegetation and landscape structure. However, agriculture can also increase biodiversity if land is managed in an environmentally friendly way (Tscharntke, Klein, Kruess, Steffan-Dewenter, \& Thies, 2005). This requires the involvement of private land owners. Yet, private incentives for land owners to manage their land in a biodiversity-friendly way are often small, because biodiversity represents a public good whose protection is mostly linked to costs (Goldman et al., 2007).

Payments for ecosystem services (PES) can be considered a promising policy tool in order to increase private incentives for biodiversity conservation. PES can be defined as voluntary transactions between beneficiaries and providers of ecosystem services that are conditional on agreed rules of natural resource management and aim at providing environmental benefits (Wunder, 2015). While PES have become a widely implemented policy instrument in both developed and developing countries, their ecological effectiveness appears to be mixed (Börner et al., 2017; Pattanayak, Wunder, \& Ferraro, 2010). One of the reasons put forward for this is that often the land use targeted under a PES-scheme does not effectively translate into an improvement of the targeted ecosystem service (Wunder, Engel, \& Pagiola, 2008).

To increase the effectiveness of PES-schemes it can be important to take into consideration landscape-level requirements for the ecosystem service targeted. Both the composition of the landscape, i.e. the proportion of different habitat types, and its configuration, i.e. the spatial arrangement of the habitat types, can be of importance (Goldman et al., 2007; Liere et al., 2017). In order to increase ecosystem services linked to pollinator diversity such as bird diversity, a minimum size of conservation area needs to be present for species that are (partially) dependent on forest cover. If the conservation area falls below this minimum, species richness and/or abundance might decline abruptly and the risk of species extinction exists (Betts, Forbes, \& Diamond, 2007; Fahrig, 2003). A second aspect, which has been shown to affect the abundance and diversity of several species, is habitat 
fragmentation (Goldman et al., 2007). Increasing distances between, and isolation of forest patches negatively correlate with the existence of several species, because of e.g. limited possibilities for populations to exchange with populations living in other patches (Martensen et al., 2012; Pardini et al., 2010). Besides evidence from forest areas, the relevance of connectivity and the existence of threshold effects have also been supported for semi-natural, conserved or restored areas in agricultural landscapes (Azhar et al., 2011; Hass et al., 2018; Tscharntke et al., 2011; With, Pavuk, Worchuck, Oates, \& Fisher, 2002).

In order to ensure that a sufficient size of conservation area is created, some authors suggest to compensate providers of ecosystem services only, if the required size of conservation area is generated at a predefined scale (Cadsby \& Maynes, 1999; Le Coent et al., 2014; Midler et al., 2015; Narloch et al., 2012). To increase the spatial connectivity between conserved areas, scholars have proposed an agglomeration bonus in addition to a uniform payment per e.g. hectare conserved, if farmers put bordering land under conservation (Parkhurst \& Shogren, 2007; Parkhurst et al., 2002). Another instrument suggested to improve the spatial connectivity are agglomeration payments, where payments are only made if farmers put bordering plots under conservation. Uniform base payments are thus not offered under such schemes (Drechsler, Wätzold, Johst, \& Shogren, 2010; Lewis, Plantinga, Nelson, \& Polasky, 2011; Wätzold \& Drechsler, 2014). Positive evidence on the effectiveness of the first two approaches is mostly provided by experimental studies (Banerjee, 2018; Banerjee, de Vries, Hanley, \& van Soest, 2014; Midler et al., 2015; Narloch et al., 2012). In contrast, evidence on the agglomeration payment is almost entirely derived from simulation studies, with the study by Ferré, Engel, and Gsottbauer (2018) that is however based on very small groups of two individuals as an exception. However, none of these approaches analyze a scenario in which the generation of environmental effects depends both on reaching a critical size of conservation area and its connectivity. Consequently, these studies cannot derive conclusions on which approaches are best suited for biodiversity conservation.

In order to test which policies could be suitable for biodiversity conservation, we implemented a framed field experiment with Indonesian oil palm farmers. In the experiment, farmers needed to decide whether to keep their land under a monoculture oil palm plantation, or whether to switch to conservation, i.e. a biodiversity-friendly mixed system that integrates trees besides oil palms. Two different PES designs are analyzed: The first one is a conditional payment where farmers are compensated for conservation if at least three farmers in a group of six 
conserve. This policy scheme especially aims at reaching critical area thresholds and is similar to the PES design analyzed in e.g. Midler et al. (2015). The second one is an agglomeration payment and compensates conserving farmers if at least three farmers with bordering land conserve in the group. Besides reaching a relevant area threshold, it sets additional incentives for improving the connectivity between conserved plots. ${ }^{1}$ This could increase both the environmental effectiveness and the budget efficiency of the PES scheme in comparison to designs without an explicit spatial target (Wätzold \& Drechsler, 2014). Given the general current challenge of (sustaining) financing of compensation schemes for landscape restoration (FAO \& Global Mechanism of the UNCCD, 2015), the latter is important for policy makers. To additionally explore the relevance of compensation sizes for conservation, these two PES designs are combined with three different payment levels.

We look at the effects of the two PES designs and the three payment levels on the individual conservation decision and on the environmental effects generated. To assess the underlying drivers of the latter, we further analyze the effects on the share of conserving farmers and on coordination, measured as the environmental effects generated per conserving farmer. These two indicators are closely linked to the provision of an environmentally relevant area size and its connectivity. Besides environmental effectiveness, we look at the environmental effects generated per unit of budget spent and the level of overall welfare generated as two efficiency indicators PES-schemes are commonly judged upon.

Our study contributes to the literature in three ways. First, we combine two strands of literature which have either looked at how PES-schemes need to be designed to meet important ecological thresholds, or at how the spatial connectivity between conserved plots can be improved by analyzing the provision of a threshold environmental good that is positively affected by increased connectivity between the conserved plots. ${ }^{2}$ Second, we provide experimental evidence on agglomeration payments. While simulation studies have highlighted positive advantages of agglomeration payments such as high budget efficiency, these studies assume that land owners will put their land under conservation if expected revenues are positive

\footnotetext{
${ }^{1}$ Simulation studies have adopted a broader definition of connectivity. Conserved plots do not need to be directly bordering. Instead, they often define a conservation density which measures the share of conserved area in total area of the landscape targeted (e.g. Wätzold and Drechsler 2014). Under this broader definition of connectivity, the two thresholds analyzed could also be understood as two agglomeration payments. In contrast to these simulation studies, the provision of environmental goods is subject to reaching the critical size of area in this study.

${ }^{2}$ With threshold good, we refer to cases where more than two individuals need to conserve to generate the public good.
} 
(Drechsler et al., 2010; Lewis et al., 2011; Wätzold \& Drechsler, 2014). Coordination failure which has often been observed in laboratory experiments (e.g. Banerjee et al. 2014 ) is therefore ignored. Consequently, evidence on whether individuals manage to coordinate under such schemes is missing. Third, we explore the behavior of farmers and thus real-world decision makers in a developing country context. Although the question of how to improve the spatial connectivity of conservation areas has received considerable attention in the experimental literature, most studies work with general students as a subject pool. The study by Ferré et al. (2018) that works with agricultural students is the exception. To our knowledge, there exist only two studies that implement spatial aspects in a framed field experiment (Liu et al., 2019; Rommel \& Anggraini, 2018), but only the former analyses compensation schemes. Since real decision makers may behave differently than university students (Levitt \& List, 2007) and since policy makers may find results generated from student samples unconvincing (Liu et al., 2019), it is important to complement existing knowledge by results from framed experiments with farmers. Indonesia is a particularly important case since the country represents one of the global biodiversity hotspots with many endemic species. However, the local biodiversity is getting under increasing pressure by the still ongoing oil palm expansion (Koh \& Wilcove, 2008). Therefore, the country is key when trying to tackle global biodiversity loss.

Our study is structured as follows. First, we give some background information about oil palm expansion in Indonesia and the related effects on biodiversity, and introduce the concept of tree planting in oil palm plantations. In the next section, the framed field experiment and the study region are presented. Moreover, we derive theoretical hypotheses for farmers' behavior in the experiment. Section 3.4 presents results and section 3.5 concludes.

\subsection{Oil palm expansion in Indonesia}

Over $85 \%$ of the global palm oil supply is produced in South-East Asia with Indonesia being the biggest producing country. Due to high global demand, the area under oil palm production in the country has expanded markedly in the last decades, reaching 6,777,498 ha of area harvested in 2018 (FAO, 2019). In comparison to 1980, this corresponds to an increase by a factor of 33 .

Smallholder farmers account for around $40 \%$ of the Indonesian palm oil production (Gatto et al., 2015). Most of them have profited from oil palm expansion 
in terms of income growth (Euler et al., 2017). However, at the same time, oil palm expansion has also spurred deforestation (Fitzherbert et al., 2008). Besides concerns over climate impacts (Dislich et al., 2017), environmentalists especially highlight the resulting threats for biodiversity (Koh \& Wilcove, 2008; Vijay et al., 2016). One of the reasons for this is that Indonesia represents one of the global biodiversity hotspots with many endemic species, many of which are dependent on forest area. Due to their reduced vegetation complexity, oil palm plantations however only harbor a very limited range of taxa and many invasive species are present (Dislich et al., 2017).

In order to increase biodiversity, some authors have suggested the planting of mixed systems, which besides oil palms include other crops and trees (Bhagwat \& Willis, 2008). If established in a spatially coordinated way, these mixed systems can serve as corridors and might link remnant forest patches in high production areas (Koh et al., 2009). Mixed oil palm systems have been shown to support more biodiversity than monoculture systems (Ashraf et al., 2018; Yahya et al., 2017). However, the relationship between species diversity and forest cover at the landscape level (Betts et al., 2007; Martensen et al., 2012), and species diversity and the number of native trees in oil palm plantations at the plot level (Teuscher et al., 2015) suggest that a minimum critical area size is likely needed to prevent an abrupt decline in species abundance and/or diversity.

Due to competition for nutrients and light, intercropping oil palms with trees potentially generates costs for farmers (Teuscher et al., 2015). The existence and size of these costs likely depend on the species chosen for intercropping (Corley \& Tinker, 2016; Miccolis et al., 2019). While some smallholders prefer mixed oil palm systems because of diversification preferences (Slingerland et al., 2019), the costs that smallholders potentially incur when switching to a more diverse system can explain why only few mixed systems exist in oil palm dominated areas such as Jambi Province in Sumatra (Teuscher et al., 2015). To increase the share of mixed systems to environmentally relevant shares at the landscape level, compensation payments might thus be needed. This motivates the analysis of PES as a potential policy instrument. 


\subsection{The conservation game}

\subsubsection{Experimental design}

In order to analyze farmers' willingness to plant trees in oil palm plantations, we use a coordination game. To increase the external validity of the results, the game was framed around the decision to maintain a pure oil palm plantation, or to switch to a mixed system with both oil palms and trees growing together. Our experiment comprises three stages. First, all farmers play a baseline scenario without compensation payments for five rounds. Afterwards, the treatments are introduced which consist of a pure compensation stage (10 rounds) and a communication stage (5 rounds). The precise set-up of the experiment, which follows a between-within design, is shown in Table 3.1. The within design, in particular the change from the baseline to the compensation stage, was chosen in order to increase the external validity of the experimental effects of a PES introduction. Several studies have shown that the introduction of monetary rewards for pro-environmental behavior might interact with non-monetary motivations which could affect the conservation outcome (Rode, Gómez-Baggethun, \& Krause, 2014). This interaction might not be adequately captured by a between design. In the following, we first describe the baseline scenario and then present the treatments.

Table 3.1: Experimental setup

\begin{tabular}{|l|l|l|l|l|}
\hline Stage & Baseline & \multicolumn{2}{|c|}{ Compensation } & Communication \\
\hline Rounds & $1-5$ & $6-10$ & $11-15$ & $16-20$ \\
\hline $\begin{array}{l}\text { Policy in- } \\
\text { strument }\end{array}$ & $\begin{array}{l}\text { no PES- } \\
\text { scheme }\end{array}$ & $\begin{array}{l}\text { PES design + } \\
\text { first payment } \\
\text { level }\end{array}$ & $\begin{array}{l}\text { PES design } \\
+ \text { second pay- } \\
\text { ment level }\end{array}$ & $\begin{array}{l}\text { PES design + sec- } \\
\text { ond payment level + } \\
\text { communication }\end{array}$ \\
\hline $\begin{array}{l}\text { Note: PES design can be either AT or AP. Payment levels include high, } \\
\text { medium or low payments. }\end{array}$ \\
\hline
\end{tabular}

\section{The baseline scenario}

In the experiment, farmers own one hectare of an established oil palm plantation. This status-quo choice is motivated by our interest in exploring policy options to support diversification in high production areas, i.e. where most farmers already have oil palm. Farmers play in groups of six. In order to model a spatial arrangement, 
Figure 3.1: Spatial arrangement of six participants

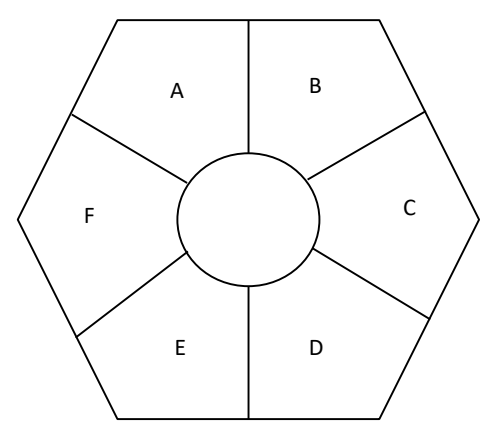

we make use of the circular network developed by Banerjee, Kwasnica, and Shortle (2012). Farmers' plantations are arranged on a circle with each plantation sharing a border with two other plantations, one to the right and one to the left (Figure 3.1). Due to the symmetric structure of the network, each farmer's plantation has the same number of bordering plantations such that farmers face the same degree of strategic uncertainty. Farmers' plot locations are determined randomly before the start of the experiment.

In each round, farmers need to decide whether to keep the one hectare of oil palm established or whether to switch to the mixed system. Revenues from one hectare of oil palm are 100 experimental points, while revenues from one hectare of the mixed system are 50 points. ${ }^{3}$ In the following, we will refer to the decision of planting the mixed system as the decision to conserve. Conservation generates environmental benefits in form of a global public good. These environmental benefits are framed as improvements in bird and other pollinator diversity. In order to activate environmental and social motives and to mimic pro-environmental behavior (Ibanez et al., 2017), the environmental benefits are modeled as donations to an environmental NGO. Modeling environmental benefits as donations further reflects

\footnotetext{
${ }^{3}$ Euler et al. (2016) find mean revenues for oil palm of approximately 10,000,000 IDR (\$71) per year and hectare. To ease the reading of the numbers, we divide revenues by 100,000 and represent them as points. The ratio of revenues from oil palm and the mixed system is based on data in the study region on returns to land for oil palm and jungle rubber, a rubber agroforestry system. Feintrenie, Schwarze, and Levang (2010) report a ratio of per hectare returns slightly below 2 . In our calculation, we additionally include costs of converting the oil palm plantation into a mixed system motivating the revenue ratio of 2 . Due to the non-availability of revenue information of oil palm-tree systems in the study region, we use rubber agroforestry as the benchmark for the mixed system. Rubber and oil palm returns have been shown to be similar (Krishna et al., 2017).
} 
that biodiversity improvements might be linked to little direct monetary effects for farmers. Burung Indonesia, which is the local branch of Birdlive international and working on reforestation in the study region, was chosen as the receiving party. ${ }^{4}$ Since birds need a minimum number of trees to survive (Radford, Bennett, \& Cheers, 2005), the environmental benefits are modeled as a threshold good which is generated if at least three hectares in a group are dedicated to conservation. Once this threshold is reached, each conserved hectare generates environmental benefits of 60 experimental points. Drawing on evidence from restored or enriched areas (Gilbert-Norton et al., 2010; Hass et al., 2018) as well as because of the supported positive effects of rainforest proximity on bird diversity in oil palm plantations (Azhar et al., 2011), proximity of the conserved plots increases the environmental benefits (Goldman et al., 2007). Therefore, upon reaching the threshold of three plots under conservation, each bordering conserved plot additionally increases environmental benefits by 10 points. ${ }^{5}$

\section{The treatments}

After five baseline rounds, a PES-scheme is implemented and compensation payments are made to farmers who conserve. Two PES designs are tested. In the first one, compensations are made if at least three farmers in the group conserve. In the second one, we additionally aim at increasing the spatial connectivity of the conserved plots. Payments are therefore made if at least three farmers with bordering plantations conserve. In contrast to experimental studies on agglomeration boni (e.g. Banerjee et al. (2014)), coordination is thus not only relevant among farmers with direct bordering plantations, but also the action of indirect neighbors, i.e. farmers whose land shares a border with the neighbor of a respective farmer, can directly influence the monetary payoffs of the respective farmer. We will refer to the first payment threshold as the area threshold (AT) and the second one as the agglomeration payment (AP).

To analyze the effects of different payment sizes on farmers' conservation decisions, three payment levels are implemented and combined with the two PES designs. The first one offers a compensation of 30 points for farmers who conserve. Therefore, $60 \%$ of the costs are refunded. In the second one, costs are fully covered.

\footnotetext{
${ }^{4}$ For more information on the NGO, please refer to https://www.birdlife.org/asia/partners/indonesia-burung-indonesia.

${ }^{5}$ Our payoff structure implies that the area size is of higher importance than its spatial configuration, which is supported by several studies (Martensen et al., 2012; Radford et al., 2005).
} 
Farmers who conserve thus receive 50 points in addition to the income generated by conservation, if the requirements of the respective PES design are met. Finally, the third one sets additional monetary incentives for conservation and overcompensates farmers who conserve. Therefore, $140 \%$ of the costs are covered resulting in a compensation payment of 70 points. Farmer $i$ 's payoff for land use $(L U)$ oil palm $(O P)$ or conservation $(C)$ can be described as

$$
\begin{array}{ll}
\mu_{i}=100 & \text { if } \quad L U_{i}=O P \\
\mu_{i}=50 & \text { if } \quad \sum_{i=1}^{6}(\text { bordering }) C_{i}<3 \text { and } L U_{i}=C \\
\mu_{i}=50+\alpha_{P E S} & \text { if } \quad \sum_{i=1}^{6}(\text { bordering }) C_{i} \geq 3 \text { and } L U_{i}=C
\end{array}
$$

where $\alpha_{P E S} \in[30 ; 50 ; 70]$. Each farmer is observed under two of these payment levels. Five rounds after implementation of the first payment, the second payment is implemented for another five rounds. All three payment levels are combined with the same frequency with the AT and the AP during the compensation stage. To prevent order effects, the order of the payments is changed randomly. The distribution of payments over PES designs is shown in Table A3.1 in the Appendix.

Several studies have highlighted the role of communication for easing cooperation (Banerjee et al., 2017; Midler et al., 2015). Communication might help to support a cooperative norm, help individuals to gain more information about the other individuals they interact with, and also might help with the clarification of experiment-related questions that arose in the course of it (Cardenas, Ahn, \& Ostrom, 2004). We test whether the introduction of cheap talk increases conservation levels after individuals already have gained experience with the PES-scheme. Moreover, we analyze whether the effect of communication differs between the two PES designs, between the three payment levels and with respect to previous coordination experience. While farmers are not allowed to communicate during the first 15 rounds, communication is allowed in rounds 16 to 20.

\subsubsection{Theoretical predictions}

In the following, we will derive theoretical predictions for farmers' behavior in the experiment. Our discussion starts with the assumption that individual $i$ derives 
only utility from the monetary payoffs he or she receives in period $t, \mu_{i t} .{ }^{6}$ First, the expected effects of the two PES designs will be discussed.

Since the introduction of monetary compensations increases the profitability of conservation, it is expected that both PES designs increase the share of farmers who conserve. However, effects might differ between the AT and the AP. Rational individuals that aim at maximizing their own payoffs will conserve only if they assume that the threshold for receiving compensation payments will be met. In comparison to the AT, the AP reduces the set of possible constellations of conserving farmers that generate compensation payments. The probability of receiving compensation payments is consequently reduced. If we assume risk-averse or risk-neutral agents, this generates our first hypothesis:

H1.: Participation, measured as the share of conserving farmers, is higher under the AT than under the AP.

However, public good experiments on different payment thresholds with varying risk levels involved often find different results. There is evidence that increasing the required contribution size, or the required number of contributors for receiving monetary rewards can increase contributions (Isaac, Schmidtz, \& Walker, 1989; Spiller \& Bolle, 2017; Suleiman \& Rapoport, 1992). Possible reasons are inter alias that the threshold might serve as a focal point that guides individual behavior (Isaac et al., 1989). Therefore, the opposite might also be true and the AP might increase farmers' conservation probability.

The AP however pushes farmers to coordinate among farmers with bordering plantations. Since environmental effects are dependent on the spatial arrangement of the conserved areas, we therefore expect higher environmental effects per conserving farmer if coordination is successful. ${ }^{7}$

H2.: Coordination, measured as the environmental effects generated per conserving farmer, is higher under the AP than under the AT.

Overall environmental effects are the product of the share of farmers who conserve (participation) and the average environmental effects per conserving farmer (coordination). The effects of the two PES designs on overall environmental benefits generated will depend on the relative size of both. ${ }^{8}$

\footnotetext{
${ }^{6}$ Only very strong non-monetary preferences change the derived predictions. For example, if individuals derive large utility from behaving in an environmentally friendly way (warm glow), even if environmental effects are not generated, their behavior might not depend on the probability of receiving compensation payments.

${ }^{7}$ This difference will be driven by groups where only three farmers conserve as higher shares of farmers automatically result in better connectivity between conserved plots.

${ }^{8}$ The effects on overall environmental effects generated are highly depending on the param-
} 
For the three payment levels, different Nash equilibria (NE) can be derived assuming pure self-interested payoff maximizers. The NE when low payments are offered is always to keep the land under oil palm production. When medium payments are offered, there exist several NE: one in which all farmers choose oil palm, and four others in which three, four, five or six (bordering) farmers conserve. The NE in which some farmers conserve bears the risk that the other conserving farmers deviate from the NE. This would result in income losses. As the income from choosing oil palm does not depend on the action of other farmers, the NE in which all farmers choose oil palm represents the risk-dominant NE (Banerjee, 2018; Straub, 1995). Risk-averse individuals, who likely represent the largest share of the farmers given the developing country context (Yesuf \& Bluffstone, 2009), will choose the risk-dominant NE. If high payments are offered, two NE exist: one in which all farmers conserve and one in which all farmers choose oil palm. Since overall monetary payoffs are higher when all farmers conserve, the latter represents the pareto-dominant equilibrium as it maximizes overall utility. In contrast, the NE in which all farmers choose oil palm represents the risk-dominant equilibrium. If we include the environmental benefits generated and attach an equal weight to individuals' payoffs and the environmental benefits, the social optimum is always reached when all farmers conserve.

However, we assume that individual utility is not only determined by the monetary payoffs received, but that individuals also have non-monetary preferences. This has been supported by several studies (Fischbacher, Gächter, \& Fehr, 2001; Levitt \& List, 2007). Non-monetary preferences may include warm glow effects and environmental and social preferences. Given the existence of non-monetary preferences, NE may also exist in which farmers conserve even though it is linked to economic costs. Assuming that only farmers with high non-monetary preferences conserve if conservation is linked to costs, we derive our third hypothesis:

H3.: The higher the monetary compensation, the more likely it is that farmers will conserve.

Since communication has often been shown to ease coordination on the paretodominant NE among individuals (Banerjee et al., 2017; Cardenas et al., 2004), we hypothesize that communication increases farmers' conservation probability when high payments are offered. Moreover, we assume that most individuals eterization of the experiment and the relative sizes of the extra effects generated by either an improved spatial structure or by more conserving farmers. In our case, the extra environmental benefits generated by increased connectivity are relatively small. 
have some degree of non-monetary preferences in favor of conservation, such that communication should also increase conservation levels when medium payments are offered. Since rational individuals would not conserve when low payments are offered, it is unclear whether communication also increases conservation under low compensation payments.

H4.: Communication increases conservation when high or medium payments are offered.

\subsubsection{Case study}

Our study takes place in Jambi Province, in Sumatra, Indonesia. Oil palm was introduced in Jambi in the 1980s through the governmental transmigration program. Within this program, poor farmers from the densely populated island of Java were resettled to less populated islands such as Sumatra and Kalimantan. The new arriving farmers were given two to three hectares of land for oil palm cultivation and contractual arrangements with government-supported palm oil mills were established (Gatto et al., 2015).

Since the beginning of the oil palm expansion in Jambi, the area under oil palm production has steadily increased becoming the dominant agricultural land use in the region in 2012 (Bou Dib, Krishna, et al., 2018). Most of its expansion happened on former forest or bush land, or on other extensive or intensive agricultural land use systems such as jungle rubber and rubber, with negative effects on ecosystem services and biodiversity (Clough et al., 2016; Gatto et al., 2015). Among all 34 provinces in Indonesia, Jambi ranks seventh with regard to the area under oil palm production (Badan Pusat Statistik, 2019).

We cover the lowland region of Jambi Province which has been most affected by rainforest transformation (Drescher et al., 2016). We selected the three regencies with the highest share of oil palm in the lowland area in 2016, which are Muaro Jambi, Batanghari and Bungo (Badan Pusat Statistik Provinsi Jambi, 2019). In total, 11 villages are part of the sample (Figure 3.2). In order to cover the heterogeneity in oil palm production, both local villages, in which mostly local Melayu farmers live, and transmigrant villages, which were founded under the transmigration program, were part of the sample. Since transmigrant villages account for the biggest share of oil palm in Jambi (Gatto et al., 2015), eight transmigrant and three local villages were included. In each village, we randomly selected 36 households. Only households owning and managing oil palm plantations 
Figure 3.2: Location of villages for framed field experiment in Jambi

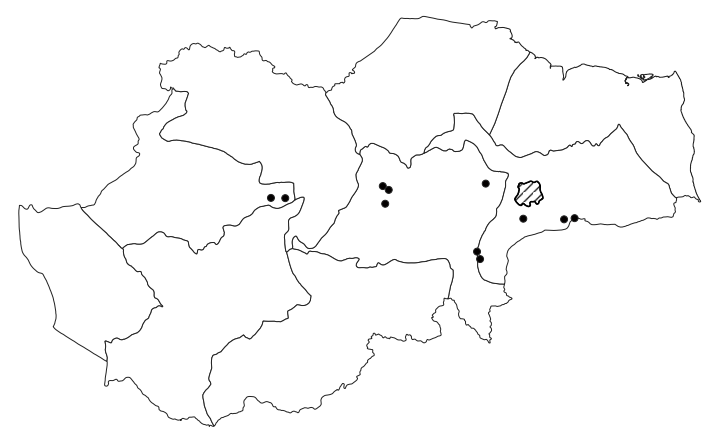

The lines indicate the regency delimiters and the shaded area the location of Jambi city.

are part of our sample. In each household, the person in charge of managing the oil palm plantation was invited to participate in the experiment. Due to logistical problems in one village, only 12 farmers could finally be selected to be part of the study. Therefore, 12 additional farmers were selected in two other villages leading to 48 farmers in these villages. In total, our sample comprises 396 farmers.

\subsubsection{Experimental setting}

66 experimental sessions were carried out between November and December 2018. Experimental sessions were organized both in the afternoon and in the evening. To maximize participation, the preferred time slot of the farmers was assessed before. Based on time preferences, group composition was randomly determined. While farmers preferring the afternoon sessions are on average older, groups taking part in afternoon or evening sessions are otherwise similar in socio-economic characteristics. ${ }^{9}$ Groups were randomly allocated to the two thresholds and the three payment sizes. To avoid correlation between village effects and treatments, each treatment was implemented with the same frequency in each village with the exception of the three villages where the number of participants does not equal 36 .

The day before the experiment, farmers completed a short pre-experimental survey in which information about socio-economics, values, trust, time and risk

\footnotetext{
${ }^{9}$ Test for mean difference was done in a linear regression framework with standard errors clustered at the experimental group level. Mean difference tests were conducted for all variables displayed in the descriptive statistics (Table 3.2). We find that farmers in the afternoon sessions are on average 4.6 years older than farmers in the evening session (p-value: 0.000 ).
} 
preferences was gathered. In case farmers did not show up for the experimental sessions, they were replaced by another oil palm farmer in the village. ${ }^{10}$ In these cases, the pre-experimental survey was conducted after the experiment.

Experimental sessions were carried out in the village office of the respective village. ${ }^{11}$ Each experimental session was organized with six farmers forming one experimental group. After arrival in the village offices, the farmers were accompanied to their seats which were arranged in a circular structure to represent the plot arrangement in the village (Figure 3.1). Afterwards, the instructor explained the baseline scenario to the farmers. To facilitate the understanding, colored posters were used displaying the most relevant pieces of information. An example is given in Figure A3.1 in the Appendix. To ease payoff calculations, farmers additionally received a sheet that showed, depending on the decision of the respective farmer and the other five farmers in the group, all feasible payoffs and resulting donations to the environmental NGO. Another sheet was distributed on which farmers could keep track of their earnings in each round. To make sure that the farmers understood the experiment, test questions were asked. Moreover, before the start of the experiment, farmers played two practice rounds. Besides the instructor, two other assistants were present who additionally helped answering farmers' questions. At the start of the experiment, farmers were not informed about the length of the experiment, nor about the possibility that the explained scenario might change.

To indicate their decisions anonymously, farmers marked on a piece of paper whether they kept the oil palm plantation established or whether they switched to conservation. Thereafter, the assistants collected the decision sheets. Farmers were asked to turn away from the others when making their decisions in order to reduce the influence of other persons in the group. After each round, the instructor announced to the group how many farmers conserved and how many of these had bordering land. Before the start of the treatment rounds, the posters as well as the sheets indicating the respective payoffs were updated.

During the first 15 rounds, farmers were not allowed to talk to each other. When communication was allowed in rounds 16 to 20, farmers could discuss about the experiment with the other farmers in the group for five minutes prior to decision making in each round. Decisions were still kept anonymous.

After the end of the experiment, farmers were told that they should not discuss

\footnotetext{
${ }^{10}$ In total, the share of replacement farmers in our sample amounts to approx. $15 \%$.

${ }^{11}$ In two villages, this was not feasible such that the sessions were organized in another farmer's house. The rooms were sufficiently large to avoid contamination of farmers' decisions by the other group members.
} 
about the experiment with other individuals in the village to avoid spill-over effects. Spill-over effects were further minimized by implementing each treatment only once in each village, with the exception of the two villages with 48 participating farmers (section 3.3.3) where two treatments were repeated.

We implemented a short post-experimental survey at the end of the experiment to gather information about the factors influencing farmers' decisions, about farmers' environmental perceptions and their opinion on oil palm. The two latter could have potentially influenced their behavior in the experiment and were therefore not included in the pre-experimental survey. Moreover, the understanding of the experiment was assessed.

In order to determine farmers' payoffs and the donations, we selected one experimental round randomly. The points were converted into local currency (IDR) by multiplying the amount of points by 1,000 . On average, farmers received 86,742 IDR (\$6.2), the maximum amount of money they could earn was 120,000 IDR (\$8.58). This is equivalent to one to two times a worker's daily wage. Payoffs were distributed upon the completion of the post-experimental survey in form of a voucher for a local shop in the village. ${ }^{12}$ The donations were transferred after the end of the experiment to the account of the local NGO. Each village received a certificate as payment proof that indicated the amount of donations generated in the respective village.

\subsection{Results}

In this section, results of the framed field experiment will be presented. First, we will present socioeconomic characteristics of the sample. In the next step, we will discuss group-level results showing the effects of the interventions on environmental effectiveness, budget efficiency as well as on other welfare measures such as farmers' income and overall efficiency levels. Finally, we parametrically analyze treatment effects on the individual conservation decision and its drivers.

\subsubsection{Socio-economic characteristics of the sample}

Descriptive statistics of the sample can be found in Table 3.2. For a more detailed explanation of the variables, please refer to Table A3.2 in the Appendix.

\footnotetext{
${ }^{12}$ The owner of the shop was not allowed to participate in the experiment.
} 
Table 3.2: Summary statistics

\begin{tabular}{lccc}
\hline \hline \multicolumn{1}{c}{ Variable } & Mean & Std. Dev. & N \\
\hline Age & 46.07 & 10.83 & 396 \\
Gender, 1=Female & 0.05 & & 396 \\
Education (in years) & 8.71 & 3.48 & 396 \\
Transmigrant Farmer, 1=Yes & 0.31 & & 396 \\
Experience as oil palm farmer (in years) & 14.94 & 7.37 & 396 \\
Javanese ethnicity, 1 = Yes & 0.69 & & 396 \\
Melayu ethnicity, 1=Yes & 0.13 & & 396 \\
Total value of assets (in Mio IDR) & 42.13 & 86.29 & 396 \\
Environmental extension received, 1=Yes & 0.10 & & 396 \\
Trust [0;10] & 4.06 & 2.31 & 396 \\
Risk preferences [0;10] & 5.00 & 2.84 & 396 \\
Time preferences [0;10] & 5.61 & 2.81 & 396 \\
Biospheric values [1;6] & 4.78 & 0.69 & 396 \\
Altruistic values [1;6] & 4.92 & 0.61 & 396 \\
Egoistic values [1;6] & 3.86 & 1.37 & 395 \\
Environmental awareness [1;6] & 4.10 & 1.50 & 395 \\
Area owned (in ha) & 4.03 & 4.17 & 396 \\
Area owned under oil palm production (in ha) & 3.31 & 2.94 & 396 \\
Trees in OP, 1= Yes & 0.20 & & 396 \\
Other crops grown besides oil palm, 1=Yes & 0.29 & & 396 \\
Replanting, 1=Yes & 0.07 & & 396 \\
Number of family members in the experimental group & 0.49 & 1.17 & 395 \\
Number of neighbors in the group & 0.95 & 1.25 & 395 \\
\hline
\end{tabular}

The average decision maker in the household is male, has approx. nine years of schooling and Javanese ethnicity. Only $30 \%$ of the farmers in our sample grow other crops besides oil palm and only $20 \%$ have trees besides oil palms growing in their plantation - among these $60 \%$ have less than 20 trees. This indicates the high level of landscape homogenization in our study area. To test for differences in socioeconomic characteristics between PES designs and payment levels, we run a total of 115 mean difference tests with group-level clustered standard errors. Results are presented in Tables A3.3 and A3.4 in the Appendix. We can detect eight statistically significant differences between PES designs or between payments levels, but the absolute difference between the mean estimates is small for all imbalanced covariates. The imbalanced covariates will be controlled for in the following analyses. ${ }^{13}$ Since only a small share of all conducted mean difference tests is significant and some imbalance can occur by chance (Morgan \& Rubin, 2012), we assume that our treatment randomization strategy was successful.

\footnotetext{
${ }^{13}$ None of the imbalanced covariates are statistically significant in the regression models (section 3.4.3).
} 


\subsubsection{Group-level results}

\section{Environmental effectiveness and its drivers}

We evaluate the effect of the two PES designs and the three payment levels on group-level environmental effects generated, reflected by the donations. This represents our measure of environmental effectiveness. Environmental effectiveness can be understood as the product of two distinct processes: First, participation that measures how many farmers are willing to conserve under the respective PESscheme, and second, coordination which we define as the environmental benefits generated per conserving farmer. Upon reaching the threshold for the generation of environmental effects, the latter measures how well connected the conserved plots are. To better understand the drivers of environmental effectiveness, we analyze treatment effects on participation and coordination. Since our three payment levels are by design balanced across the two PES designs in the compensation stage (rounds 6 to 15), treatment effects of the PES designs and payment levels are discussed separately. ${ }^{14}$

Figure 3.3: Average environmental effects generated

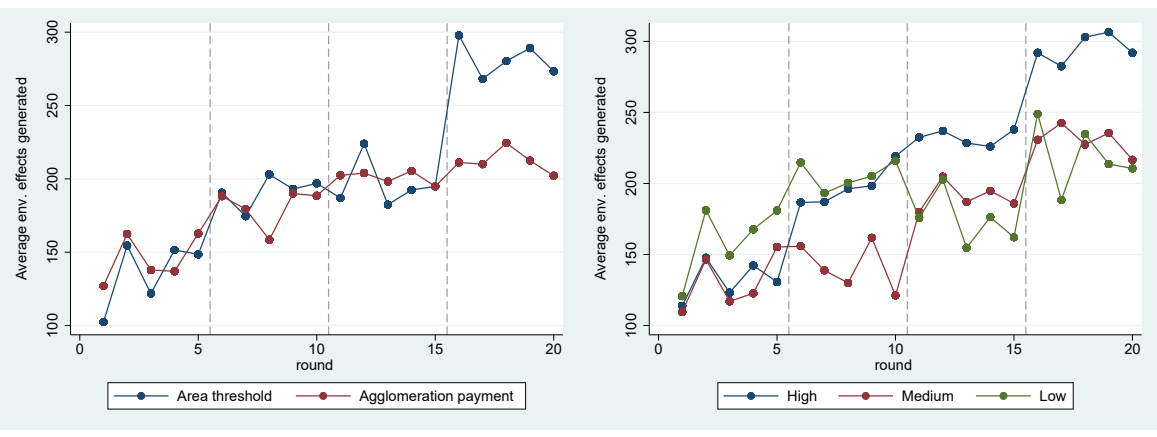

Figure 3.3 displays the evolution of the environmental effects generated over the course of the experiment. Figure 3.4 and Figure 3.5 show the evolution of participation and coordination, respectively. Descriptives of the three outcome variables at the different stages of the experiment, separated by the PES design and the payment levels, are displayed in Table 3.3. Table A3.7 in the Appendix

\footnotetext{
${ }^{14}$ Some imbalance might occur in rounds $16-20$ when communication is allowed. To test whether any of the three payment levels is combined significantly more often with either the AT or the $\mathrm{AP}$, we run a probit estimation with group-level clustered standard errors where PES design $(1=\mathrm{AT}, 0=\mathrm{AP})$ is regressed on assignment to the three payment levels in rounds $16-20$. We do not find evidence that any of the two PES designs is significantly confounded with any of the three payment levels ( $\mathrm{p}$-values of tests for share high payment=share medium payment: 0.664 , for high=low: 0.519 , for medium=low: 0.846). An overview of the distribution of payment levels across PES designs can be found in Table A3.1 in the Appendix.
} 
Figure 3.4: Average share of farmers who conserve (participation)
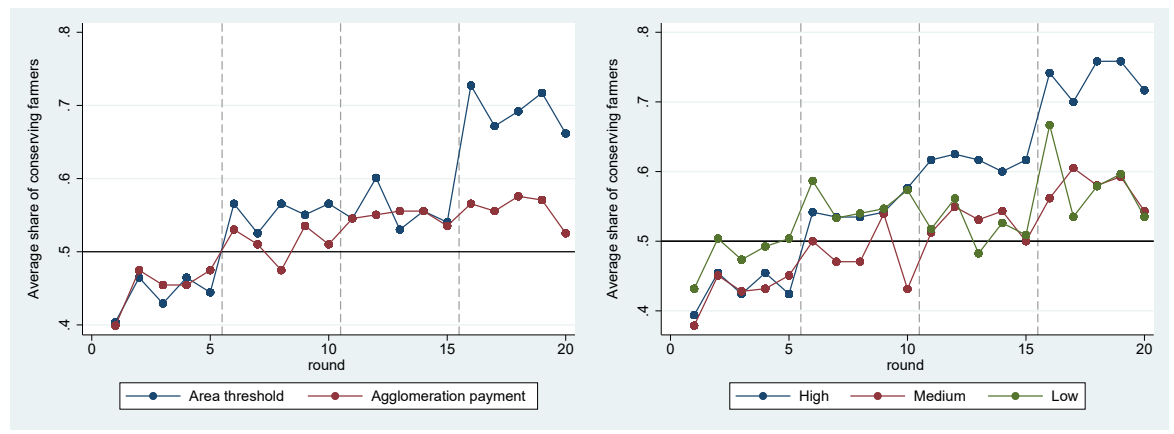

Figure 3.5: Average environmental effects generated per conserving farmer (coordination)

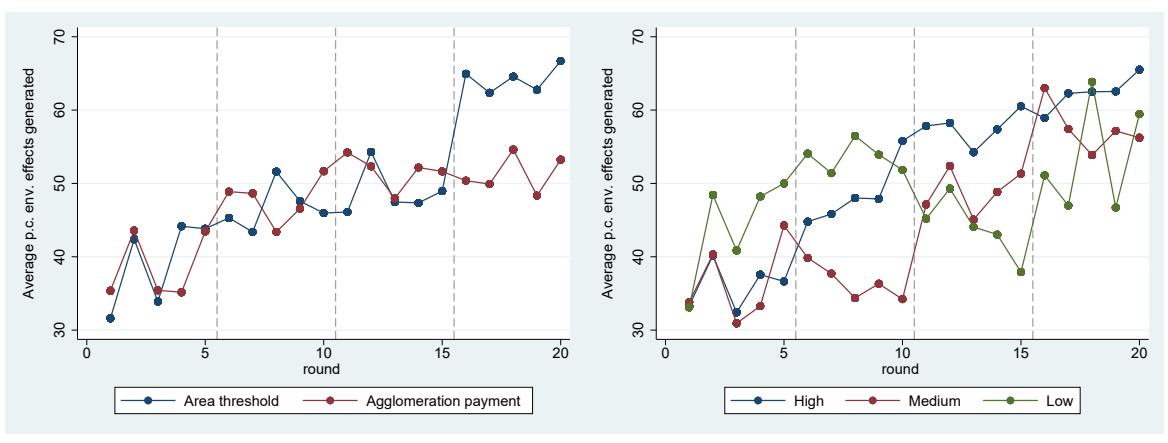

shows the descriptives for the combined effects of the two PES designs and the three payment levels.

To see whether the introduction of PES-schemes (compensation stage) has significant effects on environmental effectiveness and its drivers, we use Wilcoxon signed-rank tests for all treatments. For the two PES designs, we also use Wilcoxon signed-rank tests to compare the compensation to the communication stage. For the payment sizes, the sign rank test proposed by Fong, Huang, Lemos, and Mcelrath (2018) is used. This test is recommended for comparisons of groups where one group contains observations that cannot be matched with observations in the other group (Guo, Gao, Niu, \& Zhang, 2019). ${ }^{15}$ To test whether the effect sizes are significantly different between different treatments, we use Mann-Whitney U tests. These tests are performed on the change in the outcome variables between two stages and not on the levels to account for possible existing differences at the baseline stage. Especially farmers assigned to receive low payments tend to have higher

\footnotetext{
${ }^{15}$ This is the case when we compare the compensation to the communication stage for a certain payment. The groups that receive the respective payment first are observed with the second assigned payment when communication is allowed and can therefore not be matched.
} 
environmental outcomes in the baseline stage in comparison to farmers assigned to high or medium payments (Table 3.3). All tests are based on the group averages over all rounds at the respective stage, as these statistics are independent. The significance levels are displayed in Table 3.3. For the p-values of the respective tests, please refer to Table A3.5 in the Appendix that also provides more information on the respective tests used.

As seen in Figures 3.3 to 3.5, participation does not follow a time trend for the two PES designs, while coordination and the overall environmental effects generated tend to slightly increase over time. However, this effect appears to be very small. No common time trend can be found for the three payment levels. This validates the use of group comparisons as the results in the compensation and communication stages are unlikely to be driven by time effects.

\section{Comparison between area threshold and agglomeration payment}

The evolution of participation, coordination and the overall environmental effects generated over time is very similar under the AT and the AP in the compensation stage (rounds 6-15). The introduction of compensation payments increases the environmental effects generated at the $1 \%$ level for both PES designs (Table 3.3). The environmental effects increase by an average $42 \%$ for the AT and an average $31 \%$ for the AP. This increase stems from a significant improvement in both participation, where the average share of conserving farmers is below the ecologically relevant threshold of 0.5 in the baseline (Figure 3.4), and in coordination. Participation tends to be slightly larger under the AT than under the AP (Figure 3.4), while the AP tends to perform slightly better than the AT with regard to coordination (Figure 3.5). Both trends are supported by the average increases in the respective outcome variables (Table 3.3). However, differences are very small between the two designs in rounds 6 to 15 . Therefore, neither the effects on participation nor on coordination differ significantly between the PES designs leading also to non-significant differences in environmental effects generated (Table 3.3). Thus, while the trend is in line with our hypotheses 1 and 2 , the differences are not pronounced enough to be significant. 
Table 3.3: Group-level descriptives for environmental effectiveness and its drivers

\begin{tabular}{|c|c|c|c|c|c|c|c|c|c|}
\hline & \multicolumn{3}{|c|}{ Environmental effects } & \multicolumn{3}{|c|}{ Participation } & \multicolumn{3}{|c|}{ Coordination } \\
\hline & Baseline & Compensation & Communication & Baseline & Compensation & Communication & Baseline & Compensation & Communication \\
\hline \multirow[t]{2}{*}{$\mathrm{AT}$} & 135.76 & $193.88^{* * *}$ & $281.76^{* * * /+++}$ & 0.44 & $0.55^{* * *}$ & $0.69 * * * /+++$ & 37.26 & $47.21^{* * *}$ & $63.82^{* * * /+++}$ \\
\hline & $(132.61)$ & $(144.57)$ & $(148.70)$ & $(0.23)$ & $(0.24)$ & $(0.32)$ & $(25.91)$ & $(24.81)$ & $(14.50)$ \\
\hline \multirow[t]{2}{*}{$\mathrm{AP}$} & 145.39 & $190.94^{* * *}$ & 212.06 & 0.45 & $0.53^{* * *}$ & 0.56 & 35.66 & $46.12^{* * *}$ & 47.54 \\
\hline & $(149.85)$ & $(147.58)$ & $(172.04)$ & $(0.28)$ & $(0.28)$ & $(0.36)$ & $(30.29)$ & $(26.10)$ & $(28.46)$ \\
\hline \multirow[t]{2}{*}{ High } & 131.55 & $213.36^{* * * / \mathrm{mm} / \mathrm{ll}}$ & $295.20^{* * *}$ & 0.43 & $0.58 * * * / \mathrm{m} / 11$ & $0.73^{* * *}$ & 33.54 & $50.70^{* * * / \mathrm{mm} / 11}$ & $61.12^{* *}$ \\
\hline & $(127.41)$ & $(142.66)$ & $(137.24)$ & $(0.23)$ & $(0.26)$ & $(0.27)$ & (29.71) & $(26.24)$ & $(19.09)$ \\
\hline \multirow[t]{2}{*}{ Medium } & 130.27 & $171.59^{* * *}$ & $230.59 * *$ & 0.43 & $0.51^{* * *}$ & 0.58 & 34.23 & $42.37^{* * *}$ & $54.81^{* * *}$ \\
\hline & $(119.56)$ & $(151.50)$ & $(175.69)$ & $(0.22)$ & $(0.27)$ & $(0.39)$ & $(28.22)$ & $(29.04)$ & $(27.18)$ \\
\hline \multirow[t]{2}{*}{ Low } & 159.95 & $192.27^{* *}$ & 219.26 & 0.48 & $0.54^{* * *}$ & 0.58 & 41.61 & $47.66^{* *}$ & 51.09 \\
\hline & $(117.55)$ & $(141.23)$ & $(164.34)$ & $(0.22)$ & $(0.25)$ & $(0.33)$ & $(25.79)$ & $(25.46)$ & $(23.09)$ \\
\hline
\end{tabular}

Mean values indicated, standard deviation in parentheses. Participation measures the share of conserving farmers. Coordination measures the environmental benefits generated per conserving farmer. For paired tests, Wilcoxon signed-rank tests are used. For non-paired tests, we use Mann-Whitney U tests. For partially paired tests, we use the sign rank test proposed by Fong et al. (2018) For Mann-Whitney U tests, first differences of the outcome variables were built to control for possible differences between treatments at the baseline stage.

Sample size is 33 for AT and AP. Sample size is 22 for each payment level in the compensation stage. For the communication stage, 20 groups receive high, 27 medium and 19 low payments.

${ }^{*}$ refers to significance levels of Wilcoxon signed-rank tests. + indicates significance levels of Mann-Whitney U tests when comparing AT and AP. ${ }^{\mathrm{h} / \mathrm{m} / \mathrm{l}}$ refer to significance levels of Mann-Whitney $\mathrm{U}$ tests when comparing different payment levels, where ${ }^{\mathrm{h}}$, ${ }^{\mathrm{m}}$ and $^{\mathrm{l}}$ indicate significance levels in comparison to the high, medium or low payment. $* /+/ \mathrm{h}$ refer to $10 \%, * * /++/ \mathrm{hh}$ to $5 \%$ and $* * * /+++/ \mathrm{hhh}$ to $1 \%$ significance level. 
The introduction of communication after the compensation stage in combination with the AT leads to a significant increase at the $1 \%$ level for all three outcome variables in comparison to the compensation stage without communication (Table 3.3). In contrast, communication only marginally and insignificantly increases the value of the three outcome variables under the AP. As a consequence, environmental effectiveness is significantly greater under the AT than under the AP when communication is allowed (p-value of Mann-Whitney U test: 0.072). The diverging effects are not due to slight imbalances between the PES designs and the payment levels at the communication stage (Table A3.7 in the Appendix). ${ }^{16}$ The missing effect of communication under the AP is surprising as other studies on threshold goods or coordination games have highlighted its relevance (Midler et al., 2015; Tavoni, Dannenberg, Kallis, \& Löschel, 2011; Warziniack, Shogren, \& Parkhurst, 2007). Moreover, other studies have found that the effect size of communication does not differ depending on the implied risk level for reaching the threshold required for the public good provision (van de Kragt, Orbell, \& Dawes, 1983). Since the AP and the AT could also be interpreted as thresholds with different associated risk levels, our findings do not support previous evidence in the literature. Possible reasons for the diverging effects of communication between the two PES designs will be discussed in the context of individual farmers' conservation decisions in section 3.4.3.

\section{Comparison between three payment levels}

In the absence of communication, differences in the evolution of the three indicators are more pronounced between the three payment levels than between the two PES designs (Figures 3.3 to 3.5). This suggests that different payment levels have a stronger effect on farmers' behavior than the two PES designs when communication is not allowed. ${ }^{17}$ All three payment sizes increase the three outcome variables linked to environmental effectiveness at statistically significant levels in comparison to the baseline. Thus, farmers' decisions are likely to be also driven by non-monetary motives as under the low payment level, costs are not fully covered. However, profit

\footnotetext{
${ }^{16}$ None of the three outcome variables are significantly increased under any of the three payment levels when the AP is implemented.

${ }^{17}$ When depicting the evolution of the outcome variables under the six resulting PES-schemes, i.e. the respective combination of the two PES designs and the three payment levels, higher variations are shown for the AP. This is also supported in Tables 3.3 and A3.7 in the Appendix, where the standard deviation is in almost all cases higher under the AP than under the AT. However, when looking at the evolution of the combined effects, we also see high variation in the outcome variables under the three payment sizes such that the patterns in Figures 3.3 to 3.5 are not driven by a specific payment and PES design combination.
} 
motivations appear to play an important role for the land use decision because making conservation financially more attractive than oil palm leads to significantly higher increases in environmental outcomes than offering medium or low payments. This supports H3.

Communication eases farmers' coordination on the Nash equilibrium when high payments are offered. Participation, coordination and consequently also environmental effectiveness are significantly increased in comparison to the compensation stage without communication. Communication in combination with the medium payment also significantly increases environmental effectiveness, but this increase appears to rather stem from an improvement in coordination than from an increase in participation (Table 3.3). Our findings therefore support H4. While we can still observe a positive effect of communication when low payments are offered, the effect size is not statistically significant. ${ }^{18}$ The relevance of monetary considerations for land use decisions is supported under communication: environmental effects are significantly higher under high than under medium or low payments (p-values of Mann Whitney-U test for High=Medium: 0.03, for High=Low: 0.03), while the effects do not differ significantly between medium and low payments ( $\mathrm{p}$-value of Mann Whitney-U test: 0.991).

\section{Efficiency analysis}

The original PES idea is based on market transactions between sellers and buyers of ecosystem services. However, it can be difficult to identify the buyers of ecosystem services in practice such that they are often represented by governments, NGOs or other funding agencies (Wunder, 2015). These entities often have a restricted budget and need to decide which project to spend the available funds on. Selection criteria could be the involved budget efficiency that measures environmental effects generated per unit of budget spent, or overall efficiency reflecting the level of welfare generated. Moreover, a more informed policy analysis should also explore generated income effects for the local population to assess potential developmentenvironment trade-offs. Therefore, we analyze the effect of the two PES designs and the three payment levels on budget efficiency, overall efficiency and farmers' income (Table 3.4). We also display the share of successful coordination, i.e. how often groups coordinate on receiving compensation payments, as well as the budget spent per capita as these, in combination with environmental effects generated,

\footnotetext{
${ }^{18}$ The insignificance of the effect is likely to be driven by the AP because under the AT, all payment sizes significantly increase the outcome variables (Table A3.7 in the Appendix).
} 
drive the two efficiency measures and farmers' income.

Budget efficiency is only calculated for rounds when PES-schemes are implemented. If groups do not receive compensation payments in the respective round, they are not considered in the calculation. To account for possible baseline differences in environmental effectiveness (Figure 3.3 and Table 3.3), which could affect our budget efficiency estimates, the environmental effects for the two PES designs and the three payment levels are demeaned on their respective baseline means prior to budget efficiency calculations. Our overall efficiency measure is based on standardized net social welfare that includes farmers' income, i.e. the agricultural income plus the compensation payments, plus the environmental effects generated net of budget spending (Kuhfuss et al., 2017). ${ }^{19}$ It measures how much of the maximum achievable welfare is reached under the respective PES-scheme implemented.

Table 3.4 indicates that budget efficiency is significantly higher under the AP than under the AT in the compensation stage. The higher budget efficiency of the AP is achieved by higher average environmental benefits generated by farmers who receive compensation payments, and by a significantly smaller average budget spent per capita (Table 3.4). ${ }^{20}$ These findings are in line with the simulation study by Drechsler et al. (2010) that also supports a higher budget efficiency for the agglomeration payment in comparison to compensation mechanisms without an explicit spatial target. ${ }^{21}$

Regarding overall efficiency, both PES designs lead to significant and similar increases in comparison to the baseline. Both PES designs are consequently welfare improving. The higher levels of budget efficiency generated by the AP, while having similar overall efficiency levels than the AT, suggest that the local population bears greater costs of the environmental improvements under the AP than under the AT

\footnotetext{
${ }^{19}$ The maximum net welfare of 720 is achieved when all farmers in the group conserve. The minimum welfare of 500 is reached when two farmers in the group conserve. Our measure of overall efficiency can be described as $\frac{\sum_{i=1}^{6} \mu_{i}-\alpha * \sum_{i=1}^{6} C_{i}+\operatorname{donations}\left(\sum_{i=1}^{6} C_{i}\right)-\text { welfare }(\min )}{\text { welfare }(\text { max })-\text { welfare }(\min )}$ where $\mu_{i}=$ farmer $i$ 's income, $\alpha \in[30 ; 50 ; 70], C_{i}=1$ if $L U_{i}=C$.

${ }^{20}$ The groups that receive compensation payments under the AT generate on average 272.18 units of environmental benefits over the compensation stage. In contrast, groups that receive compensation payments under the AP generate on average 308.60 units of environmental benefits. This is significantly higher (p-value of Mann Whitney U-test: 0.018).

${ }^{21}$ In Table 3.4, we only include rounds in which groups receive compensation payments in our budget efficiency estimation. When we also consider cases in which no compensation payments are made (Figure A3.2 in the Appendix), the difference between both PES designs in the compensation stage is even more pronounced. This is because under the AP, the generation of environmental benefits is also possible in absence of compensation payments.
} 
in the compensation stage. This is supported in Table 3.4. The lower income is driven by significantly lower rates of coordination success under the AP.

When communication is introduced, the increase in overall efficiency is statistically higher under the AT than under the AP. In the communication stage, farmers under the AT reach efficiency levels of around 80\%, while under the AP efficiency levels of around $64 \%$ are reached. From a social planner's perspective who tries to maximize overall welfare, the AT consequently appears to be the preferred option if communication is allowed. Moreover, budget efficiency significantly increases under the AT when farmers can communicate with each other because of the significant increase in environmental effects generated (section 3.4.2). As a consequence, the AP no longer outperforms the AT in terms of budget efficiency when communication is allowed (p-value of Mann-Whitney U test: 0.346).

For budget and overall efficiency, conflicting patterns emerge for the three payment levels. Offering low payments is the most budget efficient policy option (Table 3.4). ${ }^{22}$ Only partial coverage of the costs, as done under low payments, however leads to lower levels of farmers' income. In contrast, the increase in overall efficiency in comparison to the baseline is significantly greater when high instead of medium or low payments are introduced. ${ }^{23}$ The highest overall efficiency levels are hence reached when farmers are overcompensated for conservation. In contrast, we do not find that the increase in overall efficiency in comparison to the baseline differs significantly between medium and low payments. ${ }^{24}$ Consequently, similar overall efficiency levels can be reached if low instead of medium payments are offered, with a statistically higher budget efficiency achieved under low payments.

\footnotetext{
${ }^{22}$ Here, we only compare budget efficiency levels in the compensation stage. The results also hold if we compare budget efficiency levels in the communication stage. P-values of Mann-Whitney $\mathrm{U}$ test to compare levels in the communication stage are 0.000 for High=Medium, 0.000 for High=Low. Under high payments, the maximum achievable environmental effects generated are fully internalized.

${ }^{23}$ This also holds when we compare the communication stage to the baseline. P-values of Wilcoxon signed-rank test: High=Medium: 0.027, High=Low: 0.034.

${ }^{24} \mathrm{P}$-value of Wilcoxon signed-rank test to compare the communication stage to the baseline is 0.806 .
} 
Table 3.4: Efficiency, income and cost measures

\begin{tabular}{|c|c|c|c|c|c|c|c|c|c|c|c|}
\hline & \multicolumn{2}{|c|}{ Budget efficiency } & \multicolumn{3}{|c|}{ Overall efficiency } & \multicolumn{2}{|c|}{$\begin{array}{l}\text { Coordination } \\
\text { success }\end{array}$} & \multicolumn{2}{|c|}{ Average farmers' income } & \multicolumn{2}{|c|}{$\begin{array}{l}\text { Average p.c. intervention } \\
\text { costs }\end{array}$} \\
\hline & Comp. & Comm. & Baseline & e Comp. & Comm. & Comp. & Comm. & Comp. & Comm. & Comp. & Comm. \\
\hline AT & $\begin{array}{c}0.70 \\
(0.23)\end{array}$ & $\begin{array}{l}0.82^{* *} \\
(0.31)\end{array}$ & $\begin{array}{l}0.47 \\
(0.24)\end{array}$ & $\begin{array}{l}0.58^{* * *} \\
(0.27)\end{array}$ & $\begin{array}{c}0.79^{* * * /+++} \\
(0.20)\end{array}$ & $0.69^{+++}$ & $0.82^{++}$ & $\begin{array}{c}96.41^{+++} \\
(6.87)\end{array}$ & $\begin{array}{l}101.46 \\
(11.94)\end{array}$ & $\begin{array}{l}24.14^{+} \\
(15.26)\end{array}$ & $\begin{array}{c}36.16^{++} \\
(19.73)\end{array}$ \\
\hline AP & $\begin{array}{l}0.82^{+} \\
(0.24)\end{array}$ & $\begin{array}{c}0.93 \\
(0.31)\end{array}$ & $\begin{array}{l}0.50 \\
(0.29)\end{array}$ & $\begin{array}{l}0.60^{* * *} \\
(0.26)\end{array}$ & $\begin{array}{l}0.66^{*} \\
(0.28)\end{array}$ & 0.42 & 0.53 & $\begin{array}{l}90.15 \\
(8.76)\end{array}$ & $\begin{array}{l}96.90^{\mathrm{a}} \\
(13.54)\end{array}$ & $\begin{array}{c}16.66 \\
(17.13)\end{array}$ & $\begin{array}{c}22.92 \\
(24.06)\end{array}$ \\
\hline High & $\begin{array}{c}0.52 \\
(0.10)\end{array}$ & $\begin{array}{c}0.60^{* * *} \\
(0.10)\end{array}$ & $\begin{array}{ll}0.47 & 0 \\
(0.28) & \end{array}$ & $\begin{array}{c}0.64^{* * * / \mathrm{m} / 1} \\
(0.28)\end{array}$ & $\begin{array}{l}0.79^{* * *} \\
(0.23)\end{array}$ & 0.6 & 0.81 & $\begin{array}{c}102.16^{\mathrm{mmm} / \mathrm{I}} \\
(14.40)\end{array}$ & $\begin{array}{c}110.62^{\mathrm{mmm} / 111} \\
(12.36)\end{array}$ & $\begin{array}{c}31.02^{\mathrm{mm} / 11} \\
(24.60)\end{array}$ & $\begin{array}{c}47.37^{\mathrm{mm} / 111} \\
(23.89)\end{array}$ \\
\hline Medium & $\begin{array}{c}0.71^{\text {hhh }} \\
(0.15)\end{array}$ & $\begin{array}{l}0.86^{* * *} \\
(0.13)\end{array}$ & $\begin{array}{l}0.46 \\
(0.26)\end{array}$ & $\begin{array}{l}0.54^{* * *} \\
(0.32)\end{array}$ & $\begin{array}{l}0.72^{* * *} \\
(0.26)\end{array}$ & 0.52 & 0.64 & $\begin{array}{c}93.07^{111} \\
(7.24)\end{array}$ & $\begin{array}{c}98.33^{111} \\
(3.24)\end{array}$ & $\begin{array}{l}18.56^{11} \\
(17.21)\end{array}$ & $\begin{array}{c}27.16 \\
(19.45)\end{array}$ \\
\hline Low & $\begin{array}{c}0.92^{\mathrm{hhh} / \mathrm{mmm}} \\
(0.32)\end{array}$ & $\begin{array}{l}1.12^{* * *} \\
(0.29)\end{array}$ & $\begin{array}{l}0.53 \\
(0.26)\end{array}$ & $\begin{array}{l}0.59^{*} \\
(0.27)\end{array}$ & $\begin{array}{l}0.66^{*} \\
(0.25)\end{array}$ & 0.55 & 0.58 & $\begin{array}{l}84.61 \\
(5.06)\end{array}$ & $\begin{array}{l}85.04 \\
(5.51)\end{array}$ & $\begin{array}{l}11.61 \\
(9.36)\end{array}$ & $\begin{array}{c}14.15 \\
(11.03)\end{array}$ \\
\hline
\end{tabular}

Group-level mean statistics with standard deviation in parentheses displayed. Comp. refers to compensation stage (rounds 6-15), Comm. to communication stage (rounds 16-20). Average farmers' income is the group-level average of farmers' income over the respective stage of the experiment. Average per capita intervention costs reflect how much compensation payments are made to an average person in a group. Sample size is 33 for AT and AP. For the high, medium and low payments, 22 groups are assigned to the respective payment size in the compensation stage. For the communication stage, 20 groups receive high payments, 27 medium and 19 low payments.

a To account for slight imbalances in the distribution of payment levels over PES designs (Table A3.1) we calculate the difference in average per capita compensation payments offered between the AT and the AP over all groups in the communication stage. The difference is added to the income of conserving farmers who receive compensations under the AP. Without correction, averages of group-level mean farmers' income are, with standard deviation in parentheses, 94.98 (12.54).

Mann Whitney-U tests are used to compare the AT and the AP, or the three payment levels. Before comparing two payment levels, the groups receiving both levels are dropped. For within test for the efficiency indicator, we use Wilcoxon signed-rank tests for paired tests. For partially paired tests, the test proposed by Fong et al. (2018) is used. For budget efficiency, Mann-Whitney U tests are performed on levels in the compensation, and on first differences in the communication stage. ${ }^{*}$ refers to significance levels for Wilcoxon signed-rank tests. ${ }^{+}$indicates significance levels for Mann-Whitney U tests when comparing AT and AP. $\mathrm{h} / \mathrm{m} / 1$ refer to significance levels of Mann-Whitney U tests when comparing different payment levels where ${ }^{\mathrm{h}},{ }^{\mathrm{m}}$ and ${ }^{\mathrm{l}}$ indicate whether the statistic is significantly different from the respective statistic for the high, medium and low payment. ${ }^{* /+/ \mathrm{h}}$ refer to $10 \%, * * /++/$ hh to $5 \%$ and $* * * /+++/$ hhh to $1 \%$ significance level. 


\subsubsection{Individual contributions}

To understand the drivers of the individual conservation decision and to derive point estimates, we present average marginal effects (AME) of mixed effects probit estimations in Table 3.5 for the two PES designs and in Table 3.6 for the three payment levels. The combined effects of the PES designs and payment levels can be found in Table A3.10 in the Appendix.

In order to account for the hierarchical structure of the error term, where errors are possibly clustered at both the individual and the group level, individual and group random effects (RE) are included. Because of the random assignment of individuals to groups, and of groups to treatments, correlations between group and individual $\mathrm{RE}$ as well as between unobserved factors and our treatment variables are unlikely, supporting the use of the mixed effects model. To avoid that order effects influence the treatment effects of the three payment levels, the order of the payments was changed randomly (section 3.3.1). However, order effects might still bias the results if experiencing a certain payment level first affects the conservation decision under the second payment, and if the size or the sign of this effect differs between payment levels (Charness, Gneezy, \& Kuhn, 2012). We test for order effects by comparing the conservation probability of farmers who receive a respective payment first to that of farmers who receive the respective payment second, after controlling for a general linear time trend. None of the differences are either significant or significantly different between the payment levels, and the effect sizes are small, such that it is unlikely that the presented results are driven by order effects. ${ }^{25}$

Since contribution patterns may change over time due to e.g. learning effects, we include a linear time trend in all estimations. To account for a possible dynamic nature of the underlying decision process, we control for the lagged conservation choice. The model specifications in columns (1) and (2) in Tables 3.5 and 3.6 assume that the initial value of the outcome variable is exogenous. In contrast, the model specification in column (3) relaxes this assumption by conditioning the conservation choice in each round on the initial value of the dependent variable and

\footnotetext{
${ }^{25}$ We estimate a mixed effects probit model for rounds 1-15, where the conservation choice of farmer $i$ in round $t$ is regressed on dummy variables for the three payment levels in rounds 6-15 and a linear time trend. To compare whether the effect sizes differ depending on whether the payment is received first or second, we include dummy variables that assume one if the respective payment is received in rounds 11-15. Marginal effects of the dummy variables indicating the difference between the respective payment level when it is received first and when it is received second are, with p-values in parentheses, -0.017 (0.465) for the high, 0.003 (0.875) for the medium and $0.018(0.432)$ for the low payment. P-values of test High (received second) $=$ Medium (received second): 0.498, High = Low: 0.243, Medium = Low: 0.636.
} 
on the initial conservation choice of the other farmers (Akay, 2009; Rabe-Hesketh \& Skrondal, 2013; Wooldridge, 2005).

Table 3.5: Effects of two PES designs on farmers' conservation decision

\begin{tabular}{|c|c|c|c|}
\hline & (1) & $(2)$ & (3) \\
\hline \multirow[t]{2}{*}{$\mathrm{AT}$} & $0.08^{* * *}$ & $0.06^{* * *}$ & $0.07^{* * *}$ \\
\hline & $(0.018)$ & $(0.018)$ & $(0.017)$ \\
\hline \multirow[t]{2}{*}{$\mathrm{AP}$} & $0.06^{* * *}$ & $0.06^{* * *}$ & $0.06^{* * *}$ \\
\hline & $(0.019)$ & $(0.018)$ & $(0.018)$ \\
\hline \multirow[t]{2}{*}{$\mathrm{AT}+\mathrm{com}$} & $0.12^{* * *}$ & $0.11^{* * *}$ & $0.11^{* * *}$ \\
\hline & $(0.019)$ & $(0.019)$ & $(0.018)$ \\
\hline \multirow[t]{2}{*}{$\mathrm{AP}+\mathrm{com}$} & 0.03 & 0.01 & 0.03 \\
\hline & $(0.019)$ & $(0.019)$ & $(0.018)$ \\
\hline \multirow[t]{2}{*}{ Conservation (lagged) } & $0.11^{* * *}$ & $0.08^{* * *}$ & $0.10^{* * *}$ \\
\hline & $(0.012)$ & $(0.011)$ & $(0.010)$ \\
\hline \multirow[t]{2}{*}{ Time preferences } & $0.01^{*}$ & $0.01^{*}$ & $0.01^{* *}$ \\
\hline & $(0.006)$ & $(0.006)$ & $(0.004)$ \\
\hline \multirow[t]{2}{*}{ Egoistic values } & -0.00 & -0.00 & -0.00 \\
\hline & $(0.011)$ & $(0.011)$ & $(0.009)$ \\
\hline \multirow[t]{2}{*}{ Biospheric values } & 0.03 & 0.03 & 0.02 \\
\hline & $(0.022)$ & $(0.021)$ & $(0.017)$ \\
\hline \multirow[t]{2}{*}{ Altruistic values } & 0.04 & 0.04 & 0.02 \\
\hline & $(0.026)$ & $(0.025)$ & $(0.020)$ \\
\hline \multirow[t]{2}{*}{ Environmental awareness } & $0.04^{* * *}$ & $0.04^{* * *}$ & $0.02^{* * *}$ \\
\hline & $(0.010)$ & $(0.010)$ & $(0.008)$ \\
\hline No. of other conserving & $0.01^{* *}$ & & $0.01^{* *}$ \\
\hline farmers (lagged) & $(0.004)$ & & $(0.004)$ \\
\hline PES requirement met & & $0.24^{* * *}$ & \\
\hline$($ lagged $)=1$ & & $(0.013)$ & \\
\hline \multirow[t]{2}{*}{ Conservation $\mathrm{t}=0$} & & & $0.37^{* * *}$ \\
\hline & & & $(0.018)$ \\
\hline No. other conserving & & & $0.04^{* * *}$ \\
\hline farmers, $\mathrm{t}=0$ & & & $(0.011)$ \\
\hline \multirow[t]{2}{*}{ Round } & -0.00 & -0.00 & -0.00 \\
\hline & $(0.002)$ & $(0.002)$ & $(0.002)$ \\
\hline Other controls $^{1}$ & Yes & Yes & Yes \\
\hline Observations & 7486 & 7486 & 7486 \\
\hline
\end{tabular}

AME from a mixed effects probit model with individual and group RE shown. Outcome variable is the individual conservation decision. Standard errors displayed in parentheses. P-values for test $\mathrm{AT}=\mathrm{AP}:$ (1) 0.466, (2) 0.924, (3) 0.510; for $\mathrm{AT}+\mathrm{com} .=\mathrm{AP}+\mathrm{com} .:$ (1) 0.000, (2) 0.000, (3) 0.000. 
1 Other controls include age, education and experience of farmer, whether a farmer is a transmigrant, land size owned, whether other crops are cultivated or trees growing in oil palm plots, recent or future replanting plans, risk and time preferences, trust measures and the number of family members and neighbors in the same experimental group.

${ }^{*} p<0.1,{ }^{* *} p<0.05,{ }^{* * *} p<0.01$

Besides general characteristics such as age, education, farmers' assets to proxy income and variables reflecting the existing farm-level degree of diversification, we include several variables capturing individual preferences. These should allow us to gain a better understanding of the non-monetary drivers of utility, for instance, whether altruistic or environmental motives matter for farmers' conservation decisions. Moreover, in specifications (1) and (3), we control for the lagged number of other farmers in the group who conserve to analyze whether other farmers' behavior affects individual conservation decisions. In model specification (2), we replace this variable with a dummy of whether the requirement for receiving compensation payments under the assigned PES design was met in the previous round, to see how past coordination success influences current conservation choices. All lagged values capturing previous behavior and coordination in the experiment are likely to be influenced by the implemented treatments. ${ }^{26}$ Therefore, our derived treatment effects capture the partial effects of the treatment after controlling for their indirect effects through the lagged conservation decision of the respective farmer and of the other farmers, as well as through lagged group coordination success. P-values for Wald tests of equality of coefficients are reported below Tables 3.5 and 3.6 in the respective notes. Coefficients and full results are available in Tables A3.8 and A3.9 in the Appendix.

\section{Effects of PES designs and payment levels on individual conservation decisions}

In line with the results for environmental effectiveness (section 3.4.2), Tables 3.5 and 3.6 support significantly positive effects of the two PES designs and all three payment levels on the individual conservation decision. While the effect sizes do not differ significantly between the AT and the AP (Table 3.5), we find significant differences between the three payment levels (Table 3.6). Offering high payments can motivate a larger share of farmers to conserve than offering medium or low payments, highlighting the relevance of monetary considerations in farmers' conser-

\footnotetext{
${ }^{26}$ We acknowledge that the lagged number of other conserving farmers and the lagged indicator of coordination success might not fulfill the strict exogeneity assumption required for the estimation of consistent partial effects in nonlinear panel data models. However, the inclusion of the variables does not affect either the point estimates or the significance levels of the other variables.
} 
vation choices (p-values indicated below Tables 3.5 and 3.6). This is in line with H3. Furthermore, as already visible in Figure 3.3, in absence of communication, differences in payment levels appear to have stronger effects on farmers' conservation decisions than differences in the requirements for receiving compensation. ${ }^{27}$

Table 3.6: Effects of three payment levels on farmers' conservation decision

\begin{tabular}{|c|c|c|c|}
\hline & (1) & $(2)$ & $(3)$ \\
\hline \multirow[t]{2}{*}{ High } & $0.11^{* * *}$ & $0.09^{* * *}$ & $0.11^{* * *}$ \\
\hline & $(0.018)$ & $(0.018)$ & $(0.017)$ \\
\hline \multirow[t]{2}{*}{ Medium } & $0.06^{* * *}$ & $0.05^{* * *}$ & $0.06^{* * *}$ \\
\hline & $(0.019)$ & $(0.019)$ & $(0.018)$ \\
\hline \multirow[t]{2}{*}{ Low } & $0.04^{* *}$ & $0.04^{* *}$ & $0.04^{* *}$ \\
\hline & $(0.017)$ & $(0.017)$ & $(0.016)$ \\
\hline \multirow[t]{2}{*}{ High +com. } & $0.11^{* * *}$ & $0.11^{* * *}$ & $0.10^{* * *}$ \\
\hline & $(0.023)$ & $(0.023)$ & $(0.022)$ \\
\hline \multirow[t]{2}{*}{ Medium+com. } & $0.06^{* * *}$ & $0.05^{* *}$ & $0.06^{* * *}$ \\
\hline & $(0.020)$ & $(0.020)$ & $(0.019)$ \\
\hline \multirow[t]{2}{*}{ Low+com. } & $0.08^{* * *}$ & $0.05^{* *}$ & $0.08^{* * *}$ \\
\hline & $(0.023)$ & $(0.023)$ & $(0.022)$ \\
\hline \multirow[t]{2}{*}{ Conservation (lagged) } & $0.10^{* * *}$ & $0.08^{* * *}$ & $0.10^{* * *}$ \\
\hline & $(0.012)$ & $(0.011)$ & $(0.010)$ \\
\hline \multirow[t]{2}{*}{ Time preferences } & $0.01^{*}$ & $0.01^{*}$ & $0.01^{* *}$ \\
\hline & $(0.006)$ & $(0.006)$ & $(0.004)$ \\
\hline \multirow[t]{2}{*}{ Egoistic values } & -0.00 & -0.00 & -0.00 \\
\hline & $(0.011)$ & $(0.011)$ & $(0.009)$ \\
\hline \multirow[t]{2}{*}{ Biospheric values } & 0.03 & 0.03 & 0.02 \\
\hline & $(0.022)$ & $(0.021)$ & $(0.017)$ \\
\hline \multirow[t]{2}{*}{ Altruistic values } & 0.04 & 0.04 & 0.02 \\
\hline & $(0.026)$ & $(0.025)$ & $(0.020)$ \\
\hline \multirow[t]{2}{*}{ Environmental awareness } & $0.04^{* * *}$ & $0.04^{* * *}$ & $0.02^{* * *}$ \\
\hline & $(0.010)$ & $(0.010)$ & $(0.008)$ \\
\hline \multirow{2}{*}{$\begin{array}{l}\text { No. of other conserving farmers } \\
\text { (lagged) }\end{array}$} & 0.01 & & 0.01 \\
\hline & $(0.004)$ & & $(0.004)$ \\
\hline \multirow[t]{2}{*}{ PES requirement met (lagged) $=1$} & & $0.23^{* * *}$ & \\
\hline & & $(0.013)$ & \\
\hline \multirow[t]{2}{*}{ Conservation $\mathrm{t}=0$} & & & $0.37^{* * *}$ \\
\hline & & & $(0.018)$ \\
\hline \multirow[t]{2}{*}{ No. other conserving farmers, $t=0$} & & & $0.04^{* * *}$ \\
\hline & & & $(0.012)$ \\
\hline
\end{tabular}

\footnotetext{
${ }^{27}$ This is also supported in Table A3.10. We do not find significant differences between the AT and the AP in the absence of communication for any of the three payment levels, while significant differences can be found between the payment levels.
} 


\begin{tabular}{lccc} 
Round & -0.00 & -0.00 & -0.00 \\
& $(0.002)$ & $(0.002)$ & $(0.002)$ \\
\hline Other controls $^{1}$ & Yes & Yes & Yes \\
Observations & 7486 & 7486 & 7486 \\
\hline
\end{tabular}

AME from a mixed effects probit model with individual and group RE displayed. Outcome variable is the individual conservation decision. Standard errors in parentheses. P-values for test High=Medium: (1) 0.000, (2) 0.029, (3) 0.000; for High=Low: (1) 0.000, (2) 0.001, (3) 0.000; Medium=Low: (1) 0.103, (2) 0.242, (3) 0.092; High+com.=Medium+com.: (1) 0.054, (2) 0.021, (3) 0.060; High+com.=Low+com.: (1) 0.353, (2) 0.033, (3) 0.339; Medium+com.=Low+com.: (1) $0.352,(2) 0.999,(3) 0.391$.

${ }^{1}$ Other controls include age, education and experience of farmer, whether farmer is a transmigrant, land size owned, whether other crops are cultivated or trees growing in oil palm plots, recent or future replanting plans, risk preferences, trust measures and the number of family members and neighbors in the same experimental group.

${ }^{*} p<0.1,{ }^{* *} p<0.05,{ }^{* * *} p<0.01$

Under the AT, communication is highly effective in promoting conservation. The approx. 12 percentage point additional effect of communication appears to be even larger than the effect of the pure introduction of the PES design. In contrast, under the AP the introduction of communication does not on average increase the conservation probability in comparison to the compensation stage. Significant increases at the $10 \%$ levels can only be observed when the AP is combined with high payments (Table A3.10 in the Appendix). ${ }^{28}$ As a result, increases in aggregate conservation probabilities over all payment levels are significantly larger under the AT than under the AP, if communication is allowed ( $\mathrm{p}$-values below Table 3.5). The larger effect size of the AT under communication holds for all payment levels considered (Table A3.10 in the Appendix).

The relevance of communication for increasing conservation levels in comparison to the pure compensation stage is supported for all three payment levels at statistically significant levels. ${ }^{29}$ While the increase is significantly larger under high than under medium payments (columns (1) to (3)), the effect sizes do not differ significantly between high and medium payments in columns (1) and (3), and between medium and low payments in all three model specifications. If we

\footnotetext{
${ }^{28}$ The respective AME are 0.06 in all model specifications.

${ }^{29}$ The effect of communication under the different payment levels has to be interpreted as the effect of communication dependent on prior experience in the experiment. We control for the lagged number of other conserving farmers as well as for whether the requirements for receiving compensation were met. Table 3.4 shows that the share of coordination failure does not differ significantly between payment levels. While we do not claim to be fully able to control for potential confounders based on prior experience, coordination successes are similar between the three groups so that we believe that potential effects should only be small.
} 
look at the combined effect of the introduction of compensation payments and communication in comparison to the baseline, we find that offering high payment leads to the significantly largest increases in conservation probability ( $\mathrm{p}$-values of t-tests are in columns (1) 0.000, (2) 0.000, (3) 0.000 for both High=Medium and High=Low in Table 3.6). In contrast, the effect sizes are not significantly different between medium and low payments (t-test, p-values in (1) 0.965, (2) 0.505, (3) 0.996 in Table 3.6). This pattern holds for both the AT and the AP (Table A3.10 in the Appendix). ${ }^{30}$ This suggests that when individuals are able to communicate with each other, one can motivate a similar share of farmers to conserve under low and medium payments. ${ }^{31}$ However, a certain part of the population is only willing to conserve when extra financial incentives are offered.

\section{Other drivers of conservation choices}

The dynamic nature of the conservation decision process is supported in all three model specifications in Tables 3.5 and 3.6. Farmers who conserved in the previous round are significantly more likely to also conserve in the current round. Besides capturing the experience farmers had in the experiment, this might partly reflect farmers' general preferences towards conservation and cooperation. The latter is supported by the very large and positive coefficient of the conservation decision in the first round. Therefore, individuals who are unconditionally cooperative, meaning that they are willing to contribute to the public good independent of the action of other persons (Fischbacher \& Gächter, 2010), are likely to continue conserving under all treatments. While we find a positive albeit small effect of the lagged number of other conserving farmers in the group in Tables 3.5 and 3.6, this effect is only significant when analyzing the treatment effects of the two PES designs. In contrast, the number of other conserving farmers in the initial period significantly increases the individual conservation probability for all treatments considered. Hence, reciprocity guides individual behavior (Narloch et al., 2012). The number of other conserving farmers could indicate a group norm in favor of conservation. However, it appears to be of particular importance for conservation choices whether sufficient farmers conserve for groups to receive compensation

\footnotetext{
${ }^{30} \mathrm{P}$-values for test of communication in comparison to the baseline are for the AT: High=Medium: (1) 0.000, (2) 0.008, (3) 0.000 and High=Low: (1) 0.011, (2) 0.027, (3) 0.008, for the AP: High=Medium: (1) 0.016, (2) 0.006, (3) 0.017 and High=Low: (1) 0.025, (2) 0.011, (3) 0.018 in Table A3.10 in the Appendix.

${ }^{31} \mathrm{~A}$ similar pattern holds in the compensation stage, but the difference between medium and low payments is marginally significantly different in columns (1) and (3).
} 
payments. This is indicated by a very large and significant effect of whether the requirements for receiving compensation payments were met in the previous round (column (2)).

Besides variables reflecting the dynamics of the experiment and cooperation preferences, other preferences appear to have a rather small impact on the conservation decision (full results available in Tables A3.8 and A3.9 in the Appendix). Individuals who are less present biased and more aware of oil palm related environmental consequences in Jambi are significantly more likely to conserve in the experiment. Finally, with respect to socio-economic characteristics, higher education levels and actual diversification levels significantly and positively affect conservation choices, at least in some of the model specifications (see full results in Tables A3.8 and A3.9 in the Appendix).

\section{Coordination failure and the effect of communication}

One potential driver of the diverging effect of communication between the AT and the AP could be different experiences with coordination success. ${ }^{32}$ As pointed out in section 3.3.2, the AP is linked to a smaller probability of reaching the requirements for receiving compensation payments and therefore involves higher risk of coordination failure. In case farmers conserve, but the group does not coordinate on receiving compensation payments, farmers might feel frustrated and could reduce their beliefs on how likely it is that further conservation choices will generate compensation payments (Fischbacher \& Gächter, 2010). To test whether coordination success in the compensation stage drives the diverging effects of communication between the two PES designs, we divide our sample into subgroups of individuals with similar coordination experience in the compensation stage. The first subgroup comprises individuals who never conserved in the compensation stage. The second subgroup subsumes individuals who received compensation payments each time they conserved in the compensation stage. Therefore, these individuals have only experienced coordination success. The last subgroup includes individuals who experienced coordination failure at least once in the compensation stage, meaning that they conserved without receiving compensation payments. Results of a linear mixed effects estimation are shown in Table $3.7 .^{33}$

\footnotetext{
${ }^{32}$ By coordination success, we mean that a farmer receives compensation payments when he or she conserves.

${ }^{33}$ Linear mixed effects model is used since estimation of a mixed effects probit model is not feasible for the first subgroup, where the AT and the AP are perfectly collinear with the decision to plant oil palm in the compensation stage.
} 
Table 3.7: Subgroup-specific effects of the two PES designs on farmers' conservation decision

\begin{tabular}{|c|c|c|c|}
\hline & $\begin{array}{c}(1) \\
\text { Never conserves }\end{array}$ & $\begin{array}{l}(2) \\
\text { Conserves and } \\
\text { always receives } \\
\text { compensation }\end{array}$ & $\begin{array}{c}(3) \\
\text { Conserves, but } \\
\text { sometimes } \\
\text { without receiving } \\
\text { compensation }\end{array}$ \\
\hline \multirow[t]{2}{*}{$\mathrm{AT}=1$} & -0.00 & $0.10^{* * *}$ & $0.14^{* * *}$ \\
\hline & $(0.017)$ & $(0.030)$ & $(0.035)$ \\
\hline \multirow[t]{2}{*}{$\mathrm{AP}=1$} & 0.00 & 0.05 & $0.10^{* * *}$ \\
\hline & $(0.017)$ & $(0.038)$ & $(0.030)$ \\
\hline \multirow[t]{2}{*}{$\mathrm{AT}+\mathrm{com} .=1$} & $0.20^{* * *}$ & $0.09^{* * *}$ & 0.01 \\
\hline & $(0.019)$ & $(0.031)$ & $(0.036)$ \\
\hline \multirow[t]{2}{*}{$\mathrm{AP}+\mathrm{com} .=1$} & $0.04^{* *}$ & $0.11^{* * *}$ & -0.01 \\
\hline & $(0.018)$ & $(0.039)$ & $(0.030)$ \\
\hline \multirow[t]{2}{*}{ Conservation (lagged) } & $0.49^{* * *}$ & $0.18^{* * *}$ & $0.16^{* * *}$ \\
\hline & $(0.022)$ & $(0.019)$ & $(0.018)$ \\
\hline No. of other conserving & $-0.02^{* * *}$ & $0.03^{* * *}$ & $0.02^{* * *}$ \\
\hline farmers (lagged) & $(0.004)$ & $(0.009)$ & $(0.007)$ \\
\hline \multirow[t]{2}{*}{ Round } & -0.00 & 0.00 & -0.00 \\
\hline & $(0.002)$ & $(0.003)$ & $(0.003)$ \\
\hline \multirow[t]{2}{*}{ Constant } & $0.05^{* * *}$ & $0.38^{* * *}$ & $0.51^{* * *}$ \\
\hline & $(0.014)$ & $(0.038)$ & $(0.034)$ \\
\hline Observations & 1919 & 2565 & 3040 \\
\hline
\end{tabular}

Outcome variable is individual conservation choice. Coefficients from a linear mixed effects model with individual and group RE displayed. Standard errors shown in parentheses. Subgroup definition is based on conservation behavior and coordination success in the compensation stage. P-values of t-test for AT=AP: (1) 0.712, (2) 0.211, (3) 0.213; for AT+com.=AP+com.: (1) 0.000, (2) $0.732,(3) 0.640$.

${ }^{*} p<0.1,{ }^{* *} p<0.05,{ }^{* * *} p<0.01$

The introduction of communication significantly increases the conservation probability of farmers who only experienced coordination success in the compensation stage, both under the AT and under the AP (column (2)). The effect size of communication does not differ between these two groups (p-values below Table 3.7). In contrast, under neither PES design does the introduction of communication significantly increase the conservation probability of individuals who experienced coordination failure in the compensation stage (column (3)). Consequently, there is no differential effect of communication in the two PES designs for farmers who conserved during the compensation stage. However, the shares of the respective subgroups in the population assigned to the AT and the AP differ significantly. 
Around $48 \%$ of the farmers assigned to the AT only experience coordination success in the compensation stage. This share is only $20 \%$ and significantly lower for the AP (Chi2 test, p-value: 0.000). ${ }^{34}$ Therefore, while farmers who conserve in the compensation stage and have similar experiences do not react differently to the introduction of communication under the AT and the AP, the shares belonging to the analyzed subgroups differ. Part of the aggregate different effect of the AT and the AP, as shown in Table 3.5, is thus likely explained by a higher occurrence of coordination failure under the $\mathrm{AP}$ in the compensation stage.

The share of farmers who never conserve during the compensation does not differ between both PES designs (p-value of Chi2 test: 0.564) and amounts to $25 \%$ for the AT and $26 \%$ for the AP. However, as indicated in column (1), these individuals react significantly different to the introduction of communication under the two PES designs: While communication has a positive and significant effect on conservation probabilities under both schemes, the increase in conservation probabilities is significantly larger under the AT than under the AP. Reasons for these differential effects could be e.g. different beliefs on how likely it is that the requirements for receiving compensation payments will be met. This could be due to different coordination success at the aggregate group level. Under the AP, $62 \%$ of the farmers who never conserve in the compensation stage are part of a group in which none of the farmers ever receive compensation payments in the compensation stage. This share is only $30 \%$ for the AT.

\subsection{Conclusion}

Results from a framed field experiment with Indonesian oil palm farmers suggest that PES might be a promising policy tool to motivate farmers to plant biodiversityfriendly mixed oil palm systems that integrate trees. While the share of conserving farmers lies below the ecologically relevant threshold of 0.5 in the baseline, the introduction of compensation payments raises this share on average above the relevant threshold, supporting the effectiveness of the implemented schemes. In the absence of communication, the two conditional PES designs tested, a threshold payment that is conditional on a minimum size of area put under conservation (AT), and an agglomeration payment that requires farmers with bordering land to conserve (AP), are similarly effective in increasing environmental effects and overall

\footnotetext{
${ }^{34} 27 \%$ of the farmers assigned to the AT and $54 \%$ of those assigned to the AP experience coordination failure in the compensation stage (Chi2 test, p-value: 0.000 ).
} 
welfare. In contrast, budget efficiency is significantly higher under the AP than under the AT. This is partly due to a shift in the costs of conservation from the policy maker to the local population. However, once farmers can communicate, the AT outperforms the AP and generates significantly higher levels of environmental effectiveness and overall welfare than the AP, while reaching similar levels of budget efficiency. The differential effect of communication between the two PES designs is partly driven by different coordination experiences. For farmers who previously only experienced coordination success, communication is similarly effective in increasing conservation probabilities under the AT and the AP. However, the higher risk involved in the AP, where farmers with bordering land need to conserve, leads to lower shares of farmers experiencing only coordination success under the AP than under the AT. In contrast, communication does not raise the conservation probabilities of farmers previously experiencing coordination failure, neither under the AT nor under the AP. Given the higher probability of coordination success, the AT appears to be the more promising policy tool to support the provision of an environmental good that is both dependent on a critical size of conservation area and its connectivity.

To generate the highest level of environmental effects and overall efficiency, additional monetary incentives should be provided under the AT because a considerable share of the population will only switch to conservation if it is financially more attractive than oil palm cultivation. In case this is not feasible under the existing budget constraints of the funding agency and if the policy maker is willing to accept lower farmers' income, only a partial coverage of the conservation costs might be a viable alternative instead of a full coverage. Similar increases in environmental effects and overall welfare are reached when $60 \%$ of the costs instead of $100 \%$ are compensated. This might be particularly relevant in the context of high-value cash crops such as oil palm, where over- or even full compensation of foregone farmers' income can represent a financial challenge (Muradian et al., 2013).

Our study represents one of the first experimental tests of the agglomeration payment. Our results suggest that the stricter payment rules might lead to coordination failure, also when costs are fully covered or when conservation is financially attractive. Therefore, further (simulation) studies analyzing the effectiveness or efficiency of the agglomeration payment should incorporate coordination failure to generate more robust results. Moreover, the stricter compensation rules might put an additional monetary burden on farmers who bear greater costs for environmental improvements under the AT than under the AP. This might bring about conflicts 
between poverty reduction goals and environmental protection, which is particularly important for developing countries such as Indonesia.

Our results highlight the importance of communication and give insights into how prior coordination experiences influence its effectiveness. To derive further insights on whether communication, if introduced in the beginning, can avoid coordination failure, a between design comparing the introduction of compensation payments with and without communication would be needed. Moreover, implementing an additional treatment that isolates the effect of communication could give a more complete picture of its relevance for supporting coordination in our context. Further research should be conducted to gain more insights into whether and when farmers manage to coordinate under agglomeration payments. In particular, allowing for more than one plot per farmer as well as different opportunity costs might be important in order to enhance the comparability of the experimental results to the scenarios considered in simulation studies, which highlight the potential advantages of agglomeration payments (e.g. Wätzold and Drechsler 2014). Moreover, the size of the environmental effects and its dependence on the spatial structure will naturally affect the experimental results. In our case, the extra benefits generated from putting bordering land under conservation are relatively small. In case the benefits are highly dependent on the spatial structure, which e.g. is the case for species with a low dispersal rate (Drechsler et al., 2010), the AP might increase its performance relative to the AT since in the equilibrium higher environmental effects will be generated under the AP than under the AT.

In comparison to other studies that experimentally analyze spatially explicit PES designs, the external validity of our study is improved since our sample comprises farmers and a framing around a real-world decision. Yet, further research should complement our study to provide additional insights into the sensitivity of the conservation behavior to different experimental parameters, such as group size, group composition, spatial structure, and the size and structure of environmental effects. Such evidence is urgently needed for policy makers to make informed decisions in the face of unprecedented biodiversity loss in rapidly intensifying agricultural landscapes. 


\section{A Appendix}

Table A3.1: Number of groups assigned to different PES designs and payment levels (rounds 6-20)

\begin{tabular}{|c|c|c|c|c|c|c|}
\hline \multirow{2}{*}{$\begin{array}{l}\text { PES de- } \\
\text { sign }\end{array}$} & \multirow{2}{*}{ Compensation } & \multicolumn{3}{|c|}{ 2nd compensation } & \multirow{2}{*}{$\begin{array}{l}\text { Rounds } \\
6-15\end{array}$} & \multirow{2}{*}{$\begin{array}{l}\text { Rounds } \\
16-20\end{array}$} \\
\hline & & High & & Low & & \\
\hline$\overline{\mathrm{AT}}$ & High & & 7 & 3 & 11 & 12 \\
\hline $\mathrm{AT}$ & Medium & 4 & & 5 & 11 & 13 \\
\hline $\mathrm{AT}$ & Low & 8 & 6 & & 11 & 8 \\
\hline $\mathrm{AP}$ & High & & 8 & 6 & 11 & 8 \\
\hline $\mathrm{AP}$ & Medium & 3 & & 5 & 11 & 14 \\
\hline $\mathrm{AP}$ & Low & 5 & 6 & & 11 & 11 \\
\hline $\mathrm{N}$ & & & & & & 66 \\
\hline \multicolumn{7}{|c|}{$\begin{array}{l}\text { The columns listed under "2nd compensation" indicate how many of the groups that receive the } \\
\text { payment size indicated in the column "Compensation" first, receive high, medium or low payments, } \\
\text { respectively, second. To test whether the share of the respective payments differ significantly } \\
\text { between the PES designs, assignment to PES design }(1=\mathrm{AT}, 0=\mathrm{AP}) \text { is regressed on the three } \\
\text { payment levels in a probit model with group-level clustered standard errors. P-values of tests } \\
\text { for share high payment = share medium payment: } 0.664 \text {, for high = low: } 0.519 \text {, for medium } \\
=\text { low: } 0.846 \text { when testing for independence between PES design and payment levels in the } \\
\text { communication stage. }\end{array}$} \\
\hline
\end{tabular}


Figure A3.1: Example of poster used for explanation of experiment

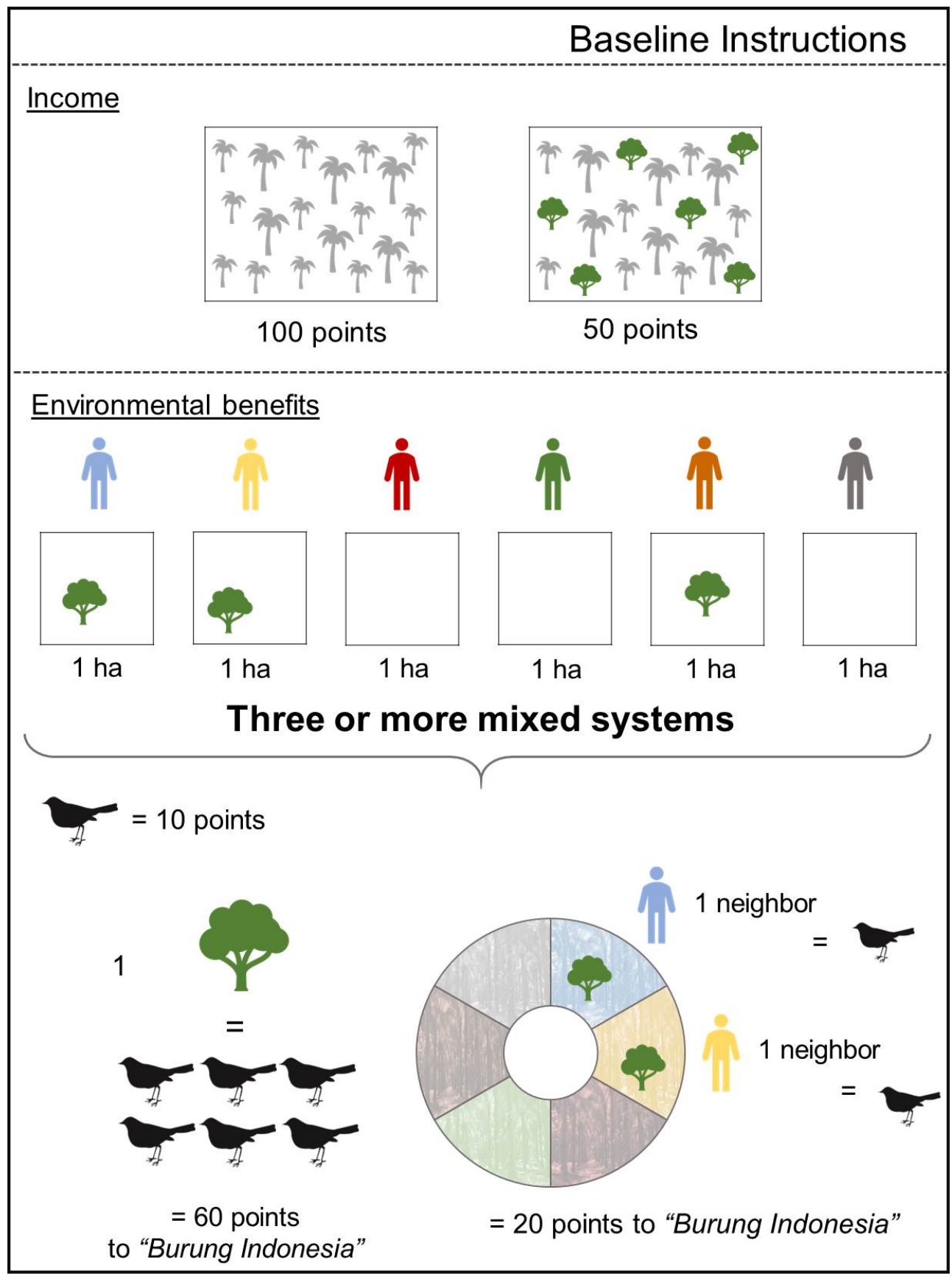


Table A3.2: Explanation of specific explanatory variables

\begin{tabular}{|c|c|}
\hline Name & Explanation \\
\hline Trust & $\begin{array}{l}\text { Reply to the question "Generally speaking, would you say that most } \\
\text { people can be trusted or that you need to be very careful in dealing } \\
\text { with people?" on a scale from } 0 \text { to } 10 \text {, where } 10 \text { means fully agree. }\end{array}$ \\
\hline Risk preferences & $\begin{array}{l}\text { Reply to the question "Are you generally a person who is fully } \\
\text { prepared to take risks or do you try to avoid taking risks?" on a } \\
\text { scale from } 0 \text { to } 10 \text {, where } 10 \text { means fully prepared. }\end{array}$ \\
\hline Time preferences & $\begin{array}{l}\text { Reply to the question "Are you generally a person who is fully } \\
\text { prepared to give up something now in order to gain more in the } \\
\text { future?" on a scale from } 0 \text { to } 10 \text {, where } 10 \text { means fully prepared. }\end{array}$ \\
\hline $\begin{array}{l}\text { Total value of as- } \\
\text { sets }\end{array}$ & $\begin{array}{l}\text { Assets considered for calculations: mobile phone, TV, motorbike, car, } \\
\text { truck, AC, fridge, electronic washing machine, computer. Farmers } \\
\text { needed to indicate how much they would receive if they sold these } \\
\text { items today. Sum of all assets expressed in mio. IDR. }\end{array}$ \\
\hline Trees in $\mathrm{OP}$ & Farmer has trees in his or her oil palm plantation, $1=$ Yes. \\
\hline $\begin{array}{l}\text { Transmigrant } \\
\text { farmer }\end{array}$ & Farmer came to Jambi within the transmigration program, $1=$ Yes. \\
\hline $\begin{array}{l}\text { Biospheric } \\
\text { values }\end{array}$ & $\begin{array}{l}\text { Reply to the question how similar a person for whom it is very } \\
\text { important to conserve the environment is to the farmer. Reply on a } \\
\text { scale from } 1 \text { to } 6 \text {, where } 6 \text { means very similar. }\end{array}$ \\
\hline Egoistic values & $\begin{array}{l}\text { Reply to the question how similar a person for whom it is very } \\
\text { important to have money and possession is to the farmer. Reply on } \\
\text { a scale from } 1 \text { to } 6 \text {, where } 6 \text { means very similar. }\end{array}$ \\
\hline Altruistic values & $\begin{array}{l}\text { Reply to a question how similar a person for whom it is very } \\
\text { important to help other persons is to the farmer. Reply on a scale } \\
\text { from } 1 \text { to } 6 \text {, where } 6 \text { means very similar. }\end{array}$ \\
\hline $\begin{array}{l}\text { Environmental } \\
\text { awareness }\end{array}$ & $\begin{array}{l}\text { Assessment of the statement "If oil palm expansion continues at the } \\
\text { current speed, we will experience an environmental catastrophe in } \\
\text { Jambi. } 1=\text { don't agree, } 6=\text { strongly agree. }\end{array}$ \\
\hline Replanting & $\begin{array}{l}\text { Farmer is intending to replant in the next } 3 \text { years, or has replanted } \\
\text { his or her oil palm plantation in the last } 3 \text { years, } 1=\text { Yes. }\end{array}$ \\
\hline $\begin{array}{l}\text { Number of fam- } \\
\text { ily members in } \\
\text { group }\end{array}$ & $\begin{array}{l}\text { Each farmer needed to indicate how many persons in the group are } \\
\text { family members. Ranges from } 0 \text { to } 5 \text {. }\end{array}$ \\
\hline $\begin{array}{l}\text { Number of neigh- } \\
\text { bors in group }\end{array}$ & $\begin{array}{l}\text { Each farmer needed to indicate how many persons in the group live } \\
\text { in his or her neighborhood. Ranges from } 0 \text { to } 5 \text {. }\end{array}$ \\
\hline $\begin{array}{l}\text { Number of other } \\
\text { conserving farm- } \\
\text { ers }\end{array}$ & $\begin{array}{l}\text { Number of other farmers in the group who conserve in a respective } \\
\text { round. }\end{array}$ \\
\hline
\end{tabular}


Table A3.3: Mean comparison tests between PES designs

\begin{tabular}{|c|c|c|c|}
\hline & $\begin{array}{c}(1) \\
\text { Area } \\
\text { threshold }\end{array}$ & $\begin{array}{c}(2) \\
\text { Agglomeration } \\
\text { payment }\end{array}$ & $\begin{array}{c}(3) \\
\text { (1) vs. }(2), \\
\text { p-value }\end{array}$ \\
\hline Age & $\begin{array}{l}46.55 \\
(0.69)\end{array}$ & $\begin{array}{l}45.58 \\
(0.88)\end{array}$ & 0.39 \\
\hline Gender, $1=$ Female & 0.06 & 0.05 & 0.83 \\
\hline Education (in years) & $\begin{array}{c}8.96 \\
(0.33)\end{array}$ & $\begin{array}{c}8.47 \\
(0.23)\end{array}$ & 0.23 \\
\hline Transmigrant Farmer, $1=$ Yes & 0.34 & 0.28 & 0.38 \\
\hline Experience as oil palm farmer (in years) & $\begin{array}{l}15.86 \\
(0.68)\end{array}$ & $\begin{array}{l}14.02 \\
(0.69)\end{array}$ & 0.06 \\
\hline Javanese ethnicity, $1=$ Yes & 0.70 & 0.67 & 0.74 \\
\hline Melayu ethnicity, $1=$ Yes & 0.12 & 0.15 & 0.55 \\
\hline Total value of assets (in Mio IDR) & $\begin{array}{l}43.52 \\
(5.80)\end{array}$ & $\begin{array}{l}40.74 \\
(5.05)\end{array}$ & 0.72 \\
\hline Environmental extension received, $1=$ Yes & 0.09 & 0.11 & 0.55 \\
\hline Trust & $\begin{array}{c}4.18 \\
(0.16)\end{array}$ & $\begin{array}{c}3.93 \\
(0.18)\end{array}$ & 0.30 \\
\hline Risk preferences & $\begin{array}{c}5.11 \\
(0.20)\end{array}$ & $\begin{array}{c}4.89 \\
(0.20)\end{array}$ & 0.43 \\
\hline Time preferences & $\begin{array}{c}5.87 \\
(0.27)\end{array}$ & $\begin{array}{c}5.34 \\
(0.23)\end{array}$ & 0.14 \\
\hline Biospheric values & $\begin{array}{c}4.79 \\
(0.05)\end{array}$ & $\begin{array}{c}4.77 \\
(0.05)\end{array}$ & 0.77 \\
\hline Altruistic values & $\begin{array}{c}4.93 \\
(0.05)\end{array}$ & $\begin{array}{c}4.92 \\
(0.04)\end{array}$ & 0.87 \\
\hline Egoistic values & $\begin{array}{c}3.92 \\
(0.10)\end{array}$ & $\begin{array}{c}3.80 \\
(0.09)\end{array}$ & 0.33 \\
\hline Environmental awareness & $\begin{array}{c}4.10 \\
(0.14)\end{array}$ & $\begin{array}{c}4.10 \\
(0.12)\end{array}$ & 1.00 \\
\hline Area owned (in ha) & $\begin{array}{c}3.95 \\
(0.25)\end{array}$ & $\begin{array}{c}4.10 \\
(0.31)\end{array}$ & 0.71 \\
\hline $\begin{array}{l}\text { Area owned under oil palm production } \\
\text { (in ha) }\end{array}$ & $\begin{array}{c}3.17 \\
(0.17)\end{array}$ & $\begin{array}{c}3.45 \\
(0.24)\end{array}$ & 0.33 \\
\hline Trees in $\mathrm{OP}, 1=$ Yes & 0.16 & 0.23 & 0.16 \\
\hline Other crops grown besides oil palm, $1=$ Yes & 0.28 & 0.29 & 0.85 \\
\hline Replanting, $1=$ Yes & 0.06 & 0.08 & 0.60 \\
\hline $\begin{array}{l}\text { Number of family members in } \\
\text { the group }\end{array}$ & $\begin{array}{c}0.57 \\
(0.22)\end{array}$ & $\begin{array}{c}0.40 \\
(0.08)\end{array}$ & 0.49 \\
\hline $\begin{array}{l}\text { Number of neighbors in } \\
\text { the group }\end{array}$ & $\begin{array}{c}0.85 \\
(0.16)\end{array}$ & $\begin{array}{l}1.05 \\
(0.12)\end{array}$ & 0.34 \\
\hline$N$ & 198 & 198 & \\
\hline
\end{tabular}

Standard errors clustered at group level in parentheses. 
Table A3.4: Mean comparison tests between payment levels

\begin{tabular}{|c|c|c|c|c|c|c|}
\hline Name & High & Medium & Low & $\mathrm{H}$ vs. $\mathrm{M}$ & $\mathrm{H}$ vs. $\mathrm{L}$ & $M$ vs. $L$ \\
\hline Age & $\begin{array}{l}45.28 \\
(0.64)\end{array}$ & $\begin{array}{l}46.18 \\
(0.75)\end{array}$ & $\begin{array}{l}46.74 \\
(0.65)\end{array}$ & 0.17 & 0.05 & 0.38 \\
\hline $\begin{array}{l}\text { Gender, } \\
1=\text { Female }\end{array}$ & 0.06 & 0.05 & 0.05 & 0.56 & 0.8 & 0.79 \\
\hline $\begin{array}{l}\text { Education } \\
\text { (in years) }\end{array}$ & $\begin{array}{c}8.58 \\
(0.22)\end{array}$ & $\begin{array}{c}8.7 \\
(0.27)\end{array}$ & $\begin{array}{c}8.86 \\
(0.26)\end{array}$ & 0.65 & 0.31 & 0.48 \\
\hline $\begin{array}{l}\text { Transmigrant Farmer } \\
1=\text { Yes }\end{array}$ & 0.29 & 0.31 & 0.32 & 0.65 & 0.48 & 0.79 \\
\hline $\begin{array}{l}\text { Experience as oil palm farmer } \\
\text { (in years) }\end{array}$ & $\begin{array}{l}14.63 \\
(0.59)\end{array}$ & $\begin{array}{l}15.01 \\
(0.59)\end{array}$ & $\begin{array}{l}15.19 \\
(0.63)\end{array}$ & 0.54 & 0.34 & 0.76 \\
\hline $\begin{array}{l}\text { Javanese ethnicity, } \\
1=\text { Yes }\end{array}$ & 0.7 & 0.68 & 0.68 & 0.74 & 0.68 & 0.95 \\
\hline $\begin{array}{l}\text { Melayu ethnicity, } \\
1=\text { Yes }\end{array}$ & 0.15 & 0.11 & 0.14 & 0.24 & 0.68 & 0.42 \\
\hline $\begin{array}{l}\text { Total value of assets } \\
\text { (in Mio IDR) }\end{array}$ & $\begin{array}{r}38.24 \\
(4.42)\end{array}$ & $\begin{array}{l}44.45 \\
(4.9)\end{array}$ & $\begin{array}{l}43.72 \\
(4.7)\end{array}$ & 0.19 & 0.26 & 0.87 \\
\hline $\begin{array}{l}\text { Environmental extension } \\
\text { received, } 1=\text { Yes }\end{array}$ & 0.09 & 0.12 & 0.09 & 0.11 & 1 & 0.13 \\
\hline Trust & $\begin{array}{c}4.01 \\
(0.14)\end{array}$ & $\begin{array}{c}3.99 \\
(0.14)\end{array}$ & $\begin{array}{c}4.17 \\
(0.16)\end{array}$ & 0.91 & 0.27 & 0.2 \\
\hline Risk preferences & $\begin{array}{c}5.02 \\
(0.17)\end{array}$ & $\begin{array}{c}5.04 \\
(0.16)\end{array}$ & $\begin{array}{c}4.94 \\
(0.19)\end{array}$ & 0.94 & 0.6 & 0.56 \\
\hline Time preferences & $\begin{array}{c}5.69 \\
(0.22)\end{array}$ & $\begin{array}{c}5.57 \\
(0.22)\end{array}$ & $\begin{array}{c}5.56 \\
(0.22)\end{array}$ & 0.58 & 0.56 & 0.99 \\
\hline Biospheric values & $\begin{array}{c}4.83 \\
(0.04)\end{array}$ & $\begin{array}{c}4.75 \\
(0.04)\end{array}$ & $\begin{array}{c}4.77 \\
(0.05)\end{array}$ & 0.09 & 0.21 & 0.54 \\
\hline Altruistic values & $\begin{array}{c}4.94 \\
(0.04)\end{array}$ & $\begin{array}{c}4.91 \\
(0.04)\end{array}$ & $\begin{array}{c}4.92 \\
(0.03)\end{array}$ & 0.37 & 0.53 & 0.92 \\
\hline Egoistic values & $\begin{array}{r}3.79 \\
(0.07)\end{array}$ & $\begin{array}{c}3.94 \\
(0.08)\end{array}$ & $\begin{array}{c}3.85 \\
(0.08)\end{array}$ & 0.08 & 0.49 & 0.24 \\
\hline Environmental awareness & $\begin{array}{c}4.08 \\
(0.12)\end{array}$ & $\begin{array}{c}4.06 \\
(0.11)\end{array}$ & $\begin{array}{c}4.16 \\
(0.11)\end{array}$ & 0.92 & 0.43 & 0.4 \\
\hline $\begin{array}{l}\text { Area owned } \\
\text { (in ha) }\end{array}$ & $\begin{array}{c}4.11 \\
(0.27)\end{array}$ & $\begin{array}{c}4.06 \\
(0.25)\end{array}$ & $\begin{array}{c}3.9 \\
(0.22)\end{array}$ & 0.82 & 0.39 & 0.55 \\
\hline $\begin{array}{l}\text { Area owned under oil palm } \\
\text { production ( } \mathrm{n} \text { ha) }\end{array}$ & $\begin{array}{l}3.36 \\
(0.2)\end{array}$ & $\begin{array}{l}3.38 \\
(0.2)\end{array}$ & $\begin{array}{c}3.18 \\
(0.14)\end{array}$ & 0.89 & 0.36 & 0.31 \\
\hline $\begin{array}{l}\text { Trees in OP, } \\
1=\text { Yes }\end{array}$ & 0.19 & 0.2 & 0.2 & 0.65 & 0.54 & 0.9 \\
\hline $\begin{array}{l}\text { Other crops grown besides oil } \\
\text { palm, } 1=\text { Yes }\end{array}$ & 0.28 & 0.28 & 0.3 & 0.88 & 0.69 & 0.83 \\
\hline $\begin{array}{l}\text { Replanting, } \\
1=\text { Yes }\end{array}$ & 0.05 & 0.06 & 0.09 & 0.45 & 0.02 & 0.05 \\
\hline $\begin{array}{l}\text { Number of family members in } \\
\text { the group }\end{array}$ & $\begin{array}{c}0.49 \\
(0.14)\end{array}$ & $\begin{array}{c}0.48 \\
(0.16)\end{array}$ & $\begin{array}{c}0.48 \\
(0.14)\end{array}$ & 0.94 & 0.95 & 1 \\
\hline $\begin{array}{l}\text { Number of neighbors in the } \\
\text { group }\end{array}$ & $\begin{array}{c}0.8 \\
(0.09) \\
\end{array}$ & $\begin{array}{c}0.94 \\
(0.13) \\
\end{array}$ & $\begin{array}{c}1.11 \\
(0.13)\end{array}$ & 0.26 & 0.02 & 0.07 \\
\hline $\mathrm{N}$ & 264 & 264 & 264 & & & \\
\hline
\end{tabular}

First three columns display means. Group-level clustered standard errors displayed in parentheses. P-values of mean comparison tests displayed in columns 5 to 6 . For comparison of two payment levels, farmers who will receive both payments in the course of the experiment are discarded. 
Table A3.5: P-values of comparison tests for environmental effectiveness outcomes

\begin{tabular}{|c|c|c|c|c|c|c|}
\hline & \multicolumn{2}{|c|}{$\begin{array}{c}\text { Environmental } \\
\text { effects } \\
\text { generated } \\
\end{array}$} & \multicolumn{2}{|c|}{ Participation } & \multicolumn{2}{|c|}{ Coordination } \\
\hline & $\begin{array}{l}\text { Baseline } \\
=\text { Com- } \\
\text { pens. }\end{array}$ & $\begin{array}{l}\text { Compensa. } \\
=\text { Com- } \\
\text { munic. }\end{array}$ & $\begin{array}{l}\text { Baseline } \\
=\text { Com- } \\
\text { pens. }\end{array}$ & $\begin{array}{l}\text { Compens. } \\
=\text { Com- } \\
\text { munic. }\end{array}$ & $\begin{array}{c}\text { Baseline } \\
=\text { Com- } \\
\text { pens. }\end{array}$ & $\begin{array}{l}\text { Compens. } \\
=\text { Com- } \\
\text { munic. }\end{array}$ \\
\hline $\mathrm{AT}$ & 0.001 & 0.000 & 0.000 & 0.001 & 0.006 & 0.000 \\
\hline $\mathrm{AP}$ & 0.000 & 0.144 & 0.000 & 0.367 & 0.003 & 0.571 \\
\hline $\mathrm{AT}=\mathrm{AP}$ & 0.484 & 0.004 & 0.411 & 0.005 & 0.647 & 0.008 \\
\hline High & 0.000 & 0.007 & 0.000 & 0.005 & 0.000 & 0.019 \\
\hline Medium & 0.001 & 0.011 & 0.001 & 0.145 & 0.005 & 0.001 \\
\hline Low & 0.029 & 0.223 & 0.008 & 0.462 & 0.040 & 0.226 \\
\hline High=Medium & 0.035 & 0.331 & 0.066 & 0.240 & 0.049 & 0.569 \\
\hline High $=$ Low & 0.021 & 0.472 & 0.029 & 0.254 & 0.016 & 0.899 \\
\hline Medium=Low & 0.300 & 0.814 & 0.459 & 0.823 & 0.508 & 0.800 \\
\hline AT+High & 0.000 & 0.024 & 0.000 & 0.014 & 0.000 & 0.040 \\
\hline AT+Medium & 0.061 & 0.022 & 0.022 & 0.169 & 0.161 & 0.001 \\
\hline AT+Low & 0.098 & 0.049 & 0.025 & 0.089 & 0.157 & 0.036 \\
\hline $\mathrm{AP}+$ High & 0.001 & 0.228 & 0.002 & 0.272 & 0.003 & 0.321 \\
\hline $\mathrm{AP}+$ Medium & 0.002 & 0.225 & 0.009 & 0.525 & 0.011 & 0.108 \\
\hline $\mathrm{AP}+\mathrm{Low}$ & 0.156 & 0.683 & 0.126 & 0.484 & 0.114 & 0.865 \\
\hline $\mathrm{AT}+\mathrm{High}=\mathrm{AT}+$ Medium & 0.168 & 0.807 & 0.278 & 0.624 & 0.168 & 0.931 \\
\hline $\mathrm{AT}+\mathrm{High}=\mathrm{AT}+\mathrm{Low}$ & 0.061 & 0.728 & 0.099 & 0.671 & 0.061 & 0.588 \\
\hline $\mathrm{AT}+\mathrm{Medium}=\mathrm{AT}+\mathrm{Low}$ & 0.645 & 1.000 & 0.554 & 0.971 & 0.817 & 0.439 \\
\hline $\mathrm{AP}+\mathrm{High}=\mathrm{AP}+$ Medium & 0.129 & 0.781 & 0.145 & 0.680 & 0.220 & 0.696 \\
\hline $\mathrm{AP}+\mathrm{High}=\mathrm{AP}+\mathrm{Low}$ & 0.271 & 0.868 & 0.129 & 0.739 & 0.178 & 0.476 \\
\hline $\mathrm{AP}+\mathrm{Medium}=\mathrm{AP}+\mathrm{Low}$ & 0.263 & 0.697 & 0.509 & 0.825 & 0.433 & 0.377 \\
\hline $\mathrm{AT}+$ High $=\mathrm{AP}+$ High & 0.327 & 0.164 & 0.311 & 0.176 & 0.330 & 0.186 \\
\hline $\mathrm{AT}+\mathrm{Medium}=\mathrm{AP}+$ Medium & 0.869 & 0.075 & 0.547 & 0.158 & 0.903 & 0.033 \\
\hline $\mathrm{AT}+\mathrm{Low}=\mathrm{AP}+\mathrm{Low}$ & 0.934 & 0.171 & 0.525 & 0.148 & 0.879 & 0.617 \\
\hline
\end{tabular}

Table presents p-values for mean comparison tests. Participation measures the share of conserving farmers. Coordination measures the average environmental effects generated per conserving farmers. For paired tests, Wilcoxon signed-rank tests are used. For non-paired tests, we use Mann-Whitney U tests. For partially paired tests, we use the sign rank test proposed by Fong et al. (2018). The test presents a linear weighted combination of test statistics comparing paired and independent samples, where the weights are inversely proportional to the respective variances. Non-paired tests, e.g. AT=AP, were conducted after taking first differences of the respective outcome variable between different stages of the experiment, i.e. between the baseline and the compensation stage, or between the compensation and the communication stage. When comparing the effect sizes of the three payment levels, we discard the overlap to ensure independence. For instance, when comparing high to medium payments, the farmers who receive both high and medium payments are not considered as they would add the same set of information to both groups. 
Table A3.6: P-values of comparison tests for efficiency outcomes

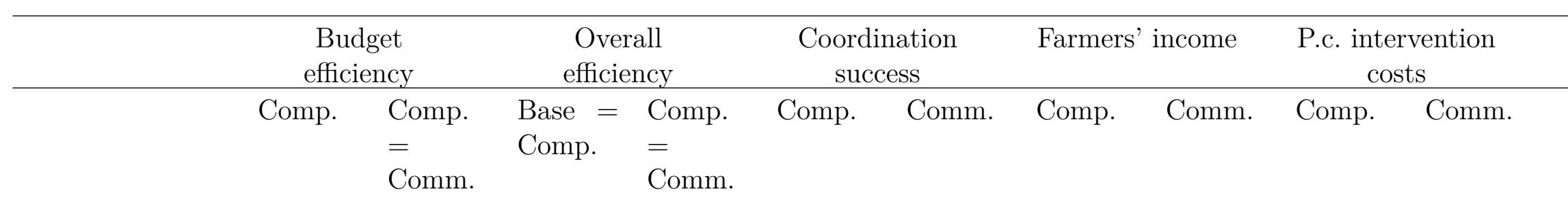

\begin{tabular}{|c|c|c|c|c|c|c|c|c|c|c|}
\hline $\mathrm{AT}$ & & 0.026 & 0.005 & 0.000 & & & & & & \\
\hline $\mathrm{AP}$ & & 0.247 & 0.000 & 0.056 & & & & & & \\
\hline $\mathrm{AT}=\mathrm{AP}$ & 0.066 & 0.601 & 0.500 & 0.003 & 0.004 & 0.015 & 0.002 & 0.142 & 0.050 & 0.016 \\
\hline High & & 0.000 & 0.000 & 0.007 & & & & & & \\
\hline Medium & & 0.001 & 0.004 & 0.000 & & & & & & \\
\hline Low & & 0.010 & 0.091 & 0.098 & & & & & & \\
\hline High $=$ Medium & 0.001 & 0.790 & 0.095 & 0.911 & 0.359 & 0.756 & 0.009 & 0.000 & 0.025 & 0.001 \\
\hline High $=$ Low & 0.004 & 0.718 & 0.063 & 0.910 & 0.556 & 0.966 & 0.000 & 0.000 & 0.066 & 0.000 \\
\hline Medium=Low & 0.010 & 1.000 & 0.184 & 0.911 & 0.386 & 0.475 & 0.000 & 0.000 & 0.554 & 0.02 \\
\hline
\end{tabular}

Table presents p-values for mean comparison tests. For paired tests, Wilcoxon signed-rank tests are used. For non-paired tests, we use Mann-Whitney

U tests. For partially paired tests, we use the sign rank test proposed by Fong et al. (2018).

Non-paired tests, e.g. AT=AP, were conducted after taking first differences of the respective outcome variable between different stages of the experiment, i.e. between the baseline and the compensation stage, or between the compensation and the communication stage. When comparing the effect sizes of the three payment levels, we discard the overlap to ensure independence. For instance, when comparing high to medium payments, the farmers who receive both high and medium payments are not considered as they would add the same set of information to both groups. 
Table A3.7: Group-level descriptives for environmental effectiveness and its drivers (combined PES-schemes)

\begin{tabular}{|c|c|c|c|c|c|c|c|c|c|}
\hline & \multicolumn{3}{|c|}{ Environmental effects } & \multicolumn{3}{|c|}{ Participation } & \multicolumn{3}{|c|}{ Coordination } \\
\hline & Baseline & Compensation & Communication & Baseline & Compensation & Communication & Baseline & Compensation & Communication \\
\hline High & 131.82 & $229.63^{* * * / 1}$ & $316.83^{* *}$ & 0.44 & $0.62^{* * * / 1}$ & $0.77 * *$ & 35.20 & $53.80^{* * * / 1}$ & $66.03^{* *}$ \\
\hline$+\mathrm{AT}$ & $(112.67)$ & $(123.78)$ & $(116.64)$ & $(0.19)$ & $(0.21)$ & $(0.24)$ & $(28.27)$ & $(23.95)$ & $(6.72)$ \\
\hline Medium & 122.18 & $165.63^{*}$ & $260.00^{* * /+}$ & 0.42 & $0.52^{* *}$ & 0.63 & 34.80 & 40.65 & $66.31^{* * * /++}$ \\
\hline$+\mathrm{AT}$ & $(103.26)$ & $(133.43)$ & $(167.71)$ & $(0.18)$ & $(0.21)$ & $(0.39)$ & $(26.00)$ & $(29.10)$ & $(11.58)$ \\
\hline Low & 153.27 & $186.36^{*}$ & $264.50^{* * /+++}$ & 0.47 & $0.53^{* *}$ & $0.67^{*}$ & 41.77 & 47.17 & $56.76^{* *}$ \\
\hline$+\mathrm{AT}$ & $(101.48)$ & $(122.57)$ & $(152.50)$ & $(0.20)$ & $(0.22)$ & $(0.30)$ & $(22.56)$ & $(26.28)$ & $(22.53)$ \\
\hline High & 131.27 & $197.09^{* * *}$ & 262.75 & 0.42 & $0.54^{* * *}$ & 0.67 & 31.88 & $47.60^{* * *}$ & 53.75 \\
\hline$+\mathrm{AP}$ & $(140.72)$ & $(133.54)$ & $(159.47)$ & $(0.26)$ & $(0.26)$ & $(0.31)$ & $(31.02)$ & $(28.03)$ & $(27.48)$ \\
\hline Medium & 138.27 & $177.54^{* * *}$ & 203.29 & 0.43 & $0.50^{* *}$ & 0.53 & 33.67 & $44.17^{* *}$ & 44.19 \\
\hline$+\mathrm{AP}$ & $(133.50)$ & $(143.27)$ & (179.68) & $(0.25)$ & $(0.28)$ & $(0.39)$ & $(30.28)$ & $(28.89)$ & $(32.62)$ \\
\hline Low & 166.64 & 198.18 & 186.36 & 0.50 & 0.55 & 0.52 & 41.44 & 48.15 & 46.97 \\
\hline$+\mathrm{AP}$ & $(131.43)$ & $(124.79)$ & $(166.14)$ & $(0.24)$ & $(0.23)$ & $(0.34)$ & $(28.68)$ & $(24.63)$ & $(22.66)$ \\
\hline
\end{tabular}

Mann-Whitney U test. For partially paired tests, we use the sirn rank test proposed by Fong et al. (2018). For Mann-Whitney U tests, first differences of the outcome variable were built to control for possible difference between treatments at the baseline stage.

* refers to significance levels of Wilcoxon signed-rank tests. ${ }^{\mathrm{h} / \mathrm{m} / 1}$ refer to significance level of Mann-Whitney $\mathrm{U}$ tests when comparing the same PES design between different payment levels where ${ }^{\mathrm{h}},{ }^{\mathrm{m}}$ and ${ }^{\mathrm{l}}$ indicate significance level in comparison to the high, medium or low payment.

$* / \mathrm{h}$ refer to $10 \%, * * / \mathrm{hh}$ refer to $5 \%$ and $* * * /$ hhh refer to $1 \%$ significance level. 
Figure A3.2: Average budget efficiency (all groups)

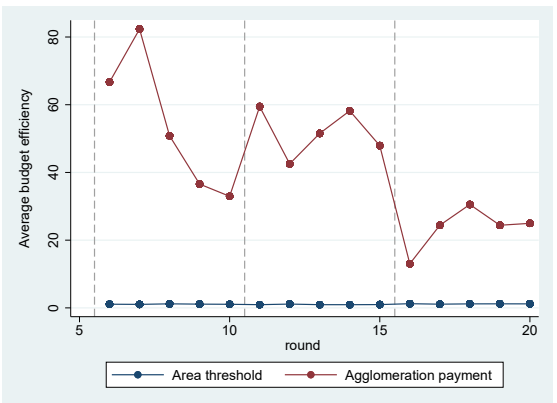

The values in the graph are not demeaned. For all rounds, a base spending of 1 unit is assumed to be able to calculate the budget efficiency also in absence of compensation payments. Groups and rounds in which no compensation payments are made are included in the budget efficiency calculation. 
Table A3.8: Effects of two PES designs on farmers' conservation decision (full tables)

\begin{tabular}{|c|c|c|c|c|c|c|}
\hline & $\begin{array}{c}(1) \\
\text { Coef. }\end{array}$ & $\begin{array}{c}(2) \\
\mathrm{AME}\end{array}$ & $\begin{array}{l}(3) \\
\text { Coef. }\end{array}$ & $\begin{array}{c}(4) \\
\text { AME }\end{array}$ & $\begin{array}{l}(5) \\
\text { Coef. }\end{array}$ & $\begin{array}{c}(6) \\
\text { AME }\end{array}$ \\
\hline $\mathrm{AT}$ & $\begin{array}{l}0.40^{* * *} \\
(0.094)\end{array}$ & $\begin{array}{l}0.08^{* * *} \\
(0.018)\end{array}$ & $\begin{array}{l}0.31^{* * *} \\
(0.098)\end{array}$ & $\begin{array}{l}0.06^{* * *} \\
(0.018)\end{array}$ & $\begin{array}{l}0.39^{* * *} \\
(0.093)\end{array}$ & $\begin{array}{l}0.07^{* * *} \\
(0.017)\end{array}$ \\
\hline AP & $\begin{array}{l}0.32^{* * *} \\
(0.098)\end{array}$ & $\begin{array}{l}0.06^{* * *} \\
(0.019)\end{array}$ & $\begin{array}{l}0.32^{* * *} \\
(0.101)\end{array}$ & $\begin{array}{l}0.06^{* * *} \\
(0.018)\end{array}$ & $\begin{array}{l}0.33^{* * *} \\
(0.097)\end{array}$ & $\begin{array}{l}0.06^{* * *} \\
(0.018)\end{array}$ \\
\hline $\mathrm{AT}+\mathrm{com}$ & $\begin{array}{l}0.61^{* * *} \\
(0.097)\end{array}$ & $\begin{array}{l}0.12^{* * *} \\
(0.019)\end{array}$ & $\begin{array}{l}0.62^{* * *} \\
(0.103)\end{array}$ & $\begin{array}{l}0.11^{* * *} \\
(0.019)\end{array}$ & $\begin{array}{l}0.61^{* * *} \\
(0.097)\end{array}$ & $\begin{array}{l}0.11^{* * *} \\
(0.018)\end{array}$ \\
\hline $\mathrm{AP}+\mathrm{com}$ & $\begin{array}{c}0.16 \\
(0.100)\end{array}$ & $\begin{array}{c}0.03 \\
(0.019)\end{array}$ & $\begin{array}{c}0.06 \\
(0.106)\end{array}$ & $\begin{array}{c}0.01 \\
(0.019)\end{array}$ & $\begin{array}{c}0.16 \\
(0.100)\end{array}$ & $\begin{array}{c}0.03 \\
(0.018)\end{array}$ \\
\hline $\begin{array}{l}\text { Conservation } \\
\text { (lagged) }\end{array}$ & $\begin{array}{l}0.55^{* * *} \\
(0.050)\end{array}$ & $\begin{array}{l}0.11^{* * *} \\
(0.012)\end{array}$ & $\begin{array}{l}0.44^{* * *} \\
(0.052)\end{array}$ & $\begin{array}{l}0.08^{* * *} \\
(0.011)\end{array}$ & $\begin{array}{l}0.54^{* * *} \\
(0.050)\end{array}$ & $\begin{array}{l}0.10^{* * *} \\
(0.010)\end{array}$ \\
\hline Age & $\begin{array}{c}-0.01 \\
(0.009)\end{array}$ & $\begin{array}{c}-0.00 \\
(0.002)\end{array}$ & $\begin{array}{l}-0.02^{*} \\
(0.009)\end{array}$ & $\begin{array}{l}-0.00^{*} \\
(0.002)\end{array}$ & $\begin{array}{c}-0.00 \\
(0.007)\end{array}$ & $\begin{array}{c}-0.00 \\
(0.001)\end{array}$ \\
\hline $\begin{array}{l}\text { Experience as oil } \\
\text { palm farmer }\end{array}$ & $\begin{array}{c}0.00 \\
(0.014)\end{array}$ & $\begin{array}{c}0.00 \\
(0.003)\end{array}$ & $\begin{array}{c}-0.00 \\
(0.014)\end{array}$ & $\begin{array}{c}-0.00 \\
(0.003)\end{array}$ & $\begin{array}{c}-0.01 \\
(0.011)\end{array}$ & $\begin{array}{c}-0.00 \\
(0.002)\end{array}$ \\
\hline Education & $\begin{array}{l}0.05^{* *} \\
(0.026)\end{array}$ & $\begin{array}{l}0.01^{* *} \\
(0.005)\end{array}$ & $\begin{array}{c}0.05^{*} \\
(0.027)\end{array}$ & $\begin{array}{c}0.01^{*} \\
(0.005)\end{array}$ & $\begin{array}{l}0.07^{* * *} \\
(0.021)\end{array}$ & $\begin{array}{l}0.01^{* * *} \\
(0.004)\end{array}$ \\
\hline $\begin{array}{l}\text { Transmigrant } \\
\text { Farmer, } 1=\text { Yes }\end{array}$ & $\begin{array}{c}0.20 \\
(0.216)\end{array}$ & $\begin{array}{c}0.04 \\
(0.042)\end{array}$ & $\begin{array}{c}0.19 \\
(0.222)\end{array}$ & $\begin{array}{c}0.03 \\
(0.040)\end{array}$ & $\begin{array}{c}0.33^{*} \\
(0.175)\end{array}$ & $\begin{array}{c}0.06^{*} \\
(0.032)\end{array}$ \\
\hline Area owned (in ha) & $\begin{array}{c}-0.03 \\
(0.020)\end{array}$ & $\begin{array}{c}-0.01 \\
(0.004)\end{array}$ & $\begin{array}{c}-0.02 \\
(0.021)\end{array}$ & $\begin{array}{c}-0.00 \\
(0.004)\end{array}$ & $\begin{array}{c}-0.02 \\
(0.017)\end{array}$ & $\begin{array}{c}-0.00 \\
(0.003)\end{array}$ \\
\hline $\begin{array}{l}\text { Other crops grown } \\
\text { besides oil palm, } \\
1=\text { Yes }\end{array}$ & $\begin{array}{l}0.49^{* *} \\
(0.209)\end{array}$ & $\begin{array}{l}0.09^{* *} \\
(0.040)\end{array}$ & $\begin{array}{l}0.43^{* *} \\
(0.204)\end{array}$ & $\begin{array}{l}0.08^{* *} \\
(0.037)\end{array}$ & $\begin{array}{c}0.22 \\
(0.165)\end{array}$ & $\begin{array}{c}0.04 \\
(0.030)\end{array}$ \\
\hline $\begin{array}{l}\text { Trees in } \mathrm{OP}, \\
1=\text { Yes }\end{array}$ & $\begin{array}{c}0.30 \\
(0.209)\end{array}$ & $\begin{array}{c}0.06 \\
(0.040)\end{array}$ & $\begin{array}{c}0.32 \\
(0.214)\end{array}$ & $\begin{array}{c}0.06 \\
(0.039)\end{array}$ & $\begin{array}{c}-0.04 \\
(0.169)\end{array}$ & $\begin{array}{c}-0.01 \\
(0.031)\end{array}$ \\
\hline Replanting, $1=$ Yes & $\begin{array}{c}0.04 \\
(0.320)\end{array}$ & $\begin{array}{c}0.01 \\
(0.062)\end{array}$ & $\begin{array}{c}0.06 \\
(0.335)\end{array}$ & $\begin{array}{c}0.01 \\
(0.060)\end{array}$ & $\begin{array}{c}0.03 \\
(0.257)\end{array}$ & $\begin{array}{c}0.01 \\
(0.047)\end{array}$ \\
\hline Risk preferences & $\begin{array}{c}0.04 \\
(0.030)\end{array}$ & $\begin{array}{c}0.01 \\
(0.006)\end{array}$ & $\begin{array}{c}0.05 \\
(0.031)\end{array}$ & $\begin{array}{c}0.01 \\
(0.006)\end{array}$ & $\begin{array}{c}0.00 \\
(0.025)\end{array}$ & $\begin{array}{c}0.00 \\
(0.004)\end{array}$ \\
\hline Trust & $\begin{array}{c}0.04 \\
(0.035)\end{array}$ & $\begin{array}{c}0.01 \\
(0.007)\end{array}$ & $\begin{array}{c}0.03 \\
(0.037)\end{array}$ & $\begin{array}{c}0.01 \\
(0.007)\end{array}$ & $\begin{array}{c}-0.01 \\
(0.029)\end{array}$ & $\begin{array}{c}-0.00 \\
(0.005)\end{array}$ \\
\hline Time preferences & $\begin{array}{c}0.05^{*} \\
(0.030)\end{array}$ & $\begin{array}{c}0.01^{*} \\
(0.006)\end{array}$ & $\begin{array}{c}0.05^{*} \\
(0.031)\end{array}$ & $\begin{array}{c}0.01^{*} \\
(0.006)\end{array}$ & $\begin{array}{c}0.05^{* *} \\
(0.024)\end{array}$ & $\begin{array}{c}0.01^{* *} \\
(0.004)\end{array}$ \\
\hline Egoistic values & $\begin{array}{c}-0.03 \\
(0.058)\end{array}$ & $\begin{array}{c}-0.00 \\
(0.011)\end{array}$ & $\begin{array}{c}-0.03 \\
(0.061)\end{array}$ & $\begin{array}{c}-0.00 \\
(0.011)\end{array}$ & $\begin{array}{c}-0.02 \\
(0.047)\end{array}$ & $\begin{array}{c}-0.00 \\
(0.009)\end{array}$ \\
\hline Biospheric values & $\begin{array}{c}0.16 \\
(0.113)\end{array}$ & $\begin{array}{c}0.03 \\
(0.022)\end{array}$ & $\begin{array}{c}0.15 \\
(0.119)\end{array}$ & $\begin{array}{c}0.03 \\
(0.021)\end{array}$ & $\begin{array}{c}0.10 \\
(0.093)\end{array}$ & $\begin{array}{c}0.02 \\
(0.017)\end{array}$ \\
\hline Altruistic values & $\begin{array}{c}0.22 \\
(0.135)\end{array}$ & $\begin{array}{c}0.04 \\
(0.026)\end{array}$ & $\begin{array}{c}0.21 \\
(0.141)\end{array}$ & $\begin{array}{c}0.04 \\
(0.025)\end{array}$ & $\begin{array}{c}0.12 \\
(0.110)\end{array}$ & $\begin{array}{c}0.02 \\
(0.020)\end{array}$ \\
\hline
\end{tabular}




\begin{tabular}{|c|c|c|c|c|c|c|}
\hline $\begin{array}{l}\text { Environmental } \\
\text { awareness }\end{array}$ & $\begin{array}{l}0.21^{* * *} \\
(0.055)\end{array}$ & $\begin{array}{l}0.04^{* * *} \\
(0.010)\end{array}$ & $\begin{array}{l}0.23^{* * *} \\
(0.057)\end{array}$ & $\begin{array}{l}0.04^{* * *} \\
(0.010)\end{array}$ & $\begin{array}{l}0.12^{* * *} \\
(0.044)\end{array}$ & $\begin{array}{l}0.02^{* * *} \\
(0.008)\end{array}$ \\
\hline $\begin{array}{l}\text { No. of family } \\
\text { members in group }\end{array}$ & $\begin{array}{l}-0.17^{* *} \\
(0.086)\end{array}$ & $\begin{array}{l}-0.03^{* *} \\
(0.017)\end{array}$ & $\begin{array}{l}-0.19^{* *} \\
(0.079)\end{array}$ & $\begin{array}{l}-0.03^{* *} \\
(0.014)\end{array}$ & $\begin{array}{c}-0.10 \\
(0.065)\end{array}$ & $\begin{array}{c}-0.02 \\
(0.012)\end{array}$ \\
\hline $\begin{array}{l}\text { No. of neighbors } \\
\text { in group }\end{array}$ & $\begin{array}{c}0.03 \\
(0.071)\end{array}$ & $\begin{array}{c}0.01 \\
(0.014)\end{array}$ & $\begin{array}{c}0.06 \\
(0.069)\end{array}$ & $\begin{array}{c}0.01 \\
(0.013)\end{array}$ & $\begin{array}{c}-0.04 \\
(0.056)\end{array}$ & $\begin{array}{c}-0.01 \\
(0.010)\end{array}$ \\
\hline $\begin{array}{l}\text { No. of other } \\
\text { conserving farmers } \\
\text { (lagged) }\end{array}$ & $\begin{array}{c}0.05^{* *} \\
(0.022)\end{array}$ & $\begin{array}{c}0.01^{* *} \\
(0.004)\end{array}$ & & & $\begin{array}{c}0.05^{* *} \\
(0.022)\end{array}$ & $\begin{array}{l}0.01^{* *} \\
(0.004)\end{array}$ \\
\hline Round & $\begin{array}{c}-0.01 \\
(0.009)\end{array}$ & $\begin{array}{c}-0.00 \\
(0.002)\end{array}$ & $\begin{array}{c}-0.01 \\
(0.009)\end{array}$ & $\begin{array}{c}-0.00 \\
(0.002)\end{array}$ & $\begin{array}{c}-0.01 \\
(0.009)\end{array}$ & $\begin{array}{c}-0.00 \\
(0.002)\end{array}$ \\
\hline $\begin{array}{l}\text { PES requirement } \\
\text { met (lagged) }=1\end{array}$ & & & $\begin{array}{l}1.32^{* * *} \\
(0.063)\end{array}$ & $\begin{array}{l}0.24^{* * *} \\
(0.013)\end{array}$ & & \\
\hline Conservation $\mathrm{t}=0$ & & & & & $\begin{array}{l}2.01^{* * *} \\
(0.152)\end{array}$ & $\begin{array}{l}0.37^{* * *} \\
(0.018)\end{array}$ \\
\hline $\begin{array}{l}\text { No. of other } \\
\text { conserving farmers, } \\
t=0\end{array}$ & & & & & $\begin{array}{l}0.20^{* * *} \\
(0.065)\end{array}$ & $\begin{array}{l}0.04^{* * *} \\
(0.011)\end{array}$ \\
\hline Constant & $\begin{array}{l}-3.75^{* * *} \\
(1.028) \\
\end{array}$ & & $\begin{array}{c}-4.02^{* * *} \\
(1.075) \\
\end{array}$ & & $\begin{array}{c}-3.67^{* * *} \\
(0.849)\end{array}$ & \\
\hline Observations & 7486 & 7486 & 7486 & 7486 & 7486 & 7486 \\
\hline
\end{tabular}

Results from a mixed effects probit with individual and group RE displayed. Standard errors shown in parentheses. Columns (1) and (2) assume exogeneity of the initial land use decision. Columns (3) and (4) condition the conservation decision in each round on the initial land use decision and the initial land use decision of the other farmers as suggested by Wooldridge (2005) and Rabe-Hesketh and Skrondal (2013). P-values for test AT=AP: (1) 0.466, (3) 0.924, (5) 0.510; for $\mathrm{AT}+$ com. $=\mathrm{AP}+$ com.: (1) 0.000, (3) 0.000, (5) 0.000 .

${ }^{*} p<0.1,{ }^{* *} p<0.05,{ }^{* * *} p<0.01$ 
Table A3.9: Effects of three payment levels on farmers' conservation decision (full tables)

\begin{tabular}{|c|c|c|c|c|c|c|}
\hline & $\begin{array}{c}(1) \\
\text { Coeff. }\end{array}$ & $\begin{array}{c}(2) \\
\mathrm{AME}\end{array}$ & $\begin{array}{c}(3) \\
\text { Coeff. }\end{array}$ & $\begin{array}{c}(4) \\
\text { AME }\end{array}$ & $\begin{array}{c}(5) \\
\text { Coeff. }\end{array}$ & $\begin{array}{c}(6) \\
\text { AME }\end{array}$ \\
\hline High & $\begin{array}{l}0.60^{* * *} \\
(0.093)\end{array}$ & $\begin{array}{l}0.11^{* * *} \\
(0.018)\end{array}$ & $\begin{array}{l}0.47^{* * *} \\
(0.097)\end{array}$ & $\begin{array}{l}0.09^{* * *} \\
(0.018)\end{array}$ & $\begin{array}{l}0.60^{* * *} \\
(0.093)\end{array}$ & $\begin{array}{l}0.11^{* * *} \\
(0.017)\end{array}$ \\
\hline Medium & $\begin{array}{l}0.33^{* * *} \\
(0.098)\end{array}$ & $\begin{array}{l}0.06^{* * *} \\
(0.019)\end{array}$ & $\begin{array}{l}0.30^{* * *} \\
(0.102)\end{array}$ & $\begin{array}{l}0.05^{* * *} \\
(0.019)\end{array}$ & $\begin{array}{l}0.33^{* * *} \\
(0.098)\end{array}$ & $\begin{array}{l}0.06^{* * *} \\
(0.018)\end{array}$ \\
\hline Low & $\begin{array}{c}0.20^{* *} \\
(0.089)\end{array}$ & $\begin{array}{c}0.04^{* *} \\
(0.017)\end{array}$ & $\begin{array}{c}0.21^{* *} \\
(0.093)\end{array}$ & $\begin{array}{c}0.04^{* *} \\
(0.017)\end{array}$ & $\begin{array}{l}0.20^{* *} \\
(0.089)\end{array}$ & $\begin{array}{c}0.04^{* *} \\
(0.016)\end{array}$ \\
\hline High+com. & $\begin{array}{l}0.56^{* * *} \\
(0.120)\end{array}$ & $\begin{array}{l}0.11^{* * *} \\
(0.023)\end{array}$ & $\begin{array}{l}0.60^{* * *} \\
(0.128)\end{array}$ & $\begin{array}{l}0.11^{* * *} \\
(0.023)\end{array}$ & $\begin{array}{l}0.56^{* * *} \\
(0.120)\end{array}$ & $\begin{array}{l}0.10^{* * *} \\
(0.022)\end{array}$ \\
\hline Medium+com. & $\begin{array}{l}0.31^{* * *} \\
(0.105)\end{array}$ & $\begin{array}{l}0.06^{* * *} \\
(0.020)\end{array}$ & $\begin{array}{c}0.28^{* *} \\
(0.110)\end{array}$ & $\begin{array}{c}0.05^{* *} \\
(0.020)\end{array}$ & $\begin{array}{l}0.31^{* * *} \\
(0.105)\end{array}$ & $\begin{array}{l}0.06^{* * *} \\
(0.019)\end{array}$ \\
\hline Low+com. & $\begin{array}{l}0.43^{* * *} \\
(0.122)\end{array}$ & $\begin{array}{l}0.08^{* * *} \\
(0.023)\end{array}$ & $\begin{array}{c}0.28^{* *} \\
(0.128)\end{array}$ & $\begin{array}{c}0.05^{* *} \\
(0.023)\end{array}$ & $\begin{array}{l}0.42^{* * *} \\
(0.122)\end{array}$ & $\begin{array}{l}0.08^{* * *} \\
(0.022)\end{array}$ \\
\hline $\begin{array}{l}\text { Conservation } \\
\text { (lagged) }\end{array}$ & $\begin{array}{l}0.55^{* * *} \\
(0.050)\end{array}$ & $\begin{array}{l}0.10^{* * *} \\
(0.012)\end{array}$ & $\begin{array}{l}0.44^{* * *} \\
(0.052)\end{array}$ & $\begin{array}{l}0.08^{* * *} \\
(0.011)\end{array}$ & $\begin{array}{l}0.53^{* * *} \\
(0.050)\end{array}$ & $\begin{array}{l}0.10^{* * *} \\
(0.010)\end{array}$ \\
\hline Age & $\begin{array}{c}-0.01 \\
(0.009)\end{array}$ & $\begin{array}{c}-0.00 \\
(0.002)\end{array}$ & $\begin{array}{l}-0.01^{*} \\
(0.009)\end{array}$ & $\begin{array}{l}-0.00^{*} \\
(0.002)\end{array}$ & $\begin{array}{c}-0.00 \\
(0.007)\end{array}$ & $\begin{array}{c}-0.00 \\
(0.001)\end{array}$ \\
\hline $\begin{array}{l}\text { Experience as oil } \\
\text { palm farmer }\end{array}$ & $\begin{array}{c}0.00 \\
(0.014)\end{array}$ & $\begin{array}{c}0.00 \\
(0.003)\end{array}$ & $\begin{array}{c}0.00 \\
(0.014)\end{array}$ & $\begin{array}{c}0.00 \\
(0.003)\end{array}$ & $\begin{array}{c}-0.01 \\
(0.012)\end{array}$ & $\begin{array}{c}-0.00 \\
(0.002)\end{array}$ \\
\hline Education & $\begin{array}{c}0.06^{* *} \\
(0.026)\end{array}$ & $\begin{array}{l}0.01^{* *} \\
(0.005)\end{array}$ & $\begin{array}{l}0.05^{* *} \\
(0.026)\end{array}$ & $\begin{array}{l}0.01^{* *} \\
(0.005)\end{array}$ & $\begin{array}{l}0.07^{* * *} \\
(0.021)\end{array}$ & $\begin{array}{l}0.01^{* * *} \\
(0.004)\end{array}$ \\
\hline $\begin{array}{l}\text { Transmigrant } \\
\text { Farmer, } 1=\text { Yes }\end{array}$ & $\begin{array}{c}0.20 \\
(0.219)\end{array}$ & $\begin{array}{c}0.04 \\
(0.042)\end{array}$ & $\begin{array}{c}0.20 \\
(0.222)\end{array}$ & $\begin{array}{c}0.04 \\
(0.040)\end{array}$ & $\begin{array}{c}0.34^{*} \\
(0.177)\end{array}$ & $\begin{array}{c}0.06^{*} \\
(0.032)\end{array}$ \\
\hline Area owned (in ha) & $\begin{array}{c}-0.03 \\
(0.021)\end{array}$ & $\begin{array}{c}-0.01 \\
(0.004)\end{array}$ & $\begin{array}{c}-0.03 \\
(0.021)\end{array}$ & $\begin{array}{c}-0.00 \\
(0.004)\end{array}$ & $\begin{array}{c}-0.03 \\
(0.018)\end{array}$ & $\begin{array}{c}-0.01 \\
(0.003)\end{array}$ \\
\hline $\begin{array}{l}\text { Other crops grown, } \\
1=\text { Yes }\end{array}$ & $\begin{array}{c}0.50^{* *} \\
(0.212)\end{array}$ & $\begin{array}{l}0.10^{* *} \\
(0.040)\end{array}$ & $\begin{array}{l}0.44^{* *} \\
(0.204)\end{array}$ & $\begin{array}{l}0.08^{* *} \\
(0.037)\end{array}$ & $\begin{array}{c}0.23 \\
(0.167)\end{array}$ & $\begin{array}{c}0.04 \\
(0.030)\end{array}$ \\
\hline $\begin{array}{l}\text { Trees in OP, } \\
1=\text { Yes }\end{array}$ & $\begin{array}{c}0.31 \\
(0.212)\end{array}$ & $\begin{array}{c}0.06 \\
(0.040)\end{array}$ & $\begin{array}{c}0.33 \\
(0.214)\end{array}$ & $\begin{array}{c}0.06 \\
(0.039)\end{array}$ & $\begin{array}{c}-0.03 \\
(0.171)\end{array}$ & $\begin{array}{c}-0.00 \\
(0.031)\end{array}$ \\
\hline Replanting, $1=$ Yes & $\begin{array}{c}0.04 \\
(0.324)\end{array}$ & $\begin{array}{c}0.01 \\
(0.062)\end{array}$ & $\begin{array}{c}0.08 \\
(0.334)\end{array}$ & $\begin{array}{c}0.01 \\
(0.060)\end{array}$ & $\begin{array}{c}0.04 \\
(0.259)\end{array}$ & $\begin{array}{c}0.01 \\
(0.047)\end{array}$ \\
\hline Risk preferences & $\begin{array}{c}0.05 \\
(0.030)\end{array}$ & $\begin{array}{c}0.01 \\
(0.006)\end{array}$ & $\begin{array}{c}0.05 \\
(0.031)\end{array}$ & $\begin{array}{c}0.01 \\
(0.006)\end{array}$ & $\begin{array}{c}0.00 \\
(0.025)\end{array}$ & $\begin{array}{c}0.00 \\
(0.005)\end{array}$ \\
\hline Trust & $\begin{array}{c}0.04 \\
(0.036)\end{array}$ & $\begin{array}{c}0.01 \\
(0.007)\end{array}$ & $\begin{array}{c}0.03 \\
(0.037)\end{array}$ & $\begin{array}{c}0.01 \\
(0.007)\end{array}$ & $\begin{array}{c}-0.01 \\
(0.029)\end{array}$ & $\begin{array}{c}-0.00 \\
(0.005)\end{array}$ \\
\hline Time preferences & $\begin{array}{c}0.06^{*} \\
(0.030)\end{array}$ & $\begin{array}{c}0.01^{*} \\
(0.006)\end{array}$ & $\begin{array}{c}0.05^{*} \\
(0.031)\end{array}$ & $\begin{array}{c}0.01^{*} \\
(0.006)\end{array}$ & $\begin{array}{c}0.05^{* *} \\
(0.024)\end{array}$ & $\begin{array}{c}0.01^{* *} \\
(0.004)\end{array}$ \\
\hline Egoistic values & $\begin{array}{c}-0.02 \\
(0.059)\end{array}$ & $\begin{array}{c}-0.00 \\
(0.011)\end{array}$ & $\begin{array}{c}-0.02 \\
(0.061)\end{array}$ & $\begin{array}{c}-0.00 \\
(0.011)\end{array}$ & $\begin{array}{c}-0.02 \\
(0.048)\end{array}$ & $\begin{array}{c}-0.00 \\
(0.009)\end{array}$ \\
\hline
\end{tabular}




\begin{tabular}{|c|c|c|c|c|c|c|}
\hline Biospheric values & $\begin{array}{c}0.16 \\
(0.114)\end{array}$ & $\begin{array}{c}0.03 \\
(0.022)\end{array}$ & $\begin{array}{c}0.14 \\
(0.119)\end{array}$ & $\begin{array}{c}0.03 \\
(0.021)\end{array}$ & $\begin{array}{c}0.09 \\
(0.094)\end{array}$ & $\begin{array}{c}0.02 \\
(0.017)\end{array}$ \\
\hline Altruistic values & $\begin{array}{c}0.22 \\
(0.136)\end{array}$ & $\begin{array}{c}0.04 \\
(0.026)\end{array}$ & $\begin{array}{c}0.21 \\
(0.141)\end{array}$ & $\begin{array}{c}0.04 \\
(0.025)\end{array}$ & $\begin{array}{c}0.12 \\
(0.111)\end{array}$ & $\begin{array}{c}0.02 \\
(0.020)\end{array}$ \\
\hline $\begin{array}{l}\text { Environmental } \\
\text { awareness }\end{array}$ & $\begin{array}{l}0.21^{* * *} \\
(0.056)\end{array}$ & $\begin{array}{l}0.04^{* * *} \\
(0.010)\end{array}$ & $\begin{array}{l}0.23^{* * *} \\
(0.057)\end{array}$ & $\begin{array}{l}0.04^{* * *} \\
(0.010)\end{array}$ & $\begin{array}{l}0.12^{* * *} \\
(0.045)\end{array}$ & $\begin{array}{l}0.02^{* * *} \\
(0.008)\end{array}$ \\
\hline $\begin{array}{l}\text { No. of family } \\
\text { members in group }\end{array}$ & $\begin{array}{l}-0.17^{*} \\
(0.088)\end{array}$ & $\begin{array}{l}-0.03^{*} \\
(0.017)\end{array}$ & $\begin{array}{l}-0.18^{* *} \\
(0.079)\end{array}$ & $\begin{array}{l}-0.03^{* *} \\
(0.014)\end{array}$ & $\begin{array}{c}-0.09 \\
(0.066)\end{array}$ & $\begin{array}{c}-0.02 \\
(0.012)\end{array}$ \\
\hline $\begin{array}{l}\text { No. of neighbors } \\
\text { in group }\end{array}$ & $\begin{array}{c}0.03 \\
(0.072)\end{array}$ & $\begin{array}{c}0.00 \\
(0.014)\end{array}$ & $\begin{array}{c}0.06 \\
(0.069)\end{array}$ & $\begin{array}{c}0.01 \\
(0.013)\end{array}$ & $\begin{array}{c}-0.04 \\
(0.056)\end{array}$ & $\begin{array}{c}-0.01 \\
(0.010)\end{array}$ \\
\hline $\begin{array}{l}\text { No. of other } \\
\text { conserving farmers } \\
\text { (lagged) }\end{array}$ & $\begin{array}{c}0.03 \\
(0.023)\end{array}$ & $\begin{array}{c}0.01 \\
(0.004)\end{array}$ & & & $\begin{array}{c}0.03 \\
(0.022)\end{array}$ & $\begin{array}{c}0.01 \\
(0.004)\end{array}$ \\
\hline $\begin{array}{l}\text { PES requirement } \\
\text { met (lagged) }=1\end{array}$ & & & $\begin{array}{l}1.29^{* * *} \\
(0.063)\end{array}$ & $\begin{array}{l}0.23^{* * *} \\
(0.013)\end{array}$ & & \\
\hline Conservation $\mathrm{t}=0$ & & & & & $\begin{array}{l}2.03^{* * *} \\
(0.154)\end{array}$ & $\begin{array}{l}0.37^{* * *} \\
(0.018)\end{array}$ \\
\hline $\begin{array}{l}\text { No. other } \\
\text { conserving farmers, } \\
t=0\end{array}$ & & & & & $\begin{array}{l}0.22^{* * *} \\
(0.066)\end{array}$ & $\begin{array}{l}0.04^{* * *} \\
(0.012)\end{array}$ \\
\hline Round & $\begin{array}{c}-0.01 \\
(0.009)\end{array}$ & $\begin{array}{c}-0.00 \\
(0.002)\end{array}$ & $\begin{array}{c}-0.01 \\
(0.010)\end{array}$ & $\begin{array}{c}-0.00 \\
(0.002)\end{array}$ & $\begin{array}{c}-0.01 \\
(0.009)\end{array}$ & $\begin{array}{c}-0.00 \\
(0.002)\end{array}$ \\
\hline Constant & $\begin{array}{c}-3.81^{* * *} \\
(1.038)\end{array}$ & & $\begin{array}{c}-4.06^{* * *} \\
(1.070)\end{array}$ & & $\begin{array}{c}-3.79^{* * *} \\
(0.856)\end{array}$ & \\
\hline Observations & 7486 & 7486 & 7486 & 7486 & 7486 & 7486 \\
\hline
\end{tabular}

Individual conservation choice is outcome variable. Coefficients and AME from a mixed effects probit model with individual and group RE shown. Standard errors in parentheses. Columns (1) to (4) assume exogeneity of the initial land use decision. Columns (5) and (6) condition the conservation decision in each round on the initial land use decision and the initial land use decision of the other farmers as suggested by Wooldridge (2005) and Rabe-Hesketh and Skrondal (2013). P-values for test High=Medium: (1) 0.000, (3) 0.029, (5) 0.000; for High=Low: (1) 0.000, (3) 0.001, (5) 0.000; Medium=Low: (1) 0.102, (3) 0.242, (5) 0.092; High+com.=Medium+com.: (1) 0.053, (3) 0.021, (5) 0.059 ; High+com.=Low+com.: (1) 0.353, (3) 0.033, (5) 0.339; Medium+com.=Low+com.: (1) $0.353,(3) 0.999,(5) 0.391$.

${ }^{*} p<0.1,{ }^{* *} p<0.05,{ }^{* * *} p<0.01$ 
Table A3.10: Effects of six PES-schemes on farmer's conservation probability

\begin{tabular}{|c|c|c|c|c|c|c|}
\hline & $\begin{array}{c}(1) \\
\text { Coeff. }\end{array}$ & $\begin{array}{c}(2) \\
\mathrm{AME}\end{array}$ & $\begin{array}{c}(3) \\
\text { Coeff. }\end{array}$ & $\begin{array}{c}(4) \\
\mathrm{AME}\end{array}$ & $\begin{array}{c}(5) \\
\text { Coeff. }\end{array}$ & $\begin{array}{c}(6) \\
\text { AME }\end{array}$ \\
\hline \multirow[t]{2}{*}{ AT + High } & $0.70^{* * *}$ & $0.13^{* * *}$ & $0.45^{* * *}$ & $0.08^{* * *}$ & $0.70^{* * *}$ & $0.13^{* * *}$ \\
\hline & $(0.113)$ & $(0.022)$ & $(0.119)$ & $(0.021)$ & $(0.112)$ & $(0.021)$ \\
\hline \multirow[t]{2}{*}{ AT+Medium } & $0.40^{* * *}$ & $0.08^{* * *}$ & $0.38^{* * *}$ & $0.07^{* * *}$ & $0.39^{* * *}$ & $0.07^{* * *}$ \\
\hline & $(0.116)$ & $(0.022)$ & $(0.123)$ & $(0.022)$ & $(0.116)$ & $(0.021)$ \\
\hline \multirow[t]{2}{*}{$\mathrm{AT}+\mathrm{Low}$} & 0.17 & 0.03 & 0.10 & 0.02 & 0.16 & 0.03 \\
\hline & $(0.107)$ & $(0.021)$ & $(0.112)$ & $(0.020)$ & $(0.106)$ & $(0.019)$ \\
\hline \multirow[t]{2}{*}{$\mathrm{AP}+\mathrm{High}$} & $0.51^{* * *}$ & $0.10^{* * *}$ & $0.45^{* * *}$ & $0.08^{* * *}$ & $0.51^{* * *}$ & $0.09^{* * *}$ \\
\hline & $(0.117)$ & $(0.022)$ & $(0.120)$ & $(0.021)$ & $(0.115)$ & $(0.021)$ \\
\hline \multirow[t]{2}{*}{$\mathrm{AP}+$ Medium } & $0.28^{* *}$ & $0.05^{* *}$ & 0.19 & 0.03 & $0.29^{* *}$ & $0.05^{* *}$ \\
\hline & $(0.122)$ & $(0.023)$ & $(0.126)$ & $(0.022)$ & $(0.120)$ & $(0.022)$ \\
\hline \multirow{2}{*}{$\mathrm{AP}+\mathrm{Low}$} & $0.26^{* *}$ & $0.05^{* *}$ & $0.31^{* *}$ & $0.05^{* *}$ & $0.27^{* *}$ & $0.05^{* *}$ \\
\hline & $(0.116)$ & $(0.022)$ & $(0.121)$ & $(0.022)$ & $(0.115)$ & $(0.021)$ \\
\hline \multirow[t]{2}{*}{ AT+High+com. } & $0.76^{* * *}$ & $0.14^{* * *}$ & $0.80^{* * *}$ & $0.14^{* * *}$ & $0.75^{* * *}$ & $0.13^{* * *}$ \\
\hline & $(0.149)$ & $(0.028)$ & $(0.157)$ & $(0.028)$ & $(0.148)$ & $(0.027)$ \\
\hline \multirow[t]{2}{*}{ AT+Medium+com. } & $0.44^{* * *}$ & $0.08^{* * *}$ & $0.44^{* * *}$ & $0.08^{* * *}$ & $0.45^{* * *}$ & $0.08^{* * *}$ \\
\hline & $(0.128)$ & $(0.024)$ & $(0.138)$ & $(0.024)$ & $(0.127)$ & $(0.023)$ \\
\hline \multirow[t]{2}{*}{$\mathrm{AT}+\mathrm{Low}+\mathrm{com}$} & $0.80^{* * *}$ & $0.15^{* * *}$ & $0.70^{* * *}$ & $0.12^{* * *}$ & $0.79^{* * *}$ & $0.14^{* * *}$ \\
\hline & $(0.169)$ & $(0.032)$ & $(0.179)$ & $(0.031)$ & $(0.168)$ & $(0.031)$ \\
\hline \multirow[t]{2}{*}{$\mathrm{AP}+\mathrm{High}+\mathrm{com}}$. & $0.31^{*}$ & $0.06^{*}$ & $0.31^{*}$ & $0.05^{*}$ & $0.32^{* *}$ & $0.06^{*}$ \\
\hline & $(0.166)$ & $(0.032)$ & $(0.183)$ & $(0.032)$ & $(0.165)$ & $(0.030)$ \\
\hline \multirow[t]{2}{*}{$\mathrm{AP}+$ Medium + com } & 0.14 & 0.03 & 0.07 & 0.01 & 0.14 & 0.02 \\
\hline & $(0.143)$ & $(0.027)$ & $(0.148)$ & $(0.026)$ & $(0.143)$ & $(0.026)$ \\
\hline \multirow[t]{2}{*}{$\mathrm{AP}+\mathrm{Low}+\mathrm{com}}$. & 0.15 & 0.03 & -0.04 & -0.01 & 0.15 & 0.03 \\
\hline & $(0.150)$ & $(0.028)$ & $(0.159)$ & $(0.028)$ & $(0.149)$ & $(0.027)$ \\
\hline \multirow{2}{*}{$\begin{array}{l}\text { Conservation } \\
\text { (lagged) }\end{array}$} & $0.54^{* * *}$ & $0.10^{* * *}$ & $0.41^{* * *}$ & $0.07^{* * *}$ & $0.52^{* * *}$ & $0.09^{* * *}$ \\
\hline & $(0.051)$ & $(0.012)$ & $(0.052)$ & $(0.010)$ & $(0.050)$ & $(0.010)$ \\
\hline \multirow[t]{2}{*}{ Age } & -0.01 & -0.00 & -0.02 & -0.00 & -0.00 & -0.00 \\
\hline & $(0.009)$ & $(0.002)$ & $(0.009)$ & $(0.002)$ & $(0.007)$ & $(0.001)$ \\
\hline \multirow{2}{*}{$\begin{array}{l}\text { Experience as oil } \\
\text { palm farmer }\end{array}$} & 0.00 & 0.00 & -0.00 & -0.00 & -0.01 & -0.00 \\
\hline & $(0.014)$ & $(0.003)$ & $(0.015)$ & $(0.003)$ & $(0.012)$ & $(0.002)$ \\
\hline \multirow[t]{2}{*}{ Education } & $0.06^{* *}$ & $0.01^{* *}$ & $0.05^{*}$ & $0.01^{*}$ & $0.07^{* * *}$ & $0.01^{* * *}$ \\
\hline & $(0.026)$ & $(0.005)$ & $(0.027)$ & $(0.005)$ & $(0.021)$ & $(0.004)$ \\
\hline Transmigrant & 0.20 & 0.04 & 0.21 & 0.04 & $0.34^{*}$ & $0.06^{*}$ \\
\hline Farmer, $1=$ Yes & $(0.220)$ & $(0.042)$ & $(0.229)$ & $(0.040)$ & $(0.178)$ & $(0.032)$ \\
\hline \multirow[t]{2}{*}{ Area owned (in ha) } & -0.03 & -0.01 & -0.03 & -0.00 & -0.03 & -0.00 \\
\hline & $(0.021)$ & $(0.004)$ & $(0.022)$ & $(0.004)$ & $(0.018)$ & $(0.003)$ \\
\hline Other crops grown, & $0.50^{* *}$ & $0.10^{* *}$ & $0.47^{* *}$ & $0.08^{* *}$ & 0.24 & 0.04 \\
\hline $1=$ Yes & $(0.213)$ & $(0.040)$ & $(0.210)$ & $(0.036)$ & $(0.168)$ & $(0.030)$ \\
\hline Trees in OP, & 0.32 & 0.06 & 0.36 & 0.06 & -0.02 & -0.00 \\
\hline
\end{tabular}




\begin{tabular}{lcccccc} 
1= Yes & $(0.213)$ & $(0.040)$ & $(0.220)$ & $(0.038)$ & $(0.172)$ & $(0.031)$ \\
Replanting, 1=Yes & 0.05 & 0.01 & 0.11 & 0.02 & 0.05 & 0.01 \\
& $(0.326)$ & $(0.062)$ & $(0.344)$ & $(0.060)$ & $(0.261)$ & $(0.047)$ \\
Risk preferences & 0.05 & 0.01 & 0.05 & 0.01 & 0.00 & 0.00 \\
& $(0.030)$ & $(0.006)$ & $(0.032)$ & $(0.006)$ & $(0.025)$ & $(0.004)$ \\
Trust & 0.04 & 0.01 & 0.03 & 0.01 & -0.01 & -0.00 \\
& $(0.036)$ & $(0.007)$ & $(0.038)$ & $(0.007)$ & $(0.029)$ & $(0.005)$ \\
Time preferences & $0.06^{*}$ & $0.01^{*}$ & 0.05 & 0.01 & $0.05^{* *}$ & $0.01^{* *}$ \\
& $(0.030)$ & $(0.006)$ & $(0.032)$ & $(0.006)$ & $(0.024)$ & $(0.004)$ \\
Egoistic values & -0.02 & -0.00 & -0.03 & -0.01 & -0.02 & -0.00 \\
& $(0.059)$ & $(0.011)$ & $(0.063)$ & $(0.011)$ & $(0.048)$ & $(0.009)$ \\
Biospheric values & 0.16 & 0.03 & 0.15 & 0.03 & 0.09 & 0.02 \\
& $(0.115)$ & $(0.022)$ & $(0.122)$ & $(0.021)$ & $(0.094)$ & $(0.017)$ \\
Altruistic values & 0.22 & 0.04 & 0.22 & 0.04 & 0.12 & 0.02 \\
& $(0.137)$ & $(0.026)$ & $(0.145)$ & $(0.025)$ & $(0.112)$ & $(0.020)$ \\
Environmental & $0.22^{* * *}$ & $0.04^{* * *}$ & $0.24^{* * *}$ & $0.04^{* * *}$ & $0.12^{* * *}$ & $0.02^{* * *}$ \\
awareness & $(0.056)$ & $(0.010)$ & $(0.058)$ & $(0.010)$ & $(0.045)$ & $(0.008)$ \\
No. of family & $-0.17^{* *}$ & $-0.03^{* *}$ & $-0.19^{* *}$ & $-0.03^{* *}$ & -0.10 & -0.02 \\
members in group & $(0.088)$ & $(0.017)$ & $(0.081)$ & $(0.014)$ & $(0.067)$ & $(0.012)$ \\
No. of neighbors & 0.03 & 0.01 & 0.06 & 0.01 & -0.04 & -0.01 \\
in group & $(0.072)$ & $(0.014)$ & $(0.071)$ & $(0.012)$ & $(0.057)$ & $(0.010)$ \\
No. of other & 0.02 & 0.00 & & & 0.02 & 0.00 \\
conserving farmers & $(0.023)$ & $(0.004)$ & & & $(0.023)$ & $(0.004)$ \\
(lagged) & & & & & & \\
PES requirement & & & $1.38^{* * *}$ & $0.24^{* * *}$ & & \\
met (lagged), & & & $(0.066)$ & $(0.013)$ & & \\
1=Yes & & & & & $2.05^{* * *}$ & $0.37^{* * *}$ \\
Conservation t=0 & & & & & $(0.155)$ & $(0.018)$ \\
No. other & & & & & $0.23^{* * *}$ & $0.04^{* * *}$ \\
conserving farmers, & & & & & $(0.067)$ & $(0.012)$ \\
t=0 & $-3.78^{* * *}$ & $(0.002)$ & $(0.010)$ & $(0.002)$ & $(0.009)$ & $(0.002)$ \\
Round & & & & & $-3.75^{* * *}$ & \\
Constant & & & & & & \\
Observations & & & & & & \\
\hline
\end{tabular}


Coefficients and AME from mixed effects probit estimation with individual and group RE displayed. Outcome variable is farmers' conservation decision. Standard errors in parentheses. P-values for test High=Medium (AT): (1) 0.003, (3) 0.497, (5) 0.003; High=Low (AT): (1) 0.000, (3) 0.001, (5) 0.000; Medium=Low (AT): (1) 0.029, (3) 0.011, (5) 0.026; for High=Medium (AP): (1) 0.038, (3) 0.026, (5) 0.045; High=Low (AP): (1) 0.026, (3) 0.221, (5) 0.026; Medium=Low (AP): (1) $0.888,(3) 0.316,(5) 0.848$;

High + com. $=$ Medium + com. $($ AT): (1) 0.070, (3) 0.055, (5) 0.091; High + com. $=$ Low + com. (AT): (1) 0.834, (3) 0.649, (5) 0.819; Medium+com.=Low+com. (AT): (1) 0.058, (3) 0.198, (5) 0.072; High + com. $=$ Medium + com. (AP): (1) 0.393, (3) 0.272, (4) 0.347; High + com. $=$ Low + com. (AP): (1) 0.426, (3) 0.115, (5) 0.396; Medium+com.=Low+com. (AP): (1) 0.965, (3) 0.559, (5) 0.933; $\mathrm{AT}=\mathrm{AP}$ (High): (1) 0.161, (3) 0.978, (5) 0.160; AT=AP(Medium): (1) 0.366, (3) 0.173, (5) 0.421; $\mathrm{AT}=\mathrm{AP}$ (Low): (1) 0.490, (3) 0.128, (5) 0.412; AT=AP(High+com.): (1) 0.027, (3) 0.025, (5) 0.033; AT=AP(Medium+com.): (1) 0.080, (3) 0.041, (5) 0.062; AT=AP(Low+com.): (1) 0.001, (3) 0.001, (5) 0.001 .

${ }^{*} p<0.1,{ }^{* *} p<0.05,{ }^{* * *} p<0.01$ 


\section{Chapter 4}

\section{The effect of soil conservation}

practices on yields and soil

carbon in smallholder oil palm

plantations

This chapter is co-authored by Nina Hennings, Michaela Dippold and Meike Wollni. NH and KR developed the research idea and the designs for the soil and economic part of the study. NH supervised the data collection in 2017 in Indonesia and the soil analysis in Goettingen. KR analyzed the data and wrote the paper. MD and MW assisted with the design of the survey and the soil sampling strategy. MW commented on result interpretation and helped with the revision of the paper. 


\subsection{Introduction}

In South-East Asia, oil palm production has been the main driver of agricultural expansion during the last three decades (Gibbs et al., 2010). Between 1990 and 2017, the cultivated area has increased six fold (FAO, 2019). Oil palm expansion has contributed to deforestation and has replaced more extensive agricultural land use systems such as rubber agroforestry (Feintrenie, Schwarze, \& Levang, 2010; Vijay et al., 2016). This has raised concern about its negative environmental consequences (Clough et al., 2016; Drescher et al., 2016; Vijay et al., 2016). In particular carbon emissions and the potential consequences for global warming have been highlighted (Rahman et al., 2018; van Straaten et al., 2015). Part of these emissions are due to losses of soil organic carbon (SOC), which is the organic fraction of the carbon stored in the soil (Guillaume et al., 2018). Among the main causes of these SOC losses are soil erosion and little litter input in oil palm plantations in comparison to forests (Guillaume et al., 2015).

Oil palm expansion is not only driven by industrial plantations, but also by smallholder farmers. Around $46 \%$ of all area under oil palm in Indonesia, which is the main palm oil producing country, is managed by smallholder farmers (Badan Pusat Statistik, 2019). Many smallholder farmers have profited from oil palm cultivation in terms of income and broader welfare gains (Krishna et al., 2017). However, smallholder oil palm yields lie well below those of industrial plantations (Euler et al., 2016; Woittiez et al., 2017) indicating the existence of yield gaps. Closing yield gaps is important from a rural development perspective (Jelsma, Slingerland, Giller, \& Bijman, 2017). Moreover, it may also be environmentally efficient if higher per hectare yields reduce land expansion (Kubitza, Krishna, Urban, Alamsyah, \& Qaim, 2018).

The adoption of improved management practices can potentially decrease yield gaps. For oil palm, one of the recommended practices is mulching with empty fruit bunches (EFB) (Comte et al., 2012; Pauli et al., 2014). EFB are the bunches of the oil fruits which remain after the oil fruits have been stripped off during the processing at the palm oil mills. EFB contain several nutrients and can be used as organic fertilizer (Abu Bakar et al., 2011). While industrial plantations in proximity to palm oil mills often apply EFB, smallholder use is much lower (Jelsma et al., 2019). If beneficial to yields in smallholdings, wider applications of EFB mulching could hence help to close the reported yield gaps. Moreover, EFB mulching might also positively affect soil properties and increase SOC (Abu 
Bakar et al., 2011; Comte et al., 2013; Moradi et al., 2015; Tao et al., 2017). This could restore part of the carbon lost during land transformation into oil palm plantations and might also support the provision of biomass producing ecosystem services, which are important to sustain crop growth (Lal, 2006; Minasny et al., 2017; Petersen \& Hoyle, 2016).

Our study presents evidence on the effect of EFB mulching on yields and SOC contents in smallholder oil palm plantations in Jambi Province, in Sumatra, Indonesia. This region represents one of the hotspots of oil palm expansion in Indonesia and has experienced important land use changes (Drescher et al., 2016). While several studies have reported yield and SOC increasing effects of EFB mulching in experimental studies in industrial plantations (Abu Bakar et al., 2011; Tao et al., 2017; Teh Boon Sung et al., 2011), we are not aware of any study that has looked at the effect of EFB mulching in smallholder plantations. Yet, results derived from experimental and large-scale plantations on the effects of EFB mulching cannot simply be extrapolated to smallholder farmers because they often face circumstances which do not match the conditions in experimental settings (Duflo et al., 2008).

Based on yearly panel data on oil palm yields and plantation management from 2015 until 2017, and soil samples collected in 2017, we estimate the effect of mulching on yields and SOC. Moreover, we explore to what extent the effect of mulching on yields operates through an improvement in SOC contents. To our knowledge, only Tao et al. (2017) have tried to analyze the impact pathways of EFB mulching on yields. The authors however only look at the effects of mulching on yields, and of SOC on yields separately. Therefore, it is not possible to separate the yield supporting effect of SOC increases from other channels.

The paper is organized as follows. First, we introduce in more detail the value chain linked to EFB procurement and how EFB mulching can affect yields. Section 4.3 presents the study region, the sampling approach and the data collected. In section 4.4, we introduce the estimation strategy. Results are presented in section 4.5 and section 4.6 concludes.

\subsection{Characteristics of empty fruit bunch mulching}

To avoid perishing, the fresh fruit bunches (FFB) need to be brought to the mills within 48 hours after harvest to get processed (Gatto et al., 2015). There, they are first sterilized to then strip off the oil containing fruits from the bunches 
(Embrandiri, Singh, Ibrahim, \& Ramli, 2012). At this stage, empty fruit bunches (EFB) are generated. In order to produce one ton of crude palm oil (CPO), around four tons of FFB are needed if hybrid varieties are used, which are widely spread among smallholder farmers in Indonesia (Woittiez et al., 2017). Per ton of CPO, around one ton of EFB is produced (Comte et al., 2013). These are then sold as organic fertilizer at the mills. As a result, access might be restricted for smallholder farmers who often are not directly linked to the mills, but sell their FFB via middlemen (Jelsma et al., 2019). Moreover, EFB need to be brought back to the plantations by trucks, but the bulkiness and heavy weight complicate their transport as well as the application in the plantations. Besides a general unawareness of the potential positive effects of mulching material and high prices, these factors can explain the low adoption rate of EFB mulching among smallholder farmers (Comte et al., 2013; Jelsma et al., 2019; Rhebergen, Fairhurst, Whitbread, Giller, \& Zingore, 2018).

EFB contain nutrients such as nitrogen $(\mathrm{N})$, potassium $(\mathrm{K})$ and phosphor $(\mathrm{P})$ which are released in the decomposition process to the soil (Moradi et al., 2015). ${ }^{1}$ Their carbon content is estimated at 44.1\% (Comte et al., 2013). Decomposition of EFB takes between one and two years (Moradi, Teh, Goh, Husni, \& Ishak, 2014). First, in particular carbon and potassium are released, while other nutrients are released at slower rates and partly only in the second year after application (Caliman et al., 2001; Chiew \& Zaharah, 2002; Moradi et al., 2014).

Evidence from experimental studies shows that EFB application can increase oil palm yields (Abu Bakar et al., 2011). While annual yields might not differ significantly, Tao et al. (2017) indicate that aggregated yield increases over a 15 year time horizon amount to $2.4 \%$ to $5.9 \%$, depending on the amount of EFB applied. $^{2}$ Other experiments report even higher yield increases of up to $19 \%$ over two years (Chiew \& Zaharah, 2002). These positive yield responses might be due to nutrient releases as well as improvements in soil conditions such as higher SOC contents.

Several papers report positive effects of EFB application on SOC contents, both in the short run after just six months (Teh Boon Sung et al., 2011) and in the

\footnotetext{
${ }^{1}$ Estimates about the nutrient content of EFB are $0.65-0.94 \% \mathrm{~N}, 0.08-0.12 \% \mathrm{P}, 1.7-3.2 \% \mathrm{~K}$, 0.11-0.34\% Ca and 0.15-0.24\% Mg on a dry weight basis (Abu Bakar et al., 2011). The nutritional content of one ton of EFB is equivalent to $6.1 \mathrm{~kg}$ urea, $1.7 \mathrm{~kg}$ TSP, $16.3 \mathrm{~kg}$ MOP and $3 \mathrm{~kg}$ kieserit (Caliman, Martha, \& Saletes, 2001).

${ }^{2}$ Yield increases are $2.4 \%, 5.9 \%$ and $4.8 \%$, when 30,60 and 90 tons EFB per hectare are applied on a yearly basis.
} 
long run (Abu Bakar et al., 2011; Comte et al., 2013; Tao et al., 2017). After six months, carbon contents increased by 0.57 percentage points for $0-15 \mathrm{~cm}$ and 0.19 percentage points for 15-30 cm soil depth on average (Teh Boon Sung et al., 2011). After ten years of application and depending on the amount of EFB applied, increases of 1 to 1.25 percentage points have been observed (Abu Bakar et al., 2011). However, soil responses to carbon inputs likely depend on the soil type and on the frequency of application, with more positive effects to be expected from a continuous application (Comte et al., 2013). Increasing SOC contents could also increase soil carbon stocks and thus improve soil carbon sequestration. Moreover, higher SOC contents could also increase the provision of several soil ecosystem services, which are important to sustain crop growth (Lal, 2006; Petersen \& Hoyle, 2016).

SOC can affect yields by improving the soil physical properties and by sustaining soil microbial activities and soil biodiversity (Lal, 2006, 2014; Petersen \& Hoyle, 2016). Higher SOC contents improve the water holding and buffer capacity of the soil and facilitate root growth (Lal, 2006). Furthermore, soil microbial activities support nutrient cycling and make nutrients directly available to the plants in the process of SOC decomposition (Petersen \& Hoyle, 2016). If any of these factors limit yields, increasing SOC potentially has a direct positive effect on yields. This could be especially important in developing countries, where e.g. insufficient fertilization is often a direct limiting factor.

Positive responses of oil palm yields to increases in SOC can be expected because insufficient nutrient supply (Euler et al., 2016; Rhebergen et al., 2018), nutrient leaching (Kurniawan et al., 2018), and water stress (Carr, 2011; Woittiez et al., 2017) have been reported as yield limiting factors and might be positively affected by higher SOC contents. In contrast to ample evidence about the yield supporting effect of SOC for annual crops (Lal, 2006, 2010; Petersen \& Hoyle, 2016; Wander \& Nissen, 2004), empirical evidence on the relationship between yields and SOC for perennial crops in general, ${ }^{3}$ and more specifically for oil palm is scarce. For oil palm, the exceptions represent Gérard et al. (2017) who find that a one percentage point increase in SOC is associated with yearly average yield increases of $24 \mathrm{~kg}$ per palm when no chemical fertilizer is applied, ${ }^{4}$ and Tao et al. (2017) who report yield increases of 1.6 tons per hectare in response to a one percentage point increase

\footnotetext{
${ }^{3}$ The few existing studies have reported positive correlations for rubber (Samarppuli, Ekanayake, and Samarppuli (1999) cited after Lal (2006)), coffee and forest trees (Ojienyi \& Agbede, 1980).

${ }^{4}$ Normally, around 144 oil palms are planted per hectare.
} 
in SOC. The latter study however does not control for other confounding factors that might be correlated with higher SOC contents such as mulching, making a full attribution of the effects to SOC difficult.

\subsection{Study region, sampling procedure and data}

\subsubsection{Study region}

Our study takes place in Jambi Province in Sumatra, Indonesia. Oil palm cultivation started in Jambi in the 1980s through the transmigration program that was supported by the Indonesian government and external donors, such as the World Bank. To spur rural development, poor farmers from the overpopulated island of Java were relocated to less populated ones, mostly to Sumatra. The arriving farmers were given two to three hectares of land for oil palm cultivation as well as extension services and inputs (Gatto et al., 2015; McCarthy, 2010). Since the introduction of oil palm in Jambi, the province has been one of the hotspots of Indonesian oil palm expansion leading to tremendous land use changes. While unprotected forest cover decreased by more than 75\% (1990-2011), in particular the area under oil palm production has grown fourfold between 1990 and 2016 and surpassed rubber as the dominant land use system in 2012 (Bou Dib, Krishna, et al., 2018). Nowadays, Jambi Province ranks seventh with regard to the area under oil palm production among all 34 provinces in Indonesia (Badan Pusat Statistik, 2019).

Our study region comprises five regencies, Muaro Jambi, Batanghari, Sarolangun, Tebo, and Bungo. These cover most of the lowland area in Jambi that was strongly affected by rainforest transformation into cash crop plantations (Gatto et al., 2015). The dominant soil type in the lowlands are Acrisols, which are characterized by a low pH and low soil fertility. However, peat soils are also frequent (Guillaume et al., 2016). Our sample represents a subsample of villages and farmers that were part of another study in the region conducted in 2015 and 2016 and for which we gathered additional information between May and August 2017. For the first study, a sample of 36 villages was randomly selected from a list of all oil palm producing villages in the region. ${ }^{5}$ From these 36 villages, we randomly selected 18 villages (Figure 4.1). In our initial sample, $12 \%$ of the farmers applied mulching on

\footnotetext{
${ }^{5}$ The precise description of the first village selection process can be found in Romero et al. (2019).
} 
Figure 4.1: Location of villages with soil samples in Jambi

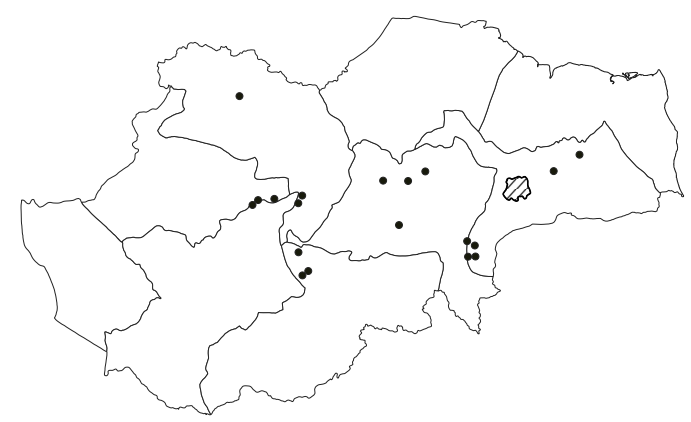

The lines indicate regency delimiters and the shaded area the location of Jambi city.

at least one plot. To ensure that the number of mulching adopters in the sample is sufficiently large for identification of the treatment effects, we stratified farmers according to whether they applied EFB on at least one plot or not in 2016. We sampled 30 farmers who applied EFB mulching and 100 control farmers. Due to high non-response rates in one village, a 19th village was additionally included in the sample. Our final sample comprises 129 farmers, of which 32 applied EFB mulching in 2016 and 97 are control farmers.

\subsubsection{Plot selection and soil sampling}

Per farmer, one plot was selected. In case farmers had several plots under mulching in the case of adopters, or without mulching in the case of control farmers the following selection procedure was applied: when several plots were located within a $1 \mathrm{~km}$ radius of the house, plot selection was done randomly. Since farmers were reluctant to guide us to plots that were further away, we otherwise selected the closest plot. ${ }^{6}$ Soil samples to assess soil organic carbon contents were collected from May till August 2017. On each plot, samples were taken in two locations: First, soil sampling was done in the interrow as a common reference point. The interrow is the row between the palms and normally kept free of frond stacks and ground vegetation. A very limited number of farmers also mulch next to the interrow (Table 4.2). We made sure that interrow soil samples were taken where no mulching

\footnotetext{
${ }^{6}$ We acknowledge that the non-random selection of plots that are rather close to the farmer's house might lead to the selection of plots with higher management intensities and might therefore not be representative for average plots in the region.
} 
Figure 4.2: Soil sampling strategy

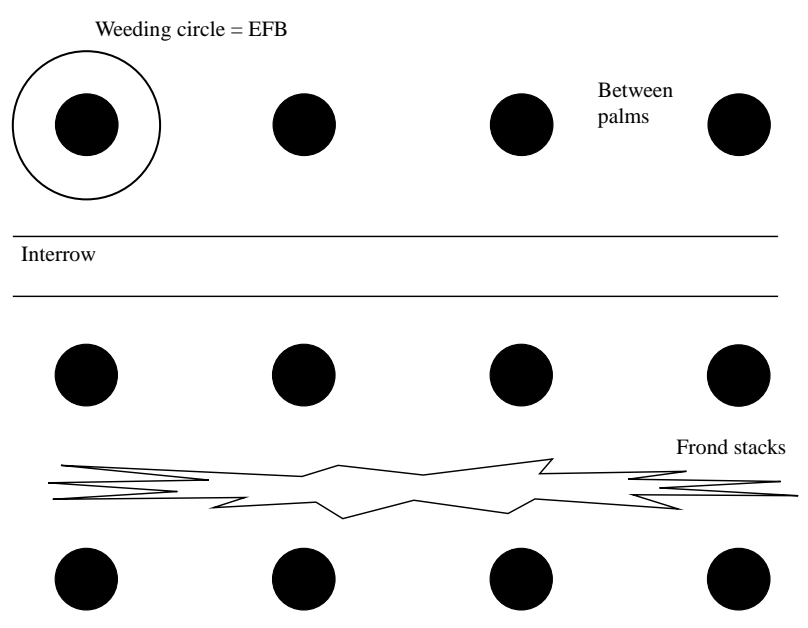

Dark circles indicate oil palms.

material was applied. Since the effect of mulching is localized (Carron et al., 2016), soil samples in the interrow should not be affected by nearby mulching. The second sampling location differed by treatment. In the EFB mulching treatment, samples were taken next to the oil palms, in the so-called weeding circle, where farmers mulch. In the control plots, we sampled in two different locations to cover the heterogeneity within oil palm plantations: in 50 plots, we took soil samples between oil palms. These locations are often covered by ground vegetation. In 47 plantations, the second sampling location was located in the frond stack area. This is where farmers put the dead or pruned frond stacks. All of the farmers in our sample with productive plots report having frond stacks in their plantations. The sampling scheme is depicted in Figure 4.2. We will refer to the sampling location in the interrow as interrow sampling location, and to the second sampling location as the management location.

Composite soil samples consisting of 25 individual subsamples were collected in each management and interrow sampling location to cover plot variations. All samples were collected with a soil ring from 0-5 cm soil depth, because most of the carbon losses are located in the topsoil (Guillaume et al., 2015). The soil was airdried and sieved $(2 \mathrm{~mm})$ and all visible roots were carefully removed. All samples were milled and weighed in tin capsules to estimate $\mathrm{C}$ and $\mathrm{N}$ content using the Vario el cube (Elementar, Langenselbold, Germany) at the Georg-August-University 
Goettingen.

\subsubsection{Socio-economic data}

We visited farmers between October and November in both 2015 and 2016 and assessed socio-economics and plot characteristics. Moreover, extensive information on plot management and harvest quantities in the last 12 months was gathered. Information included the amount of fertilizer and herbicide applied, harvest frequency as well as other maintenance done to the oil palms. In addition, we asked whether the farmers applied EFB mulching in the last 12 months. Between May and August 2017, farmers were visited again to do a short follow-up survey. In this survey, we asked information about the amount of FFB harvested and physical inputs in the last six months. Moreover, more detailed information on mulching was collected, including inter alia the length and the location of the application.

\subsection{Conceptual model and estimation strategy}

\subsubsection{Reduced form estimation}

To provide evidence on the effect of EFB mulching on yields in smallholder oil palm plantations, we run a panel data oil palm production function including information from 2015 until 2017. Yields are expressed as tons of FFB harvested. Our mulching indicator captures whether mulching material was applied on the plot in the current or the previous year to account for the fact that some nutrients are still released in the second year after application (section 4.2). This might result in a slight underestimation of our effects in the year 2015 since information on the lagged application of EFB mulching is not available. However, over $80 \%$ of the farmers reported in 2017 that they started mulching three or less years ago such that only a small share of adopters might have applied mulching in 2014 . Non-adopters do not report mulching between 2014 and 2017.

One problem arising when estimating the effect of mulching on yields is the possible endogeneity of the mulching decision. Endogeneity can stem from two sources. First, farmers applying mulching might differ in unobservables from non-adopters, which might simultaneously affect the mulching decision and yields. Second, reverse causality might be present. Since FFB are harvested continuously throughout the year, farmers might adapt their management choices in reaction to 
yields. While fixed effects (FE) estimation can help overcome endogeneity concerns linked to unobserved heterogeneity, it is found to be inefficient in case of a limited within-individual variation as present in the current case where only 20 observations change the treatment (Wooldridge, 2010). Furthermore, FE estimation does not solve potential endogeneity resulting from reverse causality. This motivates the use of instrumental variable estimation.

A valid instrument needs to fulfill two assumptions: First, it needs to be correlated with the endogenous variable. Second, it needs to be exogenous to the yield equation, meaning that it is not correlated with the error term (Angrist \& Pischke, 2009). This requires that the instrument is not a relevant predictor of yields in itself and can therefore be omitted from the yield regression, nor should it influence yields through other channels not controlled for in the regression. We propose the use of the number of palm oil mills found in a radius of $20 \mathrm{~km}$ around the farmer's village as instrument. ${ }^{7}$ The number of palm oil mills is calculated with GPS data of the locations of palm oil mills in Jambi Province (World Resources Institute et al., 2019) and of the villages. As discussed in section 4.2, farmers obtain EFB from the palm oil mills and their decision to apply mulching is likely determined by input availability. More mills in proximity to the village represent a higher availability of mulching material and are therefore expected to positively affect farmers' mulching decision. Furthermore, it is unlikely that the number of mills affects yields through other channels. Potential confounding effects as well as tests to assess the predictive power of the instrument and the validity of its omission from the yield equation will be discussed at the end of this section and in section 4.5.2.

We run a two-stage linear random effects model. The two stages ${ }^{8}$ of the equation can be represented as

$$
\begin{aligned}
& E F B_{i t}=\beta_{10} X_{i t}+\beta_{11} Z_{i}+\epsilon_{1 i t} \\
& Y_{i t}=\beta_{20} X_{i t}+\beta_{21} \widehat{E F B}_{i t}+\epsilon_{2 i t}
\end{aligned}
$$

\footnotetext{
${ }^{7}$ We have also tested the number of mills in a radius of $10 \mathrm{~km}$ and $30 \mathrm{~km}$. However, the radius of $20 \mathrm{~km}$ has a higher predictive power for the mulching decision and is thus a stronger instrument. Likewise, using a radius of $20 \mathrm{~km}$ instead of $10 \mathrm{~km}$ or $30 \mathrm{~km}$ increases the variation between villages. Five of the mills in the region are mass balanced certified with the Roundtable on Sustainable Palm Oil. Therefore, they can still process FFB from non-certified producers, such as the farmers in our sample, and are therefore not dropped.

${ }^{8}$ While being called two-stage regression, estimation can also occur in one step where the first regression is plugged in the second one (Baum, Schaffer, \& Stillman, 2003).
} 
where $E F B_{i t}$ is farmer $i$ 's decision to mulch in period $t, X_{i t}$ are the control variables treated as exogenous, $Z_{i}$ is the instrument, i.e. the number of palm oil mills in a radius of $20 \mathrm{~km}$. Based on the first stage estimations, predictions of mulching applications are made. These enter the second stage regression, where tons of FFB harvested in six months in logarithms $\left(Y_{i t}\right)$ by farmer $i$ in period $t$ are regressed on the predictions $\widehat{E F B}_{i t}$ as well as the other exogenous covariates. $\epsilon_{1 i t}$ and $\epsilon_{2 i t}$ represent the respective error terms which are assumed to be uncorrelated. To account for the potential correlation of the error terms at the village level, and since the initial sampling strategy is based on a two-stage process where first villages and then farmers within villages were randomly selected, standard errors are clustered at the village level (Abadie, Athey, Imbens, \& Wooldridge, 2017).

Our control variables include measures of the three main agricultural inputs, land, capital and labor. Land is measured as the plot size. To capture capital input, we include spending on fertilizer and herbicide in the regression. To allow for comparability between years, spending is inflation corrected. ${ }^{9}$ As a proxy for labor input, we use the harvest frequency as harvesting consumes most work in the plantation management (Euler et al., 2016). ${ }^{10}$ Moreover, a dummy for whether a farmer has pruned the palms in the respective time period is included. We control for the application of other manure and the presence of grazing animals on the plot. To model potential plot-specific yield determinants, we control for the plot age and the planting densities of the oil palms. We expect a non-linear relationship between the plot age and yields, where yields first increase until the oil palms have reached the full production potential and then decrease until replanting is required after 25 to 30 years (Woittiez et al., 2017). Since other plot characteristics initially included in the model such as the steepness, whether the plantation borders a river as well as the squared term of the planting density were found to be jointly insignificant, ${ }^{11}$ they were excluded from the estimation. At the village level, we include a dummy for whether a farmer lives in a transmigrant

\footnotetext{
${ }^{9}$ We use monetary instead of physical inputs to better reflect the quality of the fertilizer and to circumvent problems that emerge if the physical input unit is not homogeneous for all types of input used. However, local prices are also influenced by e.g. transportation costs. Both measures are closely linked, though (Pearson's correlation coefficient is 0.94 for fertilizer and 0.96 for herbicide) suggesting that the effect of using either one of the two indicators should only be small. Information on national consumer price indices with 2010 as the reference year is taken from the World Bank.

${ }^{10}$ Some farmers also weed their plantations. This is the only frequent management activity we do not have 2017 information on. Labor for fertilizer and herbicide application is very closely related to input costs and thus implicitly controlled for by the spending on fertilizer and herbicide.

${ }^{11} \mathrm{P}$-value of F-test: 0.794 .
} 
village that was founded under the transmigration program (section 4.3) or in a local village. Farmers living in transmigrant villages often have better access to inputs and information since many transmigrant farmers started growing oil palm under contractual arrangements with companies. Moreover, the dummy captures potential village effects that could be correlated with the village-level instrument because transmigrant villages were often founded in proximity to palm oil mills. We also included other potential confounders in the initial model specification capturing the effects of potentially endogenous migration to the village, better access to information or smaller risk of crop perishing because of easier access to the mills. These factors were jointly insignificant and their inclusion did not affect the results such that they have been omitted from the main model specification. ${ }^{12}$

To avoid collinearity problems, we restrict interactions between the input factors to be zero and estimate a Cobb-Douglas production function. With the exception of the planting density and the plantation age, all non-binary variables are expressed in logarithms. Before log transforming, zero input costs are changed to one to avoid dropping these observations in the estimation. The effect of these cases is captured by a dummy variable that assumes one if either fertilizer or herbicide is not applied (Battese, 1997). ${ }^{13}$ To allow for comparability between the three years, input costs and harvest amount are halved for the years 2015 and 2016 to represent six-month information (subsection 4.3.3). ${ }^{14}$ We in addition include year fixed effects to capture potential shocks. As a robustness check, we present results only based on the years 2015 and 2016 in Table A4.1 in the Appendix. Since in those years more extensive data was collected, these models also control for the full labor costs of maintaining the oil palm plantation. Finally, we cannot rule out that other management decisions such as fertilizer application are endogeneous, too. As a robustness check, we re-estimate the model after excluding management choices. Results are presented in Table A4.2, columns (3) and (4), in the Appendix.

\footnotetext{
${ }^{12}$ Since migration happened also outside the transmigration program, we control for the farmer's individual migration decision to the village. Moreover, the distance to the next palm oil mill, the FFB price received and whether an industrial oil palm plantation is bordering the village were included. Results are presented in columns (1) and (2) in Table A4.2 in the Appendix. Results are very similar to the ones presented in section 4.5.2. P-value of F-test is 0.695.

${ }^{13}$ To reduce the collinearity in the model, we do not differentiate between farmers not applying herbicide and farmers not applying fertilizer since these dummy variables are highly correlated with the respective input costs expressed in logarithms (rho: -0.964 for fertilizer and -0.956 for herbicide use).

${ }^{14}$ Because of the presence of a rainy and a dry season, as well as the fact that not all inputs are applied twice a year, we acknowledge that the data might still not be fully comparable. However, the inclusion of time dummies should capture remaining effects.
} 
To control for the fact that we oversampled farmers applying mulching (section 4.3), we additionally present results derived from pooled two-stage linear least squares (2SLS) estimation after population weights have been applied. Following Cameron and Miller (2015), we cluster errors at the highest and thus on the village instead of on the individual level. The weights reflect our sampling strategy and are based on the share of households applying EFB mulching in the full sample in 2016. Finally, we perform restricted wild bootstrapping and present resulting significance levels. This should address potential over-rejection of the null hypothesis observed when few clusters are present (Cameron \& Miller, 2015; Roodman, Nielsen, MacKinnon, \& Webb, 2019). ${ }^{15}$

\subsubsection{Pathway analysis}

The reduced form effect of mulching on yields, which represents the overall effect as shown in eqn. (4.2), can operate through several pathways. Mulching induced increases in SOC represent one such pathway. Higher SOC contents are hypothesized to positively affect yields through e.g. an improvement in the soil water holding capacity. We will refer to the effect of mulching on yields through an improvement in SOC as the indirect effect (Imai, Keele, Tingley, \& Yamanoto, 2011). Mulching might also affect yields through other channels, which we do not explicitly model. The effect of the other pathways will be referred to as the direct effect of mulching after controlling for its effect through SOC increases. We expect a positive direct effect because of nutrient releases, but the potential attraction of pests could also negatively affect yields. Our hypothesized pathways are depicted in Figure 4.3.

To test our hypothesized pathways, we estimate a set of structural equations. Estimation is based on the 2017 information collected because soil samples were collected in 2017 only. Our structural model can be represented as follows

$$
\begin{aligned}
& Y_{i}=\alpha_{0}+\alpha_{1} E F B_{i}+\alpha_{2} S O C_{i}+\alpha_{3} S O C_{i}^{2}+\alpha_{4} Z_{1 i}+u_{1 i} \\
& S O C_{i}=\beta_{0}+\beta_{1} E F B_{i}+\beta_{2} Z_{2 i}+u_{2 i} \\
& S O C_{i}^{2}=\gamma_{0}+\gamma_{1} E F B_{i}+\gamma_{2} Z_{3 i}+u_{3 i} \\
& E F B_{i}=\delta_{0}+\delta_{1} Z_{4 i}+u_{4 i}
\end{aligned}
$$

\footnotetext{
${ }^{15}$ Mulching is not applied in two villages. Therefore, the number of clusters is similar to the number of treated clusters. Having only a few clusters treated might lead to under-rejection of the null hypothesis (MacKinnon \& Webb, 2017).
} 
Figure 4.3: Hypothesized pathways

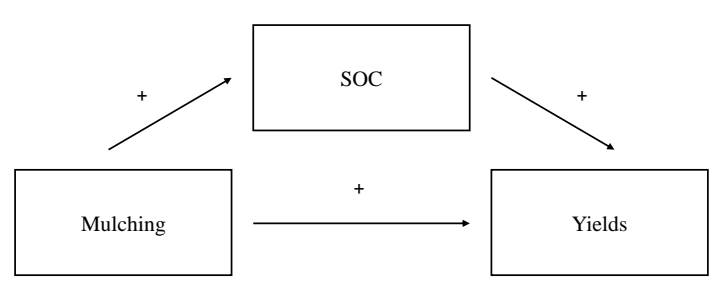

+ indicates expected positive effects.

where $Y_{i}$ represents six-month yields of farmer $i$ in 2017 in logarithmized tons of FFB, $E F B_{i}$ equals one if a farmer applies mulching, and $S O C_{i}$ is the soil carbon content in \% that also enters in squared terms in eqn. (4.3). Due to the highly skewed distribution, the carbon contents are expressed in logarithms. The respective vectors $Z$ contain other exogenous variables and the respective vectors $u$ are the error terms.

We estimate the effects of mulching on SOC based on eqn. (4.4). We assume that the error terms in eqn. (4.4) and eqn. (4.6) are uncorrelated. This assumption appears realistic since it is first unlikely that farmers' unobserved effects influence the biophysical processes underlying the SOC-mulching relationship. Second, we use carbon content in the interrow to control for the plot quality in the absence of treatment. Given a localized effect of mulching (Carron et al., 2016), the SOC contents in the interrow should not be affected by the treatment. This enables us to control for potential unobserved plot quality differences between adopters and non-adopters. Instrumentation strategies are thus not needed for identification of $\beta_{1}$ in eqn. (4.4).

In contrast, $u_{1}$ might be correlated with $u_{2}, u_{3}$ and $u_{4}$. Three instruments which induce exogenous variation are therefore required for the identification of the parameters in eqn. (4.3). As instrument for mulching, we use the number of palm oil mills found in a radius of $20 \mathrm{~km}$ around the village (subsection 4.4.1). As instrument 
for the carbon content in the management location, we use the mean interrow carbon content in the plantations of the other farmers in the village. ${ }^{16}$ Generally, within a plantation, the carbon content in the interrow is closely correlated with the carbon content in the management location $(\mathrm{rho}=0.98)$. The aggregate interrow carbon content of the other respondents in the village should also be a close correlate of an individual farmer's carbon content in the management location, because soil characteristics are correlated within a village due to e.g. similar soil types and often a similar background in the plantation establishment. ${ }^{17}$ The interrow carbon content of the other farmers in the village is plausibly exogenous since a direct effect on yields of the individual farmer is unlikely and since the interrow carbon content is unaffected by their mulching decision.

Finally, we assume a non-linear relationship between the carbon content in a plantation and yields; very high carbon contents are associated with organic soils and likely unfavorable to yields (Corley \& Tinker, 2016). The carbon content therefore also enters in squared terms in eqn. (4.3). The non-linear transformation of an endogenous variable requires an own instrument (Wooldridge, 2010) (eqn. (4.5)). We use the squared term of the interrow mean carbon content of the other farmers in the village to predict the squared carbon content.

In absence of interaction effects between the carbon content and mulching, identification of the respective coefficients in eqn. (4.3) is feasible with 2SLS regression (Burgess, Daniel, Butterworth, \& Thompson, 2015; Frölich \& Huber, 2017). ${ }^{18}$ The direct effect of mulching on yields is represented by $\alpha_{1}$; its indirect effect through SOC improvements by $\beta_{1} * \alpha_{2}$ and $\gamma_{1} * \alpha_{3}$.

\footnotetext{
${ }^{16}$ While we see that the number of individuals interviewed in a village differs, the average number of persons interviewed in a village is not significantly different between the groups of adopters and non-adopters. Therefore, the precision of the carbon content measures should be similar between both.

${ }^{17}$ The variation in SOC appears to be larger across villages than within villages. We find that the mean standard deviation within a village is smaller (4.5) than the standard deviation of the respective village means (7.95) supporting the use of village-level soil indicators as instruments.

${ }^{18} \mathrm{We}$ do not find significant interaction effects in the range of carbon contents considered in this study. Coefficient ( $\mathrm{p}$-value) of the interaction term in an OLS estimation of yields on the mulching indicator, SOC, their interaction and additional controls is $-0.28(0.21)$, if we restrict the sample to plantations whose interrow carbon content lies in the range defined by the treatment plantations. The insignificance of the interaction term also holds when we consider the full sample.
} 


\subsection{Results}

\subsubsection{Descriptives and constraints to adoption}

Table 4.1 displays socio-economic characteristics of the adopting and non-adopting farmers in our sample and related plot characteristics. Adopters of mulching are those households that apply mulching between 2015 and 2017. To compare adopters and non-adopters, we conduct t-tests with standard errors clustered at the village level. Harvest information, fertilizer and herbicide use show a highly skewed distribution. Influential outliers were replaced with the 95 percentile. For more information on outlier detection, please refer to Table A4.3 in the Appendix.

Table 4.1: Socio-econonomic and descriptive statistics

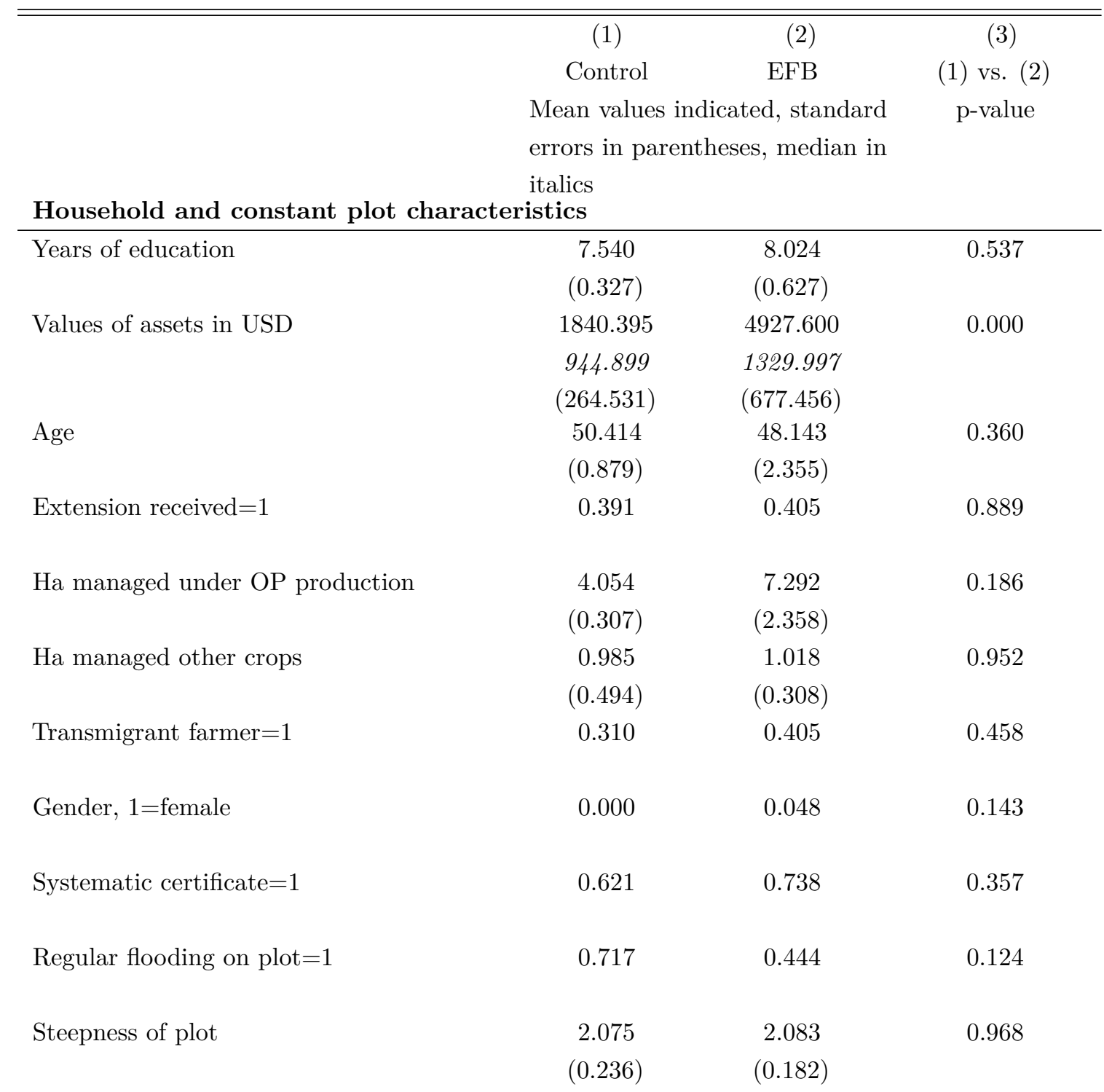




\begin{tabular}{|c|c|c|c|}
\hline River bordering $=1$ & 0.356 & 0.262 & 0.346 \\
\hline Plot size in ha & $\begin{array}{c}1.884 \\
(0.157)\end{array}$ & $\begin{array}{c}2.048 \\
(0.525)\end{array}$ & 0.717 \\
\hline Plot age in years & $\begin{array}{l}13.908 \\
(1.301)\end{array}$ & $\begin{array}{l}14.738 \\
(2.072)\end{array}$ & 0.730 \\
\hline Difficult road conditions $=1$ & 0.447 & 0.262 & 0.037 \\
\hline Carbon content interrow (\%) & $\begin{array}{c}10.017 \\
3.22,(3.169)\end{array}$ & $\begin{array}{c}4.904 \\
2.84,(1.413)\end{array}$ & 0.033 \\
\hline Carbon content management location (\%) & $\begin{array}{c}10.503 \\
3.98,(3.100)\end{array}$ & $\begin{array}{c}6.042 \\
4.49,(1.296)\end{array}$ & 0.055 \\
\hline Organic soil $=1$ & 0.172 & 0.048 & 0.039 \\
\hline$N$ & 87 & 42 & \\
\hline \multicolumn{4}{|l|}{ Variable plot information } \\
\hline $\begin{array}{l}\text { Harvest in tons of FFB per ha (six } \\
\text { months) }\end{array}$ & $\begin{array}{c}9.248 \\
8.775,(0.376)\end{array}$ & $\begin{array}{l}11.664 \\
11.700 \\
(0.690)\end{array}$ & 0.001 \\
\hline $\begin{array}{l}\text { Fertilizer spending in } 1,000 \text { IDR per ha } \\
\text { (six months) }\end{array}$ & $\begin{array}{l}712.322 \\
569.481 \\
(76.462)\end{array}$ & $\begin{array}{c}806.491 \\
591.241 \\
(122.893)\end{array}$ & 0.163 \\
\hline $\begin{array}{l}\text { Herbicide spending in } 1,000 \text { IDR per ha } \\
\text { (six months) }\end{array}$ & $\begin{array}{r}93.987 \\
69.444 \\
(20.129)\end{array}$ & $\begin{array}{c}79.464 \\
43.795, \\
(121.128)\end{array}$ & 0.355 \\
\hline Other manure applied $=1$ & 0.081 & 0.138 & 0.237 \\
\hline$N$ & 322 & 65 & \\
\hline
\end{tabular}

Village-level clustered standard errors in parentheses. Household and invariant information displayed for farmers who ever apply EFB mulching in the years considered. Variable plot information shows averages over all years in which mulching was applied. Cost variables are inflation adjusted. Tons of FFB harvested and input costs were halved for 2015 and 2016 to represent six-month information. T-tests use clustered standard errors. For a description of the selected variables, please refer to Table A4.3 in the Appendix.

The farmers who apply EFB mulching own more assets and manage, albeit not significantly, more hectares, suggesting that these farmers are richer. Since EFB need to be brought from the palm oil mills to the plantations with trucks, good road conditions facilitate mulching, as indicated by the significantly better access to mulched in comparison to control plots. Finally, we find that mulching is not applied on organic soils with a carbon content of $20 \%$ or more (IUSS Working Group WRB, 2015). These carbon-rich soils likely also drive the significant difference in 
mean interrow carbon contents between adopters and non-adopters.

These descriptive statistics mirror the constraints and preconditions for EFB adoption reported by farmers. As suitable conditions, good roads and proximity to mills $(40 \%)$ as well as plots with mineral soils and little flooding risks were mentioned (18\%). ${ }^{19}$ High costs (56\%), non-availability of mulching material (40\%) as well as time constraints, lack of information and insufficient physical strength (33\%) represented perceived barriers to adoption. Only a small share of $10 \%$ mentioned potential negative effects of mulching such as pest attraction.

Table 4.1 also shows descriptives for yields and SOC contents. We find that per hectare yields are significantly higher on mulched in comparison to control plots, whereas carbon content in the management location is significantly lower on mulched plots. ${ }^{20}$ The latter might be driven by the higher prevalence of organic soils in the control group, which is in line with the significantly higher SOC content in the interrow sampling location of the control plots.

Putting yield and SOC contents in perspective, extrapolated yearly per hectare yields in our sample appear to lie at the upper end of yearly per hectare yields reported for different smallholder groups in Sumatra that range from 12.7 tons to 19.5 tons (Euler et al., 2016; Lee, Ghazoul, Obidzinski, \& Koh, 2014). However, yields are still below those of industrial plantation that can amount to 30 tons per hectare and year (Euler et al., 2016) indicating the presence of yield gaps. If we restrict our sample to mineral soils, the median carbon content is $2.74 \%$ in the interrow. This is slightly higher than the reported median carbon content of $2.2 \%$ in other smallholder plantations in Jambi Province (Guillaume et al., 2016) and higher than mean values reported for the interrow in industrial plantations of $1.6 \%$ (Carron et al., 2015) and 2.01\% (Khasanah, van Noordwijk, Ningsih, \& Rahayu, 2015)..$^{21}$

We find large heterogeneity with regard to the amount of EFB applied per hectare, but the values lie in the range reported for industrial plantations of 15 to 60 tons per hectare (Table 4.2) (Tao et al., 2017). In contrast, the location where EFB are applied differs between smallholdings and industrial plantations:

\footnotetext{
${ }^{19}$ Farmers could mention several reasons.

${ }^{20}$ We discuss in section 4.5.2 that mulching might also have a delayed effect. The comparison of yields in Table 4.1 is based only on years when mulching is applied. This could underestimate the differences.

${ }^{21}$ Khasanah et al. (2015) and Carron et al. (2015) apply different labels for the management zones than used in this study. The harvest path in their studies represents the management zone we refer to as the interrow. The age of the industrial plantations considered in these two papers is 24 and 25 years respectively. This could partly explain why the carbon content is lower.
} 
Table 4.2: Descriptives of EFB mulching

\begin{tabular}{|lcccc|}
\hline & Mean & SD & Min & Max \\
\hline $\begin{array}{l}\text { Years of } \\
\text { application }\end{array}$ & 3.13 & 2.61 & 0.5 & 15 \\
\hline Location = WC & 0.85 & & & \\
\hline $\begin{array}{l}\text { Location = } \\
\text { WC+IR }\end{array}$ & 0.15 & & & \\
\hline Tons per ha & 53.72 & 51.31 & 3.5 & 180 \\
\hline $\mathrm{N}$ & 32 & & & \\
\hline $\begin{array}{l}\text { WC = Weeding circle, IR = next to interrow. N includes } \\
\text { adopters of EFB mulching selected for soil sampling. }\end{array}$ \\
\hline
\end{tabular}

Most industrial companies apply mulching between the palms to avoid fruit losses. In contrast, smallholder farmers appear to mostly mulch in the weeding circle (Table 4.2).

\subsubsection{Reduced form effects of mulching on yields}

Results of the reduced form effect of mulching on yields based on a random effects instrumental variable regression are reported in Table 4.3. Six plots were not reported in 2015 such that our panel data set is unbalanced. ${ }^{22}$ The validity of the results presented in Table 4.3 hinges on the validity of the assumptions we impose on the instrument. To test whether our instrument is correctly excluded from our basic model (eqn. (4.2)), we include the number of palm oil mills in a radius of 20 $\mathrm{km}$ around the village in the model. The small coefficient and its insignificance (coefficient: 0.008 , p-value: 0.534 ) support the plausibility of the excludability assumption. ${ }^{23}$ Besides its plausible exogeneity, instrumental variable estimation only reduces the bias if the instrument is a good predictor for the potentially

\footnotetext{
${ }^{22}$ These farmers did not mulch between 2014 and 2017 such that the mulching indicator in 2016 is correctly specified.

${ }^{23}$ Another potential instrument is the distance to the next paved road from the plot to capture the ease of the plot access. The distance to the next paved road is also insignificant in model specification (1) (coefficient: 0.002, p-value: 0.838). Having two instruments allows to test for overidentification of the instruments. Based on the Hansen J statistics, we cannot reject the exogeneity of our instruments (p-value: 0.682). Even though the test for weak instruments can also not be rejected, predictive power appears to be greater when one instrument is used. Therefore, only the number of palm oil mills found in a $20 \mathrm{~km}$ radius is used as instrument in our final model specification.
} 
endogenous variable (Olea \& Pflueger, 2013). We test for weak instruments and for whether the equations are identified with help of the test procedures developed by Olea and Pflueger (2013) and Kleibergen and Paap (2006), which are robust to clustered standard errors. Both tests support the strength of our instrument. ${ }^{24}$ Results of the first stage are reported in Table A4.4 in the Appendix.

Table 4.3: Instrumental variable estimation of the effect of mulching on yields

\begin{tabular}{|c|c|c|}
\hline & $(1)$ & $(2)$ \\
\hline \multirow[t]{2}{*}{ Current and/or lagged mulching } & $0.382^{* * / b}$ & $0.325^{*}$ \\
\hline & $(0.185)$ & $(0.175)$ \\
\hline Implied change & $44.01 \%$ & $36.23 \%$ \\
\hline \multirow[t]{2}{*}{ Plot size in ha (log) } & $0.870^{* * *}$ & $0.848^{* * *}$ \\
\hline & $(0.050)$ & $(0.047)$ \\
\hline Spending on fertilizer & $0.031^{* * *}$ & $0.042^{* * *}$ \\
\hline in 1,000 IDR $(\log )$ & $(0.011)$ & $(0.010)$ \\
\hline Spending on herbicide & -0.004 & 0.017 \\
\hline in 1,000 IDR $(\log )$ & $(0.017)$ & $(0.016)$ \\
\hline \multirow[t]{2}{*}{ No input application $=1$} & 0.008 & 0.128 \\
\hline & $(0.102)$ & $(0.098)$ \\
\hline \multirow[t]{2}{*}{ Other manure applied=1 } & 0.087 & $0.186^{* *}$ \\
\hline & $(0.085)$ & $(0.074)$ \\
\hline \multirow[t]{2}{*}{ Harvest frequency (log) } & $0.493^{* * *}$ & $0.390^{* *}$ \\
\hline & $(0.146)$ & $(0.185)$ \\
\hline \multirow[t]{2}{*}{ Pruning $=1$} & -0.022 & 0.028 \\
\hline & $(0.050)$ & $(0.056)$ \\
\hline \multirow[t]{2}{*}{ Grazing animals $=1$} & $-0.109^{* *}$ & $-0.144^{* * *}$ \\
\hline & $(0.051)$ & $(0.051)$ \\
\hline \multirow[t]{2}{*}{ Plot age } & $0.079^{* * *}$ & $0.083^{* * *}$ \\
\hline & $(0.021)$ & $(0.031)$ \\
\hline \multirow[t]{2}{*}{ Plot age squared } & $-0.002^{* * *}$ & $-0.002^{* * *}$ \\
\hline & $(0.001)$ & $(0.001)$ \\
\hline \multirow[t]{2}{*}{ Planting density } & $0.002^{* *}$ & $0.002^{*}$ \\
\hline & $(0.001)$ & $(0.001)$ \\
\hline \multirow[t]{2}{*}{ Wave $=16$} & $-0.189^{* * *}$ & $-0.194^{* * *}$ \\
\hline & $(0.053)$ & $(0.043)$ \\
\hline \multirow[t]{2}{*}{ Wave $=17$} & $-0.528^{* * *}$ & $-0.455^{* * *}$ \\
\hline & $(0.107)$ & $(0.157)$ \\
\hline Local village $=1$ & -0.111 & $-0.133^{* *}$ \\
\hline
\end{tabular}

\footnotetext{
${ }^{24} \mathrm{P}$-value for testing the hypothesis of under-identification is 0.024 in column (1). With regard to weak instruments, we can reject the hypothesis that the bias induced is greater than $10 \%$ of the bias resulting from OLS regression at the $5 \%$ significance level.
} 


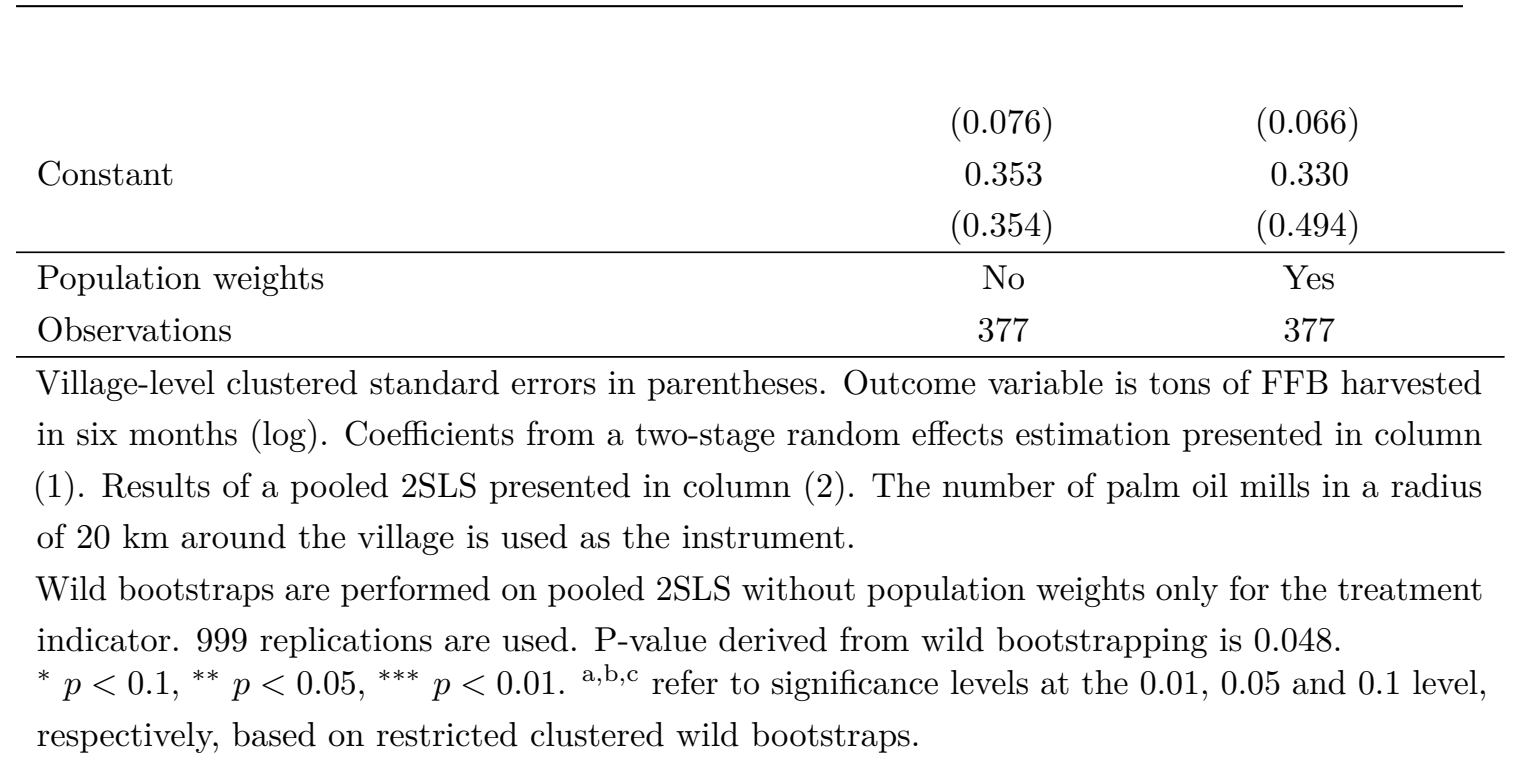

Our results support a positive and very large effect of mulching on yields with EFB mulching increasing yields by $36 \%$ (column (2)) to $44 \%$ (column (1)). ${ }^{25}$ The significance of our estimates is supported by wild bootstraps. The direction of the effects of the other explanatory variables on yields is in line with the literature analyzing oil palm smallholder yields (Euler et al., 2016; Lee et al., 2014; Woittiez et al., 2017). We find a very large land elasticity of yields; a $1 \%$ increase in plot size increases yields by approx. $0.85 \%$, which is very close to a one-to-one translation of percentage land size expansion into percentage yield increases. A 1\% increase in spending on fertilizer increases yields by around $0.04 \%$. Labor, as measured by harvest frequency, also significantly and positively affects yields. All significant coefficients on the logarithmized agricultural input factors are between zero and one, implying a positive but decreasing response of the untransformed outcome variable to increases in the input factors. Our results are robust to only using the 2015 and 2016 data with more extensive labor information (Table A4.1 in the Appendix) as well as to the exclusion of other potentially endogenous management variables (Table A4.2 in the Appendix).

Our mulching indicator in Table 4.3 does not differentiate between the effects of current and lagged mulching. Identification of the different effects of current and lagged mulching requires two separate instruments. Given the difficulties of finding suitable instruments with high predictive power, we look at correlations in a random effects panel data model to get an idea of the potential difference in effect size between current and lagged mulching. Results for the mulching indicators are

\footnotetext{
${ }^{25}$ Derivation of the percentage change is done with help of $100 *(\exp (\hat{\beta}-0.5 * \operatorname{Var}(\hat{\beta}))-1)$ (Kennedy, 1981).
} 
presented in Table 4.4, full results are available in Table A4.5 in the Appendix.

Table 4.4: Random effects panel data results of mulching on yields

\begin{tabular}{lccc}
\hline \hline & $(1)$ & $(2)$ & $(3)$ \\
\hline Current and/or lagged mulching=1 & $0.212^{* * *}$ & & \\
& $(0.056)$ & & \\
Current mulching=1 & & $0.132^{* *}$ & \\
& & $(0.062)$ & \\
Lagged mulching=1 & $0.206^{* * *}$ & \\
& $(0.062)$ & \\
Only lagged mulching=1 & & $0.210^{* *}$ \\
& & & $(0.090)$ \\
Only current mulching=1 & & 0.135 \\
& & & $(0.105)$ \\
Lagged and current mulching=1 & & $0.339^{* * *}$ \\
& & & $(0.084)$ \\
Constant & 0.341 & 0.452 & 0.449 \\
& $(0.441)$ & $(0.545)$ & $(0.528)$ \\
\hline Other controls ${ }^{1}$ & Yes & Yes & Yes \\
Observations & 377 & 257 & 257 \\
\hline Cooffirs & & & \\
\hline
\end{tabular}

Coefficients from a linear random effects model displayed. Standard errors in parentheses. Errors are clustered at the village level. The outcome variable is tons of FFB harvested in six months $(\log )$. Fertilizer and herbicide costs are inflation adjusted. Harvest and input information are scaled for 2015 and 2016 to represent six-month information.

${ }^{1}$ The same control variables as in Table 4.3 are used. Full results are available in Table A4.5 in the Appendix.

${ }^{*} p<0.1,{ }^{* *} p<0.05,{ }^{* * *} p<0.01$

Results from the random effects panel data model support significant correlations between current and/or lagged mulching and yield increases, although the effect size of approx. $23 \%$ (column (1)) is smaller than in Table 4.3. The effect of lagged mulching appears to be slightly more important than that of current mulching as the coefficient is highly significant and larger (column (2)). ${ }^{26}$ However, the difference is not significant (p-value: 0.401), which provides some support for the combined treatment variable in the instrumental variable estimation in Table 4.3. To see whether the effect sizes differ if mulching is applied in two consecutive years, we differentiate between farmers mulching only in the previous year, only in the current year, and in both the current and the previous year. While both lagged and continuous mulching in two years are significantly associated with yield increases,

\footnotetext{
${ }^{26}$ We acknowledge that in particular the effect of current mulching might suffer from potential reverse causality problems.
} 
continuous mulching in two years appears to be significantly more effective than mulching in only one year. ${ }^{27}$ Consequently, our results support a yield increasing effect of EFB mulching. In particular the slow release of some nutrients likely explains why part of the mulching effect only materializes in the second year after application.

\subsubsection{Pathway analysis}

In order to explore whether, and if so to what extent the effect of mulching on yields operates through an improvement in SOC, results of the structural equations in eqn. (4.4) and eqn. (4.3) are presented in Table 4.5, columns (2) and (3). Full model results are available in Table A4.6 in the Appendix. Since the pathway analysis is based on cross-sectional observations from 2017, we also present reduced form results of the effect of mulching on yields for comparison in column (1). First stage results for the three endogenous variables in column (3) are displayed in Table A4.7 in the Appendix. The predictive power of our instruments is sufficient for identification of eqn. (4.3). ${ }^{28}$ For comparison, OLS results are presented in Table A4.8 in the Appendix.

Table 4.5: Pathway analysis of the effect of mulching on yields

\begin{tabular}{lccc}
\hline \hline & $(1)$ & $(2)$ & $(3)$ \\
& FFB & SOC (\%, log) & FFB \\
& $\begin{array}{c}\text { harvested in } \\
\text { tons }(\log )\end{array}$ & & $\begin{array}{c}\text { harvested in } \\
\text { tons }(\log )\end{array}$ \\
\hline Mulching=1 & $0.505^{* *}$ & $0.166^{* * * / a}$ & 0.428 \\
& $(0.233)$ & $(0.056)$ & $(0.343)$ \\
Implied change & $61.29 \%$ & $17.88 \%$ & $44.68 \%$ \\
Interrow SOC $(\%, \log )$ & & $0.893^{* * *}$ & \\
\hline
\end{tabular}

\footnotetext{
${ }^{27} \mathrm{P}$-values of $\mathrm{t}$-tests for only lagged $=$ only current mulching: 0.365, for only current $=$ combined mulching: 0.047 , for combined $=$ only lagged mulching: 0.018 . We acknowledge that the power of detecting statistically significant effects could differ between the groups due to a different number of individuals belonging to the respective categories, which could explain why we do not find significant effects for current mulching. When considering the years 2016 and 2017, 21 farmers applied mulching only in the previous, 19 farmers only in the current and 35 farmers in both years.

${ }^{28}$ The Sanderson Windmeijer Chi2 test for identification in case of several endogenous variables that is robust to violations of the i.i.d. assumption (Sanderson \& Windmeijer, 2016) rejects the hypothesis of underidentification for all three endogenous variables. Respective p-values are 0.006 for mulching, 0.006 for the carbon content and 0.090 for the squared carbon content. Given the lack of clear decision mechanisms regarding instrument strengths in case of several endogenous variables and clustered standard errors, the existence of potential weak instrument problems cannot fully be assessed (Sanderson \& Windmeijer, 2016).
} 


\begin{tabular}{|c|c|c|c|}
\hline $\operatorname{SOC}(\%, \log )$ & & & $\begin{array}{c}0.119 \\
(0.560)\end{array}$ \\
\hline SOC $(\%, \log )$ squared & & & $\begin{array}{l}-0.035 \\
(0.129)\end{array}$ \\
\hline Constant & $\begin{array}{c}0.599 \\
(0.673)\end{array}$ & $\begin{array}{c}0.278 \\
(0.247)\end{array}$ & $\begin{array}{c}0.480 \\
(1.007)\end{array}$ \\
\hline Controls $^{1}$ & Yes & Yes & Yes \\
\hline Observations & $128^{2}$ & $128^{2}$ & $128^{2}$ \\
\hline
\end{tabular}

Village-level clustered standard errors in parentheses. Coefficients from a 2SLS regression shown in columns (1) and (3). Coefficients from an OLS regression displayed in column (2). The base category for column (2) is the carbon content in the combined control group of frond stack area and between oil palms. Wild bootstrap p-values for mulching are in column (1): 0.109, in (2): 0.018 , and in (3): 0.219 , for the carbon content in column (3): 0.812 and for the squared carbon content: 0.776 .

1 The same control variables as in Table 4.3 are included in columns (1) and (3). In column (2), we control for spending on fertilizer and herbicide, other manure application, plot age, plot age squared, non-application of fertilizer and/or herbicide, the planting density, grazing animals, the steepness of the plots, a bordering river, previous land use on the plot and previous fire on plot.

2 One farmer did not harvest his plot in 2017 , so he was not considered in this analysis.

${ }^{*} p<0.1,{ }^{* *} p<0.05,{ }^{* * *} p<0.01$.

a,b,c refer to significance levels at the 0.01, 0.05 and 0.1 level, respectively, based on restricted clustered wild bootstraps. Wild bootstraps are performed for the mulching treatment and for SOC with 999 replications.

\section{Effect of mulching on SOC}

Results of a linear regression of the carbon contents in the management location on the mulching dummy are displayed in column (2) in Table 4.5. In the model, we additionally include the carbon content in the interrow to control for existing imbalances in general plantation SOC contents between adopters and non-adopters (Table 4.1). EFB mulching significantly increases SOC contents by $18 \%$ in comparison to the control group, which includes samples taken in the frond stack area and between the oil palms. The significance is supported by wild bootstraps.

Table 4.6 presents several robustness checks. In column (1), we restrict our sample to plantations where the interrow carbon content lies in the same interval as that of treatment plantations, which we will refer to as common support in the following. In column (2), we further assess the influence outliers have on our results. We use Tukey's method (Tukey, 1977) for identification and replace outliers with the respective upper or lower adjacent value, depending on the direction of the 
Table 4.6: Robustness checks

\begin{tabular}{lccc}
\hline \hline & $(1)$ & $(2)$ & $(3)$ \\
\hline Mulching=1 & $0.150^{* *}$ & $0.161^{* * *}$ & $0.186^{*}$ \\
& $(0.058)$ & $(0.052)$ & $(0.100)$ \\
Implied change & $15.99 \%$ & $17.31 \%$ & $19.84 \%$ \\
Interrow SOC $(\%, \log )$ & $0.831^{* * *}$ & $0.894^{* * *}$ & $0.777^{* * *}$ \\
& $(0.066)$ & $(0.017)$ & $(0.073)$ \\
Constant & -0.070 & 0.027 & $0.521^{* *}$ \\
& $(0.355)$ & $(0.257)$ & $(0.233)$ \\
\hline Controls & $\mathrm{A}$ & $\mathrm{A}$ & $\mathrm{B}$ \\
Observations & 105 & 128 & 59 \\
\hline
\end{tabular}

Coefficients from an OLS estimation displayed. Village-level clustered standard errors in parentheses. Dependent variable is the carbon content in the treatment location in logarithms. In column (1), the sample is restricted to the common support of the interrow soil carbon. In column (2), the value of outliers was replaced with the upper or lower adjacent value, respectively. Base category for the mulching indicator in columns (1) and (2) is the carbon content in the control group, which includes samples taken in the frond stack area and between oil palms. In column (3), we combine our data set with another data set in smallholder plantations in the same study region and compare carbon contents in the weeding circle with and without mulching. We only use plantation whose interrow carbon content lies in a similar interval. Base category in column (3) is carbon content in the weeding circle in absence of mulching.

Controls (A) include spending on fertilizer and herbicide, application of other manure, plot age, plot age squared, non-application of fertilizer and/or herbicide, the planting density, grazing animals, the steepness of the plots, a bordering river, previous land use on the plot and previous fire on plot.

Controls (B) include plot age, herbicide and fertilizer input in $\mathrm{kg}$ and liter (log), non-application of fertilizer and/or herbicide and previous fire on plot.

${ }^{*} p<0.1,{ }^{* *} p<0.05,{ }^{* * *} p<0.01$

deviation from the mean. ${ }^{29}$ One outlier is replaced for EFB mulching, and five for the frond stack area and the sampling location between the palms, respectively. The treatment effects and significance levels are of similar size as in Table 4.5 supporting the robustness of our results (Table 4.6, columns (1) and (2)).

Several studies have shown that spatial heterogeneity in soil characteristics, including SOC contents, exists within oil palm plantations (Carron et al., 2015; Guillaume et al., 2016; Khasanah et al., 2015). This is because the addition of

\footnotetext{
${ }^{29}$ Outlier identification is based on the distribution of the SOC difference between the interrow and the respective management location. To account for the fact that carbon contents differ between the three management locations, outliers are separately identified for the mulching, the frond stack and the sampling location between the palms. The upper adjacent value is defined as the value of the 75 th percentile plus $3 / 2$ of the difference between the 75 th and the 25 th percentiles. The lower adjacent value is defined as the 25 th percentile minus $3 / 2$ of the difference between the 75 th and the 25 th percentiles. We define outliers as the observations with SOC differences above or below these values.
} 
organic material, e.g. through root material and ground vegetation, and machinery impact differ spatially within plantations (Carron et al., 2016). Carbon contents in the weeding circle in absence of mulching have been reported to be 0.02 percentage points (Khasanah et al., 2015) to 0.4 percentage points (Guillaume et al., 2016) higher than carbon contents between oil palms. In the frond stack area, both 0.09 percentage point higher (Khasanah et al., 2015) and 0.03 percentage point lower (Carron et al., 2015) carbon contents in comparison to the weeding circle have been reported. Our estimated mulching-induced percentage increase in carbon contents implies a 0.72 percentage point increase if the owner of an average control plantation in the common support area started mulching. ${ }^{30}$ Since this is larger than potential pre-existing differences in carbon content between the weeding circle and the other two management locations, it is unlikely that different sampling locations drive our treatment effects. Nonetheless, we run a further robustness test in which we control for related potential confounding effects.

To investigate whether differences in the sampling location between adopters and non-adopters in our sample bias the results, we construct an external control group. For this purpose, we make use of soil samples collected in the weeding circle and the interrow in 37 smallholder plantations in our study region. These were taken in the same soil depth $(0-5 \mathrm{~cm})$ and analyzed in the same laboratory as our samples (Guillaume, 2013). The soil data set is complemented by a socio-economic survey assessing the management practices farmers implement on their plot. None of the farmers in the external control group apply EFB mulching such that the soil samples can be used as counterfactual for carbon contents in the weeding circle in absence of mulching. Moreover, if we include only plantations from the external control group where the interrow carbon contents lie in the same interval as our treatment plantations, plots do not differ significantly in variables possibly affecting carbon contents, with the exception of the share of plots that were previously affected by fire that is larger in the external control group (Table A4.9 in the Appendix). ${ }^{31}$ This supports the validity of the external control group.

Column (3) in Table 4.6 supports a positive and significant effect of mulching on SOC contents when our analysis is restricted to samples taken in the weeding circle. The effect is of similar size as in the other estimations (Tables 4.5 and 4.6). EFB mulching increases SOC contents by around $20 \%$ in comparison to the

\footnotetext{
${ }^{30}$ The mean carbon content in the combined control sample in the common support area is $4.03 \%$.

${ }^{31}$ While we are missing detailed information on plot characteristics in the external control group, we assume that a balance on the interrow carbon content also balances other plot characteristics.
} 
external control group. Accordingly, adoption of EFB mulching would imply an increase in SOC contents of 0.79 percentage points for the average farmer in the external control group.

Overall, the derived treatment effects suggest that mulching increases SOC contents by around 0.72 to 0.79 percentage points. This effect size lies in the range of the effect sizes found in other studies, which range from an increase in 0.52 (Tao et al., 2017), 0.57 (Teh Boon Sung et al., 2011) to an increase of 1.24 percentage points (Abu Bakar et al., 2011).

\section{Effect of carbon on yields}

Column (3) in Table 4.5 reports results from a 2SLS estimation of yields on mulching and SOC. This pathway analysis helps to explore to what extent the reduced form effect of mulching on yields operates through an improvement in carbon contents.

Comparing columns (1) and (3) in Table 4.5 indicates that the effect size of mulching is reduced when controlling for the carbon contents in the management sampling locations. The reduction corresponds to a decrease in the effect size of around 17 percentage points, but the effect size is still large, suggesting a yield increase of around $45 \%$. However, mulching no longer significantly affects yields. While we are thus not able to support a significant direct effect of mulching in the structural model, this needs to be interpreted against a rather small sample size and a general increase in standard errors when switching from OLS to 2SLS estimation. ${ }^{32}$ In line with our expectations, our results hint to an inverted U-shaped relationship between SOC content and yields. Yields might thus first increase, but at high SOC contents, which often indicate organic soils, yields decline. The effect of SOC contents on yields is however insignificant.

Our results thus suggest that most of the effect of mulching on yields operates through other channels but an increase in SOC contents. ${ }^{33}$ Even though the mulching indicator is no longer statistically significant after controlling for SOC contents, the coefficient is of comparable size. While carbon contents have been shown to be significantly linked to yields for several annual crops, they do not appear to be a relevant predictor of yields in our context. This suggests that none

\footnotetext{
${ }^{32}$ In the OLS estimation in Table A4.8 in the Appendix, the effect of mulching is still significant after controlling for carbon contents.

${ }^{33} \mathrm{We}$ acknowledge that the effect of SOC on yields might also reflect other soil characteristics correlated with SOC contents. However, we only collected additional information on nitrogen contents. Nitrogen and SOC are however very closely correlated (rho $=0.95$ ) such that an additional inclusion of nitrogen in the regression would lead to multicollinearity problems.
} 
of the identified mechanisms through which SOC can affect yields (section 4.2) directly limit yields. Reasons could be inter alia that most of our plantations have already reached a middle age such that a potential positive effect of SOC on e.g. root development is no longer of strong relevance. Moreover, it might be that yield responses to changes in SOC materialize with a time lag, as e.g. yield responses to shocks (Woittiez et al., 2017), such that they are not captured in the contemporaneous relationship between carbon contents and yields.

\subsection{Conclusion}

Evidence from 129 smallholder plantations in Sumatra, Indonesia, shows that empty fruit bunch (EFB) mulching leads to higher soil carbon contents as well as yield increases. The minimum estimated increase in carbon content is $16 \%$, while yields are found to increase at least by $36 \%$ on average. While the estimated increases in SOC contents are similar to studies derived from industrial plantations, we find larger yield increases for EFB mulching. One of the reasons could be that smallholder plantations have greater scope for yield improvements since yield gaps are prevalent and insufficient nutrient supply could be identified as one reason (Euler et al., 2016). However, the carbon contents do not appear to be a significant predictor of yields. This suggests that the positive and significant effect of mulching on yields rather operates through other channels, e.g. direct fertilization effects or higher soil moisture as the soil is protected from direct solar irradiation.

One limiting factor of our study is that we cannot control for other soil characteristics potentially affecting yields that are correlated with SOC and could limit crop growth. Furthermore, even though our sample size is large in comparison to other studies looking at mulching or general soil characteristics in oil palm plantations (e.g. Guillaume et al. 2016; Moradi et al. 2015; Tao et al. 2017) the statistical power of our study might not be sufficient to identify significant effects of SOC on yields, in particular in view of large heterogeneity among smallholder farmers.

We complement knowledge on the effects of EFB mulching derived from largescale plantations and mostly under experimental settings with evidence from smallholder plantations. While smallholder farmers are increasingly engaged in oil palm production in Indonesia, their yields still lie well below yields reported for industrial plantations (Euler et al., 2016). Our results indicate that EFB mulching represents a management option which can help to close the reported 
yield gaps. This could hence improve the economic performance of oil palm plantations, potentially generating positive welfare effects for smallholder farmers. Moreover, mulching increases SOC contents. While we do not estimate carbon stocks, it is likely that this also supports the carbon sequestration function of the soil. Since oil palm expansion is associated with net carbon emissions (Guillaume et al., 2018), an appropriate soil management might thus be able to improve the carbon balance and consequently also the environmental performance of oil palm plantations. The focus on soils for carbon sequestration as climate mitigation strategy has also recently been highlighted by the 4 per mille Soils for Food Security and Climate initiative that was launched at the Paris Climate Conference in 2015 (Minasny et al., 2017). However, to be of climate relevance, mulching might need to cover larger areas of the plantations and should not be restricted to the weeding circle, as in the case of most smallholdings considered in this analysis. Moreover, a full assessment of the environmental performance also needs to include the emissions generated by transporting the FFB to, and the EFB from the mills back to the plantations, as well as the carbon released in the decomposition process.

While we can support yield enhancing effects, a more informed analysis of potential welfare effects of mulching should focus on profits generated for smallholder farmers. Our estimated effect size of mulching suggests yield increases of around 7 tons per hectare and year for the average non-adopter. Valued at the average price for FFB received, this corresponds to revenues of around 9.84 million IDR. The average amount of EFB applied in the sample as valued by the average regional price of around 59,000 IDR per ton implies per hectare costs of mulching of around 3.18 million IDR. Even though these rough estimates neglect e.g. labor costs, the rather huge difference between estimated revenues and costs could hint to great income increasing potentials. However, several farmers have indicated that mulching material is expensive. This might hold in particular for remote villages that are further away from the mills and where transportation costs might be high. While mulching thus represents a promising approach to close smallholder yield gaps, poor farmers, who often additionally lack access to credit markets, are likely to be excluded from its use. Furthermore, the amount of EFB provided from the mills might not suffice to satisfy the demand in the region where smallholder farmers likely compete with industrial plantations. This could thus entail distributional conflicts between industrial plantations, rich and poor smallholder farmers.

Other mulching options could be explored in order to restore SOC and increase yields. One possibility consists in the pruned oil palm fronds which are already 
available in the plantations. While being rich in nutrients, frond stacks' decomposition processes are slower due to their high $\mathrm{C} / \mathrm{N}$ ratio (Moradi et al., 2014). One way to fasten the decomposition rate and increase the amount of carbon and most nutrients released after 12 months would be by shredding or pulverizing the fronds (Teh, 2016). This is however rarely done due to e.g. a lack of machinery (Teh, 2016). Collective action at the village or farmers' group level, or external provision of such machinery at the aggregate level could potentially represent another option in order to increase both the carbon sequestration function of the soil and yields. This could offer opportunities for win-win situations where both income and environmental improvements are feasible. 


\section{A Appendix}

Table A4.1: Effect of mulching on yields (2015-16 data)

\begin{tabular}{|c|c|c|c|c|}
\hline & $(1)$ & $(2)$ & $(3)$ & $(4)$ \\
\hline Current and/or lagged mulching $=1$ & $\begin{array}{l}0.429^{* * *} \\
(0.118)\end{array}$ & $\begin{array}{l}0.403^{* *} \\
(0.163)\end{array}$ & $\begin{array}{c}0.367^{* * *} \\
(0.118)\end{array}$ & $\begin{array}{l}0.313^{* *} \\
(0.155)\end{array}$ \\
\hline Plot size in ha $(\log )$ & $\begin{array}{c}0.732^{* * *} \\
(0.078)\end{array}$ & $\begin{array}{c}0.703^{* * *} \\
(0.091)\end{array}$ & $\begin{array}{c}0.800^{* * *} \\
(0.051)\end{array}$ & $\begin{array}{c}0.776^{* * *} \\
(0.053)\end{array}$ \\
\hline $\begin{array}{l}\text { Spending on fertilizer } \\
\text { in } 1,000 \text { IDR }(\log )\end{array}$ & $\begin{array}{l}0.029^{* *} \\
(0.013)\end{array}$ & $\begin{array}{c}0.035^{* * *} \\
(0.012)\end{array}$ & $\begin{array}{c}0.035^{* * *} \\
(0.014)\end{array}$ & $\begin{array}{c}0.040^{* * *} \\
(0.011)\end{array}$ \\
\hline $\begin{array}{l}\text { Spending on herbicide } \\
\text { in } 1,000 \text { IDR }(\log )\end{array}$ & $\begin{array}{c}0.023 \\
(0.023)\end{array}$ & $\begin{array}{c}0.034 \\
(0.025)\end{array}$ & $\begin{array}{c}0.026 \\
(0.019)\end{array}$ & $\begin{array}{l}0.033^{*} \\
(0.020)\end{array}$ \\
\hline No input application $=1$ & $\begin{array}{c}0.144 \\
(0.141)\end{array}$ & $\begin{array}{c}0.205 \\
(0.157)\end{array}$ & $\begin{array}{c}0.177 \\
(0.136)\end{array}$ & $\begin{array}{c}0.225 \\
(0.138)\end{array}$ \\
\hline Other manure applied $=1$ & $\begin{array}{c}0.042 \\
(0.109)\end{array}$ & $\begin{array}{c}0.102 \\
(0.117)\end{array}$ & $\begin{array}{c}0.110 \\
(0.089)\end{array}$ & $\begin{array}{c}0.166^{*} \\
(0.093)\end{array}$ \\
\hline $\begin{array}{l}\text { Labor costs (paid) in } \\
1,000 \text { IDR (log) }\end{array}$ & $\begin{array}{c}0.166^{* * *} \\
(0.052)\end{array}$ & $\begin{array}{c}0.177^{* * *} \\
(0.049)\end{array}$ & & \\
\hline Only family labor $=1$ & $\begin{array}{l}0.988^{* * *} \\
(0.341)\end{array}$ & $\begin{array}{l}1.058^{* * *} \\
(0.314)\end{array}$ & & \\
\hline Grazing animals $=1$ & $\begin{array}{l}-0.119^{*} \\
(0.070)\end{array}$ & $\begin{array}{c}-0.160^{* * *} \\
(0.061)\end{array}$ & $\begin{array}{l}-0.118 \\
(0.080)\end{array}$ & $\begin{array}{c}-0.163^{* *} \\
(0.072)\end{array}$ \\
\hline Plot age & $\begin{array}{l}0.066^{* *} \\
(0.032)\end{array}$ & $\begin{array}{c}0.071^{*} \\
(0.036)\end{array}$ & $\begin{array}{l}0.069^{* *} \\
(0.028)\end{array}$ & $\begin{array}{l}0.077^{* *} \\
(0.032)\end{array}$ \\
\hline Plot age squared & $\begin{array}{r}-0.002^{*} \\
(0.001)\end{array}$ & $\begin{array}{r}-0.002^{*} \\
(0.001)\end{array}$ & $\begin{array}{c}-0.002^{* *} \\
(0.001)\end{array}$ & $\begin{array}{c}-0.002^{* *} \\
(0.001)\end{array}$ \\
\hline Planting density & $\begin{array}{c}0.004^{* * *} \\
(0.002)\end{array}$ & $\begin{array}{l}0.004^{* *} \\
(0.002)\end{array}$ & $\begin{array}{l}0.004^{* *} \\
(0.002)\end{array}$ & $\begin{array}{l}0.005^{* *} \\
(0.002)\end{array}$ \\
\hline Local village $=1$ & $\begin{array}{c}-0.161^{* *} \\
(0.069)\end{array}$ & $\begin{array}{c}-0.177^{* * *} \\
(0.066)\end{array}$ & $\begin{array}{c}-0.182^{* * *} \\
(0.071)\end{array}$ & $\begin{array}{c}-0.203^{* * *} \\
(0.068)\end{array}$ \\
\hline Wave $=16$ & $\begin{array}{c}-0.194^{* * *} \\
(0.049)\end{array}$ & $\begin{array}{c}-0.192^{* * *} \\
(0.050)\end{array}$ & $\begin{array}{c}-0.185^{* * *} \\
(0.049)\end{array}$ & $\begin{array}{c}-0.187^{* * *} \\
(0.051)\end{array}$ \\
\hline $\begin{array}{l}\text { Labor costs (paid and valued family } \\
\text { labor) in 1,000 IDR (log) }\end{array}$ & & & $\begin{array}{l}0.081^{* *} \\
(0.041)\end{array}$ & $\begin{array}{l}0.102^{* *} \\
(0.046)\end{array}$ \\
\hline Constant & $\begin{array}{c}0.635 \\
(0.539) \\
\end{array}$ & $\begin{array}{c}0.458 \\
(0.542) \\
\end{array}$ & $\begin{array}{c}0.962^{* * *} \\
(0.356)\end{array}$ & $\begin{array}{c}0.671^{*} \\
(0.383) \\
\end{array}$ \\
\hline Population weights & No & Yes & No & Yes \\
\hline Observations & 249 & 249 & 249 & 249 \\
\hline
\end{tabular}


Coefficients from a two-stage linear random effects model displayed in columns (1) and (3), and from a pooled 2SLS with population weights in columns (2) and (4). Village-level clustered standard errors displayed in parentheses. The outcome variable is harvest in tons of FFB (log). We use the number of palm oil mills found in a radius of $20 \mathrm{~km}$ around the village as the instrument for the mulching decision. All price variables are inflation adjusted. Due to the high collinearity between costs for fertilizer and herbicide application, and the respective labor costs, the labor costs only capture spending on harvesting and maintenance (weeding and pruning) done to the oil palms. In Indonesia, labor use is often paid as a lump sum transfer. Therefore, labor is expressed in monetary terms. In columns (1) and (2), we only include paid labor. In columns (3) and (4), family labor is included and valued with the mean price for labor. The restricted sample size does not allow to derive task or regionally disaggregated labor costs. Wages do not appear to substantially differ between tasks or regions. As with fertilizer and herbicide application, labor inputs were analyzed for outliers (Table A4.3 for more information).

${ }^{*} p<0.1,{ }^{* *} p<0.05,{ }^{* * *} p<0.01$ 
Table A4.2: Robustness checks for reduced form results of mulching on yields

\begin{tabular}{|c|c|c|c|c|}
\hline & (1) & (2) & (3) & (4) \\
\hline Current and/or lagged & $0.429^{* *}$ & $0.370^{*}$ & $0.473^{* * *}$ & $0.385^{*}$ \\
\hline mulching $=1$ & $(0.181)$ & $(0.210)$ & $(0.171)$ & $(0.205)$ \\
\hline \multirow[t]{2}{*}{ Plot size in ha $(\log )$} & $0.857^{* * *}$ & $0.835^{* * *}$ & $0.903^{* * *}$ & $0.902^{* * *}$ \\
\hline & $(0.056)$ & $(0.052)$ & $(0.049)$ & $(0.047)$ \\
\hline Spending on fertilizer & $0.030^{* * *}$ & $0.041^{* * *}$ & & \\
\hline in 1,000 IDR (log) & $(0.010)$ & $(0.010)$ & & \\
\hline Spending on herbicide & -0.006 & 0.014 & & \\
\hline in 1,000 IDR (log) & $(0.014)$ & $(0.018)$ & & \\
\hline \multirow[t]{2}{*}{ No input application $=1$} & -0.009 & 0.095 & & \\
\hline & $(0.084)$ & $(0.114)$ & & \\
\hline \multirow[t]{2}{*}{ Other manure applied $=1$} & 0.085 & $0.189^{* *}$ & & \\
\hline & $(0.077)$ & $(0.080)$ & & \\
\hline \multirow[t]{2}{*}{ Harvest frequency $(\log )$} & $0.490^{* *}$ & $0.411^{* *}$ & & \\
\hline & $(0.198)$ & $(0.203)$ & & \\
\hline \multirow[t]{2}{*}{ Pruning $=1$} & -0.019 & 0.034 & & \\
\hline & $(0.053)$ & $(0.059)$ & & \\
\hline \multirow[t]{2}{*}{ Grazing animals $=1$} & $-0.103^{*}$ & $-0.131^{* * *}$ & $-0.096^{*}$ & $-0.118^{* *}$ \\
\hline & $(0.053)$ & $(0.048)$ & $(0.057)$ & $(0.053)$ \\
\hline \multirow[t]{2}{*}{ Plot age } & $0.081^{* * *}$ & $0.085^{* * *}$ & $0.093^{* * *}$ & $0.092^{* * *}$ \\
\hline & $(0.027)$ & $(0.033)$ & $(0.027)$ & $(0.034)$ \\
\hline \multirow[t]{2}{*}{ Plot age squared } & $-0.002^{* * *}$ & $-0.002^{* *}$ & $-0.003^{* * *}$ & $-0.003^{* * *}$ \\
\hline & $(0.001)$ & $(0.001)$ & $(0.001)$ & $(0.001)$ \\
\hline \multirow[t]{2}{*}{ Planting density } & $0.002^{* *}$ & $0.002^{*}$ & $0.003^{* *}$ & $0.003^{* *}$ \\
\hline & $(0.001)$ & $(0.001)$ & $(0.001)$ & $(0.002)$ \\
\hline \multirow[t]{2}{*}{ Wave $=16$} & $-0.183^{* * *}$ & $-0.189^{* * *}$ & $-0.205^{* * *}$ & $-0.205^{* * *}$ \\
\hline & $(0.047)$ & $(0.045)$ & $(0.049)$ & $(0.048)$ \\
\hline \multirow[t]{2}{*}{ Wave $=17$} & $-0.535^{* * *}$ & $-0.471^{* * *}$ & $-0.239^{* * *}$ & $-0.224^{* * *}$ \\
\hline & $(0.158)$ & $(0.166)$ & $(0.042)$ & $(0.047)$ \\
\hline \multirow[t]{2}{*}{ Local village $=1$} & -0.072 & -0.106 & -0.130 & $-0.170^{* *}$ \\
\hline & $(0.071)$ & $(0.066)$ & $(0.080)$ & $(0.076)$ \\
\hline \multirow[t]{2}{*}{ Individual migration $=1$} & 0.045 & 0.034 & 0.034 & 0.033 \\
\hline & $(0.057)$ & $(0.058)$ & $(0.063)$ & $(0.071)$ \\
\hline Price received for one & 0.127 & 0.077 & 0.098 & 0.087 \\
\hline kg of FFB (log) & $(0.157)$ & $(0.194)$ & $(0.156)$ & $(0.193)$ \\
\hline Distance to closest palm & 0.003 & 0.002 & 0.008 & 0.006 \\
\hline oil mill (km) & $(0.009)$ & $(0.008)$ & $(0.008)$ & $(0.007)$ \\
\hline Industrial oil palm & 0.051 & 0.078 & -0.002 & 0.022 \\
\hline plantation bordering $=1$ & $(0.103)$ & $(0.109)$ & $(0.088)$ & $(0.099)$ \\
\hline \multirow[t]{2}{*}{ Constant } & 0.214 & 0.174 & $1.175^{* * *}$ & $1.164^{* * *}$ \\
\hline & $(0.479)$ & $(0.522)$ & $(0.314)$ & $(0.351)$ \\
\hline
\end{tabular}




\begin{tabular}{lcccc}
\hline Population weights & No & Yes & No & Yes \\
Observations & 377 & 377 & 377 & 377 \\
\hline
\end{tabular}

Coefficients from a 2SLS RE effects model displayed in columns (1) and (3). Coefficients from a pooled 2SLS model displayed in columns (2) and (4). Our instrument is the number of palm oil mills found in a radius of $20 \mathrm{~km}$ around the village. Village-level clustered standard errors in parentheses. Management decisions are excluded from columns (3) and (4) since these might be potentially endogenous. Only fertilizer use and pruning are significantly correlated with the number of palm oil mills found in a radius of $20 \mathrm{~km}$. The respective correlation coefficients are, with p-values in parentheses, for herbicide application -0.04 (0.943), fertilizer -0.12 (0.01), pruning $-0.12(0.021)$, other manure -0.01 (0.922), and harvest frequency $-0.01(0.825)$.

${ }^{*} p<0.1,{ }^{* *} p<0.05,{ }^{* * *} p<0.01$ 
Table A4.3: Explanation of selected variables

\begin{tabular}{|c|c|}
\hline Variables & Explanation \\
\hline Values of assets & $\begin{array}{l}\text { Indicator represents the sum of the values of televisions, motorbikes, cars, } \\
\text { fridges, washing machines and cell-phones the farmer's household owned } \\
\text { in } 2016 \text {. Values were transformed into USD using the } 2016 \text { official } \\
\text { exchange rate from the World Bank. }\end{array}$ \\
\hline $\begin{array}{l}\text { Extension } \\
\text { received }\end{array}$ & $\begin{array}{l}=1 \text { if the farmer received extension on oil palm management or soil } \\
\text { conservation between } 2015 \text { and } 2017 \text {. }\end{array}$ \\
\hline $\begin{array}{l}\text { Transmigrant } \\
\text { farmer }\end{array}$ & $=1$ if household moved to village within the transmigration program. \\
\hline $\begin{array}{l}\text { Regular flooding } \\
\text { on plot }\end{array}$ & $=1$ if farmer reports regular flooding on plot. \\
\hline Steepness of plot & $\begin{array}{l}\text { Measured on a } 1-6 \text { scale where the different values indicate } \\
0^{\circ} / 10^{\circ} / 20^{\circ} / 30^{\circ} / 45^{\circ} \text { and more than } 45^{\circ} \text { slope. }\end{array}$ \\
\hline $\begin{array}{l}\text { Difficult road } \\
\text { conditions }\end{array}$ & $\begin{array}{l}\text { Assistants rated access to plot as either difficult }(=1) \text { or not }(=0) \text { in } \\
\text { rainy season. }\end{array}$ \\
\hline Organic soil & $=1$ if a plot has at least $20 \%$ SOC in interrow. \\
\hline $\begin{array}{l}\text { Fertilizer } \\
\text { spending }\end{array}$ & $\begin{array}{l}\text { Spending on fertilizer in } 1,000 \text { IDR. Spending is inflation corrected in } \\
\text { each year. Information on national consumer price indices taken from the } \\
\text { World Bank where } 2010 \text { represents the reference year. Outlier detection } \\
\text { is based on the per hectare values of the strictly positive observations } \\
\text { and uses the box plot method developed by Tukey (1977). In case the } \\
\text { distribution is highly skewed though, too many variables might be } \\
\text { classified as outliers (Hubert \& Vandervieren, 2008). Therefore, we } \\
\text { compare the observations classified as outliers based on Tukey's method } \\
\text { to the } 95 \text { percentile of the distribution. In case Tukey's method classifies } \\
\text { more observations as outliers, we winsorize the distribution at the } 95 \\
\text { percentile. In case less observations are classified as outliers by Tukey's } \\
\text { method, only these observations are replaced with the } 95 \text { percentile. } \\
\text { Fertilizer spending was halved for } 2015 \text { and } 2016 \text {. }\end{array}$ \\
\hline $\begin{array}{l}\text { Herbicide } \\
\text { spending }\end{array}$ & $\begin{array}{l}\text { Spending on herbicide in } 1,000 \text { IDR. Spending is inflation corrected in } \\
\text { each year. Information on national consumer price indexes taken from } \\
\text { the World Bank where } 2010 \text { represents the reference year. Outlier } \\
\text { detection was done as for fertilizer spending. Herbicide spending was } \\
\text { halved for } 2015 \text { and } 2016 \text {. }\end{array}$ \\
\hline Harvest frequency & How often a farmer harvested the plot on average in six months. \\
\hline Planting density & Number of oil palms per hectare. \\
\hline
\end{tabular}


Table A4.4: First stage results (instrument strategy)

\begin{tabular}{|c|c|}
\hline & $\begin{array}{c}(1) \\
\text { Mulching }\end{array}$ \\
\hline Plot size in ha $(\log )$ & $\begin{array}{l}-0.064 \\
(0.053)\end{array}$ \\
\hline Spending on fertilizer in 1,000 IDR $(\log )$ & $\begin{array}{c}0.019^{*} \\
(0.010)\end{array}$ \\
\hline Spending on herbicide in 1,000 IDR $(\log )$ & $\begin{array}{c}0.014 \\
(0.016)\end{array}$ \\
\hline No input application $=1$ & $\begin{array}{c}0.148 \\
(0.092)\end{array}$ \\
\hline Other manure applied $=1$ & $\begin{array}{c}0.134 \\
(0.094)\end{array}$ \\
\hline Pruning $=1$ & $\begin{array}{c}0.031 \\
(0.035)\end{array}$ \\
\hline Harvest frequency $(\log )$ & $\begin{array}{c}0.211 \\
(0.153)\end{array}$ \\
\hline Plot age & $\begin{array}{c}-0.050^{* *} \\
(0.021)\end{array}$ \\
\hline Plot age squared & $\begin{array}{l}0.001^{* *} \\
(0.001)\end{array}$ \\
\hline Planting density & $\begin{array}{c}0.000 \\
(0.001)\end{array}$ \\
\hline Grazing animals $=1$ & $\begin{array}{c}0.098^{*} \\
(0.048)\end{array}$ \\
\hline Wave $=16$ & $\begin{array}{l}0.131^{* * *} \\
(0.028)\end{array}$ \\
\hline Wave $=17$ & $\begin{array}{l}-0.058 \\
(0.107)\end{array}$ \\
\hline Local village $=1$ & $\begin{array}{l}-0.103 \\
(0.092)\end{array}$ \\
\hline $\begin{array}{l}\text { Number of mills in a } \\
\text { radius of } 20 \mathrm{~km}\end{array}$ & $\begin{array}{c}0.086^{* * *} \\
(0.014)\end{array}$ \\
\hline Constant & $\begin{array}{l}-0.405 \\
(0.375)\end{array}$ \\
\hline Observations & 378 \\
\hline
\end{tabular}


Table A4.5: Effect of mulching on yields

\begin{tabular}{|c|c|c|c|}
\hline & (1) & $(2)$ & (3) \\
\hline Current and/or lagged mulching $=1$ & $\begin{array}{c}0.212^{* * *} \\
(0.056)\end{array}$ & & \\
\hline Spending on fertilizer in 1,000 IDR (log) & $\begin{array}{c}0.032^{* * *} \\
(0.009)\end{array}$ & $\begin{array}{c}0.022 \\
(0.013)\end{array}$ & $\begin{array}{l}0.022^{*} \\
(0.013)\end{array}$ \\
\hline Spending on herbicide in 1,000 IDR $(\log )$ & $\begin{array}{l}-0.003 \\
(0.013)\end{array}$ & $\begin{array}{l}-0.015 \\
(0.015)\end{array}$ & $\begin{array}{l}-0.014 \\
(0.014)\end{array}$ \\
\hline Plot age & $\begin{array}{c}0.070^{* * *} \\
(0.026)\end{array}$ & $\begin{array}{c}0.088^{* * *} \\
(0.029)\end{array}$ & $\begin{array}{c}0.087^{* * *} \\
(0.029)\end{array}$ \\
\hline Plot age squared & $\begin{array}{c}-0.002^{* * *} \\
(0.001)\end{array}$ & $\begin{array}{c}-0.002^{* * *} \\
(0.001)\end{array}$ & $\begin{array}{c}-0.002^{* * *} \\
(0.001)\end{array}$ \\
\hline No input application $=1$ & $\begin{array}{c}0.021 \\
(0.079)\end{array}$ & $\begin{array}{l}-0.079 \\
(0.099)\end{array}$ & $\begin{array}{l}-0.076 \\
(0.096)\end{array}$ \\
\hline Harvest frequency $(\log )$ & $\begin{array}{c}0.525^{* * *} \\
(0.173)\end{array}$ & $\begin{array}{l}0.419^{*} \\
(0.247)\end{array}$ & $\begin{array}{l}0.418^{*} \\
(0.237)\end{array}$ \\
\hline Planting density & $\begin{array}{l}0.003^{* *} \\
(0.001)\end{array}$ & $\begin{array}{c}0.002 \\
(0.002)\end{array}$ & $\begin{array}{c}0.002 \\
(0.002)\end{array}$ \\
\hline Grazing animals $=1$ & $\begin{array}{l}-0.103^{*} \\
(0.054)\end{array}$ & $\begin{array}{c}-0.130^{* *} \\
(0.054)\end{array}$ & $\begin{array}{c}-0.130^{* *} \\
(0.051)\end{array}$ \\
\hline Plot size in ha $(\log )$ & $\begin{array}{c}0.865^{* * *} \\
(0.052)\end{array}$ & $\begin{array}{c}0.898^{* * *} \\
(0.061)\end{array}$ & $\begin{array}{c}0.897^{* * *} \\
(0.058)\end{array}$ \\
\hline Pruning $=1$ & $\begin{array}{l}-0.020 \\
(0.054)\end{array}$ & $\begin{array}{c}0.048 \\
(0.049)\end{array}$ & $\begin{array}{c}0.049 \\
(0.048)\end{array}$ \\
\hline Other manure applied $=1$ & $\begin{array}{c}0.110^{*} \\
(0.062)\end{array}$ & $\begin{array}{c}0.090 \\
(0.096)\end{array}$ & $\begin{array}{c}0.091 \\
(0.092)\end{array}$ \\
\hline Local village $=1$ & $\begin{array}{l}-0.109 \\
(0.073)\end{array}$ & $\begin{array}{l}-0.149 \\
(0.094)\end{array}$ & $\begin{array}{l}-0.148 \\
(0.091)\end{array}$ \\
\hline Wave $=16$ & $\begin{array}{c}-0.169^{* * *} \\
(0.041)\end{array}$ & & \\
\hline Wave $=17$ & $\begin{array}{c}-0.538^{* * *} \\
(0.144)\end{array}$ & $\begin{array}{l}-0.299^{*} \\
(0.171)\end{array}$ & $\begin{array}{c}-0.297^{*} \\
(0.161)\end{array}$ \\
\hline Mulching $=1$ & & $\begin{array}{l}0.132^{* *} \\
(0.062)\end{array}$ & \\
\hline Lagged mulching $=1$ & & $\begin{array}{c}0.206^{* * *} \\
(0.062)\end{array}$ & \\
\hline Only lagged mulching $=1$ & & & $\begin{array}{l}0.210^{* *} \\
(0.090)\end{array}$ \\
\hline Only current mulching $=1$ & & & $\begin{array}{c}0.135 \\
(0.105)\end{array}$ \\
\hline Lagged and current mulching $=1$ & & & $\begin{array}{c}0.339^{* * *} \\
(0.084)\end{array}$ \\
\hline
\end{tabular}




\begin{tabular}{lccc} 
Constant & 0.341 & 0.452 & 0.449 \\
& $(0.441)$ & $(0.545)$ & $(0.528)$ \\
\hline Observations & 377 & 257 & 257 \\
\hline Coefficients from a linear random effects model displayed. Village-level clustered standard errors \\
in parentheses. The outcome variable is tons of FFB harvested in six months (log). Fertilizer \\
and herbicide costs are inflation adjusted. Harvest and input information are halved to represent \\
six-month information for 2015 and 2016. \\
${ }^{*} p<0.1,{ }^{* *} p<0.05,{ }^{* * *} p<0.01$
\end{tabular}


Table A4.6: Pathway analysis of the effect of mulching on yields

\begin{tabular}{|c|c|c|c|}
\hline & $\begin{array}{c}(1) \\
\text { FFB } \\
\text { harvested in } \\
\text { tons }(\log ) \\
\end{array}$ & $\begin{array}{c}(2) \\
\operatorname{SOC}(\%, \log )\end{array}$ & $\begin{array}{c}(3) \\
\text { FFB } \\
\text { harvested in } \\
\text { tons (log) }\end{array}$ \\
\hline Mulching $=1$ & $\begin{array}{l}0.505^{* *} \\
(0.233)\end{array}$ & $\begin{array}{l}0.166^{* * *} \\
(0.056)\end{array}$ & $\begin{array}{c}0.428 \\
(0.343)\end{array}$ \\
\hline Plot size in ha $(\log )$ & $\begin{array}{c}0.828^{* * *} \\
(0.061)\end{array}$ & $\begin{array}{c}-0.055^{* *} \\
(0.026)\end{array}$ & $\begin{array}{c}0.824^{* * *} \\
(0.089)\end{array}$ \\
\hline Spending on fertilizer in 1,000 IDR $(\log )$ & $\begin{array}{l}0.038^{* *} \\
(0.017)\end{array}$ & $\begin{array}{c}0.010 \\
(0.008)\end{array}$ & $\begin{array}{l}0.037^{*} \\
(0.020)\end{array}$ \\
\hline Spending on herbicide in 1,000 IDR $(\log )$ & $\begin{array}{l}-0.008 \\
(0.018)\end{array}$ & $\begin{array}{l}-0.004 \\
(0.014)\end{array}$ & $\begin{array}{l}-0.004 \\
(0.016)\end{array}$ \\
\hline No input application $=1$ & $\begin{array}{l}-0.050 \\
(0.136)\end{array}$ & $\begin{array}{c}0.038 \\
(0.097)\end{array}$ & $\begin{array}{l}-0.037 \\
(0.134)\end{array}$ \\
\hline Harvest frequency $(\log )$ & $\begin{array}{c}0.353 \\
(0.225)\end{array}$ & $\begin{array}{l}-0.075 \\
(0.089)\end{array}$ & $\begin{array}{c}0.374 \\
(0.259)\end{array}$ \\
\hline Grazing animals $=1$ & $\begin{array}{c}-0.140^{* *} \\
(0.064)\end{array}$ & $\begin{array}{c}0.013 \\
(0.035)\end{array}$ & $\begin{array}{c}-0.148^{* *} \\
(0.059)\end{array}$ \\
\hline Pruning $=1$ & $\begin{array}{l}-0.040 \\
(0.094)\end{array}$ & $\begin{array}{l}-0.096 \\
(0.061)\end{array}$ & $\begin{array}{l}-0.023 \\
(0.111)\end{array}$ \\
\hline Other manure applied $=1$ & $\begin{array}{c}0.133 \\
(0.125)\end{array}$ & $\begin{array}{l}-0.019 \\
(0.085)\end{array}$ & $\begin{array}{c}0.130 \\
(0.117)\end{array}$ \\
\hline Plot age & $\begin{array}{c}0.084^{* * *} \\
(0.027)\end{array}$ & $\begin{array}{c}0.005 \\
(0.008)\end{array}$ & $\begin{array}{c}0.082^{* * *} \\
(0.032)\end{array}$ \\
\hline Plot age squared & $\begin{array}{c}-0.002^{* * *} \\
(0.001)\end{array}$ & $\begin{array}{c}0.000 \\
(0.000)\end{array}$ & $\begin{array}{c}-0.002^{* * *} \\
(0.001)\end{array}$ \\
\hline Planting density & $\begin{array}{l}-0.001 \\
(0.002)\end{array}$ & $\begin{array}{l}0.002^{*} \\
(0.001)\end{array}$ & $\begin{array}{l}-0.001 \\
(0.002)\end{array}$ \\
\hline Local village $=1$ & $\begin{array}{c}0.042 \\
(0.095)\end{array}$ & & $\begin{array}{c}0.015 \\
(0.136)\end{array}$ \\
\hline Interrow SOC $(\%, \log )$ & & $\begin{array}{c}0.893^{* * *} \\
(0.017)\end{array}$ & \\
\hline $\operatorname{SOC}(\%, \log )$ & & & $\begin{array}{c}0.119 \\
(0.560)\end{array}$ \\
\hline SOC $(\%, \log )$ squared & & & $\begin{array}{l}-0.035 \\
(0.129)\end{array}$ \\
\hline Constant & $\begin{array}{c}0.599 \\
(0.673)\end{array}$ & $\begin{array}{c}0.278 \\
(0.247)\end{array}$ & $\begin{array}{c}0.480 \\
(1.007)\end{array}$ \\
\hline Observations & 128 & 128 & 128 \\
\hline
\end{tabular}


Village-level clustered standard errors in parentheses. Coefficients from a 2SLS regression shown in columns (1) and (3). Coefficients from an OLS estimation in column (2). The base category for column (2) is the carbon content in the combined sample of the frond stack area and between the oil palms.

${ }^{*} p<0.1,{ }^{* *} p<0.05,{ }^{* * *} p<0.01$ 
Table A4.7: First stage regression results (pathway analysis)

\begin{tabular}{|c|c|c|c|}
\hline & $\begin{array}{c}\text { (1) } \\
\text { Mulching }\end{array}$ & $\begin{array}{c}(2) \\
\operatorname{SOC}(\%, \log )\end{array}$ & $\begin{array}{c}(3) \\
\text { SOC }(\%, \log ) \\
\text { squared }\end{array}$ \\
\hline Number of oil mills in & $0.053^{* * *}$ & -0.005 & -0.046 \\
\hline a radius of $20 \mathrm{~km}$ & $(0.016)$ & $(0.022)$ & $(0.107)$ \\
\hline Mean interrow SOC in village, & 0.125 & $0.863^{* *}$ & 2.289 \\
\hline other farmers $(\log )$ & $(0.225)$ & $(0.343)$ & $(1.700)$ \\
\hline Mean interrow SOC in village, & -0.046 & -0.026 & 0.254 \\
\hline other farmers $(\log )$ squared & $(0.053)$ & $(0.091)$ & $(0.458)$ \\
\hline \multirow[t]{2}{*}{ Plot size in ha (log) } & -0.067 & $0.132^{* *}$ & $0.380^{*}$ \\
\hline & $(0.071)$ & $(0.059)$ & $(0.225)$ \\
\hline Spending on fertilizer & 0.005 & 0.011 & -0.012 \\
\hline in 1,000 IDR $(\log )$ & $(0.013)$ & $(0.020)$ & $(0.079)$ \\
\hline Spending on herbicide & 0.029 & 0.011 & 0.019 \\
\hline in 1,000 IDR $(\log )$ & $(0.027)$ & $(0.031)$ & $(0.133)$ \\
\hline \multirow[t]{2}{*}{ Plot age } & -0.046 & -0.030 & -0.047 \\
\hline & $(0.031)$ & $(0.031)$ & $(0.156)$ \\
\hline \multirow[t]{2}{*}{ Plot age squared } & 0.001 & 0.001 & 0.003 \\
\hline & $(0.001)$ & $(0.001)$ & $(0.005)$ \\
\hline \multirow[t]{2}{*}{ No input application $=1$} & 0.160 & 0.081 & 0.063 \\
\hline & $(0.167)$ & $(0.193)$ & $(0.854)$ \\
\hline \multirow[t]{2}{*}{ Harvest frequency (log) } & 0.045 & 0.412 & 1.989 \\
\hline & $(0.236)$ & $(0.285)$ & $(1.435)$ \\
\hline \multirow[t]{2}{*}{ Planting density } & 0.002 & -0.001 & -0.009 \\
\hline & $(0.001)$ & $(0.003)$ & $(0.012)$ \\
\hline \multirow[t]{2}{*}{ Grazing animals $=1$} & $0.146^{*}$ & -0.003 & -0.245 \\
\hline & $(0.084)$ & $(0.127)$ & $(0.629)$ \\
\hline \multirow[t]{2}{*}{ Pruning $=1$} & 0.095 & 0.062 & 0.499 \\
\hline & $(0.070)$ & $(0.107)$ & $(0.426)$ \\
\hline \multirow[t]{2}{*}{ Other manure applied $=1$} & 0.122 & $-0.385^{*}$ & $-1.760^{*}$ \\
\hline & $(0.193)$ & $(0.196)$ & $(0.926)$ \\
\hline \multirow[t]{2}{*}{ Local village $=1$} & $-0.217^{* * *}$ & -0.143 & -0.862 \\
\hline & $(0.081)$ & $(0.109)$ & $(0.553)$ \\
\hline \multirow[t]{2}{*}{ Constant } & -0.174 & -0.523 & -4.842 \\
\hline & $(0.738)$ & $(1.086)$ & $(5.424)$ \\
\hline F-test & 7.69 & 204.03 & 148.40 \\
\hline Observations & 128 & 128 & 128 \\
\hline
\end{tabular}

Coefficients from first stage linear OLS regressions displayed. Village-level clustered standard errors in parentheses.

${ }^{*} p<0.1,{ }^{* *} p<0.05,{ }^{* * *} p<0.01$ 
Table A4.8: OLS estimation of the direct mulching effect

\begin{tabular}{|c|c|}
\hline & $\begin{array}{c}(1) \\
\text { Yields }\end{array}$ \\
\hline Mulching $=1$ & $\begin{array}{c}0.297^{* * *} \\
(0.094)\end{array}$ \\
\hline $\mathrm{SOC}(\%, \log )$ & $\begin{array}{c}0.195 \\
(0.230)\end{array}$ \\
\hline SOC $(\%, \log )$ squared & $\begin{array}{l}-0.054 \\
(0.047)\end{array}$ \\
\hline Plot size in ha (log) & $\begin{array}{c}0.815^{* * *} \\
(0.081)\end{array}$ \\
\hline Spending on fertilizer in 1,000 IDR $(\log )$ & $\begin{array}{c}0.035^{*} \\
(0.018)\end{array}$ \\
\hline Spending on herbicide in 1,000 IDR $(\log )$ & $\begin{array}{c}-0.002 \\
(0.020)\end{array}$ \\
\hline No input application $=1$ & $\begin{array}{l}-0.027 \\
(0.162)\end{array}$ \\
\hline Other manure applied $=1$ & $\begin{array}{c}0.147 \\
(0.100)\end{array}$ \\
\hline Harvest frequency (log) & $\begin{array}{c}0.387 \\
(0.261)\end{array}$ \\
\hline Pruning $=1$ & $\begin{array}{l}-0.004 \\
(0.092)\end{array}$ \\
\hline Planting density & $\begin{array}{c}-0.001 \\
(0.002)\end{array}$ \\
\hline Grazing animals $=1$ & $\begin{array}{l}-0.136^{*} \\
(0.066)\end{array}$ \\
\hline Plot age & $\begin{array}{l}0.077^{* *} \\
(0.029)\end{array}$ \\
\hline Plot age squared & $\begin{array}{c}-0.002^{* * *} \\
(0.001)\end{array}$ \\
\hline Local village $=1$ & $\begin{array}{l}-0.010 \\
(0.094)\end{array}$ \\
\hline Constant & $\begin{array}{c}0.413 \\
(0.798) \\
\end{array}$ \\
\hline Observations & 128 \\
\hline
\end{tabular}

Coefficients from a linear model displayed. Village-level clustered standard errors in parentheses.

${ }^{*} p<0.1,{ }^{* *} p<0.05,{ }^{* * *} p<0.01$ 
Table A4.9: Mean difference tests between EFB farmers and external control group

\begin{tabular}{|c|c|c|c|}
\hline & $\begin{array}{c}\text { (1) } \\
\text { Control } \\
\text { Mean values } \\
\text { dard errors i }\end{array}$ & $\begin{array}{l}\quad(2) \\
\text { Mulching } \\
\text { ered stan- } \\
\text { ses }\end{array}$ & $\begin{array}{c}(3) \\
\text { (1) vs. (2) } \\
\text { p-value }\end{array}$ \\
\hline Plantation age (years) & $\begin{array}{c}13.815 \\
(1.878)\end{array}$ & $\begin{array}{c}16.742 \\
(2.523)\end{array}$ & 0.356 \\
\hline Fertilizer applied in kg (log) & $\begin{array}{c}5.319 \\
(0.399)\end{array}$ & $\begin{array}{c}5.621 \\
(0.374)\end{array}$ & 0.581 \\
\hline $\begin{array}{l}\text { Herbicide applied in } \\
\text { liter (log) }\end{array}$ & $\begin{array}{c}1.655 \\
(0.252)\end{array}$ & $\begin{array}{c}1.417 \\
(0.253)\end{array}$ & 0.508 \\
\hline No inputs applied $=1$ & 0.370 & 0.387 & 0.909 \\
\hline Plot was burned in past $=1$ & 0.333 & 0.161 & 0.067 \\
\hline Other manure applied $=1$ & 0.074 & 0.129 & 0.487 \\
\hline SOC in interrow $(\%, \log )$ & $\begin{array}{c}0.945 \\
(0.174)\end{array}$ & $\begin{array}{c}0.973 \\
(0.120)\end{array}$ & 0.895 \\
\hline$N$ & 27 & 31 & \\
\hline
\end{tabular}


Chapter 5

Conclusion 
In the last decades, the area under oil palm production has increased markedly in Indonesia and in other producing countries, and growth rates are predicted to remain positive (FAO, 2019). From an ecological perspective, this expansion has induced major negative effects and caused biodiversity loss, carbon emissions and soil degradation. Yet, from an economic perspective, it has contributed to poverty reduction and income growth for smallholder farmers. This contrast highlights potential conflicts between income generation and environmental degradation involved in oil palm expansion. The aim of this dissertation is to contribute to the identification of suitable management practices and policies to mitigate these trade-offs.

This thesis addresses two broad research objectives. The first is to investigate which policies are suitable to promote the adoption of tree planting in oil palm plantations. The second is to analyze environmental and economic outcomes of potential policies and management practices to evaluate which approaches could reduce environmental-economic trade-offs. These two research objectives are explored in three essays using primary data collected in Jambi Province, in Sumatra, Indonesia. The following conclusion first briefly summarizes the main findings. Then, it discusses limitation as well as sustainability and policy implications.

\subsection{Main findings and discussion}

The first essay looks at information and free seedling delivery as potential policy instruments to promote tree planting in oil palm plantations. Existing evidence on whether information and free input provision can spur technology adoption is mostly derived from technologies aiming at either income generation in the case of the agricultural literature, or at health improvements in the general development economics literature. We complement the literature by providing evidence on the adoption of a technology that aims to improve local and global environmental conditions, and to diversify income sources.

Results from a randomized controlled trial indicate that non-monetary interventions such as information provision can be effective to promote tree planting. When only information is provided, few farmers plant, but they plant many trees on average. Free seedling provision is important to motivate a large share of the population to adopt tree planting. On average, these farmers only plant the number of seedlings that were provided for free. Notwithstanding, free seedling provision also encourages a small share of farmers to do additional planting efforts. These 
farmers plant a similar number of trees than adopters who only receive information. Consequently, free seedling provision does not appear to crowd out own planting efforts. However, farm-level tree survival rates are lower when trees are provided for free. Non-correspondence between farmers' preferences and the species distributed could be identified as one driver of the low survival rates.

The second essay analyzes the effectiveness of different design options for payments for ecosystem services (PES) schemes to promote the adoption of mixed oil palm-tree systems with a framed field experiment. Furthermore, it assesses the biodiversity effects generated in the experiment. The diversity of a broad range of species represents an environmental good whose provision is dependent on a minimum size of conservation area at the landscape level. Increased connectivity between the conserved areas further enhances species diversity. Evidence is missing in the literature on which PES design options are best suited to provide such environmental goods.

In a hypothetical scenario, two PES designs are analyzed. In the first, the area threshold, farmers who conserve receive compensation if at least three out six farmers in a group do so. In the second, the agglomeration payment, conserving farmers receive compensation if at least three farmers with bordering land in the group conserve. The PES designs are combined with three different payment levels.

The essay shows that offering farmers monetary compensation significantly increases the probability that farmers plant mixed systems in their plantations. Biodiversity effects are higher when farmers are overcompensated for conservation. When farmers can communication with each other, the area threshold leads to higher biodiversity levels than the agglomeration payment. This suggests that setting payment rules that are hard to achieve and consequently involve the risk of coordination failure could be detrimental for biodiversity conservation.

The third essay explores whether empty fruit bunch (EFB) mulching can contribute to closing reported yield gaps, and to restoring soil organic carbon (SOC) in smallholder oil palm plantations. In addition, it looks into whether the effect of mulching on yields operates through improvements in SOC. Providing evidence from smallholdings complements knowledge on the effect of EFB mulching on yields and SOC that is almost entirely derived from large-scale plantations and experimental settings.

The results demonstrate that EFB mulching increases both yields and SOC contents. However, the effect of mulching on yields likely operates through channels other than SOC increases. While higher SOC contents are therefore not directly 
beneficial to smallholders' yields, the soil carbon sequestration function might be improved. This could help to mitigate negative climate impacts of oil palm expansion in the longer run.

Results from essays one and two suggest that policies can be effective in promoting tree planting adoption among smallholder farmers in Indonesia. However, only a small share of farmers plant trees when only information is provided. Adoption rates are significantly larger under free seedling provision, which could act as a subsidy besides relieving seed access constraints. The second essay highlights the relevance of monetary considerations for conservation choices. Put together, these findings suggest that free seedling provision or even monetary compensations are needed to motivate a large share of farmers to start planting trees.

Our results further indicate that environmental improvements and income generation can be complements. This is the case of EFB mulching, where both increases in yields as a proxy for income, and in SOC contents can be observed. In contrast, trade-offs might be present when tree planting is adopted, at least if substantial parts of the oil palms are replaced with trees as in the second essay. PES-schemes could be a way to mitigate negative income effects of farmers. If payments under these schemes are subject to collective conservation goals at the village or broader landscape level, care should be given to implement payment rules that facilitate coordination. Besides generating higher biodiversity effects, such payment rules also lead to higher farmers' income compared to rules that require higher coordination efforts. Consequently, they might be better suited to mitigate environmental-economic trade-offs.

\subsection{Limitations and scope for future research}

The first essay provides evidence on how tree planting adoption can be promoted. However, it is not possible to fully assess whether the trees planted actually improve biodiversity outcomes. We were not able to collect information on environmental outcomes on our own. Furthermore, there is a gap in the literature on ecological outcomes of trees in oil palm plantations. Some recent studies have supported positive effects of polycultural systems on biodiversity, but these systems include other crops besides trees and do not relate the number of trees planted to biodiversity outcomes (Ashraf et al., 2018; Azhar, Puan, Zakaria, Hassan, \& Arif, 2014; Syafiq et al., 2016; Yahya et al., 2017). To the best of my knowledge, there exists only one study that explicitly links the number of trees planted in oil palm plantations 
to biodiversity outcomes (Teuscher et al., 2015). Since many farmers planted a limited number of trees, it is questionable how large the generated biodiversity effects are. In addition, evidence on the economic consequences of tree planting is limited. More research regarding these issues is needed to assess the potential environment-income trade-offs, in particular if the aim is to scale up the number of trees planted, which likely requires to distribute a larger number of trees.

The first essay compares the effects of information and seedling delivery. Yet, neither information nor seedling provision is a homogeneous intervention. The information campaign had a limited scope since it consisted of the one-time screening of a movie and the distribution of a manual. Repeated campaigns and other channels of information provision, e.g. through demonstration plots or model farmer approaches, represent alternative information interventions. These could have different effects and potentially could change the conclusions on the relative performance of information dissemination and free seedling provision.

The rationale of providing seedlings was to address market access barriers. However, by distributing the seedlings for free, the intervention subsidized inputs. The design does not allow to disentangle whether relieving access constraints, or whether subsidizing inputs is the main impact channel for tree planting adoption. If relieving access barriers is sufficient to promote tree planting adoption, the costs of the interventions could be reduced and potentially higher levels of cost effectiveness achieved. Further research could therefore compare interventions that provide seedlings for free to interventions where access is provided, but farmers need to pay for the seedlings to disentangle these two channels.

Finally, it should be noted that tree planting adoption is based on farmers' self-reports, and tree survival was assessed one year after planting. Looking at tree survival in a longer time horizon could generate more informed evaluations of the two interventions. Moreover, plot visits to assess the number of trees planted could reduce measurement errors, if e.g. farmers report having planted trees in oil palm plantations to please the research team.

The second essay investigates with a framed field experiment whether PES can promote tree planting. The results highlight the relevance of communication among farmers for facilitating coordination under the area threshold. In contrast, communication does not increase conservation probabilities under the agglomeration payment. Communication was introduced after farmers had already experience with the respective PES design. A clearer identification of the causal effect of communication would require a between design. Moreover, subgroup analyses 
indicate that previous coordination success can explain part of the differential effect of communication between the two PES designs. An assessment of farmers' beliefs at all stages of the experiment or the availability of transcripts of the communication content could have improved the understanding of why the effect of communication differs between the two PES designs.

The question of whether financial compensation is promising to promote tree planting in oil palm plantations is answered in this thesis in a hypothetical scenario. Providing hypothetical evidence first to assess ex ante which PES designs might be most suited to promote tree planting is justified given the cost intensiveness of an experimental investigation implying real compensation payments and decision making. However, hypothetical scenarios might suffer from hypothetical biases, and the participants in the experiment might react to the perceived expectations from the researcher (social desirability bias). At the time of the data collection in 2018, the European Parliament negotiated the revision of the Renewable Energy Directive, which sets targets on the share of renewable energies in national energy mixes. Part of the discussions evolved around whether and to what extent biofuels derived from palm oil should be considered to meet these targets. Farmers were aware of a general critical view of many Europeans on oil palm, and also of the ongoing debate in the Parliament. Since the research team identified themselves, and could also be clearly identified by physical appearance as European, farmers might have felt that the research team expected them to behave in an environmentally friendly way. This could have pushed them to adopt the mixed oil palm system. Potential social desirability biases should not affect the relative performance of the two PES designs considered, but studies involving real decision making are eventually needed to investigate whether PES schemes in general are promising to promote tree planting. Further research using framed field experiments could increase the external validity of the results by using larger groups that comprise also farmers from different villages, and neighborhood structures, in which plantations have a different number of bordering plots. This is important since the real-world implementation of PES schemes to promote biodiversity-friendly landscape patterns would require the coordination of many farmers, partly living in different villages. Moreover, the question of how PES schemes should be designed to maximize tree survival could be addressed.

The third essay analyzes the effect of EFB mulching on yields and SOC contents. Since EFB mulching increases SOC contents, carbon sequestration in oil palm plantations is also likely improved. To fully analyze whether more carbon can be 
stored in the soil, estimating carbon stocks, i.e. the amount of carbon stored per cubic meter, is important. This should be addressed by future research in order to evaluate whether EFB mulching could improve the carbon balance of oil palm plantations.

The analysis of whether EFB mulching increases SOC contents, and whether the effect of EFB mulching on yields operates through improvements in SOC is based on cross-sectional data. The availability of panel data would allow to assess temporal dynamics as well as the potential delayed response of yields to SOC. Increasing the sample size can improve the power of detecting statistically significant effects. A higher sample size could also facilitate the analysis of heterogeneous treatment effects since responses of SOC and yields to mulching are likely to be context specific. In combination with an additional analysis of broader welfare implications of EFB mulching, e.g. regarding its effects on profits, this could help to understand to which farmers or plantations EFB might be most beneficial. Currently, the uptake of EFB mulching is still very limited among smallholder farmers in Jambi Province. Further research is thus needed to explore policy options to increase the uptake of EFB, or of similar mulching options, if identified. Given the restricted availability of EFB, and to increase aggregate effects, these policies should focus on farmers for whom EFB is expected to have the highest benefits.

All three essays area based on primary data collected in Jambi Province in Indonesia. Two particularities of Jambi Province need to be mentioned. First, oil palm cultivation in Jambi is closely linked to the transmigration program. Many smallholder farmers started growing oil palm under contractual arrangements with large-scale plantations. Second, the share of smallholder farmers in Jambi Province amounts to around $75 \%$, while the national Indonesian average is only $46 \%$ (Badan Pusat Statistik, 2019). The institutional background of the transmigration program, or spill-over effects from other smallholder farmers, who e.g. are potentially more inclined to adopt more diverse cropping systems than owners of large-scale plantations (Azhar et al., 2011), might have affected the results in the presented essays. It is consequently difficult to assess ex-ante whether similar results would be derived in newly emerging oil palm cultivation areas in Indonesia, such as Papua, or in other emerging producing regions such as South America, West Africa and other countries in South-East Asia. 


\subsection{Sustainability and policy implications}

This dissertation shows that management practices and policies promoting their uptake could potentially help to mitigate environmental-economic trade-offs involved in oil palm expansion. In order to assess whether these practices and policies can help increase the sustainability of oil palm cultivation, also social consequences such as potential distributional conflicts need to be assessed. This might be particularly important for monetary compensation schemes, such as the ones considered in the second chapter, as well as for the promotion of best management practices that involve high costs such as EFB mulching.

Furthermore, both explored management practices likely influence oil palm yields, which might increase in the case of mulching, or decrease in the case of tree planting. Changed per hectare revenues could also affect other land use systems in the region, e.g. by land expansion and related deforestation (Kubitza, Krishna, Urban, et al., 2018). Indirect effects on other land use systems should be considered for a sustainability assessment. Finally, we focus on smallholder farmers in this dissertation. Yet, around $60 \%$ of the oil palm cultivation area in Indonesia is managed by industrial plantations. A comprehensive approach to increase the sustainability of oil palm cultivation in Indonesia needs to integrate the environmental, economic and social performance of these plantations.

The focus of this thesis is on the production side of the palm oil value chain. In order to enhance the implementation, and to contribute to resulting costs of such policies in the producing countries, the consumption side of the value chain should be considered. One approach could be compulsory environmental standards for palm oil. Here, the European Union plays an important role since it represents the second biggest importing region (USDA, 2020). However, a coordinated approach with India and China as the two other main importing countries would be needed to streamline consumer power. Another approach could be certificates and related voluntary standards such as the Roundtable on Sustainable Palm Oil certificate. For these certificates to be effective, monitoring needs to be ensured and certification criteria further tightened (Carlson et al., 2018). Furthermore, the certification process needs to be adapted to smallholders' circumstances (Brandi, 2017). Price premia included in certification schemes could be used to mitigate potential income losses of farmers who manage their plantations in an environmentally friendly way. In case further research supports the potential of PES schemes to increase the sustainability of oil palm cultivation, it is important to consider how the resulting 
costs can be shared among countries. Cost sharing can be justified given the global public good character of biodiversity and climate protection. 


\section{References}

Abadie, A., Athey, S., Imbens, G., \& Wooldridge, J. (2017). When Should You Adjust Standard Errors for Clustering? (No. 24003). Cambridge, MA: National Bureau of Economic Research. doi: 10.3386/w24003

Abu Bakar, R., Darus, S. Z., Kulaseharan, S., \& Jamaluddin, N. (2011). Effects of ten year application of empty fruit bunches in an oil palm plantation on soil chemical properties. Nutrient Cycling in Agroecosystems, 89(3), 341-349. doi: $10.1007 /$ s10705-010-9398-9

Akay, A. (2009). The Wooldridge Method for the Initial Values Problem is Simple: What about Performance? IZA DP series, 3943.

Aker, J. C. (2011). Dial "A" for agriculture: A review of information and communication technologies for agricultural extension in developing countries. Agricultural Economics, 42(6), 631-647. doi: 10.1111/j.1574-0862.2011.00545 . $\mathrm{X}$

Angrist, J. D., \& Pischke, J.-S. (2009). Mostly harmless econometrics: An empiricist's companion. Princeton, NJ: Princeton Univ. Press.

Ashraf, M., Zulkifli, R., Sanusi, R., Tohiran, K. A., Terhem, R., Moslim, R., Norhisham, A. R., Ashton-Butt, A., \& Azhar, B. (2018). Alley-cropping system can boost arthropod biodiversity and ecosystem functions in oil palm plantations. Agriculture, Ecosystems \& Environment, 260, 19-26. doi: 10.1016/j.agee.2018.03.017

Ashraf, N., Berry, J., \& Shapiro, J. M. (2010). Can Higher Prices Stimulate Product Use? Evidence from a Field Experiment in Zambia. American Economic Review, 100 (5), 2383-2413. doi: 10.1257/aer.100.5.2383

Ashraf, N., Jack, B. K., \& Kamenica, E. (2013). Information and subsidies: Complements or substitutes? Journal of Economic Behavior \& Organization, 88, 133-139. doi: 10.1016/j.jebo.2012.12.031

Austin, K. G., Mosnier, A., Pirker, J., McCallum, I., Fritz, S., \& Kasibhatla, P. S. (2017). Shifting patterns of oil palm driven deforestation in Indonesia and implications for zero-deforestation commitments. Land Use Policy, 69, 41-48. doi: 10.1016/j.landusepol.2017.08.036

Azhar, B., Lindenmayer, D. B., Wood, J., Fischer, J., Manning, A., McElhinny, C., \& Zakaria, M. (2011). The conservation value of oil palm plantation estates, smallholdings and logged peat swamp forest for birds. Forest Ecology and Management, 262(12), 2306-2315. doi: 10.1016/j.foreco.2011.08.026

Azhar, B., Lindenmayer, D. B., Wood, J., Fischer, J., \& Zakaria, M. (2014). 
Ecological impacts of oil palm agriculture on forest mammals in plantation estates and smallholdings. Biodiversity and Conservation, 23(5), 1175-1191. doi: $10.1007 / \mathrm{s} 10531-014-0656-\mathrm{z}$

Azhar, B., Puan, C. L., Zakaria, M., Hassan, N., \& Arif, M. (2014). Effects of monoculture and polyculture practices in oil palm smallholdings on tropical farmland birds. Basic and Applied Ecology, 15(4), 336-346. doi: 10.1016/ j.baae.2014.06.001

Badan Pusat Statistik (2019). Indonesian oil palm statistics 2018. Retrieved 08.12.2019, from https://www.bps.go.id/publication/2019/11/22/ 1bc09b8c5de4dc77387c2a4b/statistik-kelapa-sawit-indonesia-2018.html

Badan Pusat Statistik Provinsi Jambi (2019). Production of Oil Palm by Regency / City (Ton), 2007-2016. Retrieved 09.04.2019, from https://jambi.bps.go.id/dynamictable/2018/04/18/414/produksi-tanaman -kelapa-sawit-menurut-kabupaten-kota-ton-2007-201.html

Banerjee, S. (2018). Improving Spatial Coordination Rates under the Agglomeration Bonus Scheme: A Laboratory Experiment with a Pecuniary and a Non-Pecuniary Mechanism (NUDGE). American Journal of Agricultural Economics, 100 (1), 172-197. doi: 10.1093/ajae/aax066

Banerjee, S., Cason, T. N., de Vries, F. P., \& Hanley, N. (2017). Transaction costs, communication and spatial coordination in Payment for Ecosystem Services Schemes. Journal of Environmental Economics and Management, 83, 68-89. doi: 10.1016/j.jeem.2016.12.005

Banerjee, S., de Vries, F. P., Hanley, N., \& van Soest, D. P. (2014). The Impact of Information Provision on Agglomeration Bonus Performance: An Experimental Study on Local Networks. American Journal of Agricultural Economics, 96 (4), 1009-1029. doi: 10.1093/ajae/aau048

Banerjee, S., Kwasnica, A. M., \& Shortle, J. S. (2012). Agglomeration bonus in small and large local networks: A laboratory examination of spatial coordination. Ecological Economics, 84, 142-152. doi: 10.1016/j.ecolecon.2012.09.005

Battese, G. E. (1997). A Note on the estimation of Cobb-Douglas Production Functions when some Explanatory Variables have zero Values. Journal of Agricultural Economics, 48(1-3), 250-252. doi: 10.1111/j.1477-9552.1997 .tb01149.x

Baum, C. F., Schaffer, M. E., \& Stillman, S. (2003). Instrumental Variables and GMM: Estimation and Testing. The Stata Journal: Promoting communications on statistics and Stata, 3(1), 1-31. doi: 10.1177/1536867X0300300101

Belotti, F., Deb, P., Manning, W. G., \& Norton. Edward C. (2015). Two Pm: Two part models. The Stata Journal, 1, 3-20.

Bensch, G., \& Peters, J. (2020). One-Off Subsidies and Long-Run AdoptionExperimental Evidence on Improved Cooking Stoves in Senegal. American Journal of Agricultural Economics, 102(1), 72-90. doi: 10.1093/ajae/aaz023

Benyishay, A., \& Mobarak, A. M. (2018). Social Learning and Incentives for Experimentation and Communication. The Review of Economic Studies, 95, 1082. doi: 10.1093/restud/rdy039 
Bernard, T., Dercon, S., Orkin, K., \& Seyoum Taffesse, A. (2015). Will Video Kill the Radio Star? Assessing the Potential of Targeted Exposure to Role Models through Video. The World Bank Economic Review, 29 (suppl 1), 226-237. doi: 10.1093/wber/lhv014

Betts, M. G., Forbes, G. J., \& Diamond, A. W. (2007). Thresholds in songbird occurrence in relation to landscape structure. Conservation biology : the journal of the Society for Conservation Biology, 21(4), 1046-1058. doi: 10.1111/j.1523-1739.2007.00723.x

Bhagwat, S. A., \& Willis, K. J. (2008). Agroforestry as a solution to the oil-palm debate. Conservation biology: the journal of the Society for Conservation Biology, 22(6), 1368-1369. doi: 10.1111/j.1523-1739.2008.01026.x

Börner, J., Baylis, K., Corbera, E., Ezzine-de Blas, D., Honey-Rosés, J., Persson, U. M., \& Wunder, S. (2017). The Effectiveness of Payments for Environmental Services. World Development, 96, 359-374. doi: 10.1016/j.worlddev.2017.03 .020

Bou Dib, J., Alamsyah, Z., \& Qaim, M. (2018). Land-use change and income inequality in rural Indonesia. Forest Policy and Economics, 94, 55-66. doi: 10.1016/j.forpol.2018.06.010

Bou Dib, J., Krishna, V. V., Alamsyah, Z., \& Qaim, M. (2018). Land-use change and livelihoods of non-farm households: The role of income from employment in oil palm and rubber in rural Indonesia. Land Use Policy, 76, 828-838. doi: 10.1016/j.landusepol.2018.03.020

Brandi, C. A. (2017). Sustainability Standards and Sustainable Development - Synergies and Trade-Offs of Transnational Governance. Sustainable Development, 25(1), 25-34. doi: 10.1002/sd.1639

Burgess, S., Daniel, R. M., Butterworth, A. S., \& Thompson, S. G. (2015). Network Mendelian randomization: using genetic variants as instrumental variables to investigate mediation in causal pathways. International journal of epidemiology, 44(2), 484-495. doi: 10.1093/ije/dyu176

Cadsby, C. B., \& Maynes, E. (1999). Voluntary provision of threshold public goods with continuous contributions: Experimental evidence. Journal of Public Economics, 71(1), 53-73. doi: 10.1016/S0047-2727(98)00049-8

Caliman, J. P., Martha, B., \& Saletes, S. (2001). Dynamics of Nutrient Release from Empty Fruit Bunches in Field Conditions and Soil Characteristics Changes. In Cutting-edge technologies for sustained competitiveness. Agriculture conference : Proceedings of the 2001 PIPOC International palm oil congress (pp. 550556).

Cameron, A. C., Gelbach, J. B., \& Miller, D. L. (2008). Bootstrap-Based Improvements for Inference with Clustered Errors. Review of Economics and Statistics, 90(3), 414-427. doi: 10.1162/rest.90.3.414

Cameron, A. C., \& Miller, D. L. (2015). A Practitioner's Guide to Cluster-Robust Inference. Journal of Human Resources, 50(2), 317-372. doi: 10.3368/ jhr.50.2.317

Cardenas, J.-C., Ahn, T. K., \& Ostrom, E. (2004). Communication and Co- 
operation in a Common-Pool Resource Dilemma: A Field Experiment. In S. Huck (Ed.), Advances in Understanding Strategic Behaviour: Game Theory, Experiments and Bounded Rationality (pp. 258-286). London: Palgrave Macmillan UK. doi: 10.1057/978023052337112

Carlson, K. M., Curran, L. M., Asner, G. P., Pittman, A. M., Trigg, S. N., \& Marion Adeney, J. (2013). Carbon emissions from forest conversion by Kalimantan oil palm plantations. Nature Climate Change, 3(3), 283-287. doi: 10.1038/nclimate1702

Carlson, K. M., Heilmayr, R., Gibbs, H. K., Noojipady, P., Burns, D. N., Morton, D. C., Walker, N. F., Paoli, G. D., \& Kremen, C. (2018). Effect of oil palm sustainability certification on deforestation and fire in Indonesia. Proceedings of the National Academy of Sciences of the United States of America, 115(1), 121-126. doi: 10.1073/pnas.1704728114

Carr, M. (2011). The Water Relations and Irrigation Requirements of Oil Palm (Elaeis Guineensis ): A Review. Experimental Agriculture, 47(4), 629-652. doi: 10.1017/S0014479711000494

Carron, M. P., Auriac, Q., Snoeck, D., Villenave, C., Blanchart, E., Ribeyre, F., Marichal, R., Darminto, M., \& Caliman, J. P. (2015). Spatial heterogeneity of soil quality around mature oil palms receiving mineral fertilization. European Journal of Soil Biology, 66, 24-31. doi: 10.1016/j.ejsobi.2014.11.005

Carron, M. P., Auriac, Q., Snoeck, D., Villenave, C., Blanchart, E., Ribeyre, F., Marichal, R., Darminto, M., \& Caliman, J. P. (2016). Do the impact of organic residues on soil quality extend beyond the deposition area under oil palm? European Journal of Soil Biology, 75, 54-61. doi: 10.1016/ j.ejsobi.2016.04.011

Carter, M. R., Laajaj, R., \& Yang, D. (2013). The Impact of Voucher Coupons on the Uptake of Fertilizer and Improved Seeds: Evidence from a Randomized Trial in Mozambique. American Journal of Agricultural Economics, 95(5), 1345-1351. doi: 10.1093/ajae/aat040

Charness, G., Gneezy, U., \& Kuhn, M. A. (2012). Experimental methods: Betweensubject and within-subject design. Journal of Economic Behavior \&5 Organization, 81(1), 1-8. doi: 10.1016/j.jebo.2011.08.009

Chiew, L., \& Zaharah, A. R. (2002). The effects of oil palm empty fruit bunches on oil palm nutrition and yield, and soil chemical properties. Journal of Oil Palm Research, 14 (2), 1-9.

Clough, Y., Krishna, V. V., Corre, M. D., Darras, K., Denmead, L. H., Meijide, A., Moser, S., Musshoff, O., Steinebach, S., Veldkamp, E., Allen, K., Barnes, A. D., Breidenbach, N., Brose, U., Buchori, D., Daniel, R., Finkeldey, R., Harahap, I., Hertel, D., Holtkamp, A. M., Hörandl, E., Irawan, B., Jaya, I. N. S., Jochum, M., Klarner, B., Knohl, A., Kotowska, M. M., Krashevska, V., Kreft, H., Kurniawan, S., Leuschner, C., Maraun, M., Melati, D. N., Opfermann, N., Pérez-Cruzado, C., Prabowo, W. E., Rembold, K., Rizali, A., Rubiana, R., Schneider, D., Tjitrosoedirdjo, S. S., Tjoa, A., Tscharntke, T., \& Scheu, S. (2016). Land-use choices follow profitability at the 
expense of ecological functions in Indonesian smallholder landscapes. Nature communications, 7, 13137. doi: 10.1038/ncomms13137

Cole, S. A., \& Fernando, A. N. (2016). 'Mobile'izing Agricultural Advice: Technology 'Mobile'izing Agricultural Advice: Technology Adoption, Diffusion and Sustainability (No. 13-047).

Comte, I., Colin, F., Grünberger, O., Follain, S., Whalen, J. K., \& Caliman, J.-P. (2013). Landscape-scale assessment of soil response to long-term organic and mineral fertilizer application in an industrial oil palm plantation, Indonesia. Agriculture, Ecosystems \& Environment, 169, 58-68. doi: 10.1016/ j.agee.2013.02.010

Comte, I., Colin, F., Whalen, J. K., Grünberger, O., \& Caliman, J.-P. (2012). Agricultural Practices in Oil Palm Plantations and Their Impact on Hydrological Changes, Nutrient Fluxes and Water Quality in Indonesia. In D. L. Sparks (Ed.), Advances in Agronomy (Vol. 116, pp. 71-124). Burlington: Elsevier Science. doi: 10.1016/B978-0-12-394277-7.00003-8

Corley, R., \& Tinker, P. B. (2016). The Oil Palm (Fifth ed.). Chichester, UK: John Wiley \& Sons, Ltd. doi: 10.1002/9781118953297

Cragg, J. G. (1971). Some Statistical Models for Limited Dependent Variables with Application to the Demand for Durable Goods. Econometrica, 39(5), 829-844. doi: 10.2307/1909582

Diaz, S., Settele, J., \& Brondizio, E. (2019). Summary for policymakers of the global assessment report on biodiversity and ecosystem services of the Intergovernmental Science-Policy Platform on Biodiversity and Ecosystem Services. Retrieved 24.01.2020, from https://ipbes.net/document-library -catalogue/summary-policymakers-global-assessment-laid-out

Dislich, C., Keyel, A. C., Salecker, J., Kisel, Y., Meyer, K. M., Auliya, M., Barnes, A. D., Corre, M. D., Darras, K., Faust, H., Hess, B., Klasen, S., Knohl, A., Kreft, H., Meijide, A., Nurdiansyah, F., Otten, F., Pe'er, G., Steinebach, S., Tarigan, S., Tölle, M. H., Tscharntke, T., \& Wiegand, K. (2017). A review of the ecosystem functions in oil palm plantations, using forests as a reference system. Biological reviews of the Cambridge Philosophical Society, 92(3), 1539-1569. doi: 10.1111/brv.12295

Dow, W. H., \& Norton, E. C. (2003). Choosing Between and Interpreting the Heckit and Two-Part Models for Corner Solutions. Health Services and Outcomes Research Methodology, 4(1), 5-18. doi: 10.1023/A:1025827426320

Drechsler, M., Wätzold, F., Johst, K., \& Shogren, J. F. (2010). An agglomeration payment for cost-effective biodiversity conservation in spatially structured landscapes. Resource and Energy Economics, 32(2), 261-275. doi: 10.1016/ j.reseneeco.2009.11.015

Drescher, J., Rembold, K., Allen, K., Beckschäfer, P., Buchori, D., Clough, Y., Faust, H., Fauzi, A. M., Gunawan, D., Hertel, D., Irawan, B., Jaya, I. N. S., Klarner, B., Kleinn, C., Knohl, A., Kotowska, M. M., Krashevska, V., Krishna, V., Leuschner, C., Lorenz, W., Meijide, A., Melati, D., Nomura, M., PérezCruzado, C., Qaim, M., Siregar, I. Z., Steinebach, S., Tjoa, A., Tscharntke, 
T., Wick, B., Wiegand, K., Kreft, H., \& Scheu, S. (2016). Ecological and socio-economic functions across tropical land use systems after rainforest conversion. Philosophical transactions of the Royal Society of London. Series B, Biological sciences, 371(1694). doi: 10.1098/rstb.2015.0275

Duflo, E., Glennerster, R., \& Kremer, M. (2006). Using Randomization in Development Economics Research: A Toolkit. NBER Technical Working Paper, 333. doi: 10.3386/t0333

Duflo, E., Kremer, M., \& Robinson, J. (2008). How High Are Rates of Return to Fertilizer? Evidence from Field Experiments in Kenya. American Economic Review, 98(2), 482-488. doi: 10.1257/aer.98.2.482

Dupas, P. (2014). Short-Run Subsidies and Long-Run Adoption of New Health Products: Evidence From a Field Experiment. Econometrica, 82(1), 197-228. doi: 10.3982/ECTA9508

Embrandiri, A., Singh, R. P., Ibrahim, H. M., \& Ramli, A. A. (2012). Land application of biomass residue generated from palm oil processing: its potential benefits and threats. The Environmentalist, 32(1), 111-117. doi: 10.1007/s10669-011-9367-0

Euler, M., Hoffmann, M. P., Fathoni, Z., \& Schwarze, S. (2016). Exploring yield gaps in smallholder oil palm production systems in eastern Sumatra, Indonesia. Agricultural Systems, 146, 111-119. doi: 10.1016/j.agsy.2016.04.007

Euler, M., Krishna, V., Schwarze, S., Siregar, H., \& Qaim, M. (2017). Oil Palm Adoption, Household Welfare, and Nutrition Among Smallholder Farmers in Indonesia. World Development, 93, 219-235. doi: 10.1016/j.worlddev.2016 .12 .019

Fahrig, L. (2003). Effects of Habitat Fragmentation on Biodiversity. Annual Review of Ecology, Evolution, and Systematics, 34, 487-515.

FAO (2019). Crops production data. database. Retrieved 09.10.2017, from http://www.fao.org/faostat/en/\#data

FAO, \& Global Mechanism of the UNCCD (2015). Sustainable financing for forest and landscape restoration: Opportunities, challenges and the way forward: Discussion paper. Retrieved 06.12.2019, from http://www.fao.org/ 3/a-i5174e.pdf

Fargione, J., Hill, J., Tilman, D., Polasky, S., \& Hawthorne, P. (2008). Land clearing and the biofuel carbon debt. Science (New York, N.Y.), 319(5867), 1235-1238. doi: 10.1126/science. 1152747

Feintrenie, L., Chong, W. K., \& Levang, P. (2010). Why do Farmers Prefer Oil Palm? Lessons Learnt from Bungo District, Indonesia. Small-Scale Forestry, 9(3), 379-396. doi: 10.1007/s11842-010-9122-2

Feintrenie, L., Schwarze, S., \& Levang, P. (2010). Are Local People Conservationists? Analysis of Transition Dynamics from Agroforests to Monoculture Plantations in Indonesia. Ecology and Society, 15(4), 37. doi: 10.5751/ES-03870-150437

Ferré, M., Engel, S., \& Gsottbauer, E. (2018). Which Agglomeration Payment for a Sustainable Management of Organic Soils in Switzerland? - An Experiment Accounting for Farmers' Cost Heterogeneity. Ecological Economics, 150, 
24-33. doi: 10.1016/j.ecolecon.2018.03.028

Field, R. D., van der Werf, G. R., Fanin, T., Fetzer, E. J., Fuller, R., Jethva, H., Levy, R., Livesey, N. J., Luo, M., Torres, O., \& Worden, H. M. (2016). Indonesian fire activity and smoke pollution in 2015 show persistent nonlinear sensitivity to El Niño-induced drought. Proceedings of the National Academy of Sciences of the United States of America, 113(33), 9204-9209. doi: 10.1073/ pnas. 1524888113

Fischbacher, U., \& Gächter, S. (2010). Social Preferences, Beliefs, and the Dynamics of Free Riding in Public Goods Experiments. American Economic Review, 100(1), 541-556. doi: 10.1257/aer.100.1.541

Fischbacher, U., Gächter, S., \& Fehr, E. (2001). Are people conditionally cooperative? Evidence from a public goods experiment. Economics Letters, 71 (3), 397-404. doi: 10.1016/S0165-1765(01)00394-9

Fitzgerald, J., Gottschalk, P., \& Moffitt, R. (1998). An Analysis of Sample Attrition in Panel Data: The Michigan Panel Study of Income Dynamics. The Journal of Human Resources, 33(2), 251-299. doi: 10.2307/146433

Fitzherbert, E. B., Struebig, M. J., Morel, A., Danielsen, F., Brühl, C. A., Donald, P. F., \& Phalan, B. (2008). How will oil palm expansion affect biodiversity? Trends in ecology $\& 5$ evolution, 23(10), 538-545. doi: 10.1016/j.tree.2008.06 .012

Fong, Y., Huang, Y., Lemos, M. P., \& Mcelrath, M. J. (2018). Rank-based two-sample tests for paired data with missing values. Biostatistics (Oxford, England), 19(3), 281-294. doi: 10.1093/biostatistics/kxx039

Foster, A. D., \& Rosenzweig, M. R. (2010). Microeconomics of Technology Adoption. Annual review of economics, 2, 395-424. doi: 10.1146/annurev.economics .102308 .124433

Foster, W. A., Snaddon, J. L., Turner, E. C., Fayle, T. M., Cockerill, T. D., Ellwood, M. D. F., Broad, G. R., Chung, A. Y. C., Eggleton, P., Khen, C. V., \& Yusah, K. M. (2011). Establishing the evidence base for maintaining biodiversity and ecosystem function in the oil palm landscapes of South East Asia. Philosophical transactions of the Royal Society of London. Series B, Biological sciences, 366 (1582), 3277-3291. doi: 10.1098/rstb.2011.0041

Frölich, M., \& Huber, M. (2017). Direct and indirect treatment effects-causal chains and mediation analysis with instrumental variables. Journal of the Royal Statistical Society: Series B (Statistical Methodology), $79(5), 1645-1666$. doi: $10.1111 /$ rssb. 12232

Ganzach, Y., Saporta, I., \& Weber, Y. (2000). Interaction in Linear versus Logistic Models: A Substantive Illustration Using the Relationship between Motivation, Ability, and Performance. Organizational Research Methods, 3(3), 237-253.

Gatto, M., Wollni, M., Asnawi, R., \& Qaim, M. (2017). Oil Palm Boom, Contract Farming, and Rural Economic Development: Village-Level Evidence from Indonesia. World Development, 95, 127-140. doi: 10.1016/j.worlddev.2017 .02 .013 
Gatto, M., Wollni, M., \& Qaim, M. (2015). Oil palm boom and land-use dynamics in Indonesia: The role of policies and socioeconomic factors. Land Use Policy, 46, 292-303. doi: 10.1016/j.landusepol.2015.03.001

Gérard, A., Wollni, M., Hölscher, D., Irawan, B., Sundawati, L., Teuscher, M., \& Kreft, H. (2017). Oil-palm yields in diversified plantations: Initial results from a biodiversity enrichment experiment in Sumatra, Indonesia. Agriculture, Ecosystems \& Environment, 240, 253-260. doi: 10.1016/j.agee.2017.02.026

Ghazali, A., Asmah, S., Syafiq, M., Yahya, M. S., Aziz, N., Tan, L. P., Norhisham, A. R., Puan, C. L., Turner, E. C., \& Azhar, B. (2016). Effects of monoculture and polyculture farming in oil palm smallholdings on terrestrial arthropod diversity. Journal of Asia-Pacific Entomology, 19(2), 415-421. doi: 10.1016/ j.aspen.2016.04.016

Gibbs, H. K., Ruesch, A. S., Achard, F., Clayton, M. K., Holmgren, P., Ramankutty, N., \& Foley, J. A. (2010). Tropical forests were the primary sources of new agricultural land in the 1980s and 1990s. Proceedings of the National Academy of Sciences of the United States of America, 107(38), 16732-16737. doi: 10.1073/pnas.0910275107

Gilbert-Norton, L., Wilson, R., Stevens, J. R., \& Beard, K. H. (2010). A metaanalytic review of corridor effectiveness. Conservation biology: the journal of the Society for Conservation Biology, 24(3), 660-668. doi: 10.1111/ j.1523-1739.2010.01450.x

Glennerster, R., \& Takavarasha, K. (2013). Running randomized evaluations: A practical guide. Princeton, NJ: Princeton Univ. Press.

Gneezy, U., Meier, S., \& Rey-Biel, P. (2011). When and Why Incentives (Don't) Work to Modify Behavior. Journal of Economic Perspectives, 25 (4), 191-210. doi: $10.1257 /$ jep.25.4.191

Goldman, R. L., Thompson, B. H., \& Daily, G. C. (2007). Institutional incentives for managing the landscape: Inducing cooperation for the production of ecosystem services. Ecological Economics, 64(2), 333-343. doi: 10.1016/ j.ecolecon.2007.01.012

Gregorio, N., Herbohn, J., Harrison, S., \& Smith, C. (2015). A systems approach to improving the quality of tree seedlings for agroforestry, tree farming and reforestation in the Philippines. Land Use Policy, 47, 29-41. doi: 10.1016/j.landusepol.2015.03.009

Greiner, R., \& Gregg, D. (2011). Farmers' intrinsic motivations, barriers to the adoption of conservation practices and effectiveness of policy instruments: Empirical evidence from northern Australia. Land Use Policy, 28(1), 257-265. doi: 10.1016/j.landusepol.2010.06.006

Guillaume, T. (2013). SOC in smallholder plantations - unpublished data.

Guillaume, T., Damris, M., \& Kuzyakov, Y. (2015). Losses of soil carbon by converting tropical forest to plantations: erosion and decomposition estimated by $\delta(13)$ C. Global change biology, 21 (9), 3548-3560. doi: 10.1111/gcb.12907

Guillaume, T., Holtkamp, A. M., Damris, M., Brümmer, B., \& Kuzyakov, Y. (2016). Soil degradation in oil palm and rubber plantations under land 
resource scarcity. Agriculture, Ecosystems \&6 Environment, 232, 110-118. doi: $10.1016 /$ j.agee.2016.07.002

Guillaume, T., Kotowska, M. M., Hertel, D., Knohl, A., Krashevska, V., Murtilaksono, K., Scheu, S., \& Kuzyakov, Y. (2018). Carbon costs and benefits of Indonesian rainforest conversion to plantations. Nature communications, 9(1), 2388. doi: 10.1038/s41467-018-04755-y

Guo, X., Gao, Y., Niu, C., \& Zhang, S. (2019). Letter to the editor. Biostatistics (Oxford, England), 20(2), 358-362. doi: 10.1093/biostatistics/kxy047

Hanna, R., Duflo, E., \& Greenstone, M. (2016). Up in Smoke: The Influence of Household Behavior on the Long-Run Impact of Improved Cooking Stoves. American Economic Journal: Economic Policy, 8(1), 80-114. doi: 10.1257/ pol.20140008

Harrison, S., Gregorio, N., \& Herbohn, J. (2008). A Critical Overview of Forestry Seedling Production Policies and Practices in Relation to Smallholder Forestry in Developing Countries. Small-Scale Forestry, 7(3-4), 207-223. doi: 10.1007/ s11842-008-9051-5

Hass, A. L., Liese, B., Heong, K. L., Settele, J., Tscharntke, T., \& Westphal, C. (2018). Plant-pollinator interactions and bee functional diversity are driven by agroforests in rice-dominated landscapes. Agriculture, Ecosystems \& Environment, 253, 140-147. doi: 10.1016/j.agee.2017.10.019

Höbinger, T., Schindler, S., Seaman, B. S., Wrbka, T., \& Weissenhofer, A. (2012). Impact of oil palm plantations on the structure of the agroforestry mosaic of La Gamba, southern Costa Rica: potential implications for biodiversity. Agroforestry Systems, 85(3), 367-381. doi: 10.1007/s10457-011-9425-0

Holzschuh, A., Steffan-Dewenter, I., \& Tscharntke, T. (2010). How do landscape composition and configuration, organic farming and fallow strips affect the diversity of bees, wasps and their parasitoids? The Journal of animal ecology, 79(2), 491-500. doi: 10.1111/j.1365-2656.2009.01642.x

Hubert, M., \& Vandervieren, E. (2008). An adjusted boxplot for skewed distributions. Computational Statistics \& Data Analysis, 52(12), 5186-5201. doi: 10.1016/j.csda.2007.11.008

Ibanez, L., Moureau, N., \& Roussel, S. (2017). How do incidental emotions impact pro-environmental behavior? Evidence from the dictator game. Journal of Behavioral and Experimental Economics, 66, 150-155. doi: 10.1016/ j.socec.2016.04.003

Imai, K., Keele, L., Tingley, D., \& Yamanoto, T. (2011). Unpacking the Black Box of Causality: Learning about Causal Mechanisms from Experimental and Observational Studies. American Political Science Review, 105(4), 765-789. doi: $10.1017 /$ S0003055411000414

Isaac, R. M., Schmidtz, D., \& Walker, J. M. (1989). The Assurance Problem in a Laboratory Market. Public Choice, 62 (3), 217-236.

IUSS Working Group WRB (2015). World reference base for soil resources 2014 , update 2015: International soil classification system for naming soils and creating legends for soil maps (Vol. 106). Rome: FAO. 
Jack, B. K. (2013). Private Information and the Allocation of Land Use Subsidies in Malawi. American Economic Journal: Applied Economics, 5(3), 113-135. doi: $10.1257 /$ app.5.3.113

Jack, B. K., Oliva, P., Severen, C., Walker, E., \& Bell, S. (2015). Technology Adoption Under Uncertainty: Take-Up and Subsequent Investment in Zambia. NBER Working Paper series, 21414.

Jelsma, I., Slingerland, M., Giller, K. E., \& Bijman, J. (2017). Collective action in a smallholder oil palm production system in Indonesia: The key to sustainable and inclusive smallholder palm oil? Journal of Rural Studies, 54, 198-210. doi: 10.1016/j.jrurstud.2017.06.005

Jelsma, I., Woittiez, L. S., Ollivier, J., \& Dharmawan, A. H. (2019). Do wealthy farmers implement better agricultural practices? An assessment of implementation of Good Agricultural Practices among different types of independent oil palm smallholders in Riau, Indonesia. Agricultural Systems, 170, 63-76. doi: $10.1016 /$ j.agsy.2018.11.004

Kennedy, P. (1981). Estimation with Correctly Interpreted Dummy Variables in Semilogarithmic Equations. American Economic Review, 71(4), 801.

Khasanah, N., van Noordwijk, M., Ningsih, H., \& Rahayu, S. (2015). Carbon neutral? No change in mineral soil carbon stock under oil palm plantations derived from forest or non-forest in Indonesia. Agriculture, Ecosystems 86 Environment, 211, 195-206. doi: 10.1016/j.agee.2015.06.009

Kleibergen, F., \& Paap, R. (2006). Generalized reduced rank tests using the singular value decomposition. Journal of Econometrics, 133(1), 97-126. doi: 10.1016/j.jeconom.2005.02.011

Knowler, D., \& Bradshaw, B. (2007). Farmers' adoption of conservation agriculture: A review and synthesis of recent research. Food Policy, 32(1), 25-48. doi: 10.1016/j.foodpol.2006.01.003

Koh, L. P., Levang, P., \& Ghazoul, J. (2009). Designer landscapes for sustainable biofuels. Trends in ecology $\&$ evolution, 24(8), 431-438. doi: 10.1016/ j.tree.2009.03.012

Koh, L. P., Miettinen, J., Liew, S. C., \& Ghazoul, J. (2011). Remotely sensed evidence of tropical peatland conversion to oil palm. Proceedings of the National Academy of Sciences of the United States of America, 108(12), 5127-5132. doi: 10.1073/pnas.1018776108

Koh, L. P., \& Wilcove, D. S. (2007). Cashing in palm oil for conservation. Nature, 448(7157), 993-994. doi: 10.1038/448993a

Koh, L. P., \& Wilcove, D. S. (2008). Is oil palm agriculture really destroying tropical biodiversity? Conservation Letters, 1(2), 60-64. doi: 10.1111/ j.1755-263X.2008.00011.x

Kondylis, F., Mueller, V., \& Zhu, J. (2017). Seeing is believing? Evidence from an extension network experiment. Journal of Development Economics, 125, 1-20. doi: 10.1016/j.jdeveco.2016.10.004

Kotowska, M. M., Leuschner, C., Triadiati, T., Meriem, S., \& Hertel, D. (2015). Quantifying above- and belowground biomass carbon loss with forest con- 
version in tropical lowlands of Sumatra (Indonesia). Global change biology, 21 (10), 3620-3634. doi: 10.1111/gcb.12979

Krishna, V., Euler, M., Siregar, H., \& Qaim, M. (2017). Differential livelihood impacts of oil palm expansion in Indonesia. Agricultural Economics, 48(5), 639-653. doi: 10.1111/agec.12363

Kubitza, C., Krishna, V. V., Alamsyah, Z., \& Qaim, M. (2018). The Economics Behind an Ecological Crisis: Livelihood Effects of Oil Palm Expansion in Sumatra, Indonesia. Human Ecology, 46 (1), 107-116. doi: 10.1007/s10745 $-017-9965-7$

Kubitza, C., Krishna, V. V., Urban, K., Alamsyah, Z., \& Qaim, M. (2018). Land Property Rights, Agricultural Intensification, and Deforestation in Indonesia. Ecological Economics, 147, 312-321. doi: 10.1016/j.ecolecon.2018.01.021

Kuhfuss, L., Hanley, N., Preget, R., Thoyer, S., \& de Vries, F. P. (2017). Nudging Participation and Spatial Agglomeration in Payment for Environmental Service Schemes. Discussion papers in Environment and Development Economics, 11.

Kupsch, D., Vendras, E., Ocampo-Ariza, C., Batáry, P., Motombi, F. N., Bobo, K. S., \& Waltert, M. (2019). High critical forest habitat thresholds of native bird communities in Afrotropical agroforestry landscapes. Biological Conservation, 230, 20-28. doi: 10.1016/j.biocon.2018.12.001

Kurniawan, S., Corre, M. D., Matson, A. L., Schulte-Bisping, H., Utami, S. R., van Straaten, O., \& Veldkamp, E. (2018). Conversion of tropical forests to smallholder rubber and oil palm plantations impacts nutrient leaching losses and nutrient retention efficiency in highly weathered soils. Biogeosciences, 15 (16), 5131-5154. doi: 10.5194/bg-15-5131-2018

Lal, R. (2006). Enhancing crop yields in the developing countries through restoration of the soil organic carbon pool in agricultural lands. Land Degradation 8 Development, 17(2), 197-209. doi: 10.1002/ldr.696

Lal, R. (2010). Beyond Copenhagen: mitigating climate change and achieving food security through soil carbon sequestration. Food Security, 2(2), 169-177. doi: $10.1007 / \mathrm{s} 12571-010-0060-9$

Lal, R. (2014). Societal value of soil carbon. Journal of Soil and Water Conservation, $69(6), 186 \mathrm{~A}-192 \mathrm{~A}$. doi: 10.2489/jswc.69.6.186A

Lazear, E. P., Malmendier, U., \& Weber, R. A. (2012). Sorting in Experiments with Application to Social Preferences. American Economic Journal: Applied Economics, 4(1), 136-163. doi: 10.1257/app.4.1.136

Le Coent, P., Preget, R., \& Thoyer, S. (2014). Why pay for nothing? An dexperiment on a conditional subsidy scheme in a threshold public good game. Economics Bulletin, $34(3), 1976-1989$.

Lee, D. (2009). Training, Wages, and Sample Selection: Estimating Sharp Bounds on Treatment Effects. Review of Economic Studies, 76(3), 1071-1102. doi: 10.1111/j.1467-937X.2009.00536.x

Lee, J. S. H., Ghazoul, J., Obidzinski, K., \& Koh, L. P. (2014). Oil palm smallholder yields and incomes constrained by harvesting practices and type of smallholder 
management in Indonesia. Agronomy for Sustainable Development, 34(2), 501-513. doi: 10.1007/s13593-013-0159-4

Levitt, S. D., \& List, J. A. (2007). What Do Laboratory Experiments Measuring Social Preferences Reveal about the Real World? The Journal of Economic Perspectives, 21(2), 153-174.

Lewis, D. J., Plantinga, A. J., Nelson, E., \& Polasky, S. (2011). The efficiency of voluntary incentive policies for preventing biodiversity loss. Resource and Energy Economics, 33(1), 192-211. doi: 10.1016/j.reseneeco.2010.04.012

Liere, H., Jha, S., \& Philpott, S. M. (2017). Intersection between biodiversity conservation, agroecology, and ecosystem services. Agroecology and Sustainable Food Systems, 41(7), 723-760. doi: 10.1080/21683565.2017.1330796

Lin, B. B. (2011). Resilience in Agriculture through Crop Diversification: Adaptive Management for Environmental Change. BioScience, 61(3), 183-193. doi: 10.1525/bio.2011.61.3.4

Liu, Z., Xu, J., Yang, X., Tu, Q., Hanley, N., \& Kontoleon, A. (2019). Performance of Agglomeration Bonuses in Conservation Auctions: Lessons from a Framed Field Experiment. Environmental and Resource Economics, 73(3), 843-869. doi: 10.1007/s10640-019-00330-1

MacKinnon, J. G., \& Webb, M. D. (2017). Wild Bootstrap Inference for Wildly Different Cluster Sizes. Journal of Applied Econometrics, 32(2), 233-254. doi: $10.1002 /$ jae.2508

Madden, D. (2008). Sample selection versus two-part models revisited: the case of female smoking and drinking. Journal of Health Economics, 27(2), 300-307. doi: 10.1016/j.jhealeco.2007.07.001

Manning, W. G., \& Mullahy, J. (2001). Estimating log models: To transform or not to transform? Journal of Health Economics, 20(4), 461-494. doi: 10.1016/S0167-6296(01)00086-8

Margono, B. A., Potapov, P. V., Turubanova, S., Stolle, F., \& Hansen, M. C. (2014). Primary forest cover loss in Indonesia over 2000-2012. Nature Climate Change, 4(8), 730-735. doi: 10.1038/nclimate2277

Margono, B. A., Turubanova, S., Zhuravleva, I., Potapov, P., Tyukavina, A., Baccini, A., Goetz, S., \& Hansen, M. C. (2012). Mapping and monitoring deforestation and forest degradation in Sumatra (Indonesia) using Landsat time series data sets from 1990 to 2010. Environmental Research Letters, 7(3), 034010. doi: 10.1088/1748-9326/7/3/034010

Martensen, A. C., Ribeiro, M. C., Banks-Leite, C., Prado, P. I., \& Metzger, J. P. (2012). Associations of forest cover, fragment area, and connectivity with neotropical understory bird species richness and abundance. Conservation biology : the journal of the Society for Conservation Biology, 26 (6), 1100-1111. doi: 10.1111/j.1523-1739.2012.01940.x

Matata, P. Z., Ajayi, O. C., \& Oduol, P. A. (2010). Socio-economic factors influencing adoption of improved fallow practices among smallholder farmers in Western Tanzania. African Journal of Agricultural Research, 5(8), 818823. 
McCarthy, J. (2010). Processes of inclusion and adverse incorporation: oil palm and agrarian change in Sumatra, Indonesia. The Journal of peasant studies, 37(4), 821-850. doi: 10.1080/03066150.2010.512460

McKenzie, D. (2012). Beyond baseline and follow-up: The case for more T in experiments. Journal of Development Economics, 99(2), 210-221. doi: 10.1016/j.jdeveco.2012.01.002

Meijaard, E., Garcia-Ulloa, J., Sheil, D., Carlson, K. M., Wich, S. A., Juffe-Bignoli, D., \& Brooks, T. M. (2018). Oil palm and biodiversity: a situation analysis by the IUCN Oil Palm Task Force (Vol. 20). IUCN, International Union for Conservation of Nature. doi: 10.2305/IUCN.CH.2018.11.en

Meijer, S. S., Catacutan, D., Ajayi, O. C., Sileshi, G. W., \& Nieuwenhuis, M. (2015). The role of knowledge, attitudes and perceptions in the uptake of agricultural and agroforestry innovations among smallholder farmers in subSaharan Africa. International Journal of Agricultural Sustainability, 13(1), 40-54. doi: 10.1080/14735903.2014.912493

Merten, J., Röll, A., Guillaume, T., Meijide, A., Tarigan, S., Agusta, H., Dislich, C., Dittrich, C., Faust, H., Gunawan, D., Hein, J., Hendrayanto, Knohl, A., Kuzyakov, Y., Wiegand, K., \& Hölscher, D. (2016). Water scarcity and oil palm expansion: Social views and environmental processes. Ecology and Society, 21(2). doi: 10.5751/ES-08214-210205

Miccolis, A., Robiglio, V., Cornelius, J. P., Blare, T., \& Castellani, D. (2019). Oil palm agroforestry: fostering socially inclusive and sustainable production in Brazil. In R. Jezeer \& N. Pasiecznik (Eds.), Exploring inclusive palm oil production (pp. 55-62). Wageningen: Tropenbos International.

Midler, E., Pascual, U., Drucker, A. G., Narloch, U., \& Soto, J. L. (2015). Unraveling the effects of payments for ecosystem services on motivations for collective action. Ecological Economics, 120, 394-405. doi: 10.1016/ j.ecolecon.2015.04.006

Minasny, B., Malone, B. P., McBratney, A. B., Angers, D. A., Arrouays, D., Chambers, A., Chaplot, V., Chen, Z.-S., Cheng, K., Das, B. S., Field, D. J., Gimona, A., Hedley, C. B., Hong, S. Y., Mandal, B., Marchant, B. P., Martin, M., McConkey, B. G., Mulder, V. L., O’Rourke, S., Richer-de Forges, A. C., Odeh, I., Padarian, J., Paustian, K., Pan, G., Poggio, L., Savin, I., Stolbovoy, V., Stockmann, U., Sulaeman, Y., Tsui, C.-C., Vågen, T.-G., van Wesemael, B., \& Winowiecki, L. (2017). Soil carbon 4 per mille. Geoderma, 292, 59-86. doi: 10.1016/j.geoderma.2017.01.002

Moradi, A., Teh, C., Goh, K. J., Husni, M., \& Ishak, C. F. (2014). Decomposition and nutrient release temporal pattern of oil palm residues. Annals of Applied Biology, 164(2), 208-219. doi: 10.1111/aab.12094

Moradi, A., Teh Boon Sung, C., Goh, K. J., Husni Mohd Hanif, A., \& Fauziah Ishak, C. (2015). Effect of four soil and water conservation practices on soil physical processes in a non-terraced oil palm plantation. Soil and Tillage Research, 145, 62-71. doi: 10.1016/j.still.2014.08.005

Morgan, K. L., \& Rubin, D. B. (2012). Rerandomization to improve covariate 
balance in experiments. The Annals of Statistics, 40(2), 1263-1282. doi: 10.1214/12-AOS1008

Muradian, R., Arsel, M., Pellegrini, L., Adaman, F., Aguilar, B., Agarwal, B., Corbera, E., Ezzine de Blas, D., Farley, J., Froger, G., Garcia-Frapolli, E., Gómez-Baggethun, E., Gowdy, J., Kosoy, N., Le Coq, J. F., Leroy, P., May, P., Méral, P., Mibielli, P., Norgaard, R., Ozkaynak, B., Pascual, U., Pengue, W., Perez, M., Pesche, D., Pirard, R., Ramos-Martin, J., Rival, L., Saenz, F., van Hecken, G., Vatn, A., Vira, B., \& Urama, K. (2013). Payments for ecosystem services and the fatal attraction of win-win solutions. Conservation Letters, 6(4), 274-279. doi: 10.1111/j.1755-263X.2012.00309.x

Murdiyarso, D., Hergoualc'h, K., \& Verchot, L. V. (2010). Opportunities for reducing greenhouse gas emissions in tropical peatlands. Proceedings of the National Academy of Sciences of the United States of America, 107(46), 19655-19660. doi: 10.1073/pnas.0911966107

Myers, N., Mittermeier, R. A., Mittermeier, C. G., da Fonseca, G. A., \& Kent, J. (2000). Biodiversity hotspots for conservation priorities. Nature, 403(6772), 853-858. doi: 10.1038/35002501

Narloch, U., Pascual, U., \& Drucker, A. G. (2012). Collective Action Dynamics under External Rewards: Experimental Insights from Andean Farming Communities. World Development, 40(10), 2096-2107. doi: 10.1016/ j.worlddev.2012.03.014

Obidzinski, K., Andriani, R., Komarudin, H., \& Andrianto, A. (2012). Environmental and Social Impacts of Oil Palm Plantations and their Implications for Biofuel Production in Indonesia. Ecology and Society, 17(1). doi: 10.5751/ES-04775-170125

Ochoa-Quintero, J. M., Gardner, T. A., Rosa, I., Ferraz, S. F. d. B., \& Sutherland, W. J. (2015). Thresholds of species loss in Amazonian deforestation frontier landscapes. Conservation biology : the journal of the Society for Conservation Biology, 29(2), 440-451. doi: 10.1111/cobi.12446

OECD, \& FAO (2019). OECD-FAO Agricultural Outlook 2019-2028. Paris: OECD Publishing. doi: 10.1787/agr $\backslash \backslash$ textunderscore $\}$ outlook-2019-en

Ojienyi, S. O., \& Agbede, O. O. (1980). Soil organic matter and yield of forest and tree crops. Plant and Soil, 57, 61-67.

Olea, J. L. M., \& Pflueger, C. (2013). A Robust Test for Weak Instruments. Journal of Business \&5 Economic Statistics, 31(3), 358-369. doi: 10.1080/ 00401706.2013.806694

Omotilewa, O. J., Ricker-Gilbert, J., \& Ainembabazi, J. H. (2019). Subsidies for Agricultural Technology Adoption: Evidence from a Randomized Experiment with Improved Grain Storage Bags in Uganda. American Journal of Agricultural Economics, $101(3)$, 753-772. doi: 10.1093/ajae/aay108

Pagiola, S., Ramírez, E., Gobbi, J., de Haan, C., Ibrahim, M., Murgueitio, E., \& Ruíz, J. P. (2007). Paying for the environmental services of silvopastoral practices in Nicaragua. Ecological Economics, 64 (2), 374-385. doi: 10.1016/ j.ecolecon.2007.04.014 
Pardini, R., Bueno, A. d. A., Gardner, T. A., Prado, P. I., \& Metzger, J. P. (2010). Beyond the fragmentation threshold hypothesis: regime shifts in biodiversity across fragmented landscapes. PloS one, 5(10), e13666. doi: 10.1371/journal.pone.0013666

Parkhurst, G. M., \& Shogren, J. F. (2007). Spatial incentives to coordinate contiguous habitat. Ecological Economics, 64(2), 344-355. doi: 10.1016/ j.ecolecon.2007.07.009

Parkhurst, G. M., Shogren, J. F., Bastian, C., Kivi, P., Donner, J., \& Smith, R. B. (2002). Agglomeration bonus: An incentive mechanism to reunite fragmented habitat for biodiversity conservation. Ecological Economics, 41(2), 305-328. doi: 10.1016/S0921-8009(02)00036-8

Pattanayak, S. K., Wunder, S., \& Ferraro, P. J. (2010). Show Me the Money: Do Payments Supply Environmental Services in Developing Countries? Review of Environmental Economics and Policy, 4(2), 254-274. doi: 10.1093/reep/ req006

Pauli, N., Donough, C., Oberthür, T., Cock, J., Verdooren, R., Rahmadsyah, Abdurrohim, G., Indrasuara, K., Lubis, A., Dolong, T., \& Pasuquin, J. M. (2014). Changes in soil quality indicators under oil palm plantations following application of 'best management practices' in a four-year field trial. Agriculture, Ecosystems 65 Environment, 195, 98-111. doi: 10.1016/j.agee.2014.05.005

Petersen, E. H., \& Hoyle, F. C. (2016). Estimating the economic value of soil organic carbon for grains cropping systems in Western Australia. Soil Research, 54(4), 383. doi: 10.1071/SR15101

Phalan, B., Fitzherbert, E. B., Rafflegeau, S., Struebig, M. J., \& Verwilghen, A. (2009). Conservation in oil-palm landscapes. Conservation biology : the journal of the Society for Conservation Biology, 23(2), 244-5; author reply 245-6. doi: 10.1111/j.1523-1739.2008.01151.x

Rabe-Hesketh, S., \& Skrondal, A. (2013). Avoiding biased versions of Wooldridge's simple solution to the initial conditions problem. Economics Letters, 120(2), 346-349. doi: 10.1016/j.econlet.2013.05.009

Radford, J. Q., Bennett, A. F., \& Cheers, G. J. (2005). Landscape-level thresholds of habitat cover for woodland-dependent birds. Biological Conservation, 124(3), 317-337. doi: 10.1016/j.biocon.2005.01.039

Rahman, N., de Neergaard, A., Magid, J., van de Ven, G. W. J., Giller, K. E., \& Bruun, T. B. (2018). Changes in soil organic carbon stocks after conversion from forest to oil palm plantations in Malaysian Borneo. Environmental Research Letters, 13(10), 105001. doi: 10.1088/1748-9326/aade0f

Rhebergen, T., Fairhurst, T., Whitbread, A., Giller, K. E., \& Zingore, S. (2018). Yield gap analysis and entry points for improving productivity on large oil palm plantations and smallholder farms in Ghana. Agricultural Systems, 165, 14-25. doi: 10.1016/j.agsy.2018.05.012

Rist, L., Feintrenie, L., \& Levang, P. (2010). The livelihood impacts of oil palm: smallholders in Indonesia. Biodiversity and Conservation, 19(4), 1009-1024. doi: 10.1007/s10531-010-9815-Z 
Rode, J., Gómez-Baggethun, E., \& Krause, T. (2014). Motivation crowding by economic incentives in conservation policy: A review of the empirical evidence. Ecological Economics. doi: 10.1016/j.ecolecon.2014.09.029

Romero, M., Wollni, M., Rudolf, K., Asnawi, R., \& Irawan, B. (2019). Promoting biodiversity enrichment in smallholder oil palm monocultures - Experimental evidence from Indonesia. World Development, 124, 104638. doi: 10.1016/ j.worlddev.2019.104638

Rommel, J., \& Anggraini, E. (2018). Spatially explicit framed field experiments on ecosystem services governance. Ecosystem Services, 34, 201-205. doi: 10.1016/j.ecoser.2018.10.002

Roodman, D., Nielsen, M. Ø., MacKinnon, J. G., \& Webb, M. D. (2019). Fast and wild: Bootstrap inference in Stata using boottest. The Stata Journal: Promoting communications on statistics and Stata, 19(1), 4-60. doi: 10.1177/ $1536867 X 19830877$

Ruseva, T. B., Evans, T. P., \& Fischer, B. C. (2015). Can incentives make a difference? Assessing the effects of policy tools for encouraging tree-planting on private lands. Journal of environmental management, 155, 162-170. doi: 10.1016/j.jenvman.2015.03.026

Salmon, C., \& Tanguy, J. (2016). Rural Electrification and Household Labor Supply: Evidence from Nigeria. World Development, 82, 48-68. doi: 10.1016/ j.worlddev.2016.01.016

Samarppuli, I. N., Ekanayake, A., \& Samarppuli, L. (1999). Modeling the effects of land degradation on rubber yield. Journal of Plantation Crops, 27, 179-186.

Sanderson, E., \& Windmeijer, F. (2016). A weak instrument Formula: see texttest in linear IV models with multiple endogenous variables. Journal of Econometrics, 190(2), 212-221. doi: 10.1016/j.jeconom.2015.06.004

Sheil, D. (2009). The impacts and opportunities of oil palm in Southeast Asia: What do we know and what do we need to know? CIFOR Occasional Paper, 51.

Shiferaw, B., Kebede, T., Kassie, M., \& Fisher, M. (2015). Market imperfections, access to information and technology adoption in Uganda: Challenges of overcoming multiple constraints. Agricultural Economics, 46(4), 475-488. doi: 10.1111/agec.12175

Simons, A. M., Beltramo, T., Blalock, G., \& Levine, D. I. (2017). Using unobtrusive sensors to measure and minimize Hawthorne effects: Evidence from cookstoves. Journal of Environmental Economics and Management, 86, 68-80. doi: 10.1016/j.jeem.2017.05.007

Slingerland, M., Khasanah, N., van Noordwijk, M., Susanti, A., \& Meilantina, M. (2019). Improving smallholder inclusivity through integrating oil palm with crops. In Jezeer, Rosalien Pasiecznik, Nick (Ed.), Exploring inclusive Palm oil production (pp. 147-154).

Soliman, T., Lim, F. K. S., Lee, J. S. H., \& Carrasco, L. R. (2016). Closing oil palm yield gaps among Indonesian smallholders through industry schemes, pruning, weeding and improved seeds. Royal Society open science, 3(8), 160292. doi: 
$10.1098 /$ rsos. 160292

Spiller, J., \& Bolle, F. (2017). Experimental investigations of binary threshold public good games. European University Viadrina Frankfurt (Oder) - Discussion Paper, 393.

Straub, P. G. (1995). Risk dominance and coordination failures in static games. The Quarterly Review of Economics and Finance, 35(4), 339-363. doi: 10.1016/1062-9769(95)90048-9

Suleiman, R., \& Rapoport, A. (1992). Provision of step-level public goods with continuous contribution. Journal of Behavioral Decision Making, 5(2), 133153. doi: 10.1002/bdm.3960050205

Syafiq, M., Nur Atiqah, A. R., Ghazali, A., Asmah, S., Yahya, M. S., Aziz, N., Puan, C. L., \& Azhar, B. (2016). Responses of tropical fruit bats to monoculture and polyculture farming in oil palm smallholdings. Acta Oecologica, 74, 11-18. doi: 10.1016/j.actao.2016.06.005

Tao, H.-H., Snaddon, J. L., Slade, E. M., Caliman, J.-P., Widodo, R. H., Suhardi, \& Willis, K. J. (2017). Long-term crop residue application maintains oil palm yield and temporal stability of production. Agronomy for sustainable development, 37(4), 33. doi: 10.1007/s13593-017-0439-5

Tavoni, A., Dannenberg, A., Kallis, G., \& Löschel, A. (2011). Inequality, communication, and the avoidance of disastrous climate change in a public goods game. Proceedings of the National Academy of Sciences of the United States of America, 108(29), 11825-11829. doi: 10.1073/pnas.1102493108

Teh, C. (2016). Availability, use, and removal of oil palm biomass in Indonesia: Report prepared for the International Council on Clean Transportation.

Teh Boon Sung, C., Joo, G. K., Chien, L. C., \& Seng, S. T. (2011). Short-term Changes in the Soil Physical and Chemical Properties due to Different Soil and Water Conservation Practices in a Sloping Land Oil Palm Estate. Pertanika Journal of Tropical Agricultural Science, 34(1), 41-62.

Teoh, C. H. (2010). Key Sustainability Issues in the Palm Oil Sector: A Discussion Paper for Multi-Stakeholders Consultations (commissioned by the World Bank Group). Retrieved 22.02.2020, from http://siteresources.worldbank.org/INTINDONESIA/Resources/226271 -1170911056314/Discussion.Paper_palmoil.pdf

Teuscher, M., Gérard, A., Brose, U., Buchori, D., Clough, Y., Ehbrecht, M., Hölscher, D., Irawan, B., Sundawati, L., Wollni, M., \& Kreft, H. (2016). Experimental Biodiversity Enrichment in Oil-Palm-Dominated Landscapes in Indonesia. Frontiers in plant science, 7, 1538. doi: 10.3389/fpls.2016.01538

Teuscher, M., Vorlaufer, M., Wollni, M., Brose, U., Mulyani, Y., \& Clough, Y. (2015). Trade-offs between bird diversity and abundance, yields and revenue in smallholder oil palm plantations in Sumatra, Indonesia. Biological Conservation, 186, 306-318. doi: 10.1016/j.biocon.2015.03.022

Thaler, R. (1980). Toward a positive theory of consumer choice. Journal of Economic Behavior \& Organization, 1(1), 39-60. doi: 10.1016/0167-2681(80) 90051-7 
The World Bank (2016). Indicators: Agriculture and rural Development. Retrieved 02.05.2019, from https://data.worldbank.org/

The World Bank, \& IFC (2011). The World Bank Group Framework and IFC Strategy for Engagement in the Palm Oil Sector. Retrieved 22.02.2020, from https://www.ifc.org/wps/wcm/connect/ industry_ext_content/ifc_external_corporate_site/agribusiness / resources/palmoil_strategydocument

Tscharntke, T., Batáry, P., \& Dormann, C. F. (2011). Set-aside management: How do succession, sowing patterns and landscape context affect biodiversity? Agriculture, Ecosystems \& Environment, 143(1), 37-44. doi: 10.1016/j.agee .2010 .11 .025

Tscharntke, T., Clough, Y., Wanger, T. C., Jackson, L., Motzke, I., Perfecto, I., Vandermeer, J., \& Whitbread, A. (2012). Global food security, biodiversity conservation and the future of agricultural intensification. Biological Conservation, 151(1), 53-59. doi: 10.1016/j.biocon.2012.01.068

Tscharntke, T., Klein, A. M., Kruess, A., Steffan-Dewenter, I., \& Thies, C. (2005). Landscape perspectives on agricultural intensification and biodiversity ecosystem service management. Ecology Letters, 8(8), 857-874. doi: 10.1111/j.1461-0248.2005.00782.x

Tukey, J. W. (1977). Exploratory data analysis. Reading, Mass.: Addison-Wesley. United Nations (2012). The future we want: Outcome document of the United Nations Conference on Sustainable Development. Retrieved 24.02.2020, from https://sustainabledevelopment.un.org/content/documents/ 733FutureWeWant.pdf

USDA (2020). Oilseeds: World Markets and Trade. Retrieved 16.03.2020, from https://downloads.usda.library.cornell.edu/usda-esmis/files/tx31qh68h/ c247f928p/h415pt06n/oilseeds.pdf

van Campenhout, B., van Asten, P., Rashed, A., Vandevelde, S., \& Walukano, W. (2017). Agricultural Extension Messages Using Video on Portable Devices Increased Knowledge about Seed Selection, Storage and Handling among Smallholder Potato Farmers in Southwestern Uganda. PLOS ONE, 12(1), e0169557. doi: 10.1371/journal.pone.0169557

van Campenhout, B., Walukano, W., Nattembo, F., Nazziwa-Nviiri, L., \& Blom, J. (2017). The Role of Information in Agricultural Technology Adoption: Experimental Evidence from Rice Farmers in Uganda. IFPRI Discussion Paper, 01684.

van de Kragt, A. J. C., Orbell, J. M., \& Dawes, R. M. (1983). The Minimal Contributing Set as a Solution to Public Goods Problems. American Political Science Review, 77 (1), 112-122. doi: 10.2307/1956014

van Noordwijk, M., Roshetko, J. M., Murniati, Angeles, M. D., Suyanto, Fay, C., \& Tomich, T. P. (2008). Farmer Tree Planting Barriers to Sustainable Forest Management. In P. K. R. Nair, D. J. Snelder, \& R. D. Lasco (Eds.), Smallholder Tree Growing for Rural Development and Environmental Services (pp. 429-451). Springer Netherlands. doi: 
10.1007/978-1-4020-8261-0\{\textunderscore 20

van Straaten, O., Corre, M. D., Wolf, K., Tchienkoua, M., Cuellar, E., Matthews, R. B., \& Veldkamp, E. (2015). Conversion of lowland tropical forests to tree cash crop plantations loses up to one-half of stored soil organic carbon. Proceedings of the National Academy of Sciences of the United States of America, 112(32), 9956-9960. doi: 10.1073/pnas.1504628112

Vijay, V., Pimm, S. L., Jenkins, C. N., \& Smith, S. J. (2016). The Impacts of Oil Palm on Recent Deforestation and Biodiversity Loss. PloS one, 11(7), e0159668. doi: 10.1371/journal.pone.0159668

Wander, M., \& Nissen, T. (2004). Value of Soil Organic Carbon in Agricultural Lands. Mitigation and Adaptation Strategies for Global Change, 9(4), 417-431. doi: 10.1023/B:MITI.0000038847.30124.77

Warziniack, T., Shogren, J. F., \& Parkhurst, G. (2007). Creating contiguous forest habitat: An experimental examination on incentives and communication. Journal of Forest Economics, 13(2-3), 191-207. doi: 10.1016/j.jfe.2007.02 .009

Wätzold, F., \& Drechsler, M. (2014). Agglomeration payment, agglomeration bonus or homogeneous payment? Resource and Energy Economics, 37, 85-101. doi: 10.1016/j.reseneeco.2013.11.011

With, K. A., Pavuk, D. M., Worchuck, J. L., Oates, R. K., \& Fisher, J. L. (2002). Threshold Effects of Landscape Structure on Biological Control in Agroecosystems. Ecological Applications, 12(1), 52-65. doi: 10.1890/ 1051-0761(2002)012[0052:TEOLSO]2.0.CO;2

Woittiez, L. S., van Wijk, M. T., Slingerland, M., van Noordwijk, M., \& Giller, K. E. (2017). Yield gaps in oil palm: A quantitative review of contributing factors. European Journal of Agronomy, 83, 57-77. doi: 10.1016/j.eja.2016.11.002

Wooldridge, J. M. (2005). Simple solutions to the initial conditions problem in dynamic, nonlinear panel data models with unobserved heterogeneity. Journal of Applied Econometrics, 20(1), 39-54. doi: 10.1002/jae.770

Wooldridge, J. M. (2010). Econometric analysis of cross section and panel data (2. ed. ed.). Cambridge, Mass.: MIT Press.

World Resources Institute, Rainforest Alliance, Proforest, Daemeter, Trase, Earthworm, Auriga, CIFOR, Transitions, Benedict, J., Heilmayr, R., \& Carlson, K. (2019). Universal Mill List. Retrieved 02.03.2020, from www.globalforestwatch.org

Wunder, S. (2015). Revisiting the concept of payments for environmental services. Ecological Economics, 117, 234-243. doi: 10.1016/j.ecolecon.2014.08.016

Wunder, S., \& Albán, M. (2008). Decentralized payments for environmental services: The cases of Pimampiro and PROFAFOR in Ecuador. Ecological Economics, 65(4), 685-698. doi: 10.1016/j.ecolecon.2007.11.004

Wunder, S., Engel, S., \& Pagiola, S. (2008). Taking stock: A comparative analysis of payments for environmental services programs in developed and developing countries. Ecological Economics, 65(4), 834-852. doi: 10.1016/ j.ecolecon.2008.03.010 
Yahya, M. S., Syafiq, M., Ashton-Butt, A., Ghazali, A., Asmah, S., \& Azhar, B. (2017). Switching from monoculture to polyculture farming benefits birds in oil palm production landscapes: Evidence from mist netting data. Ecology and evolution, 7(16), 6314-6325. doi: 10.1002/ece3.3205

Yesuf, M., \& Bluffstone, R. A. (2009). Poverty, Risk Aversion, and Path Dependence in Low-Income Countries: Experimental Evidence from Ethiopia. American Journal of Agricultural Economics, 91 (4), 1022-1037. doi: 10.1111/j.1467 -8276.2009.01307.x

Zemp, D. C., Ehbrecht, M., Seidel, D., Ammer, C., Craven, D., Erkelenz, J., Irawan, B., Sundawati, L., Hölscher, D., \& Kreft, H. (2019). Mixed-species tree plantings enhance structural complexity in oil palm plantations. Agriculture, Ecosystems 85 Environment, 283, 106564. doi: 10.1016/j.agee.2019.06.003

Zemp, D. C., Gérard, A., Hölscher, D., Ammer, C., Irawan, B., Sundawati, L., Teuscher, M., \& Kreft, H. (2019). Tree performance in a biodiversity enrichment experiment in an oil palm landscape. Journal of Applied Ecology, 56(10), 2340-2352. doi: 10.1111/1365-2664.13460

Zwane, A. P., Zinman, J., van Dusen, E., Pariente, W., Null, C., Miguel, E., Kremer, M., Karlan, D. S., Hornbeck, R., Giné, X., Duflo, E., Devoto, F., Crepon, B. \& Banerjee, A. (2011). Being surveyed can change later behavior and related parameter estimates. Proceedings of the National Academy of Sciences of the United States of America, 108(5), 1821-1826. doi: 10.1073/pnas.1000776108 
Appendix A

General Appendix 


\title{
A.1 Appendix Chapter 2
}

\author{
CRC 990 Indonesia \\ Follow-up Survey-2016 (shortened version)
}

This is a research project carried out jointly by the University of Göttingen in Germany, the University of Jambi and Bogor Agricultural University. We wish to learn more about the environmental conditions in Jambi Province and about the decisions that farmers make on their farms and in their communities. The survey is conducted in $\mathbf{5}$ different Districts, and your village and household was selected to be part of the study. If you agree to participate in the interview, your responses will be treated confidentially and used strictly for research purpose. The questions covered in this questionnaire are about you, your family members, farming activities, physical assets and resource management. If you have any doubts about the interview, you are free to ask questions at any time. It is important to note that there are no "right" or "wrong" answers. It is your most honest response that will help us to understand your opinion. The interview will take no longer than 2 hours. Your household number will be used for identification in the study, and therefore your name will not be used.

\section{Section 2 - General land use}

2.1 Could you please tell me, how many hectares of land your household owns? (ha)

Please note that with "household" I mean you, but also all the other members of your family that live with you and share your meals regularly. Even persons that are not related to you, but that live with you and depend on you economically should be included here. However, relatives that have their own household should not be included here.

2.2 How much of it is:

\begin{tabular}{|c|c|c|c|}
\hline Agricultural land (ha) & Forest (ha) & $\begin{array}{c}\text { Sleeping/ Fallow /Waste land } \\
\text { (ha) }\end{array}$ & $\begin{array}{c}\text { Rented out to another person } \\
\text { (ha) }\end{array}$ \\
\hline & & & \\
\hline
\end{tabular}

2.3 Which crops are you or any member of your household currently cultivating? Please include crops that you grow on your own land, but also crops that you manage on rented or share-cropped land.

\begin{tabular}{|c|c|c|c|c|c|c|c|}
\hline \multirow[b]{2}{*}{ Crop } & \multirow[b]{2}{*}{$\begin{array}{l}\text { Total } \\
\text { managed } \\
(\mathrm{Ha})\end{array}$} & \multicolumn{3}{|c|}{ From the total, how many are: } & \multirow[b]{2}{*}{$\begin{array}{c}\text { From } \\
\text { the } \\
\text { owned } \\
\text { ha, how } \\
\text { many } \\
\text { are } \\
\text { plasma }\end{array}$} & \multirow[b]{2}{*}{$\begin{array}{c}\text { Did you sell } \\
\text { any of the } \\
\text { produce? } \\
\text { Yes }=1 ; \\
\mathrm{No}=0\end{array}$} & \multirow{2}{*}{$\begin{array}{c}\text { If yes, please } \\
\text { indicate } \\
\text { where? } \\
\{\text { Code A }\}\end{array}$} \\
\hline & & $\begin{array}{c}\text { Owned } \\
\text { (ha) }\end{array}$ & $\begin{array}{l}\text { Sharecropping } \\
\text { (ha) }\end{array}$ & Rented in (ha) & & & \\
\hline 1. Oil Palm & & & & & & & \\
\hline $\begin{array}{l}\text { 2. Rubber Plantation } \\
\text { (Less than } 10 \text { other trees } \\
\text { per ha than rubber) }\end{array}$ & & & & & & & \\
\hline $\begin{array}{l}\text { 3. Jungle rubber } \\
\text { (More than } 10 \text { other } \\
\text { trees per ha than rubber) }\end{array}$ & & & & & & & \\
\hline 4. Rice & & & & & & & \\
\hline
\end{tabular}

Code $A$ : Trader=1; Company=2; Village market $=3$; Own shop=4; Other $($ specify $)=5$

2.4 Do you have homegarden? Yes/No

a) If yes, what is it the size?

2.5 Do you have oil palm in your homegarden?

a) if yes, how many oil palms do you have?

\section{Section 3 - Oil palm cultivation}

Now, I would like to ask you some questions about your oil palm plots. 
3.1 How many plots do you currently own or rent to cultivate oil palm?

Please note that with "oil palm plot" I mean a piece of land that is not spatially segmented, and where oil palms have more or less the same age and are managed in the same way.

3.2 For the following questions, we are interested in all those oil palm plots that are managed by yourself or a member of your household, no matter whether the oil palms are grown on your own land or land that you rented from somebody else to grow oil palms.

How many oil palm plots are managed by your household?

3.2 a) Please tell us how we can refer to each of these plots throughout the interview:

Plot 1:

Plot 2:

Plot 3:

3.3 Please indicate for each of these plots managed by yourself or a member of your household...

\begin{tabular}{|c|c|c|c|c|}
\hline \multirow{2}{*}{\multicolumn{2}{|c|}{ 1. Size of the plot in hectares }} & Plot 1 & Plot 2 & Plot 3 \\
\hline & & & & \\
\hline \multicolumn{2}{|c|}{ 2. Year Planting } & & & \\
\hline \multicolumn{2}{|c|}{ 3. Planting distance between oil palms in meters $\mathrm{x}$ meters } & & & \\
\hline \multicolumn{2}{|c|}{ 4. Number of productive oil palms } & & & \\
\hline \multicolumn{2}{|c|}{ 5. What is the ownership of the land? $\{$ Code A $\}$} & & & \\
\hline \multirow{4}{*}{$\begin{array}{l}\text { If Code } \\
\text { A=1 } \\
\text { (owned) }\end{array}$} & $\begin{array}{l}\text { a. Do you have a certificate for the plot? (including the certificate with your } \\
\text { name or with the name of the previous owner) }\{\text { Code B\} (if no, go to } \\
\text { question 3.4) }\end{array}$ & & & \\
\hline & $\begin{array}{l}\text { b. Do you have this certificate with you at present, or with another } \\
\text { person/ institution, e.g. a credit institution? } \\
\text { (if yes, go to d) })\end{array}$ & Yes/No & Yes/No & Yes/No \\
\hline & c. If no, who is currently holding the land title/certificate? $\{$ Code $\mathrm{C}\}$ & & & \\
\hline & d. When did you obtain this certificate? (Year) & & & \\
\hline \multirow{3}{*}{$\begin{array}{l}\text { If Code } \\
A=2 \\
\text { (rented } \\
\text { in) }\end{array}$} & a. Do you pay a rental fee for this plot? (if no, skip (b)) & Yes/No & Yes/No & Yes/No \\
\hline & b. If yes, amount of rent paid during the last 12 months? ('000 Rp.) & & & \\
\hline & c. Since when do you have this agreement? (Year) & & & \\
\hline
\end{tabular}

Code A: Owned=1; Rented-in=2

Code B: Yes, Systematic Certificate $=1$; Yes, Sporadic certificate $=2$; Yes, Letter from village head or Segal = 3, None=4

Code $C$ : Plantation company $=1 ;$ Government $=2 ;$ Bank $=3$; Others (specify) $=4$

\begin{tabular}{|l|l|l|l|}
\hline & Plot 1 & Plot 2 & \multicolumn{1}{c|}{ Plot 3 } \\
\hline 3.4 Did you acquire or managed this plot during the last 12 months? & Yes/No & Yes/No & Yes/No \\
\hline $\begin{array}{l}\text { 3.5 If no: have you cleared the whole plot and start a new plantation of oil palm during } \\
\text { the last 12 months? }\end{array}$ & Yes/No & Yes/No & Yes/No \\
\hline
\end{tabular}

If the farmer answered question 3.4 and 3.5 with "yes", please fill questions 3.6 to 3.10. Otherwise skip to section 3.11

3.6 I would now like to ask you some more detailed questions about each of these oil palm plots that you or another member of your household manage...

To fill new plot, please refer to the plot reference specified in question 3.2a

\begin{tabular}{|l|l|l|l|}
\hline & New plot: & New plot:_ & New plot: \\
\hline 1.Year of first harvest ever & & & \\
\hline 2. Number of rows & & & \\
\hline 3. Number of oil palms per rows & & & \\
\hline 4. Total number of oil palms in the plot & & & \\
\hline
\end{tabular}




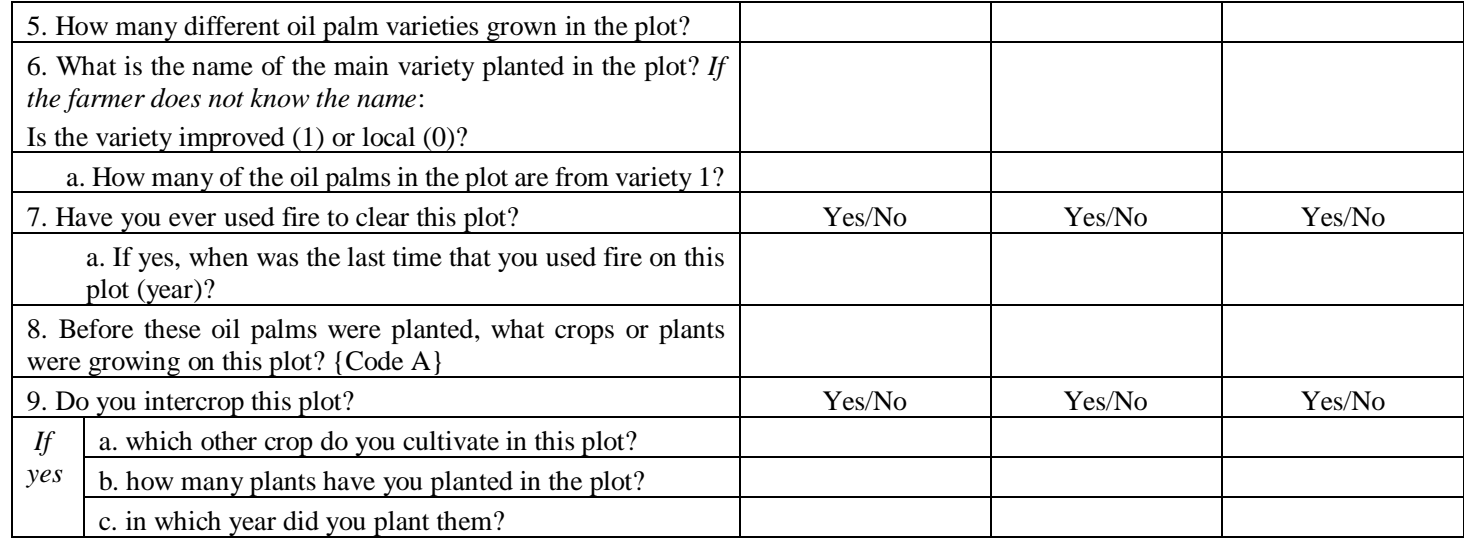

Code $A$ : oil palm $=1$; plantation rubber $=2 ;$ jungle rubber $=3$; other plantation $=4$; annual crops (specify) $=5$; grassland=6; forest $=7$; bush $=8$; others $($ specify) $=9$

Please help us to understand the location of your plots in the landscape:

3.7. How far is the plot from....

(in kilometers!) Write O if it is within 500 meters, or n.a. if Not available

\begin{tabular}{|l|l|l|l|}
\hline & New plot: & New plot: & New plot: \\
\hline $1 \ldots$ your house? & & & \\
\hline $3 \ldots$ the next paved road? & & & \\
\hline $5 . \ldots$ the closest market? & & & \\
\hline $4 \ldots$ the closest agricultural shop? & & & \\
\hline $6 \ldots$ the nearest forest? & & & \\
\hline
\end{tabular}

\begin{tabular}{|c|c|c|c|c|c|}
\hline & & & $\begin{array}{l}\text { New } \\
\text { plot: }\end{array}$ & New plot: & New plot: \\
\hline \multicolumn{3}{|c|}{ 3.8 Is there a river bordering the plot or running through the plot? } & Yes/No & Yes/No & Yes/No \\
\hline \multirow[t]{2}{*}{ If yes; } & \multicolumn{2}{|l|}{ a. How wide is it? } & meters & meters & Meters \\
\hline & \multicolumn{2}{|c|}{$\begin{array}{l}\text { b. What is the distance between the planted oil palms and } \\
\text { the river? }\end{array}$} & meters & meters & Meters \\
\hline If no; & \multicolumn{2}{|c|}{ a. How far is the next river or lake? } & meters & meters & Meters \\
\hline \multicolumn{6}{|c|}{ 3.9 Are there swamp areas on your plot? } \\
\hline \multicolumn{6}{|c|}{ 3.10 a. How steep is the plot on average? (see figure below) } \\
\hline \multicolumn{6}{|c|}{ b. How is the soil texture $\{$ Code $A\}$} \\
\hline \multirow{2}{*}{\multicolumn{2}{|c|}{$\begin{array}{l}\text { c. How is the color of the soil? } \\
\text { \{Code B }\} \\
\text { (show Card \#1 to farmer) }\end{array}$}} & Rainy Season & & & \\
\hline & & Dry Season & & & \\
\hline \multicolumn{3}{|c|}{ d. How is the water penetration? $\{$ Code $C\}$} & & & \\
\hline
\end{tabular}

Code $A$ : coarse $/$ light $($ sandy $)=1$, medium $($ loam $)=2$; fine $/$ heavy $($ clay $)=3$

Code B: Blackish=1; Brownish=2; Redish=3; Yellowish $=4$

Code $C$ : Rapid=1; Moderate $=2$; Slow $=3$; waterlogged $=4$

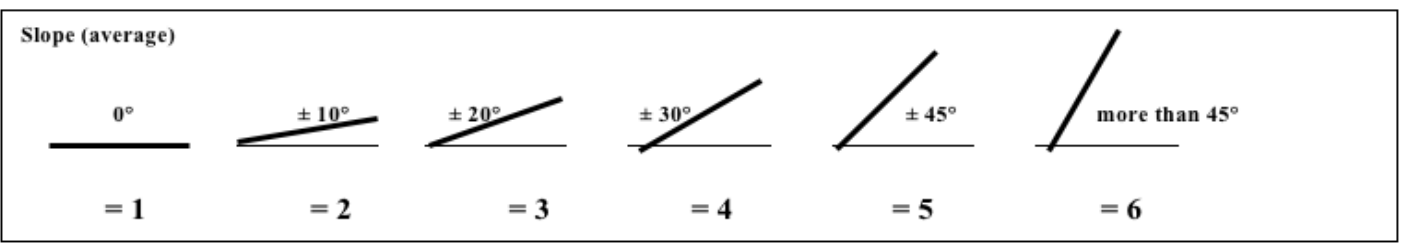


3.14 During the last 12 months, did you apply any fertilizers, soil amendments or manure on your plots? Yes/No

If no, continue with question 3.16 If yes, fill out the following table, remember to complete first the information for Plot 1, and then continue with Plot 2 .

\begin{tabular}{|c|c|c|c|c|c|c|c|c|c|c|c|c|c|c|c|c|c|c|}
\hline \multirow[b]{3}{*}{ Specify } & \multicolumn{6}{|c|}{ Plot 1} & \multicolumn{6}{|c|}{ Plot 2} & \multicolumn{6}{|c|}{ Plot 3} \\
\hline & $\begin{array}{l}\text { Lime / } \\
\text { gypsum }\end{array}$ & $\begin{array}{l}\text { Animal } \\
\text { manure }\end{array}$ & $\begin{array}{c}\text { Plant } \\
\text { manure }\end{array}$ & Fert.1 & Fert.2 & Fert.3 & $\begin{array}{l}\text { Lime/ } \\
\text { gypsum }\end{array}$ & $\begin{array}{l}\text { Animal } \\
\text { manure }\end{array}$ & $\begin{array}{c}\text { Plant } \\
\text { manure }\end{array}$ & Fert.1 & Fert.2 & Fert.3 & $\begin{array}{c}\text { Lime/ } \\
\text { gypsum }\end{array}$ & $\begin{array}{l}\text { Animal } \\
\text { manure }\end{array}$ & $\begin{array}{c}\text { Plant } \\
\text { manure }\end{array}$ & Fert.1 & Fert.2 & Fert.3 \\
\hline & & & & & & & & & & & & & & & & & & \\
\hline $\begin{array}{l}\text { 1. Number of } \\
\text { applications in } \\
\text { last } 12 \text { months: }\end{array}$ & & & & & & & & & & & & & & & & & & \\
\hline $\begin{array}{l}\text { 2. Amount per } \\
\text { application: }\end{array}$ & & & & & & & & & & & & & & & & & & \\
\hline $\begin{array}{l}\text { 3. Unit of } \\
\text { application }\{\mathrm{Co} \\
\text { A\} }\end{array}$ & & & & & & & & & & & & & & & & & & \\
\hline $\begin{array}{l}\text { 4. Price per uni } \\
\text { ('000 Rp.): }\end{array}$ & & & & & & & & & & & & & & & & & & \\
\hline $\begin{array}{l}\text { 5. Unit of } \\
\text { price }\{\text { Code A }\}\end{array}$ & & & & & & & & & & & & & & & & & & \\
\hline
\end{tabular}

Code A: Sack=1; Kilo=2; Liter=3; Gallon =4; Other (specify)=

3.15 In the past 12 months, how much did you spend on input transport for...

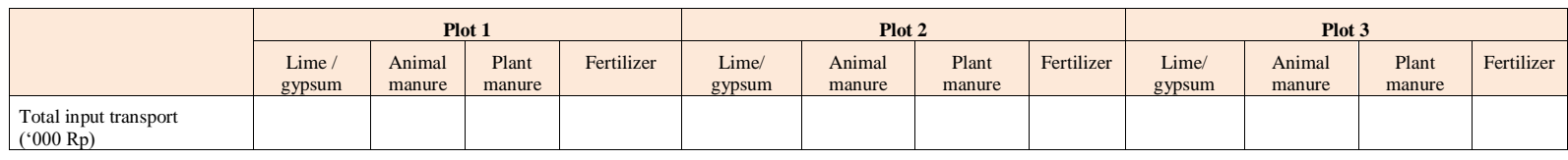


3.16 During the last 12 months, did you apply any herbicides or pesticides on your plots? Yes/No

If no, continue with question 3.18. If yes, fill out the following table, remember to complete first the information for Plot 1 , and then continue with Plot 2.

\begin{tabular}{|l|l|l|l|l|l|l|l|l|l|l|l|l|}
\hline & \multicolumn{9}{|c|}{ Plot 1 } & \multicolumn{9}{c|}{ Plot 2 } & \multicolumn{3}{c|}{ Plot 3 } \\
\cline { 2 - 12 } & Herb. 1 & Herb. 2 & Herb. 3 & Pesticide & Herb. 1 & Herb. 2 & Herb. 3 & Pesticide & Herb. 1 & Herb. 2 & Herb. 3 & Pesticide \\
\cline { 2 - 12 } & & & & & & & & & & & & \\
\hline $\begin{array}{l}\text { 1. Number of applications in } \\
\text { the last 12 months }\end{array}$ & & & & & & & & & & & & \\
\hline 2. Amount per application & & & & & & & & & & & & \\
\hline $\begin{array}{l}\text { 3. Unit of application } \\
\text { \{Code A\} }\end{array}$ & & & & & & & & & & & & \\
\hline 4. Price per unit ('000 Rp.): & & & & & & & & & & & & \\
\hline 5. Unit of price \{Code A\} & & & & & & & & & & & & \\
\hline
\end{tabular}

Code $A$ : Sack=1; Kilo=2; Liter=3; Gallon=4; Other (specify) $=5$

3.17 In the past 12 months, how much did you spend on input transport for..

\begin{tabular}{|c|c|c|c|c|c|c|}
\hline & \multicolumn{2}{|c|}{ Plot 1} & \multicolumn{2}{|c|}{ Plot 1} & \multicolumn{2}{|c|}{ Plot 1} \\
\hline & $\begin{array}{c}\text { Total transport } \\
\text { Herbicide }\end{array}$ & $\begin{array}{c}\text { Total transport } \\
\text { Pesticide }\end{array}$ & $\begin{array}{c}\text { Total transport } \\
\text { Herbicide }\end{array}$ & $\begin{array}{c}\text { Total transport } \\
\text { Pesticide }\end{array}$ & Total transport Herbicide & Total transport Pesticide \\
\hline $\begin{array}{l}\text { Total input transport: } \\
\text { ('000 Rp) }\end{array}$ & & & & & & \\
\hline
\end{tabular}


3.19 During the last 12 months, did you perform (manual) weeding or leaf pruning? Yes/No

If no, continue with question 3.20. If yes, fill out the following table, remember to complete first the information for Plot 1 , and then continue with Plot 2.

\begin{tabular}{|c|c|c|c|c|c|c|c|c|c|c|}
\hline & \multicolumn{3}{|c|}{ Plot 1} & \multicolumn{3}{|c|}{ Plot 2} & \multicolumn{3}{|c|}{ Plot 3} \\
\hline & & $\begin{array}{l}\text { Manual weeding } \\
\text { of the soil }\end{array}$ & $\begin{array}{c}\text { Manual } \\
\text { weeding of } \\
\text { the oil palm } \\
\text { stem }\end{array}$ & $\begin{array}{l}\text { Cutting } \\
\text { leaves off } \\
\text { the palms }\end{array}$ & $\begin{array}{c}\text { Manual } \\
\text { weeding of the } \\
\text { soil }\end{array}$ & $\begin{array}{c}\text { Manual weeding } \\
\text { of the oil palm } \\
\text { stem }\end{array}$ & $\begin{array}{l}\text { Cutting } \\
\text { leaves off } \\
\text { the palms }\end{array}$ & $\begin{array}{c}\text { Manual } \\
\text { weeding of the } \\
\text { soil }\end{array}$ & $\begin{array}{l}\text { Manual weeding } \\
\text { of the oil palm } \\
\text { stem }\end{array}$ & $\begin{array}{l}\text { Cutting } \\
\text { leaves } \\
\text { off the } \\
\text { palms }\end{array}$ \\
\hline & & Yes/No & Yes/No & Yes/No & Yes/No & Yes/No & Yes/No & Yes/No & Yes/No & Yes/No \\
\hline \multicolumn{11}{|c|}{$\begin{array}{l}\text { 1. Number of operations in the last } 12 \\
\text { months: }\end{array}$} \\
\hline \multicolumn{11}{|c|}{$\begin{array}{l}\text { 2. Application paid as borongan? } \mathrm{Yes}=1 \text {; } \\
\mathrm{No}=0\end{array}$} \\
\hline $\begin{array}{l}\text { If } \\
\text { yes }\end{array}$ & $\begin{array}{l}\text { a. What was the total cost? ('000 } \\
\text { Rp.) }\end{array}$ & & & & & & & & & \\
\hline \multirow[t]{7}{*}{ If no } & $\begin{array}{l}\text { b. Total number of workers per } \\
\text { application: }\end{array}$ & & & & & & & & & \\
\hline & $\begin{array}{l}\text { c. Total number of days per } \\
\text { application: }\end{array}$ & & & & & & & & & \\
\hline & d. Total number of hours per day : & & & & & & & & & \\
\hline & From the total number of workers: & & & & & & & & & \\
\hline & $\begin{array}{l}\text { e. How many of these were unpaid } \\
\text { family workers? }\end{array}$ & & & & & & & & & \\
\hline & $\begin{array}{l}\text { f. How many of these were casual } \\
\text { workers? }\end{array}$ & & & & & & & & & \\
\hline & g. Daily wage ('000 Rp.) & & & & & & & & & \\
\hline \multicolumn{2}{|c|}{$\begin{array}{l}\text { 3. Machinery cost: } \\
\text { ('000 Rp / application) }\end{array}$} & & & & & & & & & \\
\hline
\end{tabular}




\begin{tabular}{|l|c|c|c|}
\hline 3.20 During the past 12 months have you... & & & \\
\hline $1 \ldots$ left ground vegetation grow on the plot? & Yes/No & Yes/No & Yes/No \\
\hline $2 \ldots .$. left the palm leaves to cover all the soil on your plantation? & Yes/No & Yes/No & Yes/No \\
\hline $3 . \ldots$ left the palm leaves as an additional row on your plantation? & Yes/No & Yes/No & Yes/No \\
\hline $4 . \ldots$ returned the empty fruit bunches to the soil around the oil palms? & Yes/No & Yes/No & Yes/No \\
\hline $5 \ldots . .$. planted any legumes? & Yes/No & Yes/No & Yes/No \\
\hline $6 . .$. left cows graze your plot? & Yes/No & Yes/No & Yes/No \\
\hline
\end{tabular}

3.23 During the last 12 months...

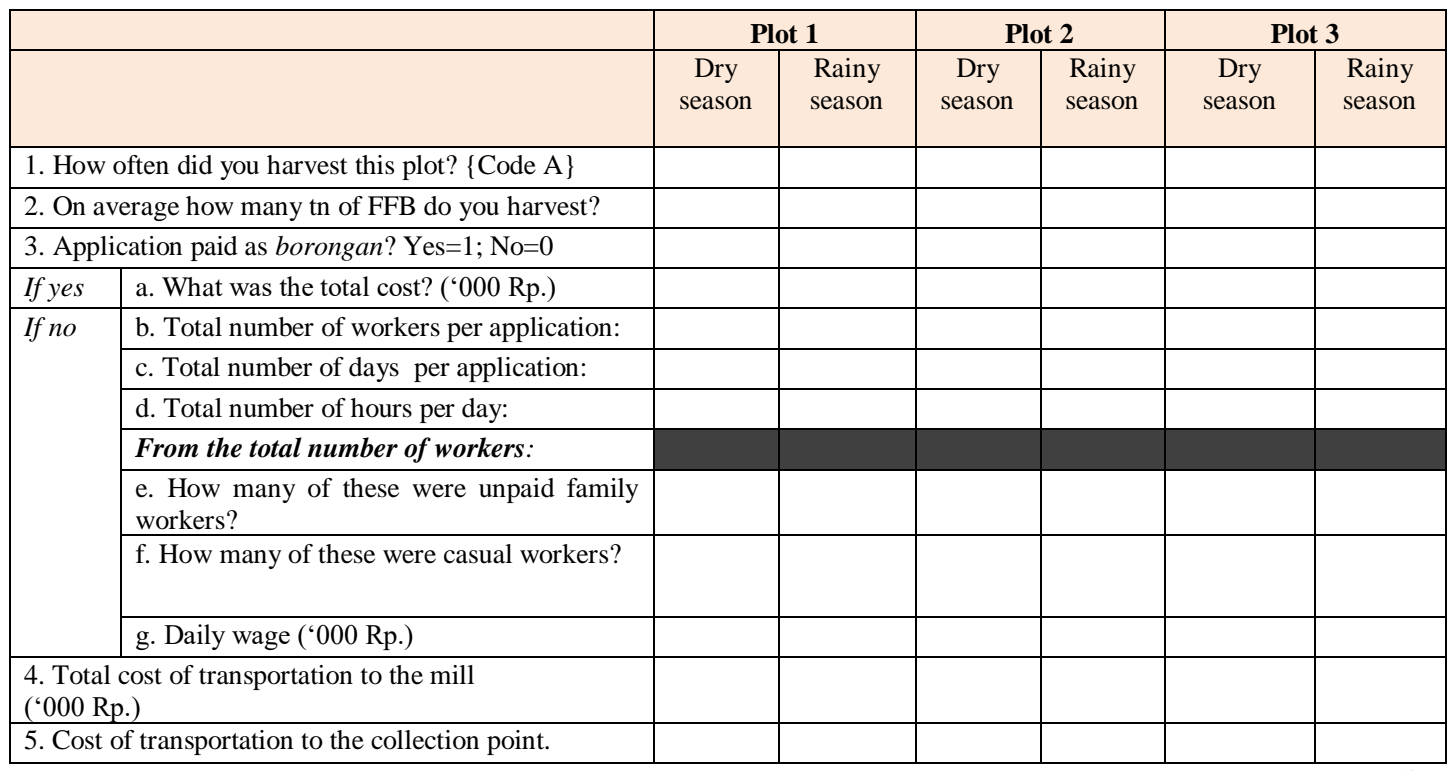

Code A: (Once every week=1); (Once every two weeks=2); (Once every three weeks=3); (Once every month=4); (Other (specify))

3.23 What is the average price that you obtained for the oil palm fruits in that season? (' $000 \mathrm{Rp} / \mathrm{kg}$ )

\begin{tabular}{|c|c|}
\hline Dry season & Rainy season \\
\hline & \\
\hline
\end{tabular}

\section{Section 4: Tree planting and cutting activities}

4.1 During the last 12 months, have you cut any trees on your oil palm plots or elsewhere on your land?

\begin{tabular}{|l|l|l|l|}
\hline & Yes=1/No=0 & $\begin{array}{c}\text { Number cut on oil palm } \\
\text { plots }\end{array}$ & $\begin{array}{c}\text { Number cut in any other } \\
\text { location } \\
\text { Specify: }\end{array}$ \\
\hline 1. Durian & & & \\
\hline 2. Petai & & & \\
\hline 3. Jengkol & & & \\
\hline 4. Meranti & & & \\
\hline 5. Sungkai & & & \\
\hline 6. Jelutung & & & \\
\hline Other: & & & \\
\hline Other: & & & \\
\hline Other: & & & \\
\hline
\end{tabular}

4.2 If you cut any trees during the last 12 months, what was the main reason? 
4.3 Did anybody ever advice you to cut trees in your oil palm plantation? Yes/No

If yes: a. please specify who:

b. What was the main reason that they gave for cutting trees in your oil palm plantation?

4.4 During the last 12 months, have you planted any trees on your oil palm plots or elsewhere on your land?

\begin{tabular}{|l|l|l|l|l|l|l|}
\hline & $\begin{array}{c}\text { Yes=1 } \\
\text { No=0 }\end{array}$ & $\begin{array}{c}\text { Number } \\
\text { planted } \\
\text { on oil } \\
\text { palm } \\
\text { plots }\end{array}$ & $\begin{array}{c}\text { How many } \\
\text { of these } \\
\text { trees } \\
\text { survived? }\end{array}$ & $\begin{array}{l}\text { Arrangement: } \\
\text { (1) dispersed } \\
\text { (2) tree islands } \\
\text { (clustered) } \\
\text { (3) around the edge } \\
\text { of the plot }\end{array}$ & $\begin{array}{c}\text { Number planted in any } \\
\text { other location }\end{array}$ & $\begin{array}{c}\text { How many of } \\
\text { Specify:- }\end{array}$ \\
survived? \\
\hline 1. Durian & & & & & & \\
\hline 2. Petai & & & & & & \\
\hline 3. Jengkol & & & & & & \\
\hline 4. Meranti & & & & & & \\
\hline 5. Sungkai & & & & & & \\
\hline 6. Jelutung & & & & & & \\
\hline Other: & & & & & & \\
\hline Other: & & & & & & \\
\hline Other: & & & & & & \\
\hline
\end{tabular}

4.5 If you planted any trees during the last 12 months, what was the main reason?

4.6 Did anybody ever advice you to plant trees in your oil palm plantation? Yes/No If yes: a. please specify who:

b. What was the main reason that they gave for planting trees in your oil palm plantation?

4.7 Who in your household decides whether to cut or plant trees?:

4.8 Did you obtain any seedlings of native trees during the last 12 months? Yes/ No

If yes, please fill out the following table. If no, go to question $\mathbf{4 . 1 2}$

\begin{tabular}{|c|c|c|c|c|c|c|c|c|}
\hline \multirow{2}{*}{\multicolumn{2}{|c|}{$\begin{array}{l}\text { 1. Where did you obtain the seedlings? \{Code } \\
\text { A\} }\end{array}$}} & Durian & Petai & Jengkol & Meranti & Sungkai & Jelutung & Others \\
\hline & & & & & & & & \\
\hline \multicolumn{9}{|c|}{ 2. How many seedlings did you obtain? } \\
\hline \multicolumn{9}{|c|}{$\begin{array}{l}\text { 3. How much did you pay per seedling? } \\
\text { ('000Rp.) }\end{array}$} \\
\hline \multicolumn{9}{|c|}{$\begin{array}{l}\text { 4. What did you do with the seedlings? \{Code } \\
\text { B\} }\end{array}$} \\
\hline If $=1$ & a. Where did you planted? & & & & & & & \\
\hline If $=2$ & b. What did you receive in return? & & & & & & & \\
\hline If $=3$ & c. How much did you receive? & & & & & & & \\
\hline
\end{tabular}

Code A: Own nursery=1; extension worker $=2$ government nursery=3; individual farmers' nursery $=4$; local shop $=5$; local trader $=6$, other $=7$ (specify)

Code $B:$ Planted $=1$ : Exchanged=2; Sold $=3$, other $=4$ (specify) 
4.9 If you received a free seedlings among the ones mentioned above, would you have liked to obtain other types of trees? Yes / No

a) If yes, which other trees would you prefer?

b) Would you plant these trees in your oil palm plantation? Yes / No

c) For the trees you have received for free, have you given any special maintenance? If no, please move to question $\mathbf{4 . 1 2}$

Yes/No

4.10 If input application and maintenance to the recently planted seedlings in oil palm plots was given, please fill out these tables:

a)

\begin{tabular}{|l|l|l|l|l|l|l|l|l|l|}
\hline & $\begin{array}{c}\text { Lime / } \\
\text { gypsum }\end{array}$ & $\begin{array}{c}\text { Animal } \\
\text { manure }\end{array}$ & $\begin{array}{c}\text { Plant } \\
\text { manure }\end{array}$ & Fert.1 & Fert.2 & Herb.1 & Herb.2 & Pest.1 & Pest.2 \\
\cline { 2 - 10 } & & & & & & & & & \\
\hline $\begin{array}{l}\text { 1. Number of applications } \\
\text { in the last 12 months }\end{array}$ & & & & & & & & & \\
\hline 2. Amount per application & & & & & & & & & \\
\hline $\begin{array}{l}\text { 3. Unit of per application } \\
\text { (Code A) }\end{array}$ & & & & & & & & & \\
\hline
\end{tabular}

Code $A$ : Sack=1; kilo=2; liter=3; Other (specify)=4

b)

\begin{tabular}{|c|c|c|}
\hline & $\begin{array}{l}\text { Manual weeding } \\
\text { around the trees }\end{array}$ & Pruning the trees \\
\hline$\rightarrow$ & Yes/No & Yes/No \\
\hline 1. Number of operations in the last 12 months: & & \\
\hline
\end{tabular}

4.12 Please name the three most important reasons, why you are not planting more native trees on or along your oil palm plots. Please give the most important reason first, then the second most important reason, and then the third most important reason:

1.

2

3

4.14 No matter whether you have planted trees during the last 12 months or not, please indicate whether you have any native trees in your oil palm plantation (planted recently or a long time ago):

a) Yes, there are native trees in my oil palm plantation

b) No, there are absolutely no native trees in my oil palm plantation

(If no, go to question 4.21)

If yes, for each of your oil palm plots, please tell me how many of the different tree species there are:

\begin{tabular}{|l|l|l|l|l|l|l|}
\hline Name of tree species & $\begin{array}{c}\text { a. Number } \\
\text { of trees }\end{array}$ & $\begin{array}{c}\text { b. How many trees } \\
\text { are productive? }\end{array}$ & $\begin{array}{l}\text { c. Did you } \\
\text { plant them? }\end{array}$ & $\begin{array}{c}\text { d. If yes, in } \\
\text { which } \\
\text { year? }\end{array}$ & $\begin{array}{c}\text { Please } \\
\text { indicate } \\
\text { plot } \\
\text { location }\end{array}$ & Arrangement \\
\hline Durian & & & & & & \\
\hline Petai & & & & & & \\
\hline
\end{tabular}




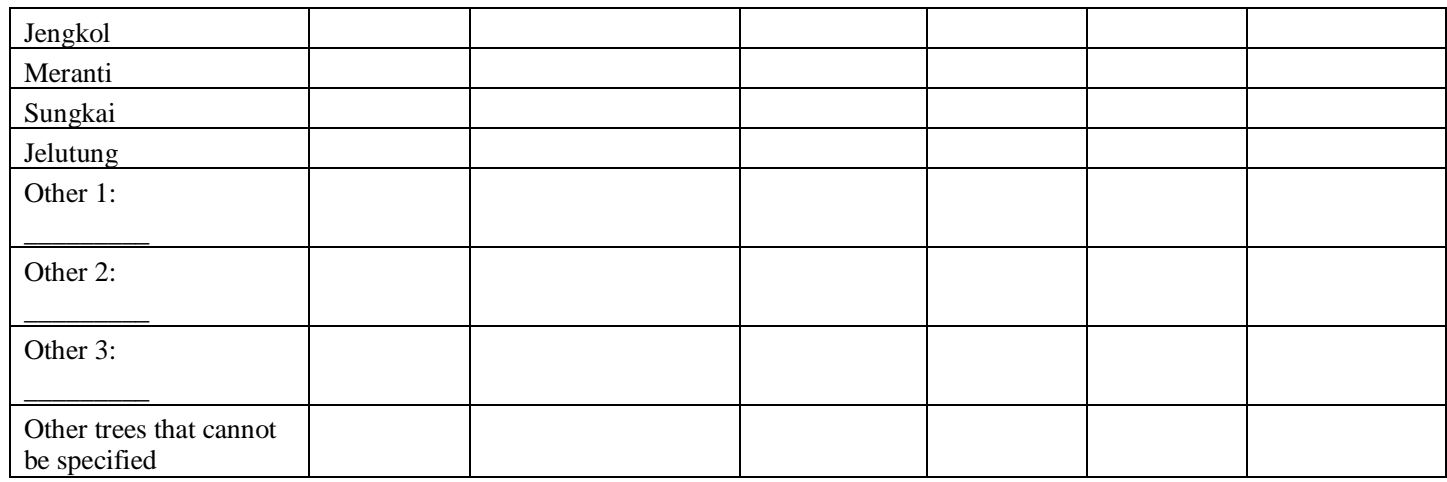

\section{Section 7 - Extension services and information}

Now, we are interested in learning about the different trainings or extension services you have received, as well as the sources from which you obtain information about oil palm management and tree planting.

7.1 Could you tell me whether during the past 12 months you have receive extension or training about...

\begin{tabular}{|l|l|l|l|}
\hline & $\begin{array}{c}\text { Received } \\
\text { extension? }\end{array}$ & $\begin{array}{c}\text { If yes, who provided this } \\
\text { extension service? } \\
\text { [Code A\} }\end{array}$ & $\begin{array}{c}\text { How many times did you receive } \\
\text { this service during the past } 12 \\
\text { months? }\end{array}$ \\
\hline 1. Oil palm management & Yes /No & & \\
\hline 2. Tree planting in oil palm plantations & Yes /No & & \\
\hline $\begin{array}{l}\text { 3. Planting and management of native } \\
\text { fruit and timber trees }\end{array}$ & Yes /No & & \\
\hline 4. Water management and conservation & Yes /No & & \\
\hline 5. Soil management and conservation & Yes /No & & \\
\hline 6. Prevention of fires & Yes /No & & \\
\hline 7. Other (specify): & Yes /No & & \\
\hline 8. Other (specify): & Yes /No & & \\
\hline
\end{tabular}

Code A: Agriculture ministry (specify) =1; Extension worker (

Cooperative $=5$; farmers group $($ specify $)=6 ;$ NGO $($ specify) $=7 ;$ Other $($ specify $)=8$

7.2 Did you obtain information on oil palm management or native fruit and timber trees from any of the following sources in the past 12 months?

\begin{tabular}{|c|c|c|}
\hline & Oil palm management & Tree planting \\
\hline 1. Internet & Yes/No & Yes/No \\
\hline $\begin{array}{l}\text { a. If yes, how frequently do you seek information from } \\
\text { this source? }\{\text { Code A\} }\end{array}$ & & \\
\hline 2. Other farmers in the village & Yes/No & Yes/No \\
\hline $\begin{array}{l}\text { a. If yes, how frequently do you seek information from } \\
\text { this source? }\{\text { Code A\} }\end{array}$ & & \\
\hline 3. Other farmers outside the village & Yes/No & Yes/No \\
\hline $\begin{array}{l}\text { a. If yes, how frequently do you seek information from } \\
\text { this source? }\{\text { Code A\} } \\
\text { b. From which village: }\end{array}$ & & \\
\hline 4. Manual or booklet & Yes/No & Yes/No \\
\hline $\begin{array}{l}\text { a. If yes, how frequently do you seek information from } \\
\text { this source? }\{\text { Code } \mathrm{A}\}\end{array}$ & & \\
\hline b. Who provided this manual? & & \\
\hline
\end{tabular}




\begin{tabular}{|l|c|c|}
\hline 5. Movie & Yes/No & Yes/No \\
\hline $\begin{array}{l}\text { a. If yes, how frequently do you seek information from } \\
\text { this source? }\{\text { Code A\} }\end{array}$ & & \\
\hline \multicolumn{2}{|l|}{ b. Who show you this movie? } & \\
\hline
\end{tabular}

Code A: Everyday=1; Once a week=2; Once every two weeks=3; Once a month=4; Other ( specify)=5

7.3 If the farmer has received an illustrative manual or watched the movie. Please ask the following questions:

a). Have you followed any advice suggested in the manual or movie? Yes/No

b). If yes, which advice did you follow?

c) Did you discuss the contents of the manual/movie with other villagers, e.g. your neighbors or friends? Yes/No

d) Would you have preferred to receive this information in another way? Yes / No

e) If yes, what way would you have found more convincing?

\section{Section 10 - Socio-demographic characteristics}

10.1 In the following, I will ask you some questions about the history and characteristics of your family.

\begin{tabular}{|c|c|c|}
\hline \multicolumn{2}{|c|}{$\begin{array}{l}\text { 1. Did your household migrate to this village? } \\
\text { If no, go to question } 2\end{array}$} & Yes /No \\
\hline \multirow[t]{3}{*}{ If yes } & a. When did you migrate to this village? (Year) & \\
\hline & b. From where did you migrate? $\{$ Code A $\}$ & \\
\hline & c. Was your household part of the "transmigrasi" program? & Yes /No \\
\hline \multicolumn{2}{|c|}{ 2. What is the religion of your family? $\{$ Code B $\}$} & \\
\hline \multicolumn{2}{|c|}{ 3. and, the religion of the household head? $\{$ Code $B\}$} & \\
\hline \multicolumn{2}{|c|}{$\begin{array}{l}\text { 4. Total number of household members who were staying with you in the } \\
\text { house during the past } 12 \text { months: }\end{array}$} & \\
\hline
\end{tabular}

Code A: Other part of Jambi = 1; Java = 2; North Sumatra = 3; South Sumatra = 4; Kalimantan = 5; Sulawesi = 6; Others (specify) $=7$

Code $B$ : Islam=1, Christian=2; Hindu=3; Buddhist=4; Others $($ specify $)=5$ 
10.2 For each of these___ persons, can you please give me their names (first name is sufficient). Enumerator: write the names into the first column; remember that the first row is for the household head.

I am now going to ask you some additional questions for each household member. Let us start with the household head.

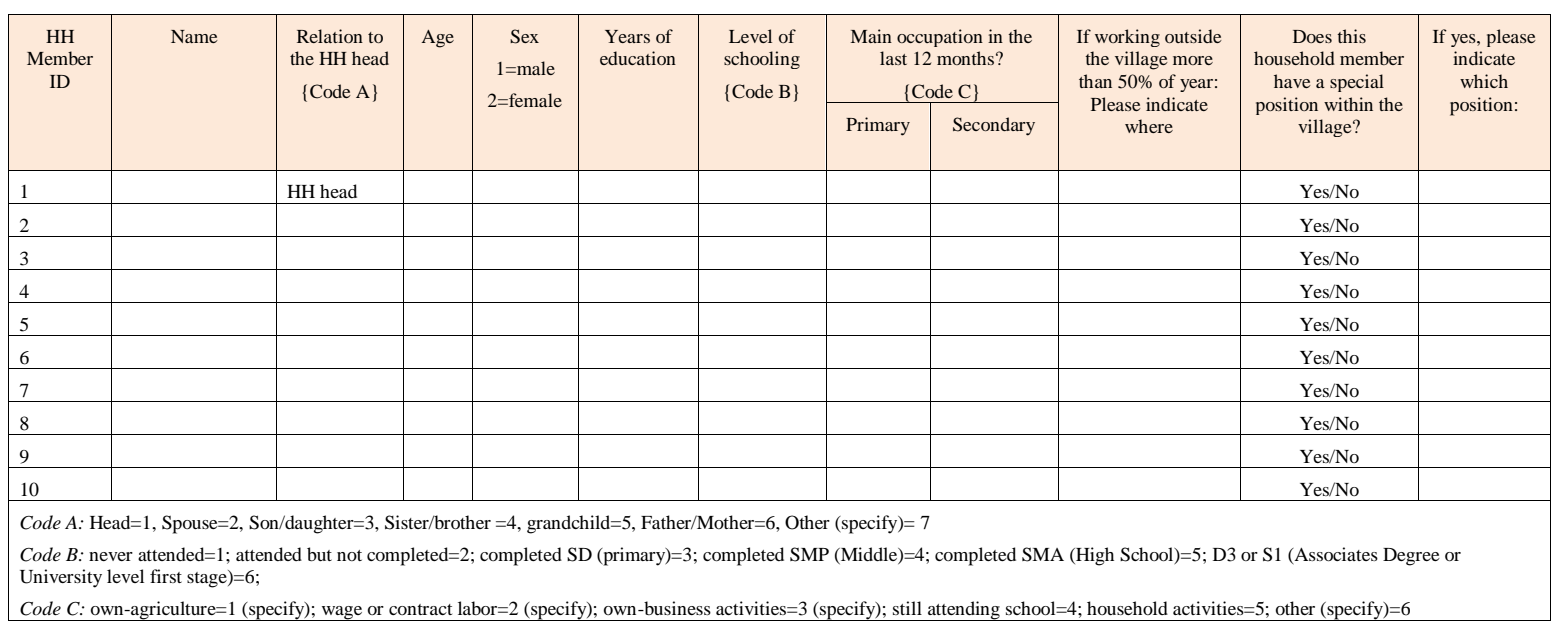




\section{Section 11 - Assets}

11.1 Now I will read a list of different items to you. Please tell me, if you currently own this item and what its value is:

\begin{tabular}{|l|l|l|}
\hline \multicolumn{1}{|c|}{ Asset } & Number owned & $\begin{array}{c}\text { If you were to sell these items today, how much money would } \\
\text { you receive? } \\
\text { ('000 Rp) }\end{array}$ \\
\hline 1. Television & & \\
\hline 2. Motorbike & & \\
\hline 3. Car & & \\
\hline 4. 4-wheel tractor & & \\
\hline 5. Jeep/Truck/Angkot & & \\
\hline 6. Fridge & & \\
\hline 7. Air conditioner (AC) & & \\
\hline 8. Fan & & \\
\hline 9. Washing machine & & \\
\hline 10. Cell-phones & & \\
\hline 11. Computers & & \\
\hline
\end{tabular}




\title{
A.2 Appendix Chapter 3
}

\author{
Instructions for framed field experiment
}

Procedure before start of the activity

1. Arrival: the respondents arrive at the location and show the message on their mobile phone which has been sent to them.

2. The research assistants hand over the sheet of informed consent to the participants. They explain to the participants that this sheet contains information about their rights not to participate in the activity or to leave early, and the consequences these decisions will have. They explain to the participants that the University of Goettingen is very keen on ensuring the security of the data. Therefore, the researcher is obliged by the European law to inform the participants about who they can contact in Germany in case they are concerned about the use of their data. They ask the participants whether they need help with reading the sheet of informed consent. The assistants tell the participants that they can take a seat somewhere in the room, raise their hands in case they need help and should come back to the assistants once they have read through the information sheet.

3. The assistants ask the farmers to pick an id. They enter this id in the identification file in excel. They hand over the corresponding envelope for the respective id. They inform the participants that they should not show this id to any other person in the room in order to ensure the confidentiality of the data. They tell the participants that it is very important that they keep their identity number until the very end, since only by showing this number they will receive the compensation that they have earned. The participants should be informed that somebody of the research team will inform them once they can give away their ids. The assistants also hand over an envelope in which the prepared decision sheets of the farmers with the respective id are. The assistants also give a seat id to the farmer. This seat id is indicated in the identification file.

4. The assistants bring the farmer to the assigned seat which is indicated in the prepared excel file.

\section{Begin general instructions}

Note: The sentences in italics represent instructions for the enumerators and should not be read out loud.

Thank you very much for following our invitation and joining this workshop! We are part of the Efforts project which is a cooperation of the university of Goettingen, in Germany, the university of Jambi, IPB Bogor and Tadulako university of Palu. Our special thanks goes to the village head/PAK/Ibu $X$ for allowing us to do the research in this village and helping us with the organization. This activity will take around 2-3 hours, including the explanations, the activity and a short survey at the end. In case you know that you will not be able to stay until the end of the activity please let us know now.

All the decisions you will make in this activity will remain private. The activity consists of several rounds. In each round you can earn points. In the end, we will select one round randomly. The points you have earned in this round will then be converted in IDR by multiplying the amount of points by 1000 . Hence, if you have made 100 points in the round, you will get $100 \mathrm{~K}$ IDR. This money together with the money that you have earned when completing our questionnaire will be given to you at the end of the activity in form of a voucher for the local shop

The reason why we use money in this activity is that it mirrors your real live where the decisions on your farm have monetary consequences for you. The money is not the private money of the researcher but has been given by the university in Goettingen, in Germany for research purposes. This means that the money is not linked to any political or environmental organization such that nobody is expecting you to behave in a specific way. Only if you behave like you would in real live, we are able to understand decision making here in Jambi.

Before we start with explaining you in detail how the activity works, we would like to raise your attention to the following points:

\section{Some general comments:}

- Please don't use your mobile phone throughout the workshop. 
- The workshop in which you participate now is different from the ones your neighbors in this village have already participated in. Hence comments you might have heard in the last days, do not apply for your session.

- All decisions you make or answers you give during the workshop will remain private, confidential and anonymous. Only the private activity identification numbers that you have received in an envelope in the beginning of the activity help us to distinguish your replies at a later moment. Please do not show your activity id to any other person in the room! So neither the other session members nor the research team are able to assign you as a person to a specific decision or earning.

- Since all your decisions are private, don't talk to each other once everybody is seated. Please do not discuss with your neighbor.

- Please follow these instructions carefully. Only by following carefully you can make informed decisions in the activity. If you have any questions, please raise your hands. A member of the research team will come to you and answer your questions.

- Please don't share your personal opinion with the group when we take questions.

Do you have any questions so far?

\section{Introduction to the activity}

In this activity you will be asked to make decisions on how to manage your oil palm plantation. Each person will have one hectare of established oil palm plantation that generates an income of 100 points per year.

(Show photo and graph of monoculture oil palm)

In this activity you can decide whether to maintain a pure oil palm plantation as shown in this picture, or whether to establish a diverse cropping system with other native trees on your plot. This would mean that you would need to remove around $40 \%$ of your oil palm trees which is costly and reduces your income also after accounting for the benefits such as fruit and timber that some of the species planted might generate. These trees can be located anywhere in your plantations but should be planted in a clustered way together to support their growth. They include mostly timber trees, such as Sungkai, but can also contain some few fruit trees such as Mangga, and Rambutan. However, the main purpose of the diversified plots is to increase the diversity of plants and animals here in Jambi. Therefore, these tree areas consist of several other tree species, and not only of one other tree or palm species that generate high income for you. It is important to notice that these tree areas do not contain any oil palms! So even if you might think of an oil palm as a tree, the word tree in this activity never refers to an oil palm.

(Show photo and graph of tree areas in oil palm)

Therefore,

.... one hectare with pure oil palms generates an income of 100 points a year

... one hectare with a diverse cropping system generates an income of 50 points a year.

It is important to note that this income already includes the economic benefits of the trees. The income of the diverse system will therefore not exceed 50 points a year.

In the end, we will pick one round. Each round has the same chance of being picked. You will get the returns from that round in form of a voucher. We will convert the points you have earned in this scenario by multiplying the amount by 1000. If you choose to plant a mixed system, you will get 50.000 IDR, if you choose to keep your oil palm plot, you will get 100.000 IDR.

These diversified plots can increase the number of bird species in Jambi. More diversity of bird species means that farmers in Jambi will experience fewer problems with pests attacking their crops and that flowers of trees or 
vegetables develop fruits. Tree areas also have positive effects on the soil, increasing water supply. We will call these positive effects on birds and water availability "environmental benefits".

In this activity, you will play several rounds. In each round you will have to decide whether you keep one hectare of oil palm fully established or whether you establish a diversified plot. In each round, your decision will determine your earnings in that specific round, as explained before.

Throughout the whole activity, you will be assigned to a group of six people. Together you represent one village. Your oil palm plantations are located around the village like this.

(Show village map with oil palm plantations located in a circle around the village)

It is important to note that each of you has two neighbors, one on each side of your plantation. Before we start with the activity, you will get to know who is in your group and who are your two neighbors. Even though you know who is in your group and who is your neighbor, at no point in time, neither during nor after the activity, you will know how they decided to manage their oil palm plantation in this activity. Equally, the other group members will never get to know your decisions that you make during the activity.

It is important to note, however, that these environmental benefits only occur if a certain minimum number of diversified plots are established in the village. Why is that so? Tree areas create a home for birds, but these animals need sufficient space to find food and shelter. Furthermore, environmental benefits are higher if neighboring farmers establish diversified plots. This is because birds can only fly a limited distance. We will now explain to you how your decisions in the activity affect the environmental benefits.

Whether environmental benefits are generated depends on your decision and on the decision of the other members of your group. If in total at least three diversified plots are established within your group, there is enough conservation area to provide a home for birds, and thus environmental benefits occur. More specifically that means, if three or more diversified plots are established by your group, each diversified plot generates six units of environmental benefits. You can think of this as each diversified plot providing a home for six additional bird species, for example. Furthermore, if neighboring farmers establish tree areas, each neighboring farmer more increases environmental benefits by one additional unit. So in case two neighboring farmers engage in tree planting, two additional environmental benefits are generated, if three neighbors plant trees, three additional units of environmental benefits will be generated. To ensure that these environmental benefits produced in the activity actually occur here in Jambi, we will give sixty points for each diversified plot planted in your group and 10 points for each additional neighbor who engages in tree planting to the organization Burung Indonesia. This organization will invest this money in tree planting and forest protection in Harapan rainforest, Jambi Province, to provide a home for birds. It is important to note that these donations do not have any direct monetary effects on you but are meant to generate the environmental effects in Jambi your action has generated.

Do you have any questions so far? If not we will now explain to you how to decide about the management of your oil palm plantation.

\section{How to make your decision on how to manage your oil palm plantation}

At the end of this activity you will receive a monetary earning and, in order to generate the environmental benefits of your decisions, donations will be made to Burung Indonesia. The size of these payments that are generated in this activity depend on your decision and on the decisions of your group members. In order to understand the possible payment sizes during the activity and to calculate your earnings later on you will receive this earning table (show earning table to farmers and distribute earning table to farmers). The earning table makes it easy for you to find out how many points you can earn in each round. It also indicates to you the possible sizes of the environmental benefits, and how much money is accordingly donated to Burung Indonesia in each round. In the first column you find the total number of diversified plots established by the other members of your group. The following columns of the earning table refer to your own decision and indicate whether you decided to establish diversified plantations or not. When you make your decision on whether to establish a diversified plantation or not you do not know how many plots will be established by the other members of your group since all decisions are made at the same time. However, by choosing the number of diversified plots you think the other members of your 
group will plant you can know how much you would earn in that case. You can also find out about the possible sizes for the environmental donations generated. Therefore, you can first choose the row that corresponds to the number of diversified plots you think the other members of your group will plant. The following columns indicate whether you decide to have a pure oil palm plot or a diversified plot. Where row and column cross, you will find the cell that contains your earning in the respective round if you and your group members indeed plant the number of diversified plots as indicated in the row and the column. This is the number which is written first in the table. In addition, you can also see the possible sizes of the environmental donations generated if you and your group members indeed establish the number of diversified plots indicated in the row and the column. These are the numbers in brackets which are written in italics below your earning. The reason why there are several possible sizes of environmental donations is that the exact amount will depend on the number of neighboring farmers who plant trees. The higher the environmental benefits generated are, the more neighboring farmers engage in tree planting. We always indicate you the minimum amount of donations generated in each case and the maximum amount. [Assistants please follow the steps explained on the big table]. It is important to note that the donations correspond to the donations generated by the whole group! As with your income, the more environmental benefits are generated by the group, the lower will be the group income.

Do you have any questions so far? If not, we will explain to you now how you can indicate your decision and how you will get to know the total number of diversified plots the group as a whole has planted.

\section{How to record your decisions and calculate your earnings}

At the beginning we will give you a sheet that shows pictures of the two management options that you can implement in your oil palm plantations. This sheet looks like this [please show the big table with the different management options again]. Next to the pictures, you can see numbers that indicate how we can refer to the chosen management option. Hence, a zero refers to a pure oil palm plantation and a one to a mixed system. At the beginning of each round, you will receive a decision sheet. (Show decision sheet to farmers.) Your private id number which we have given to you in the beginning is already written on the decision sheets which you have received in an envelope in the beginning of the activity. Please then have a look at the sheet which represents the different management options and decide about which management option you would like to implement on your oil palm plantation. Please circle the respective number of tree areas on your decision sheet.

Everybody in this room will make their decision at the same time. It is important that you do not show your decision sheet to anybody and that you do not talk to anybody in the room - this is to ensure that your decision remains private. Please turn away from the others when you make your decisions. After you have marked your decision, please fold the decision sheet - it will then be collected by one of our assistants.

As we play several rounds, it is important that you keep track of your decisions and the decisions of your group. For that purpose, we provide you with this information sheet (show information sheet to farmers). I will now explain to you how to fill out each cell of the information sheet.

Cell (1): It is very important that in each round you write down your decision on how to manage your oil palm plantation on your information sheet. Please enter in cell (1) whether you established a diversified plot or not $(1=$ Yes). This is the same number as on your decision sheet. Please copy this number before you fold and submit your decision sheet. (Show correct cell to farmers.)

- Cell (2): After collecting all the decision sheets, we will calculate the total number of diversified plots established by the group and inform you about this value. Please enter this value in the second cell "total tree areas (group)". (Show correct cell to farmers.)

- Cell (3): To obtain the number of diversified systems established by the other members of your group, which should be written in cell (3), please subtract the number of diversified systems you planted from the total number of tree areas established by the group, so either a zero or a 1 . That means, cell (2) minus cell (1) gives you the value for cell (3). (Show correct cell to farmers.)

- Cell (4): we will calculate the number of neighboring farmers in your groups and inform you about this value. Enter the number of neighboring farmers who established tree areas in your group in Cell (4).

- Cell (5): To calculate your earnings you need cell (1) and cell (3) as well as the earning table. As we have explained to you already, the earning table makes it easy for you to find out how many points you have 
earned in each round. In the first column you find the total number of diversified plots established by the other members in your group. Select the row corresponding to the value that you have entered in cell (3) on your information sheet! The following columns of the earning table refer to your own decision and indicate whether you have chosen to establish a diversified system or not. Select the column corresponding to the value that you have entered in cell (1) on your information sheet! Where row and column cross, you will find the cell that contains your earning in the respective round. Please enter the value which is written first in cell (5) on your information sheet. Please do not copy the values in brackets! (please follow the instructions on the big table)

After filling out the information sheet, we would like to ask you to hide it again so that nobody can see what is written on it.

At the end of the activity, we will randomly select one round and you will receive the monetary earning that corresponds to the selected round. It is important to note that we multiply the points that you have earned in the activity by 1,000 . Thus, if your earnings are 100 points, you are paid 100,000 IDR. If your earnings are 50 points, you are paid 50,000 IDR, and so forth. Similarly, we will assess the units of environmental benefits generated by your group in the selected round and pay Burung Indonesia accordingly. That means, if 200 points of environmental benefit are generated, Burung Indonesia receives $200 * 1,000=200,000$ IDR for tree planting in Jambi.

Practice questions

We will now get a bit familiar with the numbers and the earning table. Each of you will now receive the same earning table. Please take some time to familiarize yourself with the table [assistants wait until the farmers look up]

We will now discuss again the most important pieces of information. Pak X [choose a person from the audience. Please pay attention that you not always ask the same farmers or the farmers which are sitting in front] can you please tell us how many points you get from keeping one hectare of oil palm plantation fully established? Pak Y [please choose another person from the audience] can you please tell us what is the income of a diversified plot? What does this mean? What would be the land use option among the two management options that generates the highest amount of points? [ask that to the whole audience]. As we have told you before, birds need a minimum amount of area under tree cover to live. Pak X, [choose another person from the audience], if the group collectively plants two diversified plots, is this sufficient for birds? And you Pak Y, what do you think? If the group now established 5 diversified plots, is that sufficient? In order to understand a bit better the concept of neighboring farmers, let us have again a look at the picture that represents the situation in the village. [Please show again the table with the location of the neighbors and take stickers which represent tree areas]. The number in the plots which are located around the village refer to the plantations of Pak1, Pak 2, .., Pak 6. Let us now assume that Pak 1, Pak 3 and Pak 5 have engaged in tree planting [Please put the tree area sticker on the respective plots]. How many neighboring farmers are establishing a diversified plot on their plantations? [wait for reply] Now let us have another example. In this group, farmers 1, 2, 4 and 5 plant trees. Pak X, how many neighboring farmers establish a mixed cropping system? [Attention: here it is very important that this will not represent four neighboring farmers but $2 * 2$ neighboring farmers]. Right, in this example only two neighboring farmers engage as the farmers' plantations do not lie next to each other. In our third example, Pak 1, 2, 5 and 6 plant trees. Pak Y can you tell us how many neighboring farmers establish a diversified plot in this example?

Do you have any questions so far? If not, we will now practice how to use the earning table.

Let me give you an example. In these examples, we will know which farmers plant diversified plantations and which not. This is done in order to make ourselves again more familiar with the concept of neighboring farmers. Please remember that in reality you do not know which farmers plant trees. Pak X owns the plantation number 3. His two neighbors owning the plantation 1 and 2 both establish a diversified system, the other persons in the group plant only oil palm. Pak X decides that he would like establish a diversified plantation. In order to see how much Pak X earns in this round, we need to look at the earning table where we have the number of diversified plots the other members in the group plant and the own number of diversified plots planted. Where the column and row 
intersect we have the cell that tells us our earning. It is the first number that indicates the earning we get. Hence, in our example, Pak X will earn 50 points. To see the range in which the environmental donations generated lie, we need to have a look at numbers in parentheses which are printed in italics below the earning. The other two plant one diversified plot each and together with Pak X decision three diversified plots are planted. This would mean that the environmental effects generated in points will be between 180 and 210. Since three neighbors establish diversified plantations, the precise amount of points generated for Burung Indonesia is 210 .

Now let us do another example together. In this case, the two farmers who are located to the right of Pak X owning the plantations 4 and 5 establish together 2 diversified systems. The other persons in the group do not plant trees. Pak X decides that he would like to only plant oil palm. Pak Y [please choose a person from the audience] could you tell us how much the farmer will earn in this scenario and where you have to look at the table? [the correct answer is 100 points. Please check whether the farmer gets this correct]. Now I would like to ask you what the range of environmental benefits and donations is which will be generated? Can you tell us in which column we have to look? [Please confirm that the farmer should hint to the same cell and see that no environmental benefits are generated]. In this case, less than three diversified systems are established such that no environmental benefits are generated.

Let us now do one last example. The farmer still owns the plantation which is at the same location as plantation 3. You can now decide whether the farmer established a pure oil palm plot or a diversified plantation. Please select on your earning table the column which indicates the management option of your farmer. [please show on the big earning table where the respondent should mark the circle and wait until everybody is finished with this task]. Are you all done? The other persons in your group who establish diversified plantations are farmers 5, 6 and 1 . Please select on the table the cell which indicates how much the farmer has earned in this round and how high environmental benefits will be, depending on his own plantation management choice and the choices of the other persons in his group. We will now go around to see whether there have been any problems with finding the correct case in the earning tables.

Do you have any questions so far? If not then we will play two practice rounds. These rounds serve only for training purposes and won't be considered in the final earning calculation.

We will now distribute all the sheets you need to you. Please do not show your decision to other persons in the group and do not talk with each other. First, please take one of the decision sheets out of the envelope. Now please write P1 in the line which indicates the round. This refers to first practice round. For the farmers who own Plantation Nr. 1,2, 4 and 5, you do not establish a diversified system. The farmers who own plantation 3 and 6 decide to establish a diversified system. Please mark your decision accordingly on the decision sheet. Please copy the number of this management option in your information sheet in cell (1) and hide the paper afterwards again. You are done? Then please fold the decision sheet which we will collect now.

Assistants please check whether the farmer has copied everything on the information sheet.

We will now announce the group conservation effort to you. The group planted together 2 diversified crop systems and no neighboring farmers plant other trees than oil palm. Therefore, no donations are generated. Please copy these pieces of information on your information sheet in cell (2) and cell (4). Please calculate the number of diversified systems the other members in your group planted by subtracting cell (1) from cell (2). Write the result in cell (3). Now have a look at the earning table and choose the cell that tells you how many points you have earned in that round. Again, this is the number which you can see first. Write this amount in cell (5). [Assistant who explains should wait with next steps always until farmers are done. The other assistants check whether calculations are correct].

Now we will play practice round 2. Please take another decision sheet out of the envelope and write in the round P2 which refers to the second practice round. [wait until everybody is done] This time, everybody can decide on his or her own whether to establish a diversified system or whether to maintain a pure oil palm plantation. Please now copy your management decision on the information sheet, hide it afterwards again and please look up such that we know that you are done. [Please wait until everybody is ready now]. Please fold the decision sheet which we will collect now. 
[please collect the decision sheets. And announce group outcome]

If everybody is done, we will accompany you now to your seat. Please do not talk to your neighbors. Please take the envelope with the decision sheets and that with your id with you.

[in case the farmers are not sitting on the correct places, please bring the farmer to the assigned seat which is indicated by seat id and arrange the position of the seats in accordance to the predetermined group composition. Please make sure that he took everything with him.]

We will now start with round one. From this round on, your decisions will have real consequences for you since each round can be selected to be paid for you in form of the voucher. Please now make your decisions considering your income and the effect your action has on the environment. We would like to ask you to face the wall when making your decisions.

\section{EXAMPLE OF TREATMENT INSTRUCTIONS}

\section{Please interrupt the participants after five rounds.}

In the next rounds, imagine a program is introduced in Jambi that supports farmers who decide to conserve plant and animal diversity in their oil palm plantations. The program will make a payment to each farmer depending on the number of diversified plots established by the respective farmer. These payments will be made only if environmental benefits are generated, that means, if your group all together establishes at least three diversified plots. If your group establishes less than three diversified plots, no environmental benefits are generated, and therefore the program does not make any payments to any farmer in the group.

If your group altogether establishes three diversified plots or more, each farmer who establish a diversified plot will receive a payment. The amount of the payment depends on the exact number of diversified plots established by the farmers: for each diversified plot established each farmer receives 50 points. These payments will then be added to the agricultural income.

[Please show poster that represents Treatment 3.1.]

For example, if five farmers in your group establish one a diversified plot, and one farmer plants only oil palm, your group has a total of five diversified plots. In addition, five neighboring farmers establish a diversified plot. That means, the threshold of three diversified plots is met, and therefore each farmer receives a payment. The farmers who have established one diversified plot will receive 50 points while the farmer who only plants oil palm does not receive any payments from the program. Hence, the total income of the farmers who have planted a diversified plot will be 100 points and the total income for the farmer who has planted only oil palm is 100 points.

In another example, two farmers in the group establish a diversified plot and the other farmers keep their oil palm plots. Hence, in total two diversified plots are planted and a maximum amount of two neighbors establish a diversified plot. Therefore, the threshold of three diversified plots is not met and no payments are made. Hence, the total income of the farmers who have established a diversified plot is 50 points and the farmers who have established a pure oil palm plot is 100 points.

Apart from this program that was newly introduced in the region, everything remains the same. You still need to decide whether and how many diversified plots to establish in your oil palm plantation. Depending on your decision, your plantation generates a certain income as explained to you before. Also, as explained before, your decision and the decisions of the other group members determine whether environmental benefits are generated and the amount of donations made to Burung Indonesia. What is new now, is that your decision and the decisions of the other group members also determine whether farmers in your group who plant trees receive compensation payments.

Again, you can see how much you earn in each round using the earning table, which we now distribute. [Please distribute the earning table called Treatment 3.1 and take the old earning sheets with you]. Again, the first column indicates the number of diversified plots established by the other group members (cell (3) from your information sheet) and the following columns indicate the number of diversified plot that you chose to establish (cell (1) from 
your information sheet). Where row and column intersect you find your earning in that round (enter this value in cell (5) of your information sheet). This earning already includes the payment made by the program, in case the total number of diversified plots established by your group is at least three. Please take some minutes to familiarize yourself with the tables.

Are there any questions? If yes, please raise your hand and we will come to you. If not, then we will distribute again the decision sheets. As before, please do not talk to each other and also don't show your decisions to the other members of your group. We will resume the activity now.

\section{Please interrupt the respondent after five rounds again.}

[Please show poster that represents Treatment 3.2.]

Now a new program has been implemented in the region. Now, each farmer who established a diversified plot will receive 30 points if at least three diversified plots are established in the group. The change in payment is not linked to your behavior but purely attributable to internal budget changes of the program. We will now distribute the new earning tables [Please distribute the earning tables 3.2 to the farmers and take the old one with you]. The earning shown in the table includes already the payment made by the program, in case at least three diversified plots are planted in your group. Please take a moment to familiarize yourself with the new table. Everything else remains the same as before in the activity. [please wait until the farmers look up again]. Any questions? If not, then we will resume the activity 
Katrin Rudolf, PhD / Environmental and Resource Economics / University of Goettingen

To whom it may concern,

From the perspective of the ethics committee of the University of Göttingen, there are no objections concerning the implementation of the project as requested, as long as the data protection provisions have been taken into account.

Yours sincerely,

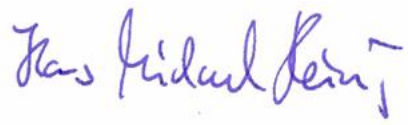

Prof. Dr. Hans Michael Heinig (Chair) 